\title{
Environmental Sciences Division Annual Progress Report for Period Ending September 30, 1990
}

\author{
R. L Van Hook Director
}

Section Heats

C. H. Gehrs, Environmental Toxicology

S. G. Hildebrand, Environmental Analyses

S. H. Stow, Geosciences

W. Van Winkle, Ecosystem Studies

\section{Program Managers}

M. P. Farrell, Carbon Dioxide Information Analysis and Research Program

D. D. Huff, Environmental Waste Program

J. W. Ranney, Biof: els Feedstock Development Program

Environmental Sciences Division Publication No. 3650

Date Published: April 1991

Prepared by the

OAK RIDGT: NATIONAL_ IABORATORY

Oak Ridge, Tennessec $37831-6285$

managed by

MARTIN MARIFTTA FNERGY SYSTTEMS, INC.

for the

II.S. DI:PARTMI:NT OF TNIERGY

under contract DF:-ACOS-\$4OK21400 


\section{Contents}

List of Technical Summaries, v

Preface, ix

In Memory, $x i$

Overview, xiii

\section{Section Activities, I}

Ecosystem Studies, 3

Introduction, 3

Technical Suınmaries 1 Through 8, 5

Section Staff, 16

Environmental Anabysex, 18

Introduction, 18

Technical Summaries 9 Through 21, 21

Section Staff, 40

Environmental Toxicology, 42

Introduction, 42

Technical Summaries 22 Through 33, 43

Scction Staff, 59

Geosciences, 61

Introduction, 61

'Technical Summarics 34 Through 58, 63

Section Staff, 100

Technical and Adminis:rativc Support, 102

Introduction, 102

Section Staff, 10.3 
2 DOE Program Activities, 105

Biofuck Feaktock Development Program, 107

Introduction, 107

Technical Summaries 59 and 60, 109

Program Staff, 112

Carbun Dioxide Information Analysis and Research Program, 114

Introduction. 114

Technical Summaries 61 Through 64, 117

Program Staff, 124

Environmental Waste Program, 125

Introduction, 125

Program Staff, 126

3 Center for Gbbal Environinental Studies, 127

4 Lists, 133

Awards and Honors, 135

Significant Accomplishments, 137

Conferences Organized or Chaircd, 139

Research and Development Subcontracts and Interagency Agrecments, 142

Technology Transfer, 152

Education Programs, 153

Afirmative Action. 160

Seminar Program, 163

Visitors Hostod, 164

Publications, 167

Prcsentations, 190

Prolessional Activitica, 214

5 Organization Chart, 24.3

Abbrcviations, 247

Author Index, 249 


\section{List of Technical Summaries}

1 Patterns of Drought-Induced Tree Mortality Demonstrate Effects of Interacting Stresses at Walker Branch Watershed

2 Stable Nitrogen Isotope Ratios Are Related to Habitat Nitrogen Status on Walker Branch Watershed

3 Upslope, Riparian, and Within-Stream Processes Regulate Nutrient Concentrations in Walker Branch During Baseflow

4 Soil Solution Chemistry in High-Elcvation Spruce-Fir Forests in the Great Smoky Mountains National Park Is Strongly Dominated by Nitrate

5 Chestnut Blight Indicates Potential of Globa! Change for Nutrient Cycling and Carbon Storage

6 Oak Ridge National Environmental Rescarch Park Is Involved in Development of Southern Appalachian Man and the Biosphere Cooperative Projects

7 Species Richness and Biotic Similarity Are Related to Physiography and Climate at the U.S. DOE National Environmental Research Parks

8 Recruitment of Yearling Smallmouth Bars Is Modeled

9 ESD Participates in the DOE Tiger Team

10 Two-Day Training Course in Environmental Laws and Regulations Is Developed for DOE Senior Managers

11 NEPA and CERCLA Processes and Documents Can Be Combined Effectively

12 Impact of Nerve Gas Incineration on Scabirds at Johnston Atoll Is Assessed

13 Analysis of Model Projections Provides Core for NAPAP Integrated Assessment of Aquatic Effects 
14 Data on Southeastem Canadian Lakewater Chemistry Are Analyzed in Relation to Acidic Deposition

15 A Regionally Unbiased Kriging Procedure Is Developed for Environmental Strvey Data from a Stratified Design

16 Roads Lead to Massive Deforestation in Rondonia. Brazil

17 Relationships Between Landscape Structure and Water Quality Are Analyzed to Determine the Effect of Different Spatial Scales

18 Burn Severity and First-Year Vegetation Responses Vary Following Large-Scale Fire on Subalpine Plateaus in Yellowstone National Park

19 Global Climate Change Studies on Reservoir Water Quality and Fish Habitat Are Initiated

20 Potential Off-Site Ecological Risks of the DOE Oak Ridge Facilities Are Identified

21 Comprehensive Review of Environmental and Health Effects from First Soviet Plutonium-Production Site Is Completed

22 Organic Contaminants Commonly Found in Association with Trichloroethylene Can Significantly Influence Its Degradation by Methane-Utilizing Bacteria

23 Consortial Microbial Activity and Resilience in the Westinghouse Savannah River Site Bioremediation Intcgrated Demonstration Are Defined

24 Microbial Degradation of Trichloroethylenc Occurs Faster in Soils Containing Plant Roots

25 Index of Biotic Integrity Is Used to Evaluate Effectiveness of Waste Treatment and Pollution Abatement on East Fork Poplar Creck

26 Effluents from the Oak Ridge Y-12 Plant Alter Patterns in Production of Benthic Invertebrates in East Fork Poplar Creck

27 Radioactive Contaminants in Migratory and Resident Waterfowl Inhabiting White Oak Lake on the Oak Ridge Rescrvation Are Assessed

28 Attached Algal and Microbial Communities Provide Insight into Natural and Anthropogenic Factors Infuencing Aquatic Systems

29 Toxicity Tests Identify Nickel as a Toxicani in Upper Bear Creck and Following a Spill in East Fork Poplar Creck

30 Dissolved Organic Matter Enhances the Transport of Cadmium and Polychlorinated Biphenyls in Soil Columns 
31 Deposition of Ozone to Foliar Surfaces Can Be Predicted for a Range of Forest Tree Species

32 Drought Resistance of Pops.lur teltoides Bartr. cv. Siouxland Is Controlled by Avoidance Mechanisms

33 Elevated Atmospheric $\mathrm{CO}_{2}$ Does Not Affect the Timing of Leaf Senescence in Tree Seedlings in the Field

34 Environmental Monitoring Program Is Developed for Transuranic Waste Storage Sites and Active Low-Level Radioactive Waste Disposal Sites

35 Hydrochemical Data Quality of Groundwater Samples from the Oak Ridge Y-12 Plant Is Evaluated

36 Subsurface Storm Flow Is Measured near ORNL

37 Long-Term Research Plan for Environmental Restoration Identified More Than 140 Basic Research Needs

38 Pumping Tests and Modeling Are Conducted to Assess Performance of an Interceptor Well System

39 ESD Staff Assist DOE in Major Plans for Environmental Restoration and Waste Operations

40 Groundwater Flow Across Ridges Is Likely on the Oak Ridge Reservation

41 An Integrated Hydrologic and Geologic Study Will Support Monitoring, Compliance, and Environmental Restoration Activities on the D_F, Oak Ridge Reservation

42 Dense Nonaqueous Phase Liquids Are Characterized in Rear Creek Valley Near Oak Ridge, Tennessee

43 Evidence from Fluid Inclusions and Stable Isotopes in Calcite Veins Suggests that the Nolichucky Shale Experienced Two Contrasting Types of Water-Rock Interactions During Burial and Fracturing, Respectively

44 Contaminant Transport Scenario Is Developed for the South Valley Superfund Site

45 Lithologic Changes and Porosity Differences Are Distinguished at the Paducah Gaseous Diffusion Plant

46 Atmospheric Chemistry and Deposition Differ Significantly Between U.S. and West German Forests

47 Engincering-Scale In Situ Vitrification Test Confirms Reduced Cesium Volatilization and Demonstrates the Uscfulncss of Temperature Sensors in Melts 
48 Leachability of Uranium from Oak Ridge Y-12 Plant Wastes Is Investigated

49 Natural Isotopic Tracers Are Used to Study Snowmelt Processes in the Arctic

50 Sediment Sources and Short-Term Sediment Remobilization in the Savannah River Estuary Are Identified with ${ }^{7} \mathrm{Be},{ }^{137} \mathrm{Cs}$, and ${ }^{210} \mathrm{~Pb}$

51 Radioactive Strontium in Contaminated Soik Is Immobilized by Phosphate Treatment

52 Geology and Geophysics Group Develops IDEM Computer Code to Determine In Situ Dynamic Elastic Moduli Values of Subsurface Soils

53 Chemical Form and Concentration of Mercury Determine Performance of Mercury-Dosed Soils on Standard Leaching Tests

54 Joint ORNL-UT Seismic-Reflector Survey Provides a Three-Dimensional Map of Groundwater Aquifers at Paducah Gaseous Diffusion Plant

55 In Situ Soil Venting Demonstration at Air Force Base Is Successfully Completed

56 Shallow Groundwater in SWSA 4 Has a Distinct Deuterium Isotope Signature

57 Extent of PCB Contamination in Upper Tributary 8 Sediments at the Bear Creek Burial Grounds Has Been Characterized

58 Westbay Multi-Pon Systems Are Installed in Core Holes at the Odk Ridge Y-12 Plant

59 A Methodology Is Developed for Assessing the Implications that Alternative Land Use Strategies Have for Carbon Emissions on a Continental Scale

60 Increased Private-Sector Production of Short-Rotation Woody Crops Is Linked to DOE Research Developments

61 Model Reconstructions of $\mathrm{CO}_{2}$ Released to the Atmosphere from Past Changes in Land Use Are Incompatible with Observed Changes in Atmospheric $\mathrm{CO}_{2}$

62 Why Should Developing Tropical Countries Plant Trees? (A Look to Biomass Fucls to Approach Zero Net $\mathrm{CO}_{2}$ Emissions)

63 Emissions of $\mathrm{CO}_{2}$ to the Atmosphere from Global Energy Usc Are Monitored

64 Global Climate Data Base Is Developed for Use in Global-Change Studies 


\section{Preface}

This progress report summarizes the research and development activities conducted in the Environmental Sciences Division of Oak Ridge National Laboratory during the period October 1, 1989, through Sepiember 30, 1990. The report is structured to provide descriptions of current activities and accomplishments in cach of the division's major organizational units. Following the sections describing the organizational units is a section devoted to lists of information necessary to convey the scope of the work in the division. 


\section{In Mernory}

The Environmental Sciences Division lost two dedicated research staff members during this reponing period. Although we miss both of them, cherished memories remain with us as we continue the important work that they started.

Wrine J. Bocth, Jr. (1931-1990) passed away on September 28, 1990, after an extended illness. Bill came to Oak Ridge National Laboratory (ORNL) in 1956 to conduct research in radioactive waste management. The first engineer in the Environmental Sciences Division, Bill was the lead overseer of the construction of Building 1505. He was often looked to for his detailed recollection of the history of people and projects at ORNL, especially those involving waste disposal, and for his valuable insight into and understanding of current problems and issues. He never failed to provide help when it was needed; if asked for an opinion, he often gave it with a distinctuve, tolerant skepticism. Bill was reierred to fondly by his colleagues as The Great Pessimist." This quality made him a good sounding board for solving problems, a person who took practical approaches and found workable solutions. Bill's selfless dedication to his wort is exemplified by his successful completion of a program milestone during the last weeks of his illness.

Ernest A Bondietti (1945-1990) passed away on February 17, 1990, as a result of an automobile accident. Ernie was a principal investigator and project leader for several research programs. He led by example, and be expected much more of himself than be did of others. Eager to use his critical abilities, he was always searching, asking questions, and seeking other points of view. Those who worked with him say that his enthusiasm for innovative research was contagious and that his animated conversations about new findings and ideas provided a vitalizing force. Ernie's independence of thought and his stubborn adherence to basic scientific precepts, along with his sound insights and excellent experimental and analytical technique, won him respect throughout the scientific community. His international reputation brought scientists from all parts of the world to work with him in his laboratory. 


\section{Overview}

The Envirormental Sciences Division (ESD) of Oak Ridge National Laboratory (ORNL) conducts research on the environmental aspects of existing and emerging energy systems and applies this information to ensure that technology development and erergy use are consistent with national environmental bealth and safety goaks. ESD performs basic and applied research, environmental assessments, environmental engineering and demonstration, technology and operational support, and program managemient for the U.S. Department of Energy (DOE), other federal and state agencies, and industry. ESD works collaboratively with a number of federal agencies, universities, and the private sector in accomplishing its programs and hos's a significant number of visiting investigators from universities, industry. and other federal agencies.

Offering an interdisciplinary resource of staff and facilities to address complex environmental problems, the division is currently providing technical leadership for major environmental issues of national concern: (1) acidic deposition and related environmental effects. (2) effects of increasing concentrations of atmospheric $\mathrm{CO}_{2}$ and the resulting climatic changes to ccosystcms and natural and physical resources, (3) hazardous chemical and radioactive waste disposal and remediation rescarch and devclopment, and
(4) decelopment of commercial biomass energy productivn systems. In addition, ESD manages DOE's Carbon Dioxide Information Analysis Center and the Oak Ridge National Environmental Research Park The division is responsible for the ORNL Center for Global Environmental Studies, which serves as a focal point for all of the Laboratory's research and assessment activities in this important area. This progress report outlines ESD's accomplishments in these and other areas in FY 1990.

\section{Ecosystem Studies Section}

Research in the Ecosystem Studies Section is directed at quantitatively characterizing the way in which terrestrial and aquatic ecosystems, communities, and populations function and respond to anthropogenic activities. Section staff conduct research to determine the factors regulating biogeochemical cycles in and between terrestrial and aquatic ecosystems. A current activity is the Walker Branch Watershed Project, which focuses on the relative importance of hydrogeochemical transport and biogeochemical cycling in regulating biological structure and primary productivity at different temporal and spatial scales. Another major focus for section staff is the devclopment and application of individual-based lish 
population modek that are designed to improve predictions of the response of fish populations to disturbance. This objective is accomplished through close

collaboration with researchers conducting off-site experimental and monitoring studies.

The section is also investigating the functioning of stream ecosystems and developing a basic understanding of forest systems through field studies as well as through mathematical simulations. In addition, the section is respnnsible for managing the Oak Ridge National Environmental Research Park and serves as the ESD liaison with the Tennessee Valley Authority Ecology Program.

\section{Emironmental Analyses Soction}

The Environmental Analyses Section develops theory and methods, analytical took, and numeric data bases to evaluate environmental issues and prepares interdisciplinary assessments of environmental issues at spatial scales ranging from the individual site to the regional landscape and the globe. The section also provides technical assistance for the development of policy concerning compliance with environmental regulations. Researchers in the section prepare impact analyses for use by sponsors within DOE, the Federal Energy Regulatory Commission, the Nuclear Regulatory Commission, and the U.S. Department of Defense as part of their compliance with the National Environmental Policy Act; conduct a variety of regulatory analysis and environmental compliance activities in support of a number of sponsors, such as the DOE Environmental Guidance Division, the Hazardous Waste Remedial Actions Program, and the U.S. Air Force; and quantify ccological risks associated with technology-related environmental stresses.
The section also conducts basic research leading to analyses of natural systems tha: incorporate patterns in space and time and develops and applies modeling techniques-including simulation, optimization, statistics, uncertainty analysis, and geographic information system applications-to solve environmental problems. The section's Geographic Information and Computing Facility Group provides operational and support services to ESD for the remote batch station, the geographic information system, the computing network, office automation, and personal computers.

\section{Environmental Toxicology Section}

The Environmental Toxicology Section is involved in basic and applied research on both the mechanisms through which contaminants affect biological systems and the ways in which receiving systems affect the availability and distribution of materials to which they are exposed. Research is conducted from the subcellular and biochemical level to the ecosystem level with experimental, observational, and simulation studies. Researchers investigate both the role of molecular, biochemical, and physiological processes regulating the biological accumulation of contaminants and the adverse effects these contaminants have on the environment.

Other section activities center on the response of Oak Ridge Reservation strcams to waste management and cleanup activities and on the development of capabilities for predicting direct and indirect effects of contaminants relcased to the environment. Further areas of research are biogenchemical cycling. environmental transport, fate of contaminants in aquatic environments, response of vegetation to natural and anthropogenic stresses, and biogeochemistry of contaminants. Rescarch in the section also) addresses :he sources of chronic and acutc toxicity in 
wastewaters and streams on the Oak Ridge Reservation and the development of in situ and laboratory tests to detect and quantify toxicity. In addition to these activities, a new research group was formed during FY 1990 to explore the role of microbes in contaminated and uncontaminated environraents.

\section{Geosciences Section}

\section{Staff of the Geosciences Section} engage in basic and applied research and conduct demonstration projects directed toward understanding and controlling the physical and chemical mechanisms that influence the movement of material through the lithosphere, hydrosphere, and atmosphere. The major areas of emphasis involve geochemistry, geology, geophysics, environmental chemistry, soil science, bydrology, atmospheric chemistry, oceanography, and environmental engineering. The scope of the studies includes field characterization, testing and demonstration, laboratory experiments, and mathematical and computer modeling.

The Geosciences Section strives to maintain a balance between basic and applied studies. The common theme of most section activities is the study of waste materials and by-products from energy production, and activities span major portions of the energy cycle. Innovative waste treatment technologies that have been developed include bioremediation of organic contaminants and mercury, as well as nxidation and venting of organic contaminants that occur in soils and groundwater. The staff of the Gcosciences Section are heavily committed to investigating many of the critical issues that are essential in dealing with the cleanup of DOE facilitics in order to bring them into environmental compliarce. The staff are also addressing issues that are necessary to understand the impact of energy technologies on the environment.
Biofuct Foodslock Developuent Progrom

The Biofuets Feedstock Development Program (BFDP) is a .tational program that manages DOE's research on the production of dedicated energy crops. The program is supported by the DOE Office of Transportation Technologies. The primary objective of the BFDP is to develop systems for producing biomass feedstocks for liquid transportation fuek that are cost-effective and environmentally acceptable.

The program emphasizes a number of high-priority species (both woody and herbaceous) and a number of regions for crop production. Research on specific crops is primarily subcontracted to landgrant universities and to U.S. Department of Agriculture research facilities.

Resource assessment and environmental and economic studies, including basic physiology and nutrient-cycling research, are performed mainly within ESD and ORNL, with some subcontracted support. In FY 1990 the BFDP had four major research components-Model Wood Energy Species, Model Herbace.Jus Energy Species, Environmental Resea ch and Analysis, and Economic Analysis and Integration.

\section{Carbon Dioxide Information Analycis and Research Program}

The Carbon Dioxide Information Analysis and Research Program (CDIARP) is operated at ORNL for the DOE Carbon Dioxide Research Program (CDRP), Office of Basic Encrgy Science. CDIARP consists of threc components: the Carbon Dioxjde Information Analysis Center (CDLAC), the Resource Effects Group, and the Globai Carbon Cycle Rescarch Program. The objective of CDIAC is to acquire, compile, evaluate, archive, document, and distribute $\mathrm{CO}_{2}$ rclated data and information in support of CDRP. CDIAC is a fully integrated 
information analysis zenter that supports CDRP's research program and provides $\mathrm{CO}_{2}$-related data and information fres of charge to an international audience of researchers, policy makers, and students. CDIAC staff engaged in several activities toward this end, including both organizing and attending symposia and workshops, presenting papers at conferences, and working with researchers to obtain and distribute importani $\mathrm{CO}_{2}$ data sets.

The Resource Effects Group is charged with managing and implementing the appropriate research and analytical tasks to address issues involving changes in climate and vegetation that result from increasing concentrations of atmospheric $\mathrm{CO}_{2}$, in addition to assuming responsibility for evaluating various adaptive or corrective measures.

Researchers in the Global Carbon Cycle Program are examining the processes and perturbations behind observed changes in aimospheric $\mathrm{CO}_{2}$ levels in order to estimate the $\mathrm{CO}_{2}$ increases that can result from future fossil fuel use. Mathematical models that describe the earth systems controlling $\mathrm{CO}_{2}$ levels are used to interpret atmospheric measurements and related data and to project $\mathrm{CO}_{2}$ conceratrations. Iterative model refinements and model experiments aimed st understanding newty available data continue to yield substantial progress.

\section{Environmental Waste Program}

The Environmental Waste Program (EWP) helps to ensure the technical consistency and scientific validity of environmental restoration work across all Martin Marietta Energy Systems, Inc., sites. The scope includes site characterization and cleanup projects at the three Oak Ridge facilities, the Portsinouth Gaseous Diffusion Plant, and the Paducah Gaseous Diffusion Plant, as well as the investigation of contamination of the Clinch River and the Tennessee River systems. In this capacity, the EWP supplies professional experts to review important issues, provides professional guidance, and assists in identifying relevant data and interpretive information. Technical review of remedial investigation and planning is the principal component of site-specific assistance. These functions are accomplished with the full support of ESD management and other key personnel within Energy Systems. 


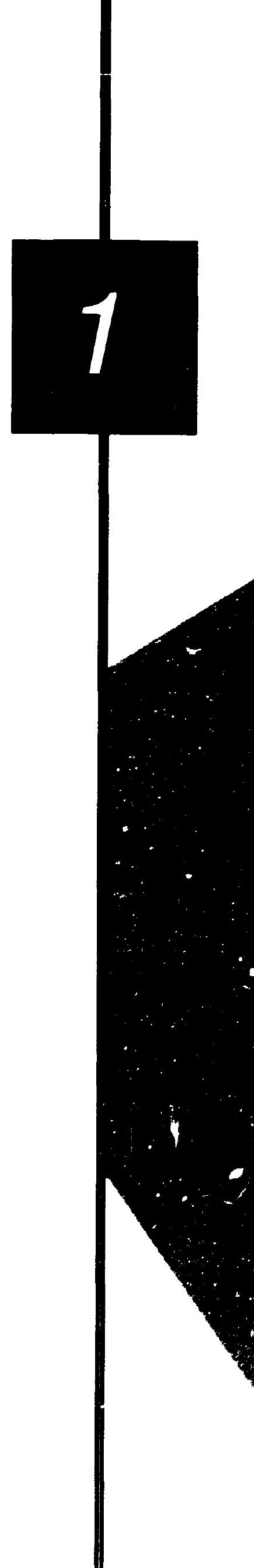




\section{Ecosystem Studies}

\section{Introduction}

Research in the Ecosystem Studies Section of the Envircnmental Sciences Division (ESD) at Oak Ridge Nationai Laboratery (ORNL) is directed at quantitatiwly characterizing how terrestrial and aquatic ecosystems, communities, and populations function and respond to anthropogenic activities. The section is organized into three complementary groups: Biog sochemical Cycling, Aquatic Systems, and Terrestrial Systerrs. In addition, the section is rcsponsible for management of the Oak Ridge National Environmental Rescarch Park and serves as the ESD liaison with the Tennessee Valley Authority (TVA) Ecology Program.

The Ecosystem Studies Section is fortunate to have a wide variety of sponsors. The three major funding sources are the Office of Health and Environmental Research (OHER) of the U.S. Department of Energy (DOE), the Electric Power Research Institute (EPRI), and the National Science Foundation (NSF). Other sponsors and organizations with whom we interact are the U.S. Department of Agriculture Forest Service (USFS), TVA, the National Park Service Great Smoky Mountains National Park, the National Oceanic and Atmospheric Administration's Atmospheric Turbulence and Diffusion Division, and a number of universities (c.g., University of Georgia, University of Wisconsin, University of Maryland, and University of Rhode Island).

Staff in the Biogeochemical Cycling Group are engaged in rescarch to determine the factors regulating biogeochemical cycling of nutrients in regulating primary productivity, species composition, and stability of natural ecosysiems. The group is currently involved in research in two primary areas: (1) the OHER-funded Walker Branch Watershed Project, which focuses on the relative importance of hydrogeochemical transport and biogeochemical cycling in regulating biological structure and primary productivity at different temporal and spatial scales, and (2) the USFS-funded project en atmospheric deposition, red spruce nutrition, and aluminum toxicity in the Great Smoky Mountains National Park, which builds on results of the multiyear and multisite EPRI-funded Integrated Forest Study.

The primary areas of research currently pursued in the Aquatic Systems Group involve the functioning ot stream ecosystems and fish population dynamics. Included are the NSF-funded project on nutrient cycling, ecosystem structure, and ecosystem stability, which focuses on phosphorous and nitrogen dynamics in laboratory stream channels, and the EPRIfunded project on compensatory mechanisms in fish populations, which is designed to improve predictions of fish population response to disturbance through a combination of modeling and collaboration with off-site experimental and monitoring studies.

The primary focus of the Terrestrial Systems Group is to develop a basic understanding of forest systems through field studies as well as mathematical simulations. Ecosystem theory and stand growth models are used to study forest succession in temperate and tropical forests. Arcas of rescarct. include sensitivity and unccrtainty analysis of forest succession models and investigation of methods of applying forest models to 
landscapes. The application of models is focused primarily on determining the effects of $\mathrm{CO}_{2}$-induced climatic change.

The OHER-funded project on the Oak Ridge National Environmental Research Park is directed at analysis, synthesis, modeling, and marketing of ecological researith performed on the Oak Ridge Reservation. The emphasis is on coordination of research efforts and comparison of results at the seven DOE Research Park sites.

Significant accomplishments during FY 1990 include the following:

- Interacting stresses at Walker Branch Watershed were demonstrated to affect the patterns of drought-induced tree mortality.

- Stable nitrogen isotope ratios were determined to be related to the habitat nitrogen status on Walker Branch Watershed.

- Monitoring studies indicated that nutrient concentrations in Walker Branch during base flow are regulated by upslope, riparian. and within-stream processes.
- Mcasurements demonstrated that soil solution chemistry in high-elevation spruce-fir forests in the Griat Smoky Mountains National Park is strongly dominated by nitrate.

- An analysis of the impact of the decline of American chestnut indicated the potential for an impact on the nutrient dynamics and carbon storage of eastern North American forests.

- Application of an individual-based smallmouth bass population model demonstrated that a high level of mortality in the first year may lead to higher recruitment.

- The Oak Ridge National Environmental Research Park continued to play an active role in the implementation of projects for the Southern Appalachian Man and the Biosphere Cooperative.

- Species richness and biotic similarity were related to physiography and climate at the network of DOE National Environmental Research Parks. 


\section{Technical Summaries}

4

Patterns of DroughtInduced Tree Mortality Demonstrate Effects of Interacting Streses at Waller Branch Watershed

M. A. Huston and J. M. Chason ${ }^{1}$

'Science Applications International Coporation, Oak Ridge, Tennessee.
A severe drought in the critical early summer growing period in 1988 culminated 4 years of below-average precipitation in the vicinity of Oak Ridge, Tennessce. Drought-related stress effects on forest trees included increased incidence of disease and insect otitbreals; branch loss and crown dieback; and a general increase in nortality, particularty in the smaller size classes. Research conducted in 1989 documents a spatially nonrandom pattern of mortality in saplings of yellow poplar, a fast-growing, important timber species that is widely distributed across Walker Branch Watershed.

Mortality and survival of yellow poplar saplings (0.5 to $12 \mathrm{~m}$ in height) were recorded at a site on a dry ridgetop and at a site in a moist valley bottom. Locations, heights, diameters, number of neighbors and distance to neighbors, and the light level at the top of all saplings, living and dead, were recorded in an effort to determine factors associated with mortality. Of a total of 21 saplings on the dry ridgetop, only 6 were alive, whereas all 15 saplings along the stream valley were living. At the dry site, there was no relation between survival and sapling height nor between survival and basal area of neighbors. The primary factor related to mortality at the dry site was the amount of light available at the top of the saplings (light available during the drought was inferred from measurements made in 1989). For saplings that received less than $60 \%$ of full sunlight, mortality was $100 \%$, whereas for saplings that received greater than $60 \%$ of full sunlight, mortality was only $33 \%$. It is significant tiat all saplings at the moist site, where survival was $100 \%$, received less than $45 \%$ of full sunlight, a light level associated with $100 \%$ mortality at the dry site.

This pattern of yellow poplar mortality and survival illustrates the interaction between light stress and water stress that was hypothesized by Smith and Huston and used as input for a physiologically based ecosystem model. The critical relationship is that the shade tolerance of an individual piant decreases as its environment hecomes drier; that is, it necds more light to survive under dry conditions than under moist conditions. 
This interaction between two common types of stress has significant implications for changes in forest productivity and structure in response to climate change. In a drier and'or hotter climate, changes in the relative cumpetitive ability of trees as a result of differential decreases in shade tolerance are likely to alter forest structure in ways that can only be predicted if these interactive stress responses are taken into account.

-T. M. Sminh and M. A. Huston, A Theory of the Spatial and Temporal Dynamics of Plant Communitiex," Vequtatio 83:49-69 (1989).

Stable Nitrogen Lotope Ratios Are Related to Habitat Nitrogen Status on Walker Branch Wateribed

C. T. Garten, Jr.
Over complex forest terrain there may be considerable spatial variation in ecosystem function, including nitrogen cycling. Studies on Walker Branch Watershed show that differences in stable nitrogen isotope ratios $\left({ }^{15} \mathrm{~N}:{ }^{14} \mathrm{~N}\right)$ in plant foliage are associated with spatial variation in soil nitrogen mineralization/nitrification potential, which varies with topography. Altiough the ${ }^{15} \mathrm{~N}$-abundance of total soil nitrogen is relatively constant across the watershed (mear: $\delta^{15} \mathrm{~N}_{\text {ir }} \pm \sigma=+3.9 \pm 0.6 \%$ \% $n=18$ ), there is spatial variation in foliar ${ }^{15} \mathrm{~N}$-abundance.

Extractions of fresh soil samples and laboratory incubations show that available soil nitrogen and nitrification potential is extremely limited at many sites on the watershed. However, riparian zone ivalley bottom) soils, which have the highest concentrations of total soil nitrogen and the lowest carbon:nitrogen ratios, are an exception to this trend. In soils of riparian zones there is measurable nitrification potential (as determined by laboratory incubations), and nitrogen mineralization in soil is expected in exceed immobilization by soil heterotrophs. According to published models, which can be applied to nitrogen-deficient systems, the isotopic composition of available soil ni:. ugen is affected by the relative rates of nitrogen immobilization and nitrification. With increasing immobilization in relation to nitrification, available soil nitrogen becomes isotopically lighter.

Tree and icrn leaves are isotopically lighter $\left(\delta^{15} \mathrm{~N}_{\text {air }} \approx\right.$ $-3.4 \%$ ) in those habitats that have less available soil nitrogen, higher carbxnn:nitrogen ratios, and lower nitrification potential. typically ridges, in comparison with lcaves $\left(\delta^{15} N_{\text {arr }} \approx-0.9 \%\right)$ in habitats where soils cxhibit 
higher available soil nitrogen, lower carbon:nitrogen ratios, and higher nitrification potential, iypically valley bottoms. Thus, abundance of foliar ${ }^{\text {is }} \mathrm{N}$ in habitats on the watershed appears to be related to nitrogen cycling, particularty the relatise ratio of nitrogen mineralization to immobilization in soil.

The abundance of ${ }^{15} \mathrm{~N}$ in foliage clearly suggests that the principal nitrogen source to trees on the watershed is isotopically depleted (i.e., $\delta^{15} \mathrm{~N}_{2 \mathrm{rr}}<0$ ) or that isotopic fractionations intervene and result in an isotopically light

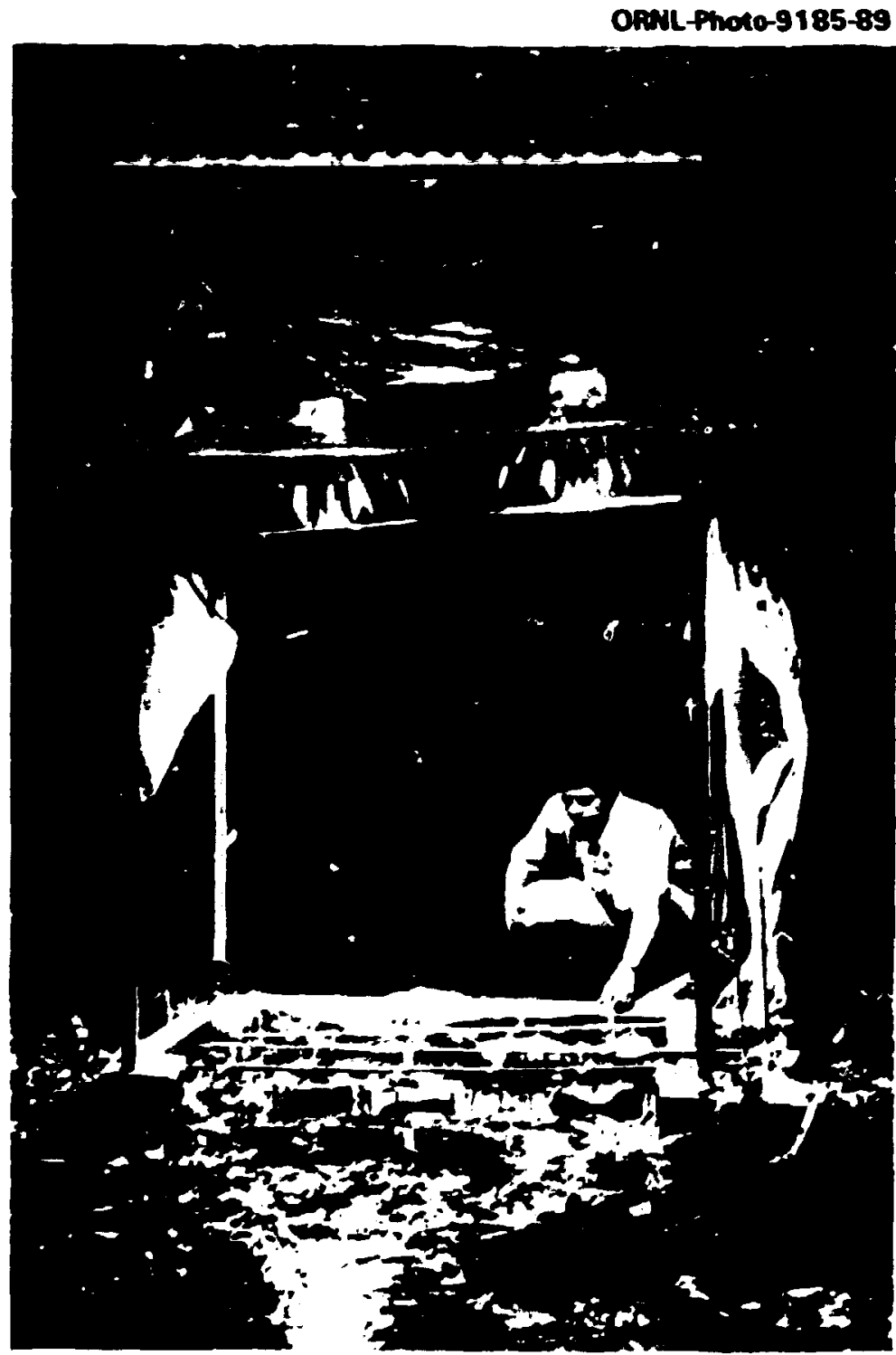

Patrick Mulholland (in collaboration with Alan Steinman and Amy Rasemond) examines the effect of light on the growth and taxonomic composition of the algal community by experimensally increasing light levels in a heavily shaded forest stream ecosystem at Walker Branch Watershed. 
nitrogen conient in leaves. Twe likely sources of isotopically depleted nitrogen have been identified: ammonium- $\mathbf{N}$ in precipitation and soil nitrate. More work is needed :0 resolve the reasons why foliar nitrogen is isotopically different from total soil nitrogen, but relative differences in the nitrogen isotope composition of leaves within the watershed suggest that the nitrogen isotope composition of tree foliage may be related to the nitrogen status of the habitat.

Nutrient concentrations ( $N$ and $P$ ) in streams that drain forested areas may be influenced by processes involving immobilization, change in chemical form, and release occurring in terrestrial soik as well as within the stream. Although occupying only a small fraction of the watershed, the riparian zone (valley bottom) may be particularly important in regulating stream water nutrients because that is where subsurface flow emerges as streamflow. Immobilization and release of nutrients within the stream, particularly associated with decomposition of leaf inputs from the terrestrial system, may also influence stream water nutrient concentrations.

To determine the influence of biogeochemical processes occurring in both the terrestrial system and the stream on stream water nutrient concentrations, we made monthly measurements of water chemistry in riparian groundwater, springs, and at scveral locations in the stream at baseflow over a 2-year period, beginning in November 1987. Similar data on precipitation and upslope soil water were available from past studies. Ratios of ${ }^{15} \mathrm{~N} /{ }^{4} \mathrm{~N}$ in $\mathrm{NO}_{3}$ werc also measured from these sites to determine the importance of denitrification.

Concentrations of inorganic $\mathbf{N}$ and $\mathbf{P}$ in the soil solution of upslope soils were very low compared with their concentrations in precipitation and throughfall. indicating that upper soil horizons are an extremely strong sink for these nutricnts. Concentrations of $\mathrm{NO}_{3}$ and $\mathrm{P}$ were higher in springs than in upslope soil water, and correlations of these nutrients with $\mathrm{Ca}$ were strong, suggesting that weathering of the dolomite bedrock is an important source of $\mathrm{NO}_{3}$ and $P$ to the strcam. Concentrations of $N$ and $P$ in riparian groundwater were strongly influcnced by redox state, with net immobilization 
of $\mathrm{N}$ and $\mathrm{P}$ at high Jissolved oxygen (DO) concentrations and release of $\mathrm{NH}_{4}$ and $\mathrm{P}$ at low $\mathrm{DO}$. Although $\mathrm{NO}_{3}$ concentrations were generally low when DO levels were low, ${ }^{15} \mathrm{~N} / \mathrm{N}$ ratios did not indicate high levels of denitrification in riparian groundwater. Concentrations of $N$ and $P$ in stream water varied seasonally, with lowest concuntrations during autumn and winter and highest during the summer. The seasonal pattern in stream water $N$ and $P$ was primarily the result of (1) high rates of immobilization associated with kaf decomposition and periphyton grouth in the stream during the period from midautum. to earty spring and (2) low immobilization rates during the summer when decomposing leaves were scarce and periphytor growth was light-limited.

These results indicate that although upslope terrestrial processes limit stream water $\mathbf{N}$ and $\mathbf{P}$ concentrations in Walker Branch at baseflow, processes within the stream, and to a lesser extent in riparian soik, establish a strong seasonal pattern, with highest concentrations in summer and lowest concentrations in autumn and winter.

\section{$M$}

Sol Solution Chemistry in High-Elevation Spruce-Fur Forests in the Great

Smoky Mountains National Park Is Strongly Dominated by Nitrate

H. Van Micgroct, D. W. Johnson.' ant D. E. Todd

'Desent Research Instiute, Reno, Nevada.
The co-occurrence of acid deposition and the unexplained decline of red spruce in the northeastem United States has led to considerable debate as to the role of acid dsposition in this phenomenon. Numerous hypotheses have been proposed including aluminum toxicity, aluminum-induced calcium and magnesium deficiency, and growth stress due to high nitrate levels in solution. The spruce-fir zone in the Smoky Mountains is subject to high nitrogen and sulfate inputs from the atmosphere through precipitation, cloudwater, dry deposition, and gaseous constituents. A regime of such high acid deposition unay strongly affect the chemistry of the water moving through the soil.

Atmospheric inputs, soil solution chemistry, and nutrient cycling fluxes were monitored over a 3-year period in two spruce forests near Clingman's Dome, North Carolina. More recently, additional soil solution measurements were taken in plots immediately below and above one of these sites to further inveatigate the influence of elevation and soil tension on soil water chemistry.

The anionic component of the soil solutions consisted of sulfate and nitrate, with nitrate being the most 
Opint Proco-6279-90

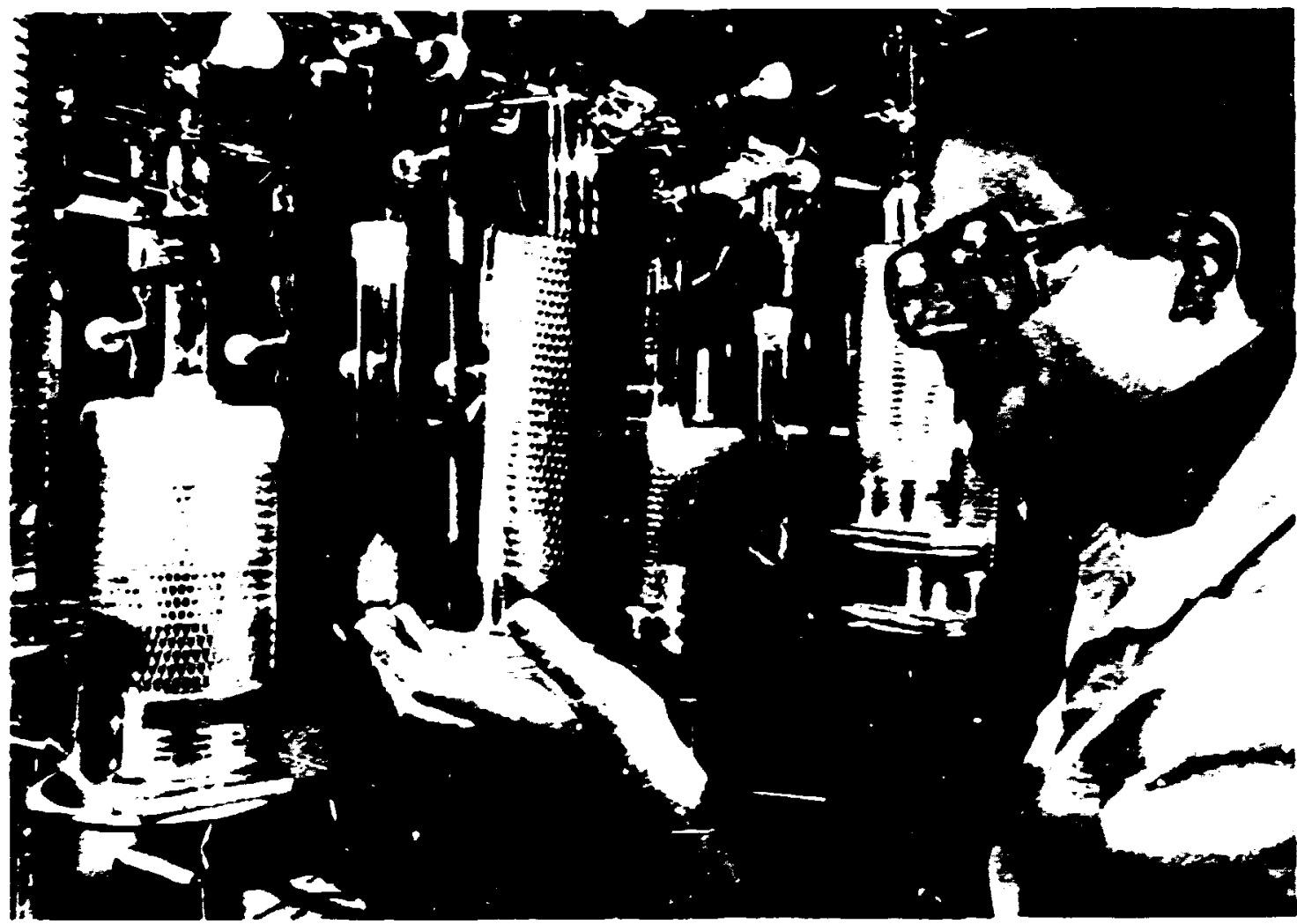

Lee Cooper checks the vacusum status on a manifold for extracting water from leaves. The apparatus is used to study the effects that elevated levels of carton dioxide have on isotopic fractionation during water upiake by plants.

imporant. Sulfate fluxes were mostly due to atmospheric inputs, whereas nitrate fluxes were derived from atmospheric deposition and from internal sources (i.c., from mincralization of soil organic matter by microorganisms). Both anions, but nitrate in particular. showed large tenuporal concentration fluctuations, which caused concomitant changes in cation solution concentrations, especially of aluminum and hydrogen. Aluminum pulses in the upper soil occasionally approached threshold toxicity levels reported for red spruce secdlings. Solutions held at greater tension in the soil. which is the water that plant roots are likely to encounter as the soil dries, had significantly higher nitrate concentrations than gravitational watcr. Nitratc levels in 
those solutions were ako greater at lower elevation, receiving less nitrogen input via precipitation and cloudwater. Sulfate concentrations, on the other hand did not differ significantly between high-tension and gravitational water or with elevation. Higher nitrate solution levels were accompanied by a significant increase in the concentrations of bydrogen and some base cation: but not always of total and monomeric shuminum.

These observations are important because they illustrate that al!bough atmospheric acid deposition clearly influences the solution chemistry at these high-elevation spruce forests, internal processes, especially nitrification, are akso important. Nitrate appears to play a key role in soil water chemistry and the quality of the soil solution as a substrate for plant uptake and growh.

5

Cheatur Botight Indicates Potentivl of Global Change for Notrient Goling end Centon Slorese

W. M. Post and M. A Huston
Global changes resulting from increases in atmospheric $\mathrm{CO}_{2}$ are expected to alter forest composition, productivity, and consequent carbon dynamica. Foreat responses to global changes depend not only on fast-time-ecale physiological responses, but atwo on the slower processes of decomposition and nutrient cycting. Over longer time periods of years to decades, responeses will depend on species composition changes that are induced by changes in environmental and biological factors. Results of an experiment indicate that the disappearance of American chestnut caused by the chestnut blight epidemic may have altered the productivity and carbon storage of eastern North America through its effect on soil nutrients and forest succession over the last 50 years.

Changes in net ecosystem production resulting from changes in nitrogen availability can result in changes in the amount of carbon stored in ecosystems. Nitrogen availability, in turn, depends on the decompocition rate of forest litter. The fallen leaf litter of different tree species decomposes at different rates. The rate of litter decomposition depends, in large part, on the levels of lignin and nitrogen, which yary among species litters. Species that produce litter having low lignin and high nitrogen concentrations (low lignin:nitrogen ratio) decompose rapidly and make more nitrogen available than species that produce litter having high lignin:nitrogen ratios. 
Literature information indicated that American chestnut leaf litter decomposes fairty rapidly. To test this hypothesix, we collected chestnut leaves from mature sprouts, placed them in litter bags, and placed the bags in Walker Branch Watershed. For comparison, we a'so collected, bagged, and placed in the area leaf litter from tulip poplar and lobblly pine (species with high and low litter quality, respectively). At time intervak, we collected some of the litter bags to determine how much of the original material remained. After 18 months, tulip poplar had lost an average of $64 \%$ of its initial weight, loblolly pine lost 53\%, and American chestnut lost 72\%.

American chestnut leaf litter appears to decompose extremely rapidly. Because American chestnut has been replaced with oats and hictories (species having litter quality intermediate between tulip poplar and ioblolly pine) we hypothesize that available nitrogen has declined in those forests once dominated by American chestnut. We infer further that eastern North American forests may have been more productive and stored more carbon in living biomass and soik than the forests that have developed since the chestnut blight.

To quantify these inferences concerning the response of eastern North Amcrican forests to the disappearance of the Amcrican chesinut, we will analyze the original and partially lecomposed chestnut litter for lignin and nitrogen concentration. We will use this information to develop model parameters for chestnut and perform computer simulations of the impact of American chestnut decline on the nutrient dymamics and carbon storage of eastem North American forests since chestnut blight was introduced at the beginning of this century.

Oat Ridge National Environmented Researeh Part Is Imolved in Developencent of Southers Appalachian Man and the Biosphere Cooperative Projocts

P. D. Parr and $M$. Cunningham'
A Southern Appalachian Man and the Biosphere (SAMAB) Cooperative was established in August 1988 to promote knowledge and understanding of the natural resources of the Southern Appalachian region; to encourage wise use of the area's natural resources; and to foster environmental research, education, and training to help build a model of cooperative, integrated, regional resource management. The area served by SAMAB includes the three units of the Southern Appalachian Biosphere Reserve (Oak Ridge National Environmental 
'Ecology Program, The Universiny of Tennessee, Knawilie.

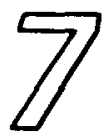

Species Richness and Biotic Similarity Are Rehted to Ptysiography and Climate at the U.S. DOE National Eovironmental Research Parts

M. Cunningham' and

P. D. Parr

'Ecology Program, The University of Tennessee, Knarville.
Research Park, Great Smoky Mountains National Park, and Coweeta Hydrologic Laboratory) and covers five states. This SAMAB Cooperative will be used as a model program for the Man and the Biosphere program. Oak Ridge National Environmental Research Park personnel are actively involved with the SAMAB Environmental Education and Training Committee and the Public Aftairs Committee. The Environmental Education and Training Committee has prepared a draft directory of eavironmental education resources in the SAMAB region to be distributed to schook, citizen organizations, and others who are interested. Other objectives of this committee during FY 1990 are to (1) visit Pittman Center and determine the environmental education needs, (2) design an educational campaign directed at a major emvironmental issue, (3) determine support for a Coordinated Resource Management course of study, and (4) prepare a formal presentation to be given at national meetings of environmental educators. The Public Afrairs Committee developed a draft brochure on SAMAB and displayed a poster at the Acid Rain Conference in Gatlinburg in November. This committee will be developing a role and mission statement for SAMAB as well as other various materials for disseminating the information to the public. Involvement in the SAMAB has increased interaction with other agencies and will lead to development of joint proposals in various research and educational areas.

Species response to climate gradients and to potentially changing climate is a topic of national interest. Shifts in species distribution and abundance in response to climate change have been hypothesized. A continental network of protected sites including the U.S. DOE National Environmental Research Parks (known as ParkNet), the National Science Foundation Long-Term Ecological Rescarch sites, and private research sites, can provide a basis for investigating species response to climate change. Thirteen participants from six ParkNet sites attended a workshop on cross-site synthesis of biotic and climatic data. The DOE-sponsored workshop was organized by the Oak Ridge Rescarch Park and hela in Oak Ridge in October 1989. 
Factors affecting species richness at the six ParkNet sites were evaluated by using principal components anałysis. Results indicated a continental-scale climate gradient across the ParkNet sites and significant correlation between the climate gradient and species richness for vascular plants, breeding birds, amphibians, and reptiles. Elevation and size of the sites were ako important factors in species richness. Richness of mammak and fish, however, was not significantly correlated with the demonstrated climate gradient.

Similarity indices for genera of vascular plants and mammak were calculated for pairs of sitex. Values for both plants (0.15-0.39) and mammak (0.22-0.56) were relatively low. Similarity indices for mammal genera were higher than expected for some paired sites in comparion with the corresponding index for vascular plants. Similarity of plants was inversely related to distance between the sites, but this pattern was not evident for mammak.

Study of species richness in relation to area for ParkNet showed that the sites fall into two groups: small, heterogenous sites with high vascular plant richness in relation to area and large, homogenous sites with reduced vascular plant richness in relation to area. Within a site, a similar pattern emerged when vascular plant richness for cach major habitat was compared with area for that habitat on-site. We hypothesize that moisture gradients across and within sites are the primary factor in these patterns. Changes in moisture regime associated with projected temperature change should influence the patterns.

Results of cross-site comparison demonstrate the opportunity to formulate and test hypotheses about the responses of species and communities to global climate change.

Recruitment of Yearling Smallmouth Bas Is Modeled

D. L. DeAngelis and

L. Godbout
One of the most important and least understood aspects of fish ecology is the role of density-dependent regulation, or compensation, in the dynamics of fish populations. Compensation may be defined as the tendency of populations to experience a decrease in death rate or an increase in birth rate as population density declines. This effect is expected to occur in many fish 
populations and may moderate to some extent the effects of anthropogenic impacts on the populations. However, density dependence in populations is extremely difficult to quantify.

Data collection and modeling that are focused on high levels of aggregation (population numbers) are unable to characterize many of the subtle mechanisms through which

ORNL Photo-5812-90

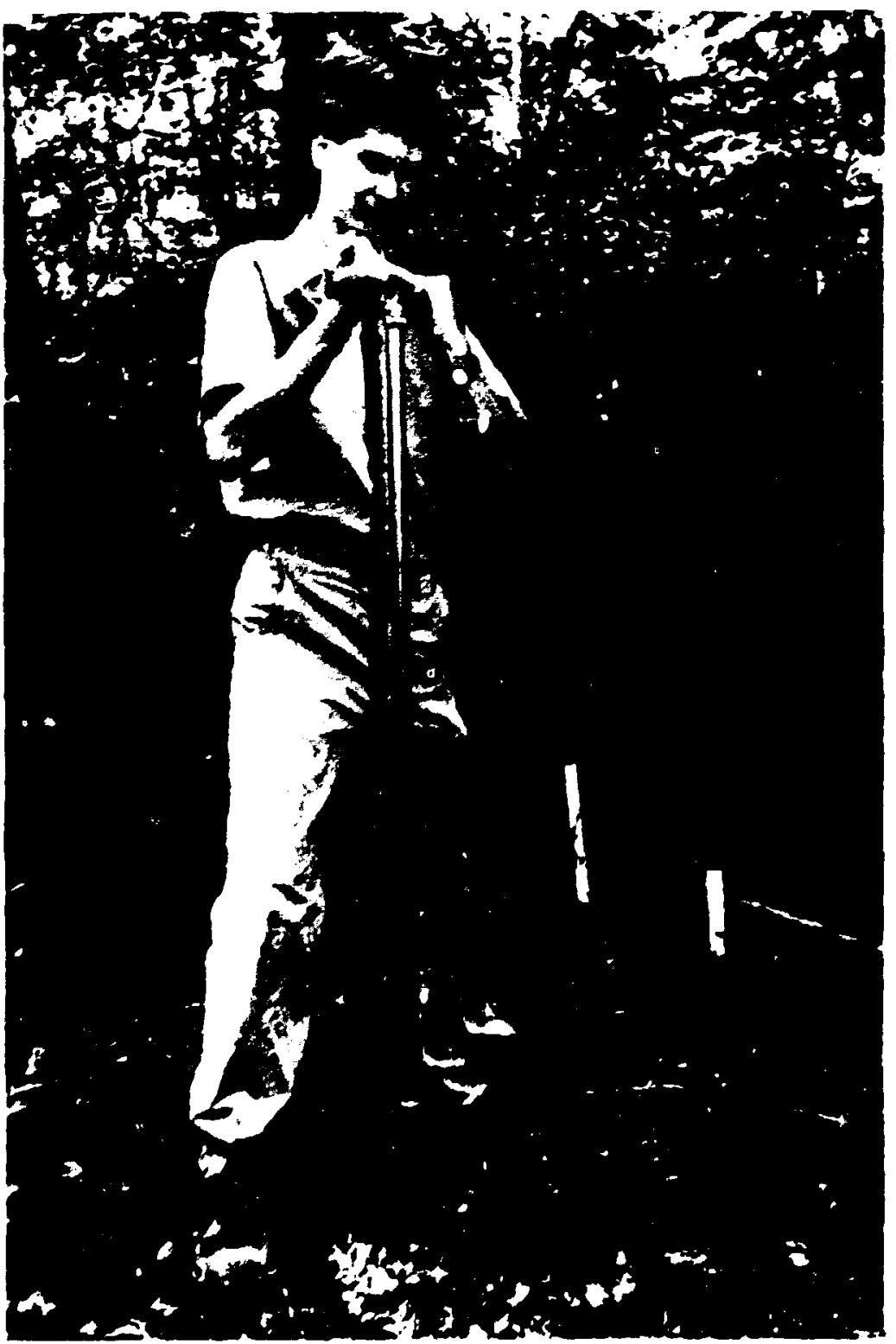

Eric Hartzell

demonstrates how to collect a soil sample. Under the direction of Michael Huston and Don Todd, a team of 3 students collected over 200 samples at Walker Branch Watershed on the Oak Ridge Reservation. Analysis of the samples will provide data about spatial variation in the chemistry of forest soils and thus give researchers insight into forest response to acid deposition and climate change. 
compensation can occur. To improve the ability to describe and predict this phenomenon in fish populations, we have developed an individual-based model of a smallmouth bass population as part of a project on Compensatory Mechanisms in Fish Populations (CompMech), which is funded by the Electric Power Research Institute. This model follows simultaneously the foraging, energetics, growth, behavior, competitive interactions, and different types of mortality of a large sample (several hundred) of smallmouth bass in a population. A variety of indirect feedbacks that could result in density-dependent regulation are built in!) the model.

The model parameters have been quantified by using data for smallmouth bass populations in southern Ontario lakes. The model has proven capable of accurately simulating the growth and mortality of individuals in the population. These simulations have been used to test the effects of different levels of imposed mortality on recruitment to the yearling life stage a: various degrees of prey availability. Initial findings indicate that a high level of mortality early in the first year may lead to higher recruitment of yearlings: high initial mortality reduces competition for prey, and reduced competition leads to increased sizes of surviving fish and a higher probability of survival through the irst winter.

\section{Section Staff}

W. Van Winkle

\begin{tabular}{|c|c|c|c|}
\hline $\begin{array}{l}\text { T. J. Blasing } \\
\text { M. A. Brewer' } \\
\text { J. M. Chason' } \\
\text { J. C. Cole } \\
\text { L. W. Cooper } \\
\text { J. H. Cowan' } \\
\text { M. Cranford' } \\
\text { M. Cunningham } \\
\text { D. L. DeAngelis } \\
\text { G. L. Edwards } \\
\text { J. W. Elwood }\end{array}$ & $\begin{array}{l}\text { W. R. Emanuel } \\
\text { T. E. Flum }{ }^{3} \\
\text { C. T. Garten } \\
\text { D. P. Genereaux } \\
\text { C. L. Hardy } \\
\text { M. A. Huston } \\
\text { J. B. Hyman } \\
\text { J. D. Joslin } \\
\text { J. M. Kelly } \\
\text { A. W. King } \\
\text { S. G. Lawson }\end{array}$ & $\begin{array}{l}\text { K. H. Light' } \\
\text { B. B. Lu } \\
\text { L. K. Mann } \\
\text { P. A. Mays } \\
\text { R. A. Minear' } \\
\text { P. J. Mulholland } \\
\text { R. G. Otto } \\
\text { A. F. Parker } \\
\text { P. D. Parr } \\
\text { C. B. Phillips } \\
\text { W. M. Post }\end{array}$ & $\begin{array}{l}\text { L. R. Pounds } \\
\text { A. D. Rosemond } \\
\text { A. D. Steinman } \\
\text { A. } \\
\text { T. J. Stephens } \\
\text { D. E. Todd } \\
\text { A. S. Trebitz } \\
\text { H. Van Micgroct } \\
\text { M. H. Wolfe } \\
\text { C. L. Wylic }\end{array}$ \\
\hline
\end{tabular}


1. Consultant

2 Science Applications International Corporation, Oak Ridge, Tennessee.

3. Graduate student, The University of Tennessee, Knowille.

4. Research associate, The University of Tennessee, Knowille.

5. Chesapeake Biological Laboratory, University of Maryland, Solomons.

6. Tennessee Valley Authority, Knaville, Tennessee.

7. Graduate sudent, Massachusetts Institute of Technology, Cambridge.
8. Director, Institute for Environmental Studies, University of Illinois, Urbana.

9. President, R. G. Otto and Associates, Arlington, Virginia.

10. Advanced Sciences, Inc., Oak Ridge, Tennesree.

11. Graduate student, Vanderbilt University, Nashville, Tennessee.

12. Laboratory Graduate Participation Program, Oak Ridge Associated Universities, Oak Ridet. Tennessee.

13. Biology Division, ORNL 


\section{Environmental Analyses}

\section{Introduction}

The Environmental Analyses Section of the Environmental Sciences Division (ESD) develops theory and methods, analytical tools, and numeric data bases to evaluate environmental problems and issues and prepares interdisciplinary assessments of environmental issues at spatial scales ranging from the individual site to the regional landscape and the globe. The section also provides technical assistance for the development of policy concerning compliance with environmental regulations. These objectives are accomplished by the six groups into which the section is divided.

\section{Ervironmental Ascesument}

The Environmental Assessment Group prepares impact analyses for use by sponsors within the U.S. Department of Energy (DOE), the Federal Energy Regulatory Commission (FERC), the Nuclear Regulatory Commission, and the U.S. Department of Defense as part of their compliance with the National Environmental Policy Act (NEPA). These analyses assess impacts on terrestrial and aquatic ecological resources, land and water use, and water quality for environmental impact statements and related documents. Staff members also provide technical reviews and analyses of NEPA documents and related issues for the DOE Office of NEPA Oversight. The goal of the Environmental Assessment Group is to apply statc-of-the-art assessment tools to complex issues at individual plants, at sites that are large geographically, and in areas that are programmatic in scope.
In FY 1990, staff played an important role in assessing NEPA compliance at DOE facilities as members of Tiger Teams and provided NEPA training for DOE managers. The group is also analyzing the environmental implications of relicensing nuclear power plants, disposing of the U.S. stockpile of chemical monitors, and continuing the U.S. Antarctic Program.

\section{Environmental Compliance}

The Environmental Compliance Group conducts a variety of regulatory analysis and environmental compliance activities in support of a number of sponsors, such as the DOE Office of Environmental Guidance, the Hazardous Waste Remedial Actions Program, and the U.S. Air Force. Intense pressure to clean up and protect the environment at federal sites is currently being cxerted by Congress, the regulatory authorities, and the public. The regulatory programs that implement the major federal environmental statutes-including the Resource Conservation and Recovery Act; the Comprehensive Environmental Response, Compensation, and Liability Act; and others-are complex mazes of rules, procedures, and technical requirements that change frequently as the regulatory authorities respond to statutory mandates. The Environmental Compliance Group is composed of professional regulatory specialists who maintain an up-to-date working knowledge of the existing federal environmental laws and regulations, as wcll as legislative and regulatory actions now under consideration by Congress and the regulatory agencies. The group tracks and analyzes new regulations both to facilitate sponsor understanding of technical requircments and to determine their impact on the facilitics and programs of 
DOE and other sponsors. The group also performs environmental compliance audits and provides training in environmental laws and regulations.

In FY 1990, members of the Environmental Compliance Group developed and presented both 2- and 4-day training courses in environmental laws and regulations for DOE senior and mid-level managers nationwide. These training programs, sponsored by the Office of Environmental Guidance, recently won praise from the DOE Inspector General's Office, which found that "DOE and contractor management have an improved awareness of their responsibilities and potential liabilities" as a result of the programs.

\section{Regional Resources}

The Regional Resources Group conducts basic research leading to analyses of natural systems that incorporate patterns in space and time. Scientist' develop theory and methods to understand the processes regulating current landscape patterns to predict change in pattern as a function of change in environment. The group applies regional-scale theory and methods to synthesize information and to assess environmental problems at regional, national, and global scales.

During FY 1990 the group has provided input to assessn.ents of major national problems, including acidic precipitation and global climate change. DOE and the Environmental Protection Agency (EPA) are major sponsors of this work through thei- commitments to programs such as the National Acid Precipitation Assessment Program (NAPAP). Other key working relationships of the group include the National Park Service, the U.S. Forest Service, and the National Acronautics and Space Administration.
Staff in the group played a key role in the final anabysis, synthesis, and assessment of data from NAPAP by providing lead authorship for 2 of the 27 NAPAP stateof-science (SOS) documents, and contributing authorship to 5 additional SOSs. These critical reviews of the current knowledge relative to acidic precipitation became the foundation on which members of the group contributed to the aquatic and terrestrial ecosystem effects sections of the NAPAP Final Integrated Assessment. The assessment not only evaluated the current status of ecosystem responses to acidic precipitation, but also evaluated model projections of future response as a result of a variety of possible sulfur and nitrogen emissions control scenarios.

The group continued to assist EPA in the development of the Environmental Monitoring and Assessment Program (EMAP). The goal of this program is to -quantify the current extent of natural resources at risk of loss, alteration, or damage from human activity and to provide long-term trend monitoring at regional and national scales. During FY 1990, the group participated in the development and evaluation of indicators of landscape heterogeneity useful for analyzing change in large-scale patterns that might be indicative of landscape-scale response to environmental disturbance. Indices of landscape spatial pattern are also being used by the group to evaluate the burn severity and early vegetation responses following the recent large-scale fire disturbances in Yellowstone National Park

\section{Environmental Systems Anałysis}

The Environmental Systems Analysis Group develops and applies modeling 
techniques-including simulation, optimization, statistics, uncertainty analysis. and geographic information system applications-to solve environmental prublems. Currently, the group applies geostatistics to the assessment of surface water chemistry, evaluates the biological effects of acidic deposition to fish at a regional scale, develops reservoir simuiation models for use in the Clinch River RCRA Facilities Investigation, and contributes to a number of NEPA documents. A major focus of the group is biotic and abiotic components of water resource issues. Important accomplishments this year include the completion of the SOS report on effects of acid precipitation on aquatic biota for the National Acid Precipitation Program, and an analysis of the effects of global climate change on reservoir water quality and fish habitat.

Currently, the primary extramural working relationships of the group are with the FERC Office of Hydropower Licensing and the DOE Office of Renewable Technologies in work related to hydroclectric development and with the EPA Aquatic Effects Task Group and NAPAP in work related to the biological effects of acidic deposition. Internally, we have a strong involvement with the waste management and emergency response activities of Martin Marictta Encrgy Systems, Inc., in work related to modeling the transport and fate of contaminants discharged into surface waters surrounding the Oak Ridge Reservation.

The group continues to address national issues by applying computer modeling to environmental assessment problems, particularly in the area of water resources. Our research includes new applications of simulation and optimization models in environmental impact statements and new applications of geostatistics in regional asscessments.

\section{Environmental Risk}

The Environmental Risk Group quantifics ccological risles associated with technology-rclated esvironmental stresses. The group was involved in a number of important local and national environmental assessments during FY 1990. Major activities included (1) development and application of methods for assessing the responses of fish populations to lake and stream acidification. (2) assessment of the environmental rists associated with off-site migration of contaminants from the Oak Ridge Reservation, and (3) assessment of the effects that oil field wastes have on wildlife populations.

Major sponsors of our risk activities include the Energy Systems Environmental Restoration Division, the DOE Elk Hilk Naval Petroleum Reserve, and EPA. The group has a strong institutional tie to the National Academy of Science through staff membership on the Board of Environmental Studies and Toxicology and the Committee on Risk Assessment Methodology.

\section{Goographic Information and Computing Facility}

The Geographic Information and Computing Facility Group provides operational and support services to ESD for the remotc batch station, the gcographic information system, the computing network, office automation, and personal computers. These computing facilities complement the services of the Computing and Telecommunications Division at Oak Ridge National Laboratory (ORNL). Many ESD projects use these resources for regional spatial and statistical analyses and assessments. The computing resources are also used for modcling and simulation projects in the section and other units of the division. 


\section{Technical Summaries}<smiles>c1ccccc1</smiles>

ESD Participates in the DOE Tiger Team

L L Sigal, G. F. Cada, G. K. Eddlemon, and C. G. Heckman
On June 27, 1989, Secretary of Energy Watkins announced a ten-point initiative to strengthen environmental protection and waste management activities in DOE One of the initiatives is to conduct Tiger Team assessments of DOE operating facilities. The purpose of these assessments is to provide the Secretary with information on the current status of compliance with environmental, safety, and health regulations at each facility, including associated vulnerability, root causes for noncompliance, adequacy of DOE and site contracts management programs, response actions to identified problems, ar 1 , eventually, DOE-wide compliance trends and root ca: ses. Each Tiger Team report: to Secretary Watkins anc is composed of environment, management, and safety and health groups. A subgroup that assesses consistency with the National Environmental Policy Act (NEPA) as part of the environment group is composed of three to four members having NEPA expertise and auditing experience.

Early in 1989, the DOE Office of NEPA Oversight (EH-25) asked staff in ESD to assist them in developing a protocol for assessing compliance with NEPA. Thus, at the time of the Secretary's announcement, EH-25 and ESD were prepared to assist in the Tiger Team activities immediately. The objectives of a NEPA compliance assessment are to evaluate a facility's NEPA management and review processes; to identify problems that lead to inappropriate procedures or inadequate NEPA documentation; and to evaluate consistency with the statute, Council of Environmental Quality regulations, and DOE NEPA Guidelines. The overall goal of the NEPA compliance ausessment is to foster improved and environmentally sound decision making for those DOE actions having the potential for significant impacts on the environment.

The NEPA protocol ensures a comprehensive, consistent approach to assessing compliance at each facility. The protocol includes four chapters that describc the design and conduct of the NEPA compliance assessment. The introduction describes DOE policy on environmental issues and reviews statutory guidance as 
Orent photo-10341-90

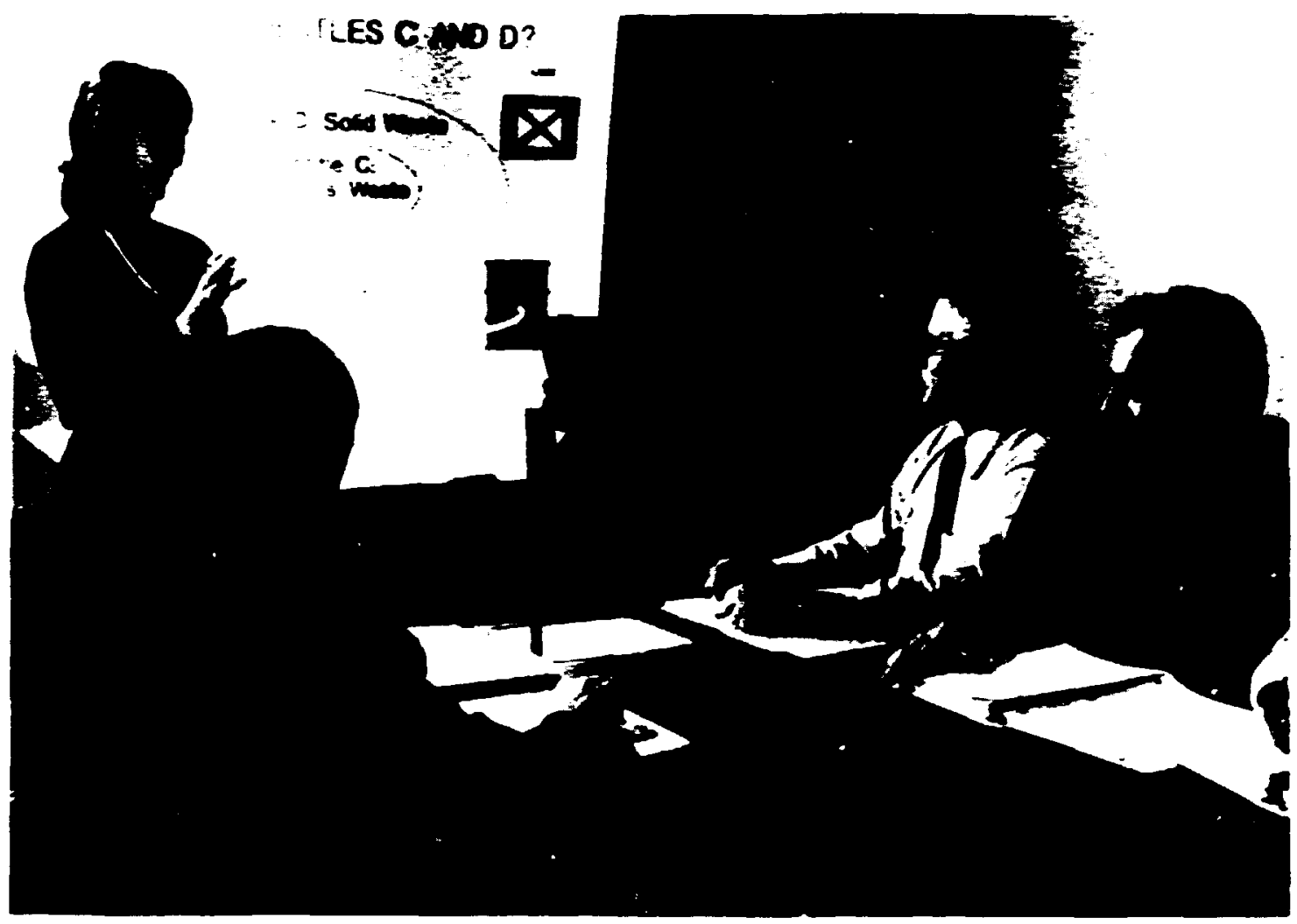

Beth Levine presents material from the Senior Management Training Couse in ORNL to clarify their roles and responsibilities in comphing with laws and Environmental Laws and Regulations. The course was offered to midlevel managers at regulations that apply to DOE facilities.

they apply to the NEPA review and compliance process. The protocol includes worksheets designed to focus the team's lines of inquiry.

To date, staff in ESD have participated in Tiger Team visits to the Rocky Flats Plant, Feed Production Material Center (Fernald), West Valley, Pantex, and the Mound Plant. An additional three sites are scheduled for $\mathrm{CY}$ 1989, with an additional 27 sites planned for CY 1990 and the first half of CY 1991.

In the past, compliance with NEPA had not been part of most auditing programs, which usually $\mathrm{cmphasize}$ meeting standards and regulatory and permit requirements. Nevertheless, inadequate or inappropriate NEPA 
documents increase agency vulnerability and may result in litigation. To the best of our knowledge, DOE is the first to develop and use a NEPA compliance protocol; as such, this protocol har epplication for all other federal agencies.

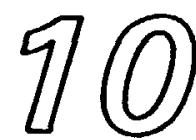

Two-Dy Training Course in Ervioneatel Lus and Regulation $\mathbf{E}$ Developed for DOE Senior Mnongers

M. B. Levine, F. E Sharples, C. F. Sigmon, and C. F. Baes III
As part of his ten-point initiative for improving DOE's environmental performance record, the Secretary of Energy has stressed that DOE is committed to operating its facilities in full compliance with environmental laws and regulations. The Secretary intends that senior and midlevel managers in all departmental elements will be beld fully accountable for safe and environmentally sound operations at their facilities. In order to fulfill their responsibilities, DOE managers will need to be educated about the various environmental laws and regulations.

To begin this educational process, DOE mandated a 2-day training course for senior managers. ESD's Environmental Compliance Group was asked by the DOE Office of Environmental Guidance to provide technical support and assistance in developing and presenting this course.

The 2-day course is designed to provide senior managers with an overview of the statutory and regulatory requirements and the civil and criminal liabilities under the following environmental statutes:

- Resource Conservation and Recovery Act;

- Comprehensive Environmental Response, Compensation, and Liability Act;

- Clean Air Act;

- Clean Water Act;

- Safe Drinking Water Act;

- Toxic Substances Control Act; and

- National Environmental Policy Act.

The course also addreseses legal concepts applicable to federal facilities (e.g., sovereign immunity and the unitary executive theory), issues of criminal liability and investigation, the U.S. Environmental Protection Agency's Federal Facilities Compliance Strategy, and DOE's Compliance Strategy.

The 2-day course has been presented at 15 different DOE sites nationwide. More than 700 people have 
attended, and feedback on the courses has been excellent. Because this training program is an outgrowith of the Secretary's ten-point plan, it has gained considerable visibility in the DOE system.

\section{9}

NEPA and CERCA Proceves and Docaments Con Be Combinad Efioctively

E. D. Smith, M. B. Levine, F. E Sharples, and G. K. Eddlemon
The Comprehensive Environmental Response, Compensation, and Liability Act (CERCLA, sometimes called the "Superfund law") requires that decisions on site remediation be made through a formal process called a Remedial Investigation/Feasibility Study (RIFS) and documented in a report of the same name. The RI/FS process is similar in some key respects to the National Emvironmental Policy Act (NEPA) process; for cxample, both involve public participation and a comparative evaluation of alternatives. There are, however, some significant substantive differences between the two processes. CERCLA actions undertaken by the U.S. Environmental Protection Agency at nonfederal sites do not normally require NEPA documentation, but similar actions by other federal agencies must comply with NEPA. A 1989 DOE order calls for integrating NEPA and CERCLA requirements by conducting a single decision process and issuing a single set of documents that meets the requirements of both laws. Adjustments must be made in order to combine the processes successfully. To assist DOE facilities in complying with the DOE order, we developed recommendations on (1) procedures for implementing a combined NEPA-CERCLA process and (2) the appropriate content for a combined CERCLA RL/FS and NEPA environmental impact statement (EIS).

Perhaps the most important element for successful NEPA-CERCLA integration is early planning to incorporate NEPA requirements in the RI/FS process. For example, RIFS project mectings to discuss the scope of the project and develop work plans could be conducted as public scoping meetings under NEPA in order to elicit public input on the issues and alternatives to be addressed in the RI/FS-EIS process. For complex remedial action sites that will be divided into several "operable units" under CERCLA, the best way to comply with NEPA's requirements to evaluate cumulative impacts of connected actions and to implement NEPA "at the carliest possible time" may be to prepare a sitewide programmatic EIS on 
the set of actions planned for the site. Later decision documents can then be tiered to the programmatic document

Hybrid RLFS-EIS documents generally should follow the RIFS format, which is less flexible than that of an EIS. Modifications are necessary, however, to accommodate features required by NEPA. For ecample, NEPA documents generally consider a broader soope of environmental consequences over a larger gecgraphic area than do RIFS documents. We think that an effective way to incorporate this material is to present anabyes of environmental consequences of alternatives in the same section of the RI/FS in which ahernatives are evaluated against CERCLA decivion criteria.

Orin these-2671-s0

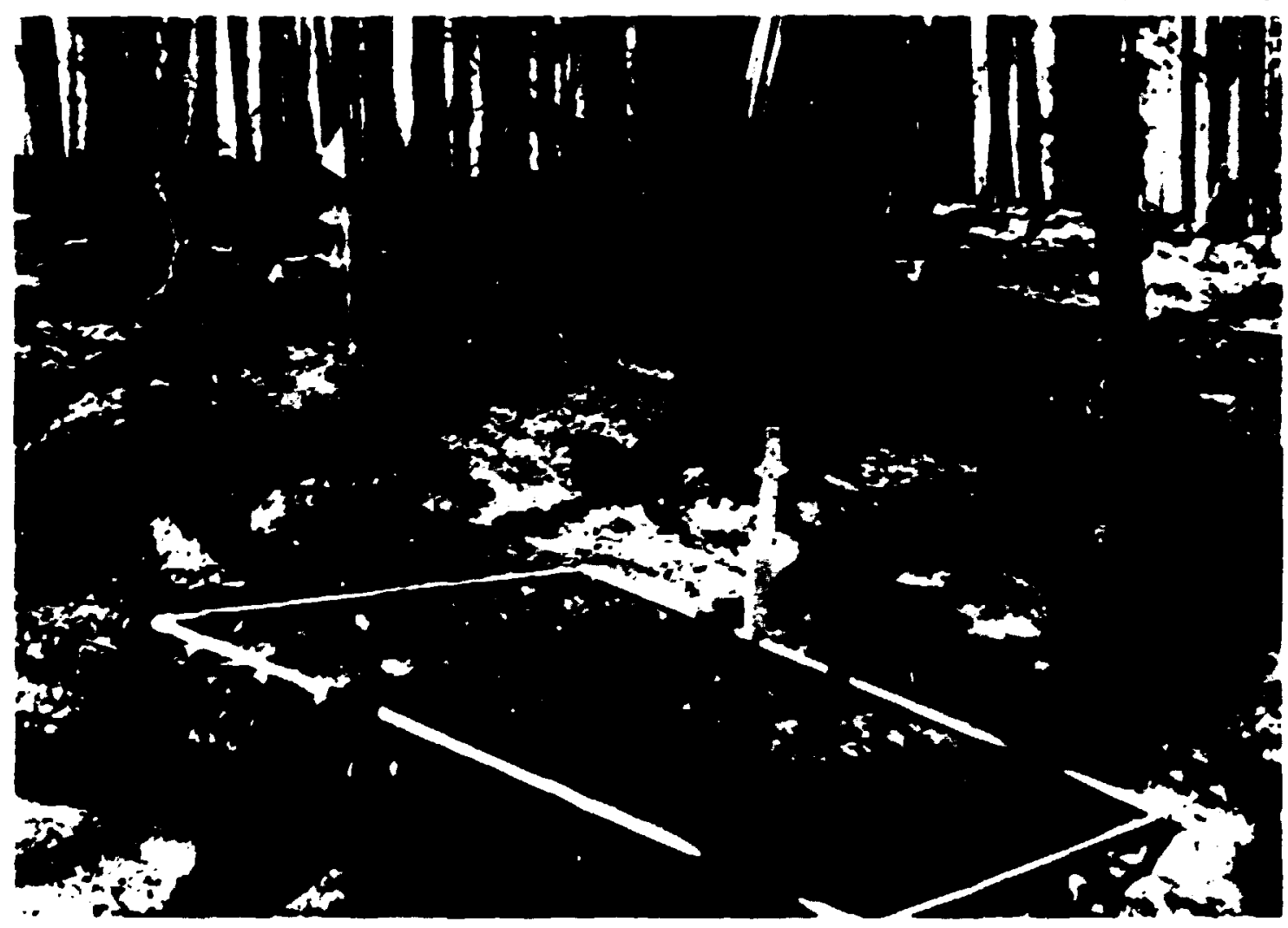

A quadrat frame sets the boundaries for sampling vegetation at Yellowstone National Park Bob Gardner and Monica Tumer used such frames in studying vegetation response 10 large-scale forest fires. As part of the study, the researchers established a variety of parameters, including the depth to which soil was charred. 
Our complete recommendations are presented in an ORNL report. We believe that our recommended approach will help DOE and other federal agencies to integrate the NEPA and CERCLA processes effectivety and to avoid durdication of eftor. By cnsuring that all potentially relerant factors are considered, the integrated process should belp yield the best possible decisions on remedial actions at federal sitex.

-M. B. Levine, E D. Saith, F. E Sharples, and G. K. Eddemon,

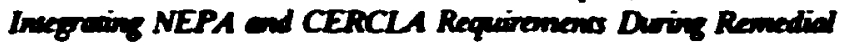
Repouses a DOE Fucities, ORMLTM-11564, Obl Ridge Noricon Laborary, 1990

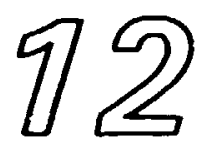

Ipect of Nerve Ges Incineretion on Secbids a Johriton Aloll E Areciod

R. L Kroodsma
The United States made an agreement with Weat Germany to remove by December 1992 all U.S. chemical munitions stored in that country. The U.S. Army proposes to transport, store, and ultimately destroy the munitions at its existing incineration facility on Johnston Atoll, which comprises four islands $\mathbf{8 0 0}$ miles west-southwest of Hawaii and which is a National Widlife Refuge. The incineration facility, Johnston Atoll Chemical Agent Disposal System (JACADS), is part of a large existing U.S. Department of Defense base on one of the islands and was constructed to destroy, over a 3-year period, munitions currently stored on Johnston Atoll. The destruction of the munitions from Germany would extend the operation of JACADS by about 3.5 months.

The Army contracted ORNL to prepare an environmental impact statement addressing impacts of the extended operation of JACADS. A major concern was the potential impact on nesting seabirds, the most important natural resource of the Johnston Aloll other than strictly marine life. Because the number and size of oceanic islands for seabird nesting are limited, such islands must be protected to prevent significant declines in these bird populations. The assessment of impacts on seabirds considered seabird ccology, routine emissions from JACADS, possible accidental releases of chemical agents, and prevailing wind directions.

Approximately 231,000 pairs of 13 seabird species nested on Johnston Atoll during 1989. About $0.7 \%$ of the nests were on Johnston Island, which is the westernmost island of the Atoll and which supports the Department of 
Defense base. The other nests were on East Island (94\%), Sand Island (5\%), and North Island (0.8\%), which are located from 3 to 5 miles northeast of JACADS. Prevailing winds are easterly (i.e., from the east), and winds from the southwest quadrant occur only $5 \%$ of the time. Seabirds feed primarily west of the atoll in areas where marine life is abundant.

Construction of the JACADS facility had little impact because it was located near the western end of Johnston Island where there are few seabird nesting sites. Routine atmospheric emissions during JACADS operation are not expected to contain concentrations of toxic substances high enough to be harmful to seabirds or other biota. The worst-case scenario, an accident which could destrcy much of the bird colonies, would require a combination of an airplane crash into the munitions storage area. worst-case meteorological conditions (which occur only at night), and a southwesterty breeze. The probability of such a combination, however, is extremely low. A less severe yet lethal accident is ako highly unlikely to occur and would not be expected to significantly affect seabird populations. However, some seabirds could be killed in their primary feeding area west of JACADS. The chance that major seabird nesting areas (located to the northeast) would be affected by such an accident is very small because the combination of an accident and a southwesterly wind is very unlikely. The environmental impact statement therefore concludes that the seabirds at Johnston Atoll would not be significantly affected by the destruction of German munitions at JACADS.

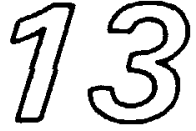

Analysis of Model Projections Provides Core for NAPAP Integrated Arroument of Aquatic Eficots

P. F. Ryan,' R. S. Turner. C. C. Brandt, ${ }^{2}$ and D. D. Schmoyer ${ }^{3}$
The National Acid Precipitation Assessment Program (NAPAP) is producing an integrated assessment of the effects of acidic precipitation to provide guidance to policymakers who must decide between proposed air quality regulations. As part of NAPAP's Aquatic Efrects Task Group, we have taken a weight-of-evidence approach to produce an assessment of the effects on aquatic resources.

Models of watershed biogeochemical processes were used to project future chemical conditions of lakes and streams for a number of alternative deposition scenarios in those regions of the United States expected to be most sensitive to acidic deposition. The models indicate that 
'Science Applications Intemational Caporation, Oak Ridge, Tennessee. 'Engineering Physics and Mathematics Division, ORNL

${ }^{3}$ Computing and

Telecommunications Division Martin Marietta Energy Systems, Inc.

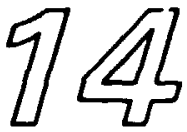

Data on Southeastem Canadian Lakewater Chemiutry Are Anabyoed in Relation to Acidic Deparition

R. J. Olson, R. B. Cook, B. M. Ross-Todd, and J. J. Bcauchamp'

'Engineering Physics and Mothematics Division, ORNL. the sensitivity of surface water chemistry to change is highly variable from watershed to watershed within a region but, on average, very similar from region to region in the previously glaciated northeastem United States. The projected median change in the acid neutralizing capacity (ANC) of lakes in the Northeast was an increase of $-3 \mu \mathrm{eq} / \mathrm{L}$ over 50 years for each kilogram per hectare per year decrease in sulfur deposition. Paleolimnological evidence (ANC inferred from species of diatoms present in lake sediments) implies similar rates of change, but only for the lakes with very low ANC. The diatom data imply a correlation between historical ANC decline and current ANC: ANC derlines are smaller for lakes with higher ANC. Historical fieid observations are consistent with the paleolimnological data in showing little change in ANC for surface waters that currently have an ANC $>50 \mu e q / L$

Judged from other evidence of ANC change, the model results, which provide our only quantitative estimates of future surface water conditions under alternative deposition scenarios, appear to be appropriate for only the most sensitive systems, that is, for lakes with the lowest current ANC. Because low-ANC systems are of greatest interest and have the largest potential biotic response to changes in acid-base chemistry, a useful assessment can be made despite the discrepancies in the results for lakes with higher ANC. The discrepancies point to the need for further research to quantify the processes responsible for ANC change in surface waters and the need for continued monitoring to verify model projections.

Lakewater chemistry data were obtained for $\mathbf{8 5 0 6}$ lakes in southeastern Canada to study relationships between atmospheric deposition and the acid-base chemistry as part of the National Acid Precipitation Assessment Program State-of-Science/Technology reports. In southeastern Canada, 3035 (37\%) of the sampled lakes have an acid-neutralizing capacity (ANC) $\leq 50 \mu \mathrm{eq} / \mathrm{L}$. Of these, 381 (5\% of the sampled lakes) are acidic (ANC $\leq 0 \mu \mathrm{eq} / \mathrm{L}$ ). The Sudbury/Noranda region has the grcatest percentage of sampled acidic lakes (24\%), which comprise $43 \%$ of the sampled acidic lakes in all of southeaster., Canada. In contrast, 90 of the 764 sampled rakes $(12 \%)$ in the South Atlantic region and 86 of the 


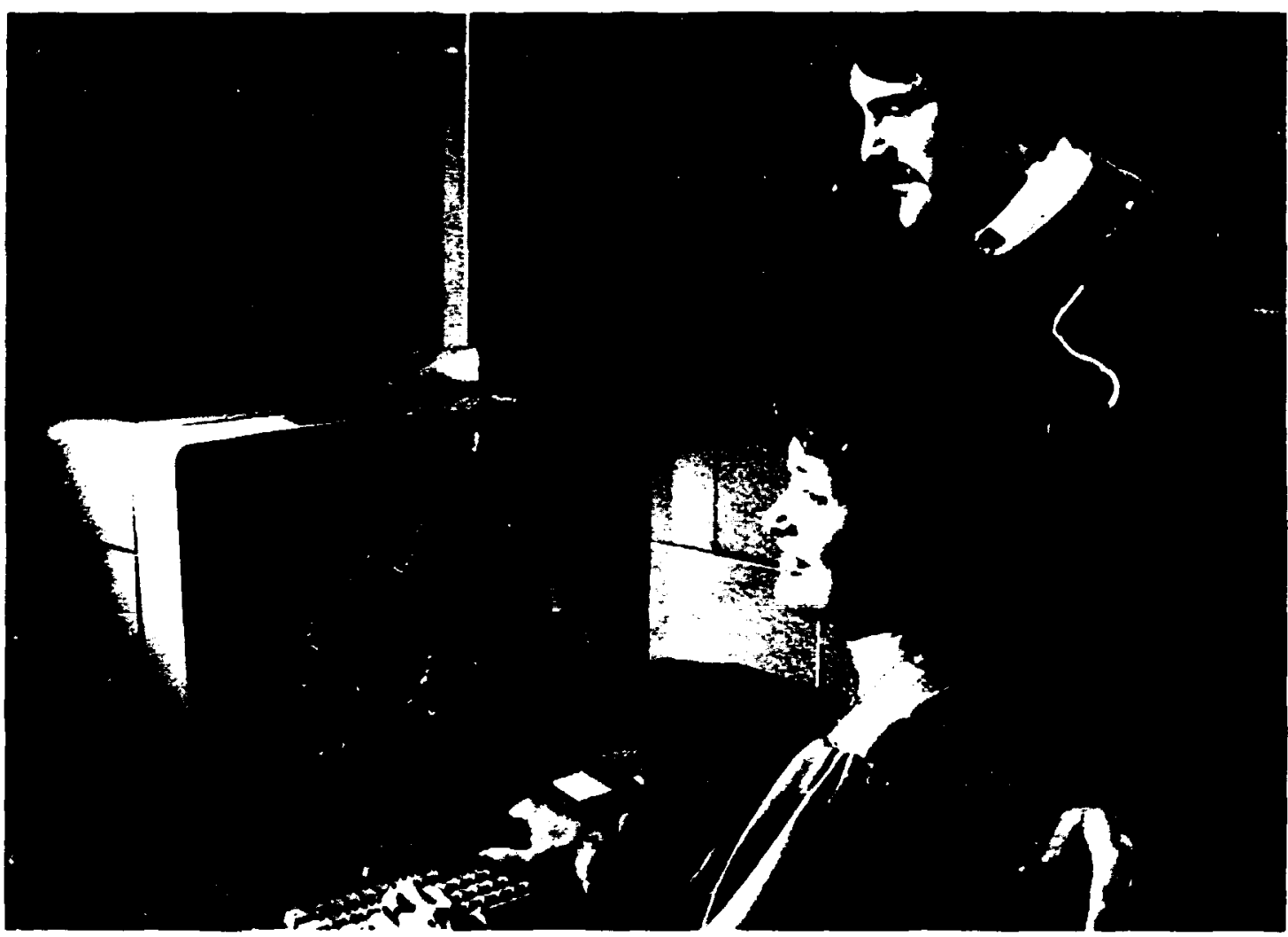

Kris Dearstone and Mike Sale evaluate the distribution of hydroelectric projects in the upper Ohio River Basin that are under review by the Federal Energy Regulatory Commission. By linking geographic locations with sife characteristics and experimental data, ESD's geographic information system enables scientists to address environmental questions pertaining to the facilities.

2086 sampled lakes (4\%) in southeastern Ontario are acidic. No acidic lakes were sampled in West Ontario. Acidic lakes totaled $<1 \%$ of the 1382 lakes sampled in North Ontario, a region characterized by generally low atmospheric deposition and high levels of dissolved organic carbon in its lakes.

Using a subset of 4017 lakes that have a relatively complete set of water-chemistry variables, we identified sulfate- vs organic-dominated low-ANC systems. Lakes with $\mathrm{ANC} \leq 0 \mu \mathrm{cq} / \mathrm{L}$ and roncentrations of $\mathrm{SO}_{4}{ }^{2-}$ greater than $\left[\mathrm{Ca}^{2+}+\mathrm{Mg}^{2+}\right]$ are primarily located in Sudbury/Noranda (106 of 230 acidic lakes). These 
106 lakes have relatively low organic anion concentrations and have experienced acidification due to historically high $\mathrm{SO}_{4}{ }^{2-}$ deposition originating from local smelters.

Lakes with ANC $\leq 0 \mu \mathrm{eq} / \mathrm{L}$ and concentrations of $\mathrm{SO}_{4}{ }^{2-}$ greater than $\left[\mathrm{Ca}^{2+}+\mathrm{Mg}^{2+}\right]$ are also located in southeastem Ontario and in the Maritime Provinces. For these acidic lakes, lakewater $\mathrm{SO}_{4}{ }^{2-}$ is much greater than organic anion concentrations, suggesting that these lakes have experienced some acidification due to atmospheric deposition. For the acidic lakes in Maritime Provinces with concentrations of $\mathrm{SO}_{4}{ }^{2-}$ greater than $\left[\mathrm{Ca}^{2+}+\mathrm{Mg}^{2+}\right]$, organic anions are present at concentrations similar to but less than those of $\mathrm{SO}_{4}{ }^{2-}$, indicating that a combination of mineral acids and organic acids is responsible for the current acid-base chemistry.

Twenty-eight acidic lakes (ANC $\leq 0 \mu \mathrm{eg} / \mathrm{L}$ ) located in the South Atlantic region (primarily Nova Scotia) have concentrations of organic anions greater than $\mathrm{SO}_{4}{ }^{2-}$ and greater than $\left[\mathrm{Ca}^{2+}+\mathrm{Mg}^{2+}\right]$. These proportions of anions suggest that the acidity is substantially influenced by organic acids.

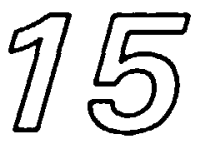

\section{A Regionally Unbiasod Kriging Procedure Is Developed for Environmental Survey Data from a Stratificed Derign}

\section{H. I. Jager and W. S.} Overton ${ }^{1}$

'Oregon State University, Corvallis.
The U.S. Environmental Protection Agency is undertaking a national survey, the Environmental Monitoring and Assessment Program (EMAP), designed to detect trends in environmental resources. The proposed sampling design is stratified into various resource categories within each ecosystem. Because these resources are interspersed over the landscape, a combined interpolation from multiple resources needs to be developed. A concern is that the detection of local trends from EMAP survey data through the use of interpolation methods will be biased by the unequal representation of the various strata in the sample. To address this concern, we have developed a kriging approach that reduces this bias by maintaining a regional balance in the local predictions.

Because data are not yet available from the EMAP survey, our method is being tested with data from the Adirondack region of New York State. Lakes from three alkalinity classes were selected in different proportions, with an overrepresentation of the lowest alkalinity stratum, which is of greatest interest. The large numhers of low- 
alkalinity lakes in the sample would normally cause a bias in interpolation. However, our kriging method maintains a regional balance in the estimates by combining local information from closer lakes (regardless of stratum) with regional information from lakes belonging to the corresponding stratum (regardless of distance).

This procedure reflects our philosophy about how to partition the spatial structure of environmental variables $(Z)$ between a deterministic ( $G=$ gradient) and a stochastic $(R=$ random) portion: $Z(x)=G(x)+R(x)$. Observed spatial autocorrelation usually results from interactions with covarying environmental gradients that are themselves autocorrelated. When the spatial pattern is sufficiently clear, these gradients are aligned with the spatial coordinates, and the location is said to influence the mean. In reality, location is usually a surrogate for these undertying causal factors. Thus, to the extent that predictive relationships can be found with geographic variables that are available for all items in the population, spatial autocorrelation can be explained as part of a deterministic gradient. Our approach differs from traditional geostatistical approaches in two ways: (1) the spatial gradient is regional instead of local-regional similarities among lakes belonging to the same stratum are modeled as empirical relationships that hold for each stratum over the entire region and (2) the spatial gradient is modeled as a function of basic environmental gradients rather than as a function of spatial location.

Our method with Adirondack lakes is to develop stratum-specific regression models based on explanatory environmental factors for which we have spatially extensive information. An iterative, generalized least-squares approach is needed to circumvent the problem of simultaneously estimating regression parameters of $\boldsymbol{G}(\boldsymbol{x})$ and the covariance model parameters of $R(x)$. A key requirement for the models is that their residuals share a common spatial autocorrelation structure across strata. Regionally unbiased local estimates are produced by adding (1) the mean predicted by a stratum-specific regression model and (2) the local random fluctuation predicted by kriging at each lake. Ultimately, our goal is to use this kriging approach in EMAP to identify locations that have experienced large temporal trends according to data from multiple resources. 


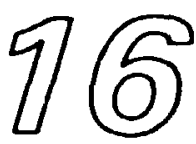

Roads Lead to Massive Deforestation in

Roodonia, Brazil

V. H. Dale, R. C. Frohn,

F. Southworth, ${ }^{2}$ R. V.

O'Neill, and E Hillsman ${ }^{2}$

'University of California, Santa Barbara.

${ }^{2}$ Energy Division, ORNL.
The Amazon Basin of Brazil has the largest tract of moist tropical rainforest in the world (more than $3.3 \times 10^{6} \mathrm{~km}^{2}$ ). Within the past two decades, the forests of Brazil have undergone large-scale clearing, which has serious global and local consequences. Global effects include a decrease in biodiversity; increases in atmospheric carbon dioxide, which may affect climate; and disruption of hydrological regimes. Local effects include soil erosion, siltation, decreases in soil fertility, loss of extractive resources, and disruption of indigenous populations.

Nowhere in the Brazilian Amazon has deforestation increased at a faster rate than in the state of Rondonia. Colonization programs in Rondonia successfully attracted a large number of migrants because soil quality there, although not good, was much better than other areas in the Amazon. The result of numerous migrants entering Rondonia and clearing forest for farming is rapid and large-scale deforestat:on. Current (1987) estimates of cumulative deforested area range from 16 to $19 \%$ of the state. If current rates of deforestation were to be maintained, all forested land in Rondonia would be cleared well before the year 2000 .

This project integrates colonization and ecological models to estimate patterns and rates of deforestation in Rondonia under different immigration and road devclopment scenarios. Deforestation in Rondonia is a function of road development, colonization, and individualfarmer clearing rates. As more roads are built or improved, more migrants enter a previously inaccessible area of forest and clear a portion of it for settlement. The presence of more colonists in the area justifics the construction of more roads, continuing the deforestation process. Roads increase the value of land and stimulate colonists to sell land to newcomers, who often have more resources and greater capabilitics to clear more land than the original landowners. The rate of deforestation in Rondonia will continue to increase as more roads are constructed to provide migrants access to the forest. 
4

Relationship Between Landscape Structure and Water Quality Are Analyoed to Determinc the Effect of Different Spatial Scales

C. T. Hunsaker, B. L Jackson, ${ }^{1}$ and S. P. Timmins $^{2}$

'Computing and Telecommunications Division, Martin Marietta Energy Systems, Inc. ${ }^{2}$ Analysas Corporation, Oak Ridge, Tennessee.
Understanding how landscape structure influences ecosystem function is critical for effective land use management and environmental policy. Thus, we are developing methods for identifying landscape factors that affect water quality and analyzing them at different geographic scales. Specifically, we are analyzing land use and water chemistry (e.g., nitrogen, phosphorus, turbidity, alkalinity, and conductivity) and explicitly considering their spatial context. Analyses are being applied to two study sites to determine the robustness of the results: an Illinois site, which covers $\sim 1 \times 10^{6}$ ha and contains 47 hierarchical watersheds grouped into 5 size classes, and a North Carolina site, which covers $1.1 \times 10^{6}$ ha and contains 11 watersheds grouped into 3 size classes. We are using correlations and analysis of variance to evaluate the strength of relationships between landscape indices (e.g., dominance, contagion, and amount of edge) based on land use and water chemistry. The influence of data resolution on landscape indices has been evaluated for a subset of the Illinois watersheds. Currently we are comparing the characteristics for entire watersheds, corridors along streams, and overland flow areas as determined from topography. We are also developing computer techniques to identify the areas contributing to overland flow in watersheds of different sizes and different degrees of relief.

Because land use is a good indicator of risk to water quality, the proportion of landscape in a particular land use is often correlated with water chemistry. In Illinois, for example, the amount and type of land use in a watershed usually accounts for $<20 \%$ of the variance in stream concentrations of total phosphorus and total inorganic nitrogen, except for the larger watersheds $\left(>1 \times 10^{5} \mathrm{ha}\right)$, where it accounts for 40 to $50 \%$. Moderate- (with 80-m pixels) and coarse-grained data (with 200-m pixels) are adequate for characterizing general land use: changes in landscape indices were not significant for changes in data resolution. These results will contribute to (1) the management of non-point-source watcr pollution by helping to refine analysis methods and identifying factors that are important in monitoring design and (2) the understanding of the influence of spatial scale and the effect of landscape pattern on water quality. This work also will help bridge the gap between existing 
research based on small experimental watersheds and management of watersheds at all scales. Related research will be supported by the Environmental Monitoring and Assessment Program under the aegis of the U.S. Environmental Protection Agency.

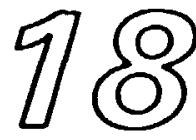

Bum Severity and Fint-Year Vezetation Rexpones Vary Following Lrgescale Fire on Sublpine Plateaus in Yellowstone National Part

M. G. Tumer, W. H. Romme, and R. H. Gardner

'Fon Lewis College, Durango, Colorado.
The fires in Yellowstone National Park in 1988 created an extremely heterogeneous landscape in terms of both the overall burning patterns and the variable fire severity within burned areas. However, few studies to date have dealt explicitly with the spatial variation of fire effects. To document the heterogeneity of the fires, we initiated field studies in 1989 at three sites located on subalpine plateaus (2500- to 2800-m elevation) in Yellowstone Park At each site, we sampled 100 points distributed regularly in a 1-km by $1-\mathrm{km}$ grid, recording information on several parameters of burn severity (severity class, depth of ash, depth to which soil was charred, and percent mineral soil exposed), prefire community structure (forest suciessional stage; tree density; tree species; and tree size, measured by diameter at breast height), first-year plant responses (percent cover of graminoids, forbs, and low shrubs; dominant species; and number of seedlings of Pinus contona var. latifolia), and general site characteristics (slope and aspect). Four burn-severity classes were used: unburned; light surface burn, in which canopy trees still have green needles although stems may be scorched; moderate burn, in which needles on canopy trees are dead but were not consumed by fire; and crown fire, in which needles of canopy trecs were completely consumed by fire. All burn-scverity classes were represented on each site. The depth to which soil was charred increased with burn scverity, ranging from an average ot $5.8 \mathrm{~mm}$ in lightly burned sites to $13.6 \mathrm{~mm}$ in sites that experienced crown fircs. Among burn-scverity classes, unburned sites had the highest vegetative cover in forbs $(11.7 \%)$, graminoids $(18.2 \%)$, and low shrubs $(19.5 \%)$. Total vegetative cover declined somewhat in lightly burned sites but was extremely low in moderately burned $(<10 \%)$ and crown fire sites $(<4 \%)$. The percent cover of exposed mineral soil was greatest in crown fire sites $(81.9 \%)$ and lowest in unburned sites $(4.9 \%)$. Secdlings of the dominant trec species, $P$. contona, tended to occur in or near arcas that were lightly to moderatcly burned. Our results demonstrate tremendous 


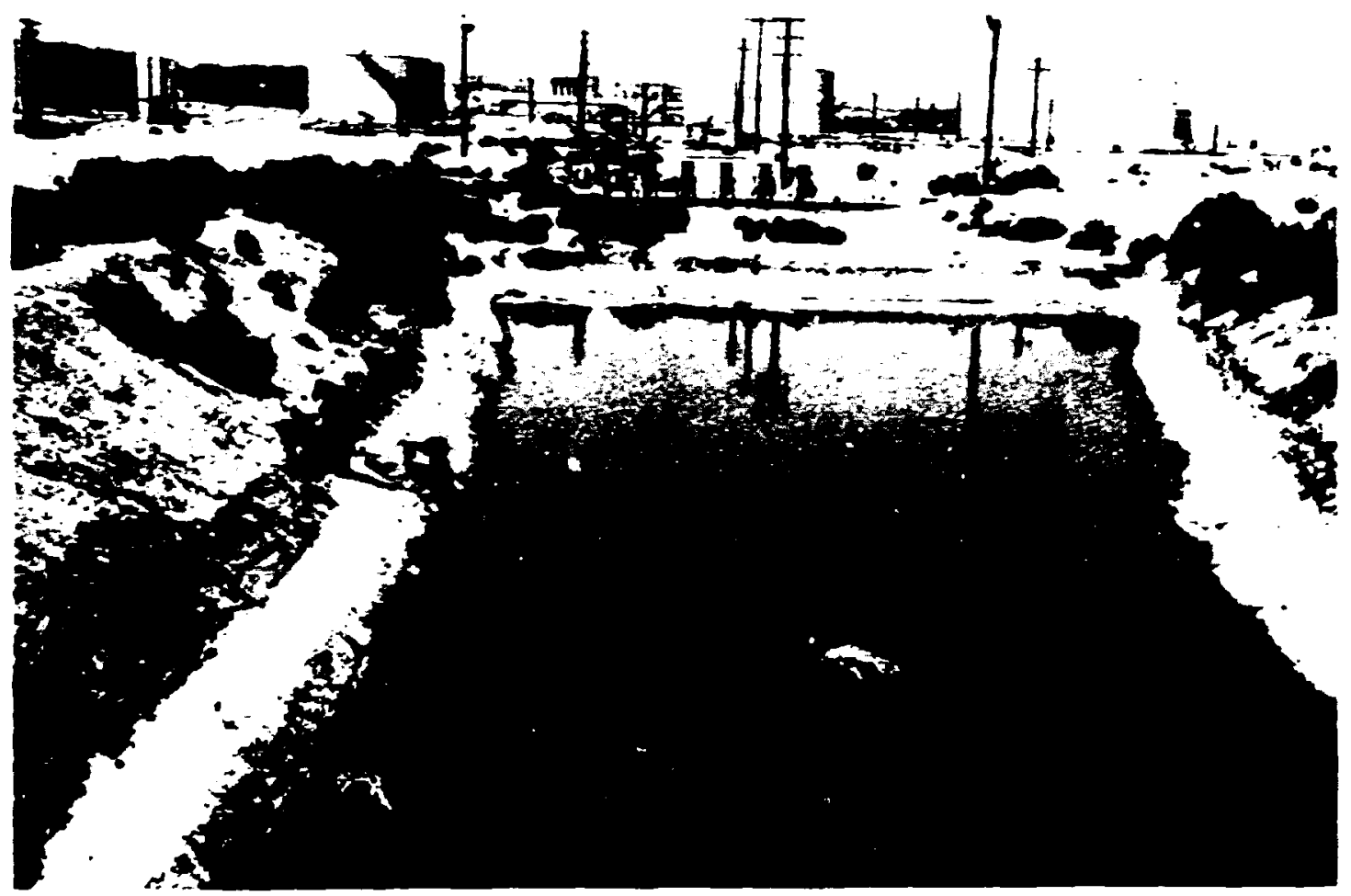

Researchers collect samples from a water sump at the Elk Hills Naval Petroleum Resenve No. 1 in the San Joaquin Valley, California. As part of an ongoing DOE project, Glenn Suter, Lamy Bamihouse,
John McCarthy, and Kirty Gustin have analyzed chemical concentrations in the oil fields and studied their effects upon mammalian wildlife.

heterogeneity in burn severity and first-year plant responses in areas burned by the 1988 fires.

The field data also provided the basis for broad-scale analyses of the Yellowstone landscape using the park's geographic information system. Data from our three $1-\mathrm{km}$ by $1-\mathrm{km}$ grids were compared with a classified Landsat image obtained in October 1988. Agreement between burn severity recorded in the field and that recorded in the Landsat image ranged from 85 to $95 \%$. Using the Landsat data, we then examined patterns of bum severity as a function of stand age across the entire subalpine plateau in Yellowstone. Fires that burned carly and late during the summer of 1988 were compared. Throughout 
the summer, severe ?ires occurred most frequently in old-growth stands (>300 years old). However, a significantly greater proportion of tounger stands ( 0 to 150 years old) bumed late in the summer when conditions were extremely dry and windy than burned early in the summer. This analysis suggests that the amount and spatial distribution of old-growth stands may influence fire patterns when weather conditions represent a "typical" dry year but may have less influence on fire behavior under extreme conditions.

40

Global Climate Change Studies on Reservoir Water Quality and Fus Habitat Are Initiated

S. F. Railsback and L. $H$. Chang'

'Duke University, Durham, North Carolina.
A preliminary assessment was made concerning the effects of global climate change on fish habitat in a southeastern reservoir. Climate change potentially could alter a number of parameters that control the suitability of reservoirs for cool water fisheries, including air temperatures, inflow water temperatures, humidity, river flow rates, wind speeds, and solar radiation.

Simulations of current water quality at Douglas Lake, a multipurpose Tennessee Valley Authority reservoir, were made by using an existing model of reservoir water quality, along with baseline data on meteorology, hydrology, and inflow water quality for Douglas Lake for 1 year. For each day, the model computed total adult striped bass habitat, defined as the reservoir volume having acceptable or optimal temperatures and acceptable or optimal dissolved oxygen concentrations.

Output from recent runs of general circulation models (GCMs), in which atmospheric $\mathrm{CO}_{2}$ concentrations had been doubled, was used to adjust the baseline input data for the reservoir model. Six different scenarios for greenhouse effects and climate change were modeled by using two grid cells for each of three GCMs. The reservoir model determined striped bass habitat for cach climate scenario. The reservoir volumes with optimal, suboptimal, and unsuitable temperatures and dissolved oxygen concentrations were predicted for a 1-year period.

All six climate change scenarios predicted overall declines in amounts of available summer striped bass habitat, mostly due to lake water temperatures exceeding striped bass tolerances. Some scenarios showed loss of habitat due to decreased oxygen concentrations, whereas some showed little change in oxygen concentrations, and others showed increases. 
The resenoi: model was found to be useful for assessing impacts of climate change. Some of the assumptions required to apply GCM output to the reservoir model illustrate the problems of scale in using grid cell output to assess small-scale impacts. These scale differences could be overcome with additional models and methods.

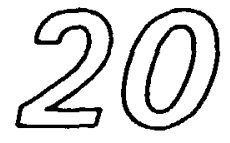

Potential OffSite Ecological Rists of the DOE Oak Ridge Facilities Are Identified

\section{G. W. Suter II and L A Hook $^{1}$}

'Science Applications Intemational Corporation, Oak Ridge, Tennessee.
The three major facilities on the DOE Oak Ridge Reservation have released radionuclides and toxic chemicals that have entered the off-site environment through tributaries of the Clinch River. As part of the Environmental Restoration Program at Oak Ridge, a remedial investigation has been instigated to determine the risks posed by these materials to humans and to nonhuman organisms. Existing data on chemicals in offsite waters, fishes, and sediments were compiled. These data were used to screen the chemicals to determine what additional data must be obtained in the remedial investigation. The data were assigned to reaches that could be associated with contaminated tributaries (McCoy Branch, White Oak Creek, and Poplar Creek), to the downstream reach (Watus Bar Reservoir), or to reference reaches (Norris Reservoir, Tennessee River, upper Poplar Creek, and East Fork Poplar Creek).

This assessment considered potential effects on fish. benthic organisms, and piscivorous wildlife. The method employed was comparison of concentrations in water, sediment, and fish to three screcring criterion concentrations: an upper criterion at which acute lethality or other severe effects would occur, an intermediate criterion at which chronic reductions in productivity would occur, and a lower criterion at which no effects should occur. Effects would not necessarily occur if critcria are exceeded in the actual environment. This is because the measurements often included chemical forms that are not available to organisms in field environments. Upper and intermediate critcria for aquatic organisms were based on National Water Quality Criteria; other criteria were derived from the toxicological literature.

Significant findirgs included the following:

(1) aqueous concentrations of 16 chemicals exceeded their upper or intermediate critcria; (2) survival or reproduction of piscivorous wildlife may be affected by mercury, PCBs, sclenium, and DDT; and (3) concentrations of mercury in 
water. sediment, and fish exceeded the upper or intermediate criteria for fish. benthic organisms, and piscivorous wildlife in reaches below White Oak Creek and Poplar Creek Many organic chemicals were not detected but. because past analytical methods were relatively insensitive, had limits of detection above their intermediate criteria. These results are preliminary, further risk assessments that incorporate both the new data being generated and better risk models will be conducted.

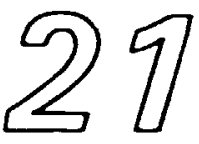

Comprehensive Review of Environmental and Health Efrods from Firs Soviet Plutonium-Production Site Is Completed

J. R. Trabalka and S. I. Auerbach
Much information about a 1957 chemical explosion of high-level radioactive waste (HLW) at the Chelyabinsk-40 nuclear complex $(\mathrm{Ch}-40)$ in the Urals is available, but seeming inconsistencies limit interpretation of information on causalities and consequences. This situation is exacerbated by the complicated history of radioactive releases from $\mathrm{Ch}-40$. Casualties resulting from the 1957 accident have been widely reported but are still unconfirmed. However, the occurrence of (1) chronic radiation sickness and high cancer incidence among $\mathrm{Ch}_{-40}$ workers and (2) excess leukemia incidence in some off-site residents has recently been confirmed.

The total radioactivity released by the 1957 accident was $20 \mathrm{MCi}$-ten times more than first reported and comparable to that from the Chernobyl reactor accident ( $50 \mathrm{MCi})$. The activity of ${ }^{90} \mathrm{Sr}$ plus ${ }^{137} \mathrm{C}$ s was also comparable to that from the Chernobyl accident. Whereas ${ }^{137} \mathrm{C}$ s represented about $80 \%$ of the activity of long-lived materials from Chernobyl, it comprised either 0.66 or $12 \%$ of the 1957 release! About $10 \%$ of this was more widely dispersed and deposited along a 345-km-long track and over an area of 15,000 to $23,000 \mathrm{~km}^{2}$. The most highly contaminated portion ( $22 \mathrm{Ci} / \mathrm{km}^{2}{ }^{90} \mathrm{Sr}$ ) encompassed a $1000-\mathrm{km}^{2}$ area, outside of which effects appear to have been slight (e.g., radiation doses to residents 1 to $10 \%$ of background).

A total of 10,730 or more persons were evacuated from 19 or 23 populated places in a $90-\mathrm{km}$-long $\left(700-\mathrm{km}^{2}\right)$ zone contaminated with 2 to $4 \mathrm{Cikm}{ }^{20} \mathrm{Sr}$, and severe land-use restrictions still exist over $24 \%$ of this area. Approximately 1100 people were rcmoved within 7 to $10 \mathrm{~d}$ from arcas with a reported mcan ${ }^{50} \mathrm{Sr}$ concentration of 500 $\mathrm{Ci} / \mathrm{km}^{2}$, and the rest were evacuated in stages over 250 to 
$670 \mathrm{~d}$. Acute radiation effects on aquatic and forest ecosystems were observed primarily in areas where earty evacuations of the human population occurred. Farm animals were dying from acute radiation sickness at about the time of the firs: evacuations (9 to $12 \mathrm{~d}$ ). Maximum effective radiation dose equivalents (ERDEs) in those evacuated were supposedly about $100 \mathrm{rem}$, and no significant health effects were recorded over a 30-year period. However, only a fraction of the evacuated population received medical examinations within 2 years after the accident-none before 9 months. Critical

Oral Photo-1254-91

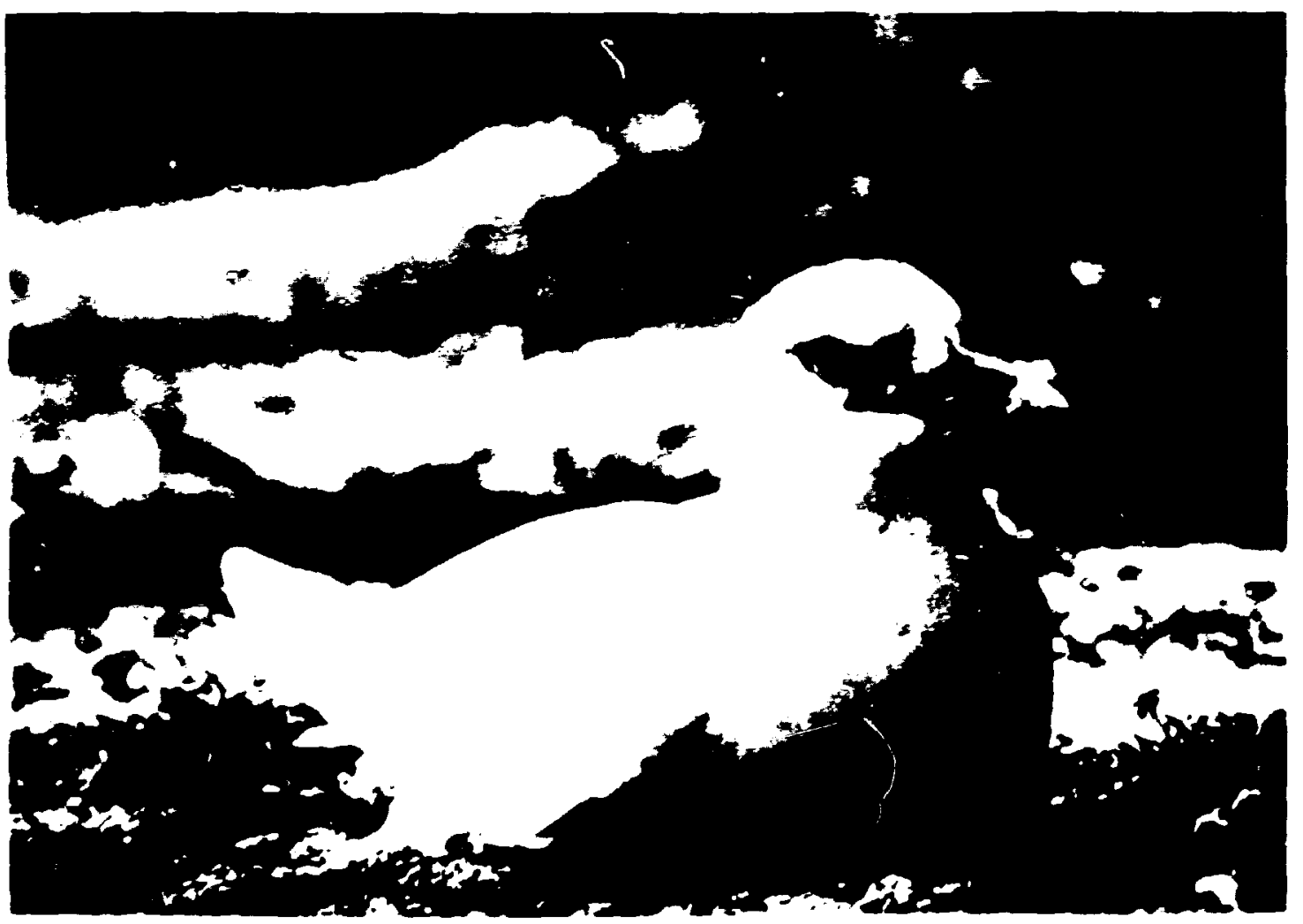

ESD researchers studied the potential impacts that a nerve gas incineration facility would have on marine biota and thineen species of seabirds (including the Red-tailed Tropicbird, shown here) that nest on the islands comprising Johnston Atoll. As part of an ORNL team, Paul Kancinuk, Roger Kroodsma, and Glenn Surer helped prepare an environmental impact statement for the U.S. Army, which operates the facility on Johnston Island, 750 miles southwest of Hawaii. 
information about acute radiation effects could have been lost over this period. Other questions about the health effects studies currently prevent a complete assessment of the accident's effects.

Releases from Ch-40 (3 MCi from 1949 to 1952) contaminated the adjacent Techa River drainage, required the cvacuation of $\geq 7500$ persons prior to 1957 , and resulted in radiation exposures (ERDEs up to $140 \mathrm{rcm}$ ) to a much larger population. Onc result was an excess keukemia incidence of about 20 cases over a 25 -year period. A small reservoi (Karachay) at the site, containing $120 \mathrm{MCi}$ of radioactivity (apparently from early intermediate-level and/or HLW disposal practices), was the source of additional releases-both liquid and aerosol.

Wind-oorne sediments from its shoreline contaminated a $1800-\mathrm{km}^{2}$ area with $600 \mathrm{C} \mathrm{i}$ (mainly ${ }^{90} \mathrm{Sr}$ and ${ }^{137} \mathrm{Cs}$ ) in 1967. $A$ number of unconfirmed reports of reactor accidents also exist, some from seemingly authoritative sources (c.g.. Andre Sakharov). The extent to which other con:amination sources from $\mathrm{Ch}-40$ contributed to reports of casualties or to the need for the massive hydrologic isolation system in evidence near the site are still major unresolved questions.

\section{Section Staff}

S. G. Hildebrand

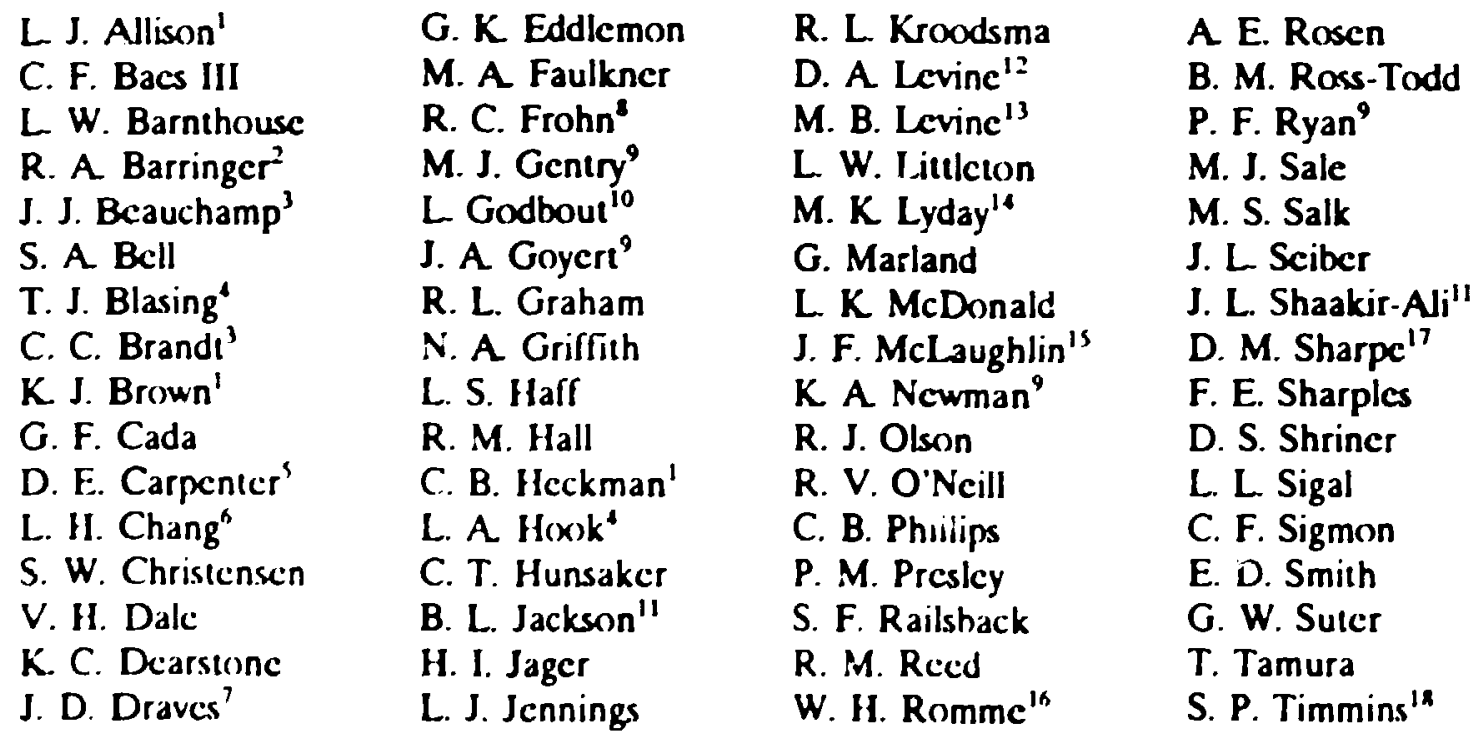



V. R. Tolbert
M. G. Turner
L. D. Voorhees
J. W. Webb
J. R. Trabalka
R. S. Turner
R. O. Wadlington
Y. Wu
C. S. Tucker
K. C. Van Hoesen'
J. A Watts

1. Health and Salety Research Division, ORNL

10. Posedoctoral fellow.

2 JAYCOR, Oak Ridge, Teanessee.

3. Engineering Physios and Mathematios Division, ORNL

4. Foosystem Studies Section, ESD.

5. Graduate student, University of California, Los Angeles.

6. Professional Intern Program. Oak Ridge Associated Universities, Oat Ridge, Te.messee.

7. Graduate Student Research Paricipation Progran, Oak Ridge Associated Universities, Oak Ridge, Tennessee.

11. Computing and Telecommunications Division, Martin Marietta Energy Systems, Inc.

12. Graduate student, Indiana University, Bloomington.

13. Postmasters fellow.

14. Automated Sciences Group, Inc., Oak Ridge, Tennessee.

15. Holbender fellow.

16. Fon Lewis Colkge, Durango, Colorado.

17. Southern Illinois University, Carbondale.

18. Analysas Corporation, Oak Ridge, Tennessee.

8. Miami University, Oxford, Ohio.

9. Science Applications International Corporation, Oak Ridge, Tennessee. 


\section{Environmental Toxicology}

\section{Introduction}

The Environmental Toxicology Section of the Environmental Sciences Division (ESD) is involved in basic and applied research on both the mechanisms through which contaminants affect biological systems and the ways in which receiving systems affect the availability and distribution of materials to which they are exposed. Research is conducted from the subcellular and biochemical level to the ecosystem level with experimental. observational. and simulation studies. The seven groups that constitute the section are supported by the U.S. Department of Energy (DOE); the U.S. Department of Defense; the L.S. Department of Agriculture; the - S. Environmental Protection Agency: the Electric Pouer Rescarch Institute: and the remedial action, waste disposal, and environmental restoration projects at Oak Ridge National Laboratory (ORNL), the Oak Ridge Y-12 Plant, the Oak Ridge Gascous Diffusion Plant, the Paducah Gascous Diffusion Plant, the Portsmouth Gascous Diffusion Plant, and various other DOE facilitles (e.g., the Savannah River Plant).

The Biological Chemistry Group investigates both the role of molecular, biochemical, and physiological processes regulating the biological accumulation of contaminants and the adverse effects these contaminants have on the environment. Identification and evaluation of potential biological markers are significant components of these studies. The dispersal of contaminants through the subsurface environment is also being examined. especially with respect to the role of organic and inorganic collosidal particles in cohancing the mohility of hazardous chicmica!s in groundwatcr.
Activities of the Biomonitoring and System Recovery Group center on the response of Oak Ridge Reservation streams to waste management and remedial action activities. Long-term monitoring of the biota and evaluation of the mechanisms affecting the recovery of these streams are the primary objectives of this wurk. Emphasis is also placed on developing criteria needed to determine the ecological health of streams.

The Environmental Toxicology Modeling Group is developing capabilities for predicting direct and indirect effects of contaminants released to the environment. Sinulation modeling and mathematical tools are used by this and other groups in forecasting the fate and effects of contaminants in the environment.

The Microbial Interactions Group is a new group focusing on the role of microbes in degrading, mobilizing, or immobilizing contaminants and in modifying the environment to enhance the occurrence of any of these processes. The role and the activities of microbes in uncontaminated environments are also a focus of this group.

Biogeochemical cycling, environmental transport, and fatc of contaminants in aquatic environments are evaluated in the Matcrials Transport and Fate Group. A primary thrust is the invesligation of the factors ontrolling contaminant distribution and availability in the ccosystems of river reservoirs. The groun is also responsible fo; off-site activities asinciated with the Oak Ridge Reservation's RCRA (Resource Conservation and Recovery Ait) Facilities Investigation.

The Physiological Ecology Group is responsible for studies related 10 the response of vegetation $(O)$ natural and anthropogenic stresses and the biogecohemistry of contaminants in terrestrial ecosystems. Current emphasis is 
on developing a better understanding of the effects that acidic deposition, ozone, other oxidants, and $\mathrm{CO}_{2}$ have both on individual tree seedlings in controlled field exposure systems and on forest stands.

Research in the Toxicology Laboratory Group focuses on identifying the sources of chronic and acute toxicity in wastewaters and streams on the Oak Ridge Reservation. The group also develops in situ and laboratory tests to detect and quantify toxicity and empirically determines how environmental and chemical conditions interactively influence test inter retation.

The following pages contain selected summaries reflecting ongoing activities during the past year. Three of these highlighc our increased activity in microbial processes and focus on the ability of microbes to degrade complex organics or enhance their degradation. Two of the others deal with the response of biota to effluents and the use of such response in evaluating effluent releases. The movement of materials in surface water, subsurface water, and biota continues to be an important aspect of research of great utility in evaluating waste management activities and remedial actions. Three highlights focus on these studies. Finally, understanding the physiological aspects of plant responses to stress remain a scientific focus that is covered in the last three summaries included in this section.

\section{Technical Summaries}

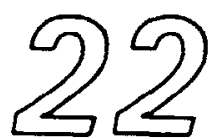

Organic Contaminants Commonly Found in Association with Trichloroethylene Can Significantly Influence Its Degradation by MethaneUtilizing Bacteria
A. V. Palumbo, W. Eng,
P. A Boerman, and
S. E. Herbes
'The University of
Tennessee, Knoxville.

In preparation for field demonstrations of biodegradation of chlorinated solvents at a DOE site in Oak Ridge, Tennessee, the impact of mixtures of organic contaminants on the biodegradation of trichloroethylene (TCE) by methane-utilizing bacteria is being assessed. The contaminants at DOE sites in Oak Ridge include anacrobic degradation products of TCE [c.g., dichloroethylenes (DCEs)] and compounds disposed of with the TCE, including tetrachloroethylene (PCE), toluene, other aromaties, and numerous chlorinated and nonchlorinated compounds. The effects of carbon and energy sources other than methane on microbial degradation rates werc also tested.

Both 1,1-DCE and PCE, at concentrations of $6 \mu \mathrm{M}$, were found to significantly decrease degradation rates of other chlorinated ethylenes (c.g., trans-1,2-DCE at 50 to $800 \mu M)$ by Methylosinus trichosporium sirain OB.3b. These compounds are also either very slow to degrade 
(1,1-DCE) or are not degraded at all (PCE). Estimated maximum velocitics $\left(\mathrm{V}_{\text {max }}\right.$ ) for 1,1-DCE, cis-1,2-DCE, trans-1,2-DCE and TCE degradation were 16, 28, 21, and $14 \mathrm{nmol} \bullet \mathrm{h}^{-1} \bullet \mathrm{mg}^{-1}$ of protein, respectively. Preliminary experiments with mixed methane-utilizing batch cultures have indicated that low concentrations $(2 \mu M)$ of toluene do not significantly reduce TCE degradation.

Methanol was found to relieve growth inhibition of OB3b at high TCE concentrations (106.5 $\mu M)$. However, the addition of methanol to cultures grown on methane significantly reduced the rate of TCE degradation.

Although methanol reduces the toxicity of TCE to the cultures, biodegradation of TCE cannot be sustained in methanol-grown cultures. Because high TCE concentrations appear to inhibit methane uptake and growth the primary toxicity of TCE appears to be directed toward methane monnoxygenase (MMO). Future work will evaluate the effect of formate, which should provide energy to the cells without inhibiting either MMO production or degradation of TCE.

These results demonstrate that other crganic contaminants in water can significantly alter the rate of TCE degradation by methanotrophs. Examination of the effects of additional aromatic compounds and chlorinated ethenes present in groundwater at the demonstration site is planned prior to initiation of the ficld demonstration. Effects of contaminants in the site water will be evaluated by the usc of molecular probes being developed as indicators of methanotroph biomass and activity as well as by measurements of TCE degradation. These studies will enable the rates of degradation of the field bioreactor demonstrations to be optimized and will increase the understanding of the factors that affect TCE degradation in the bioreactor system.

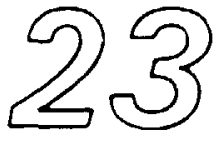

Consortial Microbial Activity and Resilience in the Westinghousc Savannah River Site Bioremediation Integrated Demonitration Ave Defincd
Objectives of this study were (1) to define the baseline microbial community structure and nutritional status of the endogenous microbiota recovered from the plume in the horizontal well system at Westinghouse Savannah River Sitc (WSRS) prior to the initiation of warm air and methane co-metabolite introduction using the in situ signature hiomarker system developed with the subsurface science program and (2) (1) establish microbial consortia 
D. C. White, T. J. Phelps, and D. B. Ringelberg'

'The University of Tennessee, Knawille. recovered from contaminated plumes at WSRS in bioreactors to test for substrate specificity, biogradation capacity, and resiliency to stresses.

Subsurface samples were recovered from between the horizontal wells in the WSRS integrated demonstration by using proper anticontamination procedures. The sediments were lyophilized; extracted by means of the reversed serial one-phase solvents extraction; fractionated into neutral lipids, glycclipids, and polar lipids; and

\section{ORNL Photo-6284-90}

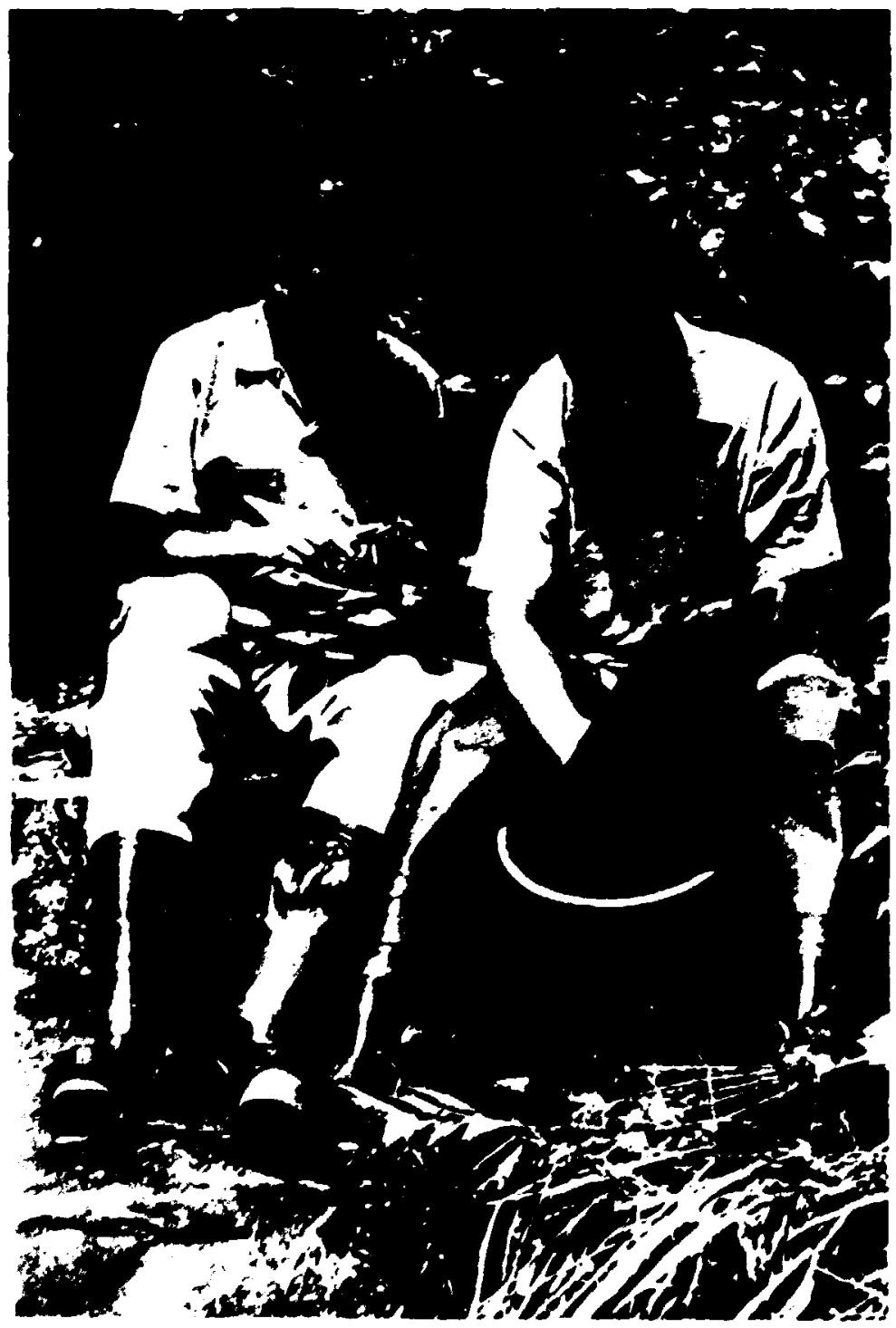

John Smith (right) and Tony McWhorter gather and measure the length of small freshwater clams that have been maintained in Whise Oak Creek Growth and mortality of the clams are being studied to determine the species' suitability for use as bioindicators in assessing the water quality of selected streams on and adjacent to the Oak Ridge Reservation. 
derivatized from capillary gas chromatographic separation with detection by chemical ionization-extracted ion mass spectrometry. Phospholipid ester-linked fatty acids (PLFA) provide in situ community structure and nutritional status definitions that shift with manipulation and contamination. The initial predemonstration baseline samples show an in situ low biomass of -1 picomole of PLFA per gram of dry weight $\left(<10^{5}\right.$ microbacteria per gram), with evidence of nutritional stress-an ideal community for manipulation for fortuitous biodegradation.

Microbial consortia have been recovered from contaminated plumes at the WSRS site and used in gastight recycling bioreactors for aerobic fortuitous metabolism of mixtures of organic halogenated hydrocarbons and benzene-toluene-xylene (BTX) recovered from Oak Ridge Y-12 Plant wells utilizing methane and propane as co-metabolites. One to three orders of magnitude decreases in chlorinated hydrocarbons, trichloroethylene (TCE), dichloroethylenes, vinyl chloride (VC), and BTX were demonstrated. Mineralization of ${ }^{14} \mathrm{C} \mathrm{TCE}$ to ${ }^{14} \mathrm{C} \mathrm{CO}_{2}$ established biodegradation. Slow aerotic breakdown of perchloroethylene and rapid inducible VC mineralization have been demonstrated.

\section{4}

Microbial Degradation of Trichloroethylene Occurs Faster in Soits Containing Plant Roots

B. T. Walton and T. A Anderson ${ }^{1}$

${ }^{1}$ The University of Tennessee, Knarville.
The possibility that vegetation may be used to actively promote microbial restoration of chemically contaminated soils was tested by using rhizosphere and nonvegetated soils collected from a field site contaminated by trichlorethylene (TCE). The field site was formerly a shallow basin excavated from the soil which was used as a chemical disposal site for chlorinated solvents and other chemicals from ca. 1956 to ca. 1974. Fill was added, and the site was graded to an area of $\sim 100$ by $100 \mathrm{~m}$. Several characteristics of the site made it a favorable location for exploring the potential for vegetation to be managed as an integral part of site remediation. Specifically, the area is small and inaccessible to the public, TCE and other hazardous chemicals are present in relatively low concertrations, and no imminent hazard to human health exists. Moveover, the site has become vegetated naturally during the 10 or more years since chemical disposal stopped; thus, sufficient time has passed for the 
populations or consortia of TCE-degrading microorganisms to be enriched in the rhizosphere.

We collected soil samples from the rhizospheres of the four predominant plant species [a grass, Paspalum notatum var. saurage Parodi; a legume, Lespedeza cuneata (Dumont); a composite herb, a Solidago sp.; and loblolly pine, Pinus taeda L/ and from the nonvegetated (edaphosphere) soils. Biomass determinations of microorganisms, disappearance of TCE from the headspace of spiked soil slurries, and mineralization of $\left.{ }^{14} \mathrm{C}\right]-\mathrm{TCE}$ to ${ }^{14} \mathrm{CO}_{2}$ all showed that microbial activity is greater in rhizosphere soils than in edaphosphere soils and that TCE degradation occurs faster in the rhizosphere than in the edaphosphere. These studies indicated that vegetation may be an important variable affecting microbial degradation of hazardous orgenic compounds and can be managed to achieve biological restoration of chemically contaminated surface and near-surface soils.

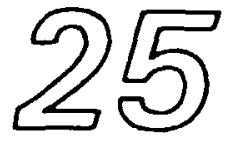

Index of Biotic Integrity Is Used to Evaluate Effectiveness of Waste Treatment and Pollution Abatement on East Fork Poplar Creek

M. G. Ryon and J. M. Loar
The Biological Monitoring and Abatement Program (BMAP), a requirement of the National Pollutant Discharge Elimination System permit issued in May 1985 for the Oak Ridge Y-12 Plant, includes a task to assess the effects of plant operations on the fish communities in East Fork Poplar Creek (EFPC). A major component of this task is the application of the Index of Biotic Integrity (IBI). Biotic integrity is defined as "the ability to support and maintain a balanced, integrated, adaptive community of organisms having a species composition, diversity, and functional organization comparable to that of natural habitat of the region."

The IBI is an impact assessment methodology that incorporates data on species richness and composition, trophic composition, and fish abundance and condition. Twelve individual metrics within these three categories are ranked on a scale of 5,3, or 1 and then summed to provide a numerical index that raies the biotic integrity of the fish community from excellent to very poor. Bccause the IBI was designed for the Midwest, several metrics were modified to represent expected conditions for streams in East Tennessee. Data on fish species richness and abundance at sites on minimally disturbed strcams in the Hinds Creck watershed northeast of Clinton, Tennessce, were plotted as a function of watershed area to estimate maximum IBI mctric valucs. 
ORNL-Photo-6276-90

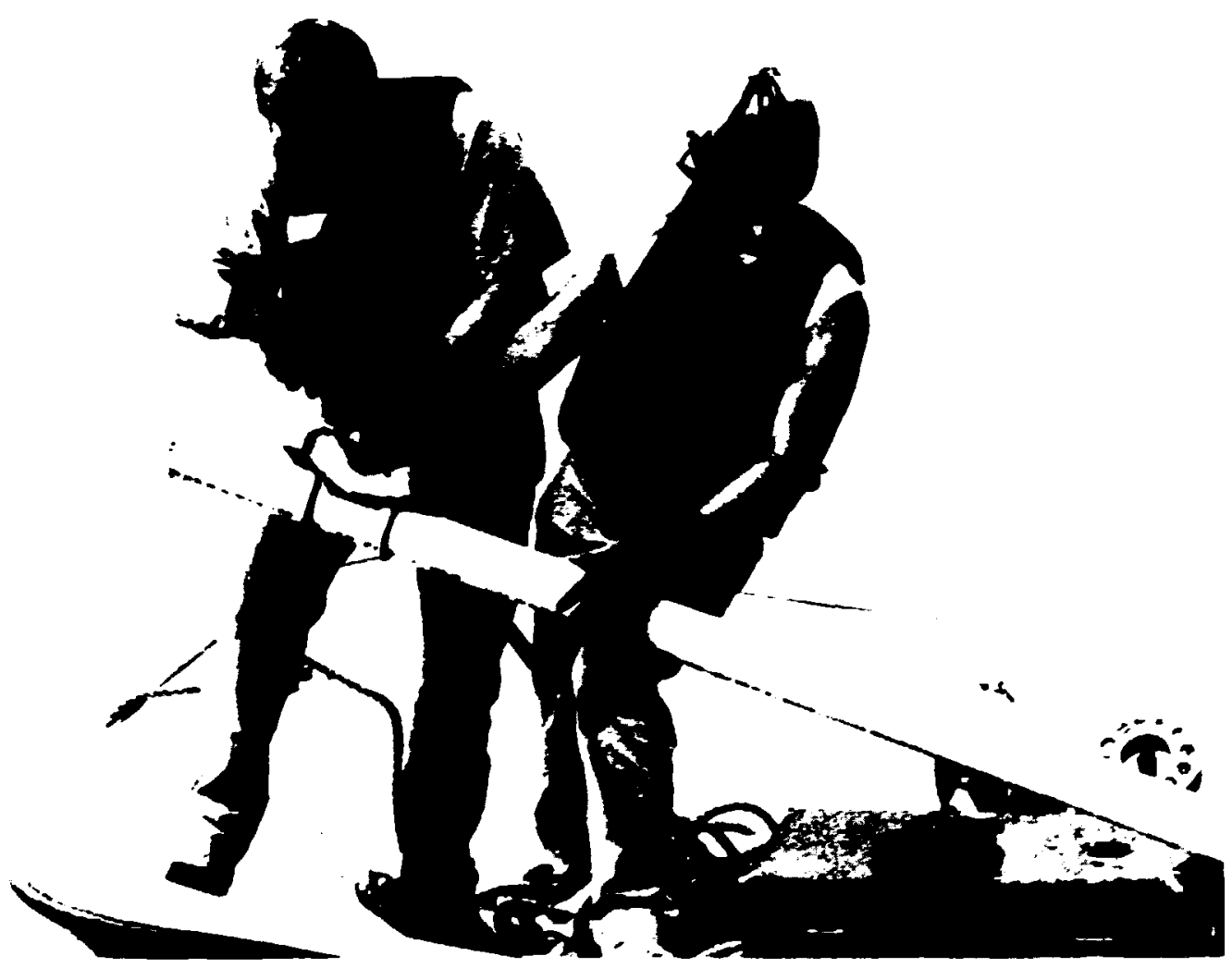

Clell Ford (left) removes part of a vibracore device from a sediment core tube with the assistance of Scott Niemela. Researchers are collecting sediment cores from area resenoirs to analyze concentrations of metal, onganic, and radionuclide contaminants. Results of the analyses will help researchers determine the nature and extent of off-site contamination both upstream and downstream from the Oak Ridge Reservation.

The fish communities in EFPC were analyzed for the period $1985-1989$ by using the regionally modified IBI. Both temporal and spatial improvements in the IBI ratings were observed during this period. The two sites closest to the Y-12 Plant had the most ratings of very poor, while sites further downstream were usually rated higher (poor to fair). An increase in the IBI rating at the site closest to the plant corresponded in time with the startup of a major new wastewater treatment facility. The improvement was altributable $t(0)$ an increasc in specics abundance but was not supported by increases in species richness or trophic 
composition. Temporal improvements in all major categories were also observed at downstream sites, suggesting a broader recovery. These patterns of change in the IBI rating indicate that a gradual and consistent recovery is occurring in EFPC. However, the fish community in EFPC is still more impacted than the fish assemblages that inhabit other local streams in watersheds with similar levels of agricultural and urban development.

Use of the IBI to monitor long-term responses of the fish community in EFPC will provide one of the best assessments of the effectiveness of pollution abatement measures and remedial actions at the Y-12 Plant. Because the IBI integrates information from several levels of biolggical organization, ranging from the individual to the ecosystem, it provides a sound ecological basis for assessing water quality. Applications of the IBI will be expanded to include streams that are part of other biological monitoring programs on the DOE Oak Ridge Reservation.

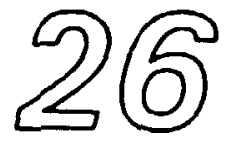

Efilvents from the Oak Ridge Y-12 Plant Aler Patterns in Production of Benthic Invertebrates in Eaxt Fort Poplar Creek

J. G. Smith and J. M. Loar
East Fork Poplar Creek (EFPC) originates within the boundaries of the DOE Oak Ridge Y-12 Plant and receives numerous discharges within a $1.5-\mathrm{km}$ reach of its headwaters before flowing through the city oi Oak Ridge, Tennessee, where additional perturbations occur. The objectives of this study were to (1) obtain preliminary estimates of secondary production of the benthic invertebrate community at six sites in EFPC and (2) relate these estimates to the sources and types of known perturbations.

Monthly invertebrate samples were collected over a 2 year period at each site, and community production was estimated by using the size-frequency and production to biomass ratio methods. Production ranged from 7.5 to $321.0 \mathrm{~g}$ wet weight $\bullet \mathrm{m}^{-2}$ year ${ }^{-1}$, with the lowest and highest values in both years occurring at the headwater and midreach sites, respectively. Chironomids and oligochactes dominated production in the headwater sites, but their contributions decreased considerably with increasing distance from the Y-12 Plant. In contrast, contributions to production by longer-lived taxa (e.g., Trichoptera and Ephemeroptera) increased with increasing distance from the Y.12 Plant. 
The decreasing contributions of shorter-lived taxa io production with increasing distance from the Y-12 Plant suggest that episodic releases of toxicants (e.g., chlorine) may be one of the main factors controlling benthic invertebrate community structure and pruduction in upper EFPC. As the magnitude and frequency of the perturbations decrease with distance downstream, the more stable conditions allow longer-lived taxa to become established and increase their contributions to community production.

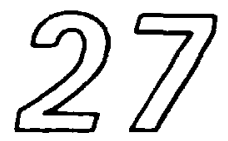

Radioactive Contaminants in Migratory and Resident Waterfow Inhabiting White Oak Lake on the Oak Ridge Reservation Are Areseod

B. G. Blaylock and A. E. Waters'

${ }^{1}$ The University of Tennessee, Knowille.
White Oak Lake (WOL) has served as the final settling basin for low-level radioactive effluents from ORNL since the lake was created in 1943. Biota in the lake, which has a surface area of $\sim 6.8 \mathrm{ha}$, contain elevated levels of radionuclides, primarily ${ }^{60} \mathrm{Co},{ }^{137} \mathrm{Cs}$, and ${ }^{90}$ Sr. Migratory waterfowl use the lake as a resting area, and several hundred ducks have been observed on the lake during peak migration periods. A major concern is that hunters who harvest and consume migratory ducks that have accumulated radioactivity in their tissues during their residency on WOL will receive a significant dose of radiation.

To determine the accumulation of radionuclides in waterfowl tissue, an experiment was conducted in which two groups of domestic wing-pinioned mallards were released on WOL. Thirty-eight birds were released in May 1989, and 38 were released in October 1989. The second release of birds paralleled the arrival of fall migrants on the lake and provided a basis for evaluating seasonal differences in tissue concentrations of radionuclides. Ducks were collected at intervals over a period of 77 and $95 \mathrm{~d}$ for the first and second groups, respectively. Birds were sacrificed, and the concentration of radionuclides in their tissues was determined.

Cesium-137 was the primary radionuclide detected in all mallard tissues except bone, where levels of ${ }^{90} \mathrm{Sr}$ exceeded the concentration of ${ }^{137} \mathrm{Cs}$. Low levels of ${ }^{60} \mathrm{Co}$ were also found in several whole-body, gastrointestinal tract, gizzard content, and liver samples.

For the first group of mallards, maximum concentrations of ${ }^{137} \mathrm{C}$ in the breast tissue increascd from below detcctable on day 2 to $354 \mathrm{~Bq} / \mathrm{kg}$ on day 77 . For the second group mean concentrations of ${ }^{137} \mathrm{Cs}$ increased 
from $5.2 \pm 1.1 \mathrm{~Bq} / \mathrm{kg}$ on day 2 to $277 \pm 29 \mathrm{~Bq} / \mathrm{kg}$ on day 61. The concentration of ${ }^{13} \mathrm{Cs}$ in breast tissue over time was not significantly different in the two groups. Because most migratory ducks spend only a few days on WOL, they would be expected to have lower concentrations of radionuclides in their tissues than would domestic mallards, which spent from 77 to $95 \mathrm{~d}$ on the late. Assuming that the mallard, with the maximum concentration of ${ }^{13} \mathrm{C}$. (354 Bq/kg), was taken by a hunter shortly after leaving the lake, the potential effective dose equivalent from consuming the edible tissuc $(350 \mathrm{~g})$ is $1.7 \mathrm{\mu Sv}(0.17 \mathrm{mrem})$ or a lifetime risk of $1.4 \times 10^{-7}$. Because the concentration of ${ }^{60} \mathrm{Co}$ was very low or less than detectable in the mallards and because "Sr concentrates in bone, which is usually not consumed, the radiation dose from these two radionuclides was considered insignificant. Although results from the mallard experiment indicate that migratory ducks should not accumulate significant levels of ${ }^{137} \mathbf{C}$. during their stay on WOL and therefore would not present a significant risk to humans who consume one or more of them, the possibility exists for waterfow to remain on WOL for much longer periods.

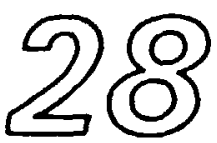

Attached Alpol and Microbial Communitics Provide Inipht into Natural and Anthropogenic Fectors Influencing Aquatic Sytem

H. L. Boston, W. R. Hill, and $A$. J. Stewart
Periphyton is a complex matrix of algae and heterotrophic microbes attached to submersed surfares in aquatic systems. The periphyton photosynthetically fues carbon, processes organic matter, and is important for nutrient cycling in many flowing water systems. Periphyton communities are sensitive to anthropogenic stress and can be entry points for contaminants into aquatic food chains. Over the past several years, we have been conducting studies involving the periphyton communities in streams in the Oak Pivige vicinity.

Because periphyton is ubiquitrus and cologically important, it is useful for toxicity assessment. In systems where toxicity is intermittent or subtle, community photosynthesis (PS) is an casily measured, ecologically meaningful process that responds to stress. We used analysis of covariance to compare PS rates as an indicator of physioiogical condition for communities having different biomass from different environments. The data were well correlated with information for fish and invertebrate communities and allowed us to characterize and document 
biotic conditions in streams receiving effluents from DOE facilities.

The periphyton at sites near industrial discharges had high concentrations of potentially toxic metals. Because several taxa of periphyton-grazing invertebrates were coincidentally absent from those sites, we conducted a 5-week laboratory experiment to assess the effects of metals on the growth of two species of invertebrates. Invertebrates grazing on contaminated periphyton accumulated metals; however, their growth was correlated with algal biomass and apparently was not influenced by the metals in the periphyton that they coniumed.

We have measured the PS response to irradiance for periphyton communities and have evaluated PS rates for algae from different depths within the matrix The PS responses of periphyton from light or shade conditions are fundamentally different from those for phytoplankton and may reflect the influences of the matrix on community PS. Experimental manipulations in streams addressed the effects of grazing by fish and invertebrates on periphyton biomass, turnover, and primary production. Grazing could either stimulate or decrease the rate of algal growth and so alter the potential food available, depending on the grazer, grazer density, and environmental conditions.

Recently, we began to use lipid analysis to investigate the microbial component of the periphyton. We are developing methods to identify sources of organic carbon (energy) for the microbes, measure rates of carbon flow through the community, and evaluate and track the condition of the microbes.

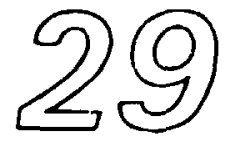

Toxicity Tests Identify Nictel as a Toxicant in Upper Bear Crock and Following a Spill in East Fork Poplar Crock

L. A. Kszos, A J. Stcwart, and P. A Taylor'

'Chemical Technology Division, ORNL.
Nickel is used extensively in manufacturing and production, resulting in about $3.8 \times 10^{9} \mathrm{~g}$ year of nickel being discharged worldwide. Ambient toxicity due to nickel has not been previously documented for streams on the DOE Oak Ridge Reservation. In this study, ambient toxicity tests of water from Bear Creck (BC) and East Fork Poplar Creck (EFPC), chemical analyses, and experiments with a nickel-sclective resin were used to assess the toxicity of water from upper BC and EFPC.

Toxicity tests of water from upper $B C$ indicated that the water was highly toxic to Ceriodaphnia dubia but not to fathead minnows (Pimephales promelas). The 
Opur thoto-9196-89

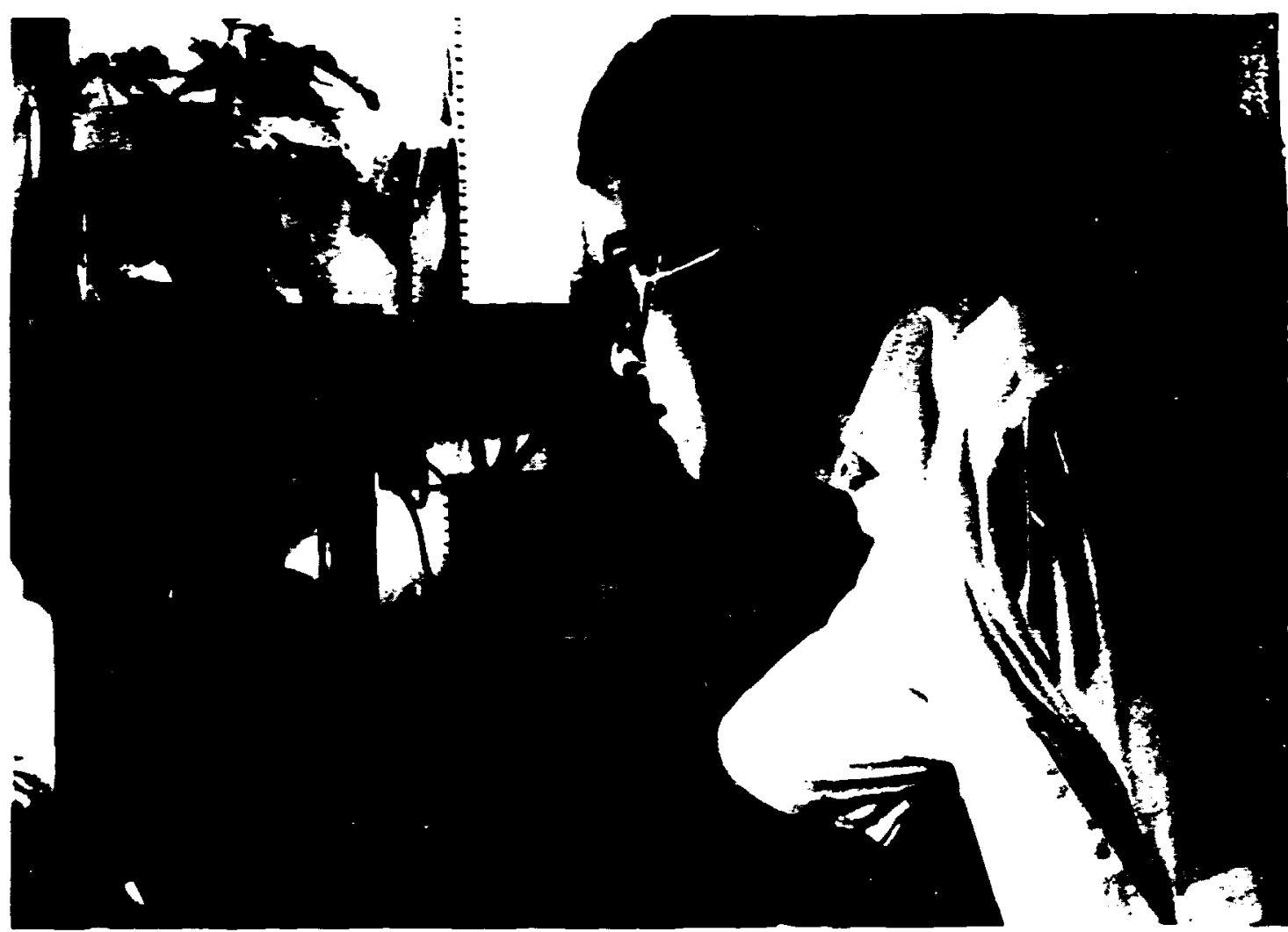

Paul Hanson installs a hardwood seedling in a gas reaction chamber to measure deposition of trace nitrogen gases on foliar surfaces. Results are used to assess the relationship between biogeochemica! cycling and global climate change.

concentration of nickel in BC water was $43 \mu \mathrm{g} / \mathrm{L}$, which is below the U.S. Environmental Protection Agency (EPA) water quality criteria for aquatic life $(160 \mu \mathrm{g} / \mathrm{L})$, but nickel was implicated as a toxicant because it was one of the few metals whose concentration decreased with distance downstream. During a test with water from upper EFPC (February 5-12, 1987), C. dubia survival and fecundity were high until the seventh day of the test; then all of the animals died. In concert with the $C$. dubia kill, the concentration of nickel increased from $<7 \mu \mathrm{g} / \mathrm{L}$ to $204 \mu \mathrm{g} / \mathrm{s}$

Laboratory tests confirmed that nickel was extremely toxic to $C$. dubia and much less toxic to fathead minnows. Mortality of $C$. dubia exposed to $7.5 \mu \mathrm{g} / \mathrm{L}$ of nickel as 
$\mathrm{NiCl}_{2}$ or $\mathrm{Ni}\left(\mathrm{NO}_{3}\right)_{2}$ for $7 \mathrm{~d}$ was $100 \%$. Minnows were not affected even at $16 \mathrm{mg} / \mathrm{L}$ of nickel. Thus, these tests showed that the concentration of $\mathrm{Ni}$ in $\mathrm{BC}$ and EFPC following a spill was high enough to kill $C$. dubia.

Toxicity tests with BC water that was treated with a nickel-selective resin verified that nickel was responsible for much of the toxicity in the water. In two experiments, the nickel was reduced from $43 \mu \mathrm{g} / \mathrm{L}$ and $49 \mu \mathrm{g} / \mathrm{L}$ to below detection. Similarly, the toxicity of the water to $C$. dubia was reduced sixfold.

Our results show that water in upper BC is contaminated with nickel at concentrations toxic to $C$. dubia. Water from the Oak Ridge Y-12 Plant entering EPFC also has the potential to contain concentrations of nickel that are lethal to $C$. dubia. The nickel contamination may prevent colonization of these areas by pollution-sensitive macroinvertebrates. EPA water quality criteria for nickel are based primarily on studies conducted with fish and Daphnia magna. Our results show that $C$. dubia (a common toxicity-testing organism) is much more sensitive than either of these species. This study has farreaching implications for water quality criteria and potentially for waste-treatment operations that invoke nickel-contaminated wastes.

\section{(5)}

Direolved Organic Matter Enhances the Transport of Cadmium and Polychlorinated Biphenyts in Soil Columns

F. M. Dunnivant,' $P$. M. Jardine, D. T. Taylor, ${ }^{2}$ and J. F. McCarthy

'Oak Ridge Associated Universities, Oak Ridge, Tennessee.

${ }^{2}$ Advanced Sciences, Inc., Oak Ridge, Tennessee.
Previous groundwater models contain errors in their predictions of contaminant transport. Recent publications propose that the enhanced transport of contaminants in aquifers results from the presence of mobile colloidal-sized particles. We used laboratory soil columns to investigate the transport of naturally occurring dissolved organic matter (DOivi) to determine if contaminants such as PCBs and cadmium are cotransported. All data were summarized in the form of breakthreugh curves, which are plots of (1) effluent contaminant concentrations vs (2) volume of water pumped through the soil column.

Results show that nonequilibrium conditions existed during DOM adsorption and that DOM subcomponents were selectively retained by aquifer materials; this retention resulted in a slow, tailing breakthrough of DOM from soil columns. Selective adsorption of DOM components was confirmed by spectrographic analysis of effuent samples and column chromotography bascd on 
hydrophobicity. The transport of the contaminant $2,2^{\prime}, 4,4^{\prime}, 5,5^{\prime}$-hexachlorobiphenyl increased as the concentration of DOM in solution increased. DOM adsorption onto soil (with $<0.1 \%$ organic carbon by weight) did not affect the transport of PCBs. The transport of cadmium was also augmented by increases of DOM in solution but reduced by higher levels of soilbound organic matter. The ability of DOM to increase the transport of contaminants, including PCBs (which are hydrophobic) and ionic cadmium, results from the presence of a mobile, colloidal phase that posseses a high binding affinity for contaminants. Therefore, DOM acted as a third phase in our experiments, increasing the capacity of the solution phase and reducing the capacity of the solid phase. Thus the presence of naturally occurring DOM in groundwater can increase the transport of contaminants. Equilibrium-based models more accurately predict the cotransport of contaminants if a three-phase approach is used (water, mobile organic matter, and soil).

\section{(5) 4}

Deporition of Orone to Foliar Surfaces Cun Be Prodicted for a Range of Fored Tree Spocies

\author{
P. J. Hanson, C. A \\ Gunderson, and G. E. \\ Taylor, Jr.
}

Numerous studies have documented the relationship between ambient ozone exposures and reductions in crop and forest productivities, but less emphasis has been placed on the capacity of forest canopies to function as sinks for tropospheric ozone. In addition, although ozone's detrimental effects are expected to be directly related to deposition to internal foliar surfaces, few studies have based their conclusions on measured internal uptake. A quantitative relationship for the prediction of internal ozone uptake for muitiple plant species would benefit studies of ozone effects and atmospheric chemistry.

Ozone deposition measirements were conducted in a whole-shoot gas exchange system on a variety of deciduous and conifer seedlings representing a wide range of morphological and ecological characteristics (red maple, Acer rubrum L; ginkgo, Ginkgo biloba L; sycamore, Platanus occidentalis L; northern red oak, Quercus rubra $L_{i}$; and loblolly pine, Pinus taeda L). Deposition measurements were conducted during a 5- to 6 -h period under moderate light conditions and at ozone levels representative of ambient background or high episodic periods ( 40 and $120 \mathrm{~nL} / \mathrm{L}$ of ozone, respectively). These short ozone exposures did not negatively impact the 
photosynthetic or stomatal properties of the exposed leaves.

For both concentrations of ozone, rates of ozone deposition per unit of leaf area were greatest for sycamore and maple and lowest for ginkgo and oak Deposition rates to loblolly pine were intermediate. The combined data set for all five species showed a linear relationship between ozone deposition and stomatal conductance to water vapor. The conclusion that one relationship is applicable to a wide range of species indicates that a model based on stomatal physiology can be used to predict ozone deposition to individual leaves and plant canopies.

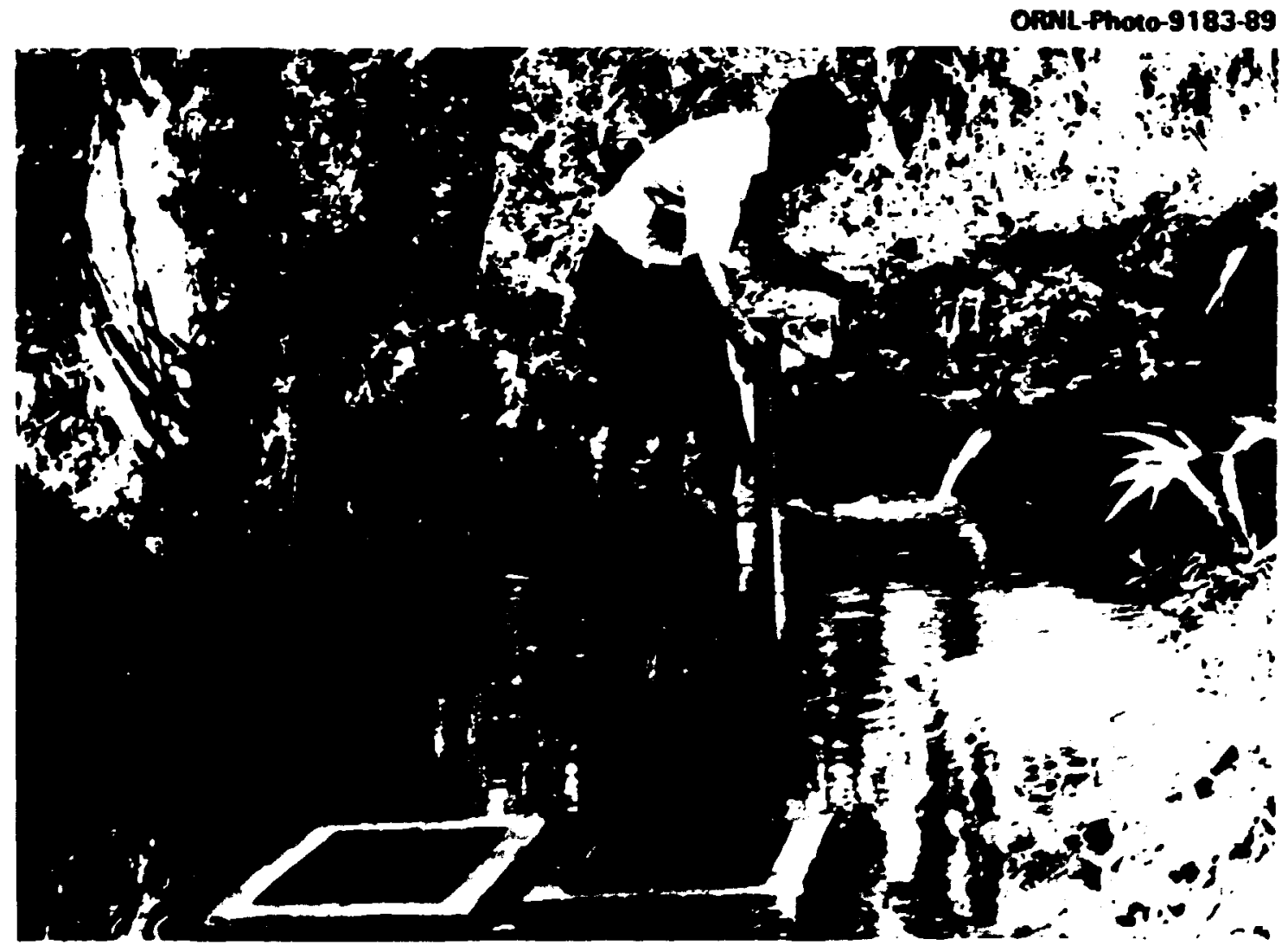

An Stewan studies the distribution and movement pattems of snails on different substrates in Ish Creek, a site within the Oak Ridge National Environmental Research Park. The snails are abundant (up to 3000 per square meter) in many streams on the Oak Ridge Reservation. Because they are sensitive to the presence of toric materials, they can be used in in situ tests of water quality. 
Predicted shoot conductances to ozone were calculated from a model based on analogy to the transfer of water vapor, and the predicted values were compared with the measured ozone conductances determined from the exposure concentrations and deposition rates (internal ozone concentration equals zero). Agreement between the measured and the predicted values was acceptable, implying a multispecies predictive capacity.

Documentation that ozone deposition to leaf surfaces occurs in a manner that can be largely predicted from the stomatal characteristics of foliage is an essential step in our ability to predict ozone exchange across the atmosphere-canopy interface. In addition, models based on this observation should allow greater understanding of the direct effects of ozone by permitting direct calculations of internal ozone exposures of physiologically sensitive plant tissues.

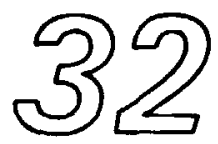

Drought Resistance of Popuhus delioides Bartr. cv. Sioudand Is Controlled by Avoidance Mechanisms

T. J. Tschaplinski
The mandate to grow woody crops for energy conversion will necessitate the use of marginal lands where the occurrence of water stress may be more critical, especially given the predictions of increased frequency and severity of drought associated with the greenhouse effect. Trees tolerate water stress by osmotic adjustment, the active accumulation of solutes. Species having drought tolerance mechanisms maintain cell turgor and growth under low lcaf water potential. Water stress studies on Populus sp. are ongoing to determine the extent and hiochemical basis of tolerance.

Six-month-old $P$. deltoides Bartr. cv. Siouxland were subjected to 2-d drying cycles for $43 \mathrm{~d}$ and compared with a daily watered control. This cultivar is planted in the Great Plains and is considered drought tolerant.

Measurements taken twice during the drought cycles included relative growth rate, gas exchange, and leaf water potential. Tissues sampled for biochemical analyses during ine last drought cycle included expanding foliage, fully expanded foliage, coarse roots, and fine roots. Tissues were analyzed for soluble carbohydrates by capillary gas chromatography and for primary amino acids by highpressure liquid chromatography.

Relative growth rate of the watered control was 1.6 times greater than that of the droughted trees. C. 1 a 
stressed day, net photosynthesis of well-watered trees was 2.6 times greater than for stressed trees, whereas stomatal conductance of water vapor was 5.1 times greater. The internal $\mathrm{CO}_{2}$ concentration of stressed trees was $32 \mu \mathrm{L} / \mathrm{L}$ lower, indicating that the degree of stomatal limitation on photosynthesis had increased. Midday leaf water potential of stressed trees was $0.26 \mathrm{MPa}$ lower. This cultivar maintained high leaf water potential by reduced stomatal conductance and, thereby, effectively avoided drought. There was no evidence of large-scale osmotic adjustment of soluble carbohydrates to water stress in any tissues. Stressed trees accumulated high concentrations of aminerich amino acids such as arginine and asparagine in all tissues sampled, which may be detrimental to protein function. Fully expanded leaves of water-stressed trees had 3.4 times the concentration of total amino acids compared with the watered control. These results suggest that studies of drought tolerance must characterize the accumulation of amino acids as well as carbohydrates. Ideally, the ratio of $\mathrm{C}: \mathrm{N}$ metabolites of water stress-tolerant species should remain stable or increase under water stress.

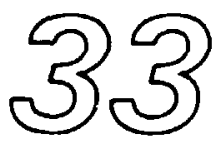

Elevated Atmospheric $\mathrm{CO}_{2}$ Does Not Afrect the Timing of Leaf Sencscence in Tree Seedlings in the Field

R. J. Norby, M. Cockrill,

E. G. O'Neill, and T. Grizzard

'Kalamazoo College, Kalamazoo, Michigan.
Many of the effects of elevated atmospheric $\mathrm{CO}_{2}$ on plant growth and physiology are now well known. Prediction of the responses of long-lived perennial plants (e.g., forest trees) to gradually increasing levels of atmospheric $\mathrm{CO}_{2}$ remains difficult, however, because many of the mechanisms of response are not easily addressed in short-term, controlled-environment experiments. One such mechanism relevant to the responses of trees to $\mathrm{CO}_{2}$ is phenological adjustment, which cculd alter the relationship between short-term effects on photosynthesis and long-term whole-plant carbon gain.

We have established a 4-year field study of tree responses to elevated $\mathrm{CO}_{2}$ that provides us with the opportunity to observe phenological responses directly under realistic ficld conditions. Ycllow-poplar (Liriodendron tulipifera L.) and whitc oak (Quercus alba L.) secdlings were planted in the ground in six open-top ficld chambers in May 1989. The atmospheres in the chambers were enriched with $\mathrm{CO}_{2}$ to threc levels [+0 ppm (ambient), $+150 \mathrm{ppm}$, and $+300 \mathrm{ppm}$ ), using two replicate 
chambers per treatment. The working hypothesis was that the stimulation of photosynthesis in elevated $\mathrm{CO}_{2}$ would maintain a positive carbon balance in leaves longer into the autumn, thereby delaying leaf senescence and abscission. During autumn 1989, photosynthesis was measured with a Li-Cor 6200 Portable Photosynthesis System, and chlorophyll concentrations were measured spectrophotometrically. Leaf abscission was followed by measuring leaf area at the end of the 1989 growing season.

Photosynthesis increased with increasing $\mathrm{CO}_{2}$ in both species, affirming the basic premise undertying the hypothesis on senescence. The stimulation of photosynthesis was maintained to the end of the growing season. Chlorophyll concentrations in both species were lower in elevated $\mathrm{CO}_{2}$, but the decline in chlorophyll, which began in late October, was similar in all treatments. All of the yellow-poplar leaves abscised during the month of November, and no differences existed between treatments in the rate of abscission. Abscission in white oak took much longer, and some leaves were retained until spring. The patterns of abscission with time were similar in all treatments until about $50 \%$ of leaves had abscised. Oaks in the +300 -ppm treatment retained the remaining leaves longer in late fall and winter.

Nevertheless, there was only an 8-d difference in time to $80 \%$ abscission between +0 - and +300 -ppm treatments, and the leaves at this time (early January) were desiccated and nonfunctional.

Although photosynthesis was higher in elevated $\mathrm{CO}_{2}$ and the enhancement was maintained late into the growing season, this did not lead to a delay in leaf senescence; thus, the hypothesis was rejected. Leaf senescence responds to a complex set of environmental cues; the effect of elevated $\mathrm{CO}_{2}$ in our system appears to be inconsequential compared with the influences of photoperiod or temperature.

\section{Section Staff}

C. W. Gehrs
S. M. Adams
B. K. Beane ${ }^{2}$
T. A. Anderson'
M. S. Bevelheimer ${ }^{3}$
P. A Boerman'
D. L. Bunting ${ }^{6}$
R. D. Bailey
M. C. Black'
H. B. Boston
R. S. Burlage
S. M. Bartell
B. G. Blaylock
A. L. Brenkert
W. D. Burton'
S. D. Bulls
B. A. Carrico? 

B. F. Clark ${ }^{7}$
P. J. Hanson
D. A. Mohrtacher 6
A U. Sheard
R. B. Cook
W. M. Harris ${ }^{6}$
D. L Morgans
G. P. Morris ${ }^{10}$
L. R. Shugart
D. K. Cox
G. J. Hayes
J. L. Morris ${ }^{12}$
G. A. Smith'
J. S. Cox
D. B. Hedrick?
S. L Niemela ${ }^{3}$
J. G. Smith
D. W. Crumby ${ }^{3}$
R. S. Hilgarth'
J. A. Cunningham ${ }^{6}$
W. R. Hill ${ }^{1}$
W. C. Dickinson?
R. L. Hinzman'
D. E. Nivens ${ }^{6}$
R. J. Norby
R. T. DiGiulio ${ }^{8}$
F. O. Hoffman
N Dowling'
S. J. D'Surney ${ }^{1}$
C. L Gettys Hull ${ }^{6}$
E. G. O'Neill
G. R. Southworth
F. M. Dunnivant ${ }^{1}$
J. Jackson'
B. D. Jimenez
A. V. Palumbo
A. F. Parker?
A. D. Steinman ${ }^{1}$
L. B. Edwards ${ }^{6}$
B. L Kimmel
N. T. Edwards
M. L. Kirby
D. F. Parkhurst ${ }^{1}$
D. B. Peakall ${ }^{13}$
A. J. Stewart
E. J. Stine ${ }^{1}$
W. Eng ${ }^{\text {I }}$
W. C. Kyker
R. G. Epler
L. S. Ewald ${ }^{10}$
L. M. Kszos
G. H. Ezell'
L. Liang ${ }^{6}$
B. F. Faison
J. M. Loar
C. J. Ford ${ }^{2}$
B. A Lowes
S. D. Fosters
R. J. Luxmoore
R. P. Mackowskia
M. L. Frank
N. E McAllister ${ }^{2}$
M. J. Franklin'
J. F. McCarthy
R. H. Gardner
R. V. Graham ${ }^{6}$
S. B. McLaughlin
M. S. Grecley, Jr.
M. K. McLeod ${ }^{11}$
T. Grizzard
O. McLeod ${ }^{12}$
C. A. Gunderson
J. A. McNabbs
M. J. Peterson ${ }^{3}$
C. M. Pettway ${ }^{12}$
L. M. Stubbs
E. L. $\operatorname{Tan}^{12}$
D. L Taylor
G. E. Taylor
W. J. Templeton"
S. M. Pfiffner'
B. H. Thaiker'
T. J. Phelps
S. E. Price?
T. D. Richardson ${ }^{\mathfrak{l}}$
C. W. Theodorakis ${ }^{6}$
K. R. Trowbridge ${ }^{l}$
T. J. Tschaplinskj ${ }^{3}$
J. Richmond ${ }^{10}$
A. A. Vass
D. B. Ringleberg'
B. T. Walton
C. Rois-Velazquez ${ }^{1}$
B. W. Ward
I. R. Rosario'
O. F. Webb ${ }^{9}$
K. A Rose
K Roy
M. G. Ryon
D. C. White
A. W. McWhorter ${ }^{7}$
B. A. Satmark ${ }^{14}$
S. M. White ${ }^{15}$
S. S. White
L. F. Wicker
M. K. Gustin ${ }^{6}$
D. E. Miller ${ }^{3}$
C. E. Guzman ${ }^{2}$
D. Millsap ${ }^{2}$
T. K. Sawyer
E. M. Schilling ${ }^{3}$
K. J. Wilkinsons
R. S. Halbrook'
M. W. Mittleman ${ }^{6}$
C. P. Schulthess ${ }^{1}$
J. A. Wojtowicz'
M. S. Woodall'
C. T. Woodard
S. K Sharp ${ }^{1}$
D. E. Zanb: Ow

1. Oak Ridge Asscciated Universities, Oak Ridge, Tennessce.

2. Advanced Sciences, Inc., Oak Ridge, Tennessee.

3. Automated Sciences Group, Inc., Oak Ridge, Tennessee.

4. Science Applications International Corporation, Oak Ridge, Tennessce.

5. Roane State Community College, I Jarriman, Tennessee.

6. The University of Tennessee, Knowille.

7. JAYCOR, Oak Ridge: Tennesce.

8. Duke University, Durham, North Carolina.

9. ORNLJUT Distinguished Scientist Program.

10. Oak Ridge Research Institute, Oak Ridge, Tennessee.

11. University of Missouri, Columbia.

12. Knoxville College, Knoxville, Tennessee.

13. National Wildife Research Center, Canadian Wildlife Service, Otlawa, Ontario, Canada.

14. Chalmers University, Sweden.

15. Project SFED Participant. 
chambers per treatment. The working hypothesis was that the stimulation of photosynthesis in elevated $\mathrm{CO}_{2}$ woult maintain a positive carbon balance in leaves longer into the autumn, thereby delaying leaf senescence and abscission. During autumn 1989, photosynthesis was measured with a Li-Cor 6200 Portable Photosynthesis System, and chlorophyll concentrations were measured spectrophotometrically. Leaf abscission was followed by measuring leaf area at the end of the 1989 growing season.

Photosynthesis increased with increasing $\mathrm{CO}_{2}$ in both species, affirming the basic premise undertying the hypothesis on senescence. The stimulation of photosynthesis was maintained to the end of the growing season. Chlorophyll concentrations in both species were lower in elevated $\mathrm{CO}_{2}$ but the decline in chlorophyll, which began in late October, was similar in all treatments. All of the yellow-poplar leaves abscised during the month of November, and no differences existed between treatments in the rate of abscission. Abscission in white oak took much longer, and some leaves were retained until spring. The patterns of abscission with time were similar in all treatments until about $50 \%$ of leaves had abscised. Oaks in the +300 -ppm treatment retained the remaining leaves longer in late fall and winter.

Nevertheless, there was only an 8-d difference in time to $80 \%$ abscission between +0 and +300 -ppm treatments, and the leaves at this time (early January) were desiccated and nonfunctional.

Although photosynthesis was higher in elevated $\mathrm{CO}_{2}$ and the enhancement was maintained late into the growing season, this did not lead to a delay in leaf senescence; thus, the hypothesis was rejected. Leaf senescence responds to a complex set of environmental cues; the effect of elevated $\mathrm{CO}_{2}$ in our system appears to be inconsequential compared with the influences of photoperiod or temperature.

\section{Section Staff}

C. W. Gehrs
S. M. Adams
B. K. Bcane ${ }^{2}$
P. A Boerman'
D. L. Bunting 6
T. A. Anderson ${ }^{1}$
M. S. Bevelheimer ${ }^{3}$
H. B. Boston
M. C. Black'
A. L. Brenkert ${ }^{4}$
R. S. Burlage'
R. D. Bailey
B. G. Blaylock
S. D. Bulls
W. D. Burton'
S. M. Bartell
B. A. Carrico ${ }^{7}$ 


\begin{tabular}{|c|c|c|c|}
\hline B. F. Clark ${ }^{\top}$ & P. J. Hanson & D. A. Mohrbacher ${ }^{\circ}$ & A. U. Sheard \\
\hline R. B. Cook & W. M. Harris ${ }^{6}$ & D. L Morgan & L. R. Shugart \\
\hline D. K Cox & G. J. Hayes & G. P. Morris ${ }^{10}$ & G. A Smith ${ }^{9}$ \\
\hline J. S. Cox & D. B. Hedrick9 & J. L. Morris ${ }^{12}$ & I. G. Smith \\
\hline D. W. Crumby ${ }^{3}$ & R. S. Hilgarth' & S. L Niemela ${ }^{3}$ & G. R. Southworth \\
\hline J. A Cunningham 6 & W. R. Hill ${ }^{1}$ & D. E. Nivens ${ }^{6}$ & A. D. Steinman ${ }^{1}$ \\
\hline W. C. Dickinson' & R. L Hinzman' & R. J. Norby & A. J. Stcwart \\
\hline R. T. DiGiulio ${ }^{8}$ & F. O. Hoffman & E G. O'Neill & E. J. Stine ${ }^{\mathbf{I}}$ \\
\hline N. Dowling' & C. L. Gettys Hull & A V. Palumbo & L M. Stubbs \\
\hline S. J. D'Surney' & J. Jackson ${ }^{5}$ & A F. Parker' & E L $\operatorname{Tan}^{12}$ \\
\hline F. M. Dunnivant ${ }^{1}$ & B. D. Jimenez & D. F. Parkhurst ${ }^{1}$ & D. L Taylor ${ }^{2}$ \\
\hline L B. Edwards 6 & B. L Kimmel & D. B. Peakall ${ }^{13}$ & G. E Taylor \\
\hline N. T. Edwards & M. L Kirby9 & M. J. Peterson ${ }^{3}$ & W. J. Templeton' \\
\hline W. Eng' & W. C. Kyker & C. M. Pettway ${ }^{12}$ & B. H. Thacker' \\
\hline R. G. Epler & L. M. Kszos & S. M. Pfiffner' & C. W. Theodorakis ${ }^{6}$ \\
\hline L S. Ewald ${ }^{10}$ & L L Liang ${ }^{6}$ & T. J. Phelps 9 & K. R. Trowbridge ${ }^{1}$ \\
\hline G. H. Ezell ${ }^{1}$ & J. M. Loar & S. E. Price ${ }^{9}$ & T. J. Tschaplinski ${ }^{3}$ \\
\hline B. F. Faison & B. A. Lowe & T. D. Richardson' & A A Vass \\
\hline C. J. Ford ${ }^{2}$ & R. J. Luxmoore & J. Richmond ${ }^{10}$ & B. T. Walton \\
\hline S. D. Fosters & R. P. Mackowski9 & D. B. Ringleberg' & B. W. Ward \\
\hline M. L Frank & N. E McAllister ${ }^{2}$ & C. Rois-Velazquez' & O. F. Webb' \\
\hline M. J. Franklin ${ }^{6}$ & J. F. McCarthy & I. R. Rosario & D. C. White \\
\hline R. H. Gardner & S. B. McLaughlin & K. A Rose & S. M. White ${ }^{\text {IS }}$ \\
\hline R. V. Graham ${ }^{6}$ & M. K McLeod ${ }^{11}$ & K. Roy & S. S. White' \\
\hline M. S. Greeley, Jr." & O. McLeod 12 & M. G. Ryon & L F. Wicker \\
\hline T. Grizzard & J. A. McNabb ${ }^{5}$ & B. A Satmark 14 & K J. Wilkinsons \\
\hline C. A. Gunderson & A. W. McWhorter? & T. K. Sawyer & J. A Wojtowicz ${ }^{7}$ \\
\hline M. K. Gustin ${ }^{6}$ & D. E. Miller ${ }^{3}$ & E M. Schilling ${ }^{3}$ & M. S. Woodalls \\
\hline C. E. Guzman ${ }^{2}$ & D. Millsap? & C. P. Schulthess' & C. T. Woodard \\
\hline R. S. Halbrook ${ }^{1}$ & M. W. Mittleman ${ }^{6}$ & S. K Sharp' & D. E. Zamzow \\
\hline
\end{tabular}

1. Oak Ridge Assuciated Unversitles, Oak Ridge, Tennessice.

2. Advanced Sciences, Inc., Oak Ridge, Tennessee.

3. Automated Sciences Group. Inc., Dak Ridge, Tennessee.

4. Science Applications International Corporation, Oak Rudge, Tennessce.

5. Roane State Community College, IJarriman, Tennessee.

6. The Universuty of Tennessec. Knoxville.

7. JAYCOR, Oak Ridge. Tennessec.

8. Duke University, Durham, North Carolina.

9. ORNLUT Distinguished Scicntist Program.

10. Oak Ridge Ressarch Institute, Oak Ridge, Tennessee.

11. University of Miscouri, Coiumbia.

12 Knoxville College, Knowville, Tennessec.

13. National Wildlife Research Center, Canadian Wildufe Service, Otrawa, Ontario, Canada.

14. Chalmers University, Swerten.

15. Project SF:FD Participant. 


\section{Geosciences}

\section{Introduction}

Staff of the Geosciences Section of the Environmental Sciences Division (ESD) at Oak Ridge National Laboratory (ORNL) engage in basic and applied research and conduct demonstration projects directed toward understanding and controlling the physical and chemical mechanisms that influence the movements of material through the lithosphere, hydrosphere, and atmosphere. Whereas most activities are highly interdisciplinary, the major areas of emphasis in the section involve geochemistry, geology, geophysics, environmental chemistry, soil science, hydrology, atmospheric chemistry, oceanography, and environmental engincering. The scope of the studies includes field charactcrization, testing and demonstration of innovative remedial action alternatives, laboratory experiments, and mathematical and computer modeling. The section consists of six groups, each designated by a disciplinary title that reflects the training of the staff.

The section strives to maintain a balance between basic and applied studies. The common theme of most section activities is the study of waste materials and by-products from energy production. Activities span major portions of the energy cycle. For instance, a significant part of the rescarch involves charactcrization of disposal sites-past sites as well as future ones, whereas another major part is directed toward an understanding of the physical and chemical factors that lcad to migration of matcrials away from disposal sitcs in groundwater, surface watcr, and the atmosphere. Closcly coupled with this effort are projects that deal with the development of quantitative capabilities for predicting the behavior of natural systems. Another part of the energy cycle-also related to waste-involves in situ treatment of disposed materials in the ground to mitigate their movement into the environment. Throughout its efforts, the section is substantially involved in science education at all levels, from precollege to graduate and postgraduate.

In the area of site characterization, the section has been involved in the study of fracture and fault systems that dominate the rock strata underlying many sites at Oak Ridge; these fractures are a major influence on groundwater flow. In addition, consicierable site work has been conducted at other U.S. Department of Energy (DOE) and U.S. Department of Defense (DOD) facilities, such as the Paducah Gascous Diffusion Plant, and at various U.S. Air Force bases. With regard to the movement of encrgy-related byproducts and wastes in the environment, we have been heavily engaged in studies of acid deposition and its impact on forest systems and soils, as well as studies of the movement of radioisotopes in marine and freshwater systems. The scope of predictive investigations ranges from geostatistical models for estimating groundwater clevations to geochemical studies of mineral solubilities and sorption characteristics.

Innovative waste treatment technologics that have been developed include bioremediation of organic contaminants and mercury, as well as oxidation and venting of organic contaminants that occur in soils and groundwater. The staff of the Geosciences Section are heavily committed to investigating many of the critical issues essential in dealing with the clcanup of DOF: facilitics to bring them into 
environmental compliance. The staff are also addressing issues that are necessary to understand the impact of energy technologies on the environmene.

The Geosciences Section is fortunate to have a wide variety of sponsors. The single greatest area of support reflects the need for on-site characterization of geologic and hydrologic conditions on the Oak Ridge Reservation, at other DOE facilities (such as the Paducah Gaseous Diffusion Plant), and at DOD sites. Much of this support is through the Environmental Restoration and the Defense Waste and Environmental Restoration programs, plus direct funding from some of the facilities; activities funded through DOE's Hazardous Waste Remedial Actions Program are included. The Office of Health and Environmental Research provides some of the fundamental support for the section's basic research on subsurface transport phenomena, as well as for work in marine and arctic environments. Funding for geophysical and geochemical research came from the Office of Basic Energy Sciences; support from the Office of Civilian Radioactive Waste Management for work directed toward permanent disposal of high-level nuclear waste in a mined repository continued at a decreased level during the year. In addition, staff in the section generated support from other national laboratories for geochemical research. The section also performed research for a number of non-DOE sponsors. Perhaps the most significant of these is the work done for the Electric Power Rescarch Institute (EPRI) in the study of acid deposition on forests. Other non-DOE sponsors include the Tennessee Valley Authority and the U.S. Environmental Protection Agency.

During FY 1990 the section had a number of significant achicvements:
- Tishnical activities in the 5-year-long Integ:ated Forest Studies project for the Electric Power Research Institute was completed.

- A comprehensive hydrologic and geologic study of the Oak Ridge Reservation was started.

- Two-dimensional groundwater flow modeling for flow below ridges on the Reservation was initiated with the use of data from deep wells.

- A seed money-supported project was completed that showed that a borescope can be used to identify colloids in groundwater and determine velocity and direction of movement.

- A prototype Geochemical Expert System was developed for analyzing the geochemical behavior of contaminants in groundwater systems.

- High-temperature thermocouples and optical pyrometers were successfully demonstrated in an engincering-scale in situ vitrification test.

- Tritium in samples collected by condensing water released by evapotranspiration was used to map a shallow contamination plume below a burial site.

- The Distinguished Scieniific Achicvement Award conferred by American Women in Science was presented to K. L. Von Damm.

- The DOE High School Science Honors Program was conducted at ORNL for 58 top-quality high school students from each state, the District of Columbia, and 7 forcign countrics. 
- Geophysical studies at the Paducah Gasesus Diffusion Plant in support of (1) evaluation of seismic-induced structural damage studies and (2) contaminant migration studies for groundwater were successfully completed.

- First-time collection of leachate samples from uranium waste burial grounds showed low kevels of uranium in solution, providing valuable initial information to be used in remedial action designs.

- A comprehensive monitoring program to evaluate performance of active low-level radioactive waste disposal and transuranic waste storage sites was developed and implemented.

- Four groundwater assessment plans and two corrective action plans were prepared for the DOE Kansas City Plant, averting a notice of violation from the regulators.
- The demonstration of the fact that trace chemicals in coastal bays can be introduced from oceanic materials in greater amounts than from terrestrial sources caused a reexamination of oceanic/coastal transport-fate models.

- A more environmentally acceptable technique was developed for measuring void volume of waste burial trenches by air pressurization, rather than flooding with water.

- Staff member (C. R. Olsen) received the Martin Marietta Corporate Jefferson Cup; the Martin Marietta Energy Systems, Inc., Author of the Year Award; and the Martin Marietta Energy Systems, Inc., Technical Merit Award.

- A draft of the midterm to long-term basic research plan for environmental restoration activities at DOE sites was completed for the Office of Energy Research.

\section{Technical Summaries}

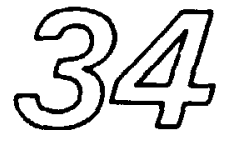

Environmental Monitoring Program Is Developed for Transuranic Waste Storage Sitcs and Active LowLevel Radioactive Waste Disposal Sites

T. L. Ashwood, D. S. Wickliff, C. M. Morrisscy, and J. Switck
ORNL currently stores transuranic (TRU) wastes in the northern portion of Solid Waste Storage Area (SWSA) 5 and disposes of solid low-level radioactive wastes (LLW) in various portions of SWSA 6. Environmental monitoring of all TRU storage areas and those LLW disposal facilities active on or after September 1988 is required (DOE Order 5820.2A) to provide for carly detection of contaminant migration before such migration threatens worker or public health or the environment. This monitoring is distinct from compliance monitoring required by various cnvironmental laws and by U.S. Environmental Protection Agency regulations. 
Active LLW disposal sites can be grouped into three technology classes: (1) lined auger holes with concrete bottoms, (2) vertical concrete silos in trenches, and (3) tumulus (above-grade storage in concrete boxes on concrete pads that are eventually covered with impermeable caps). In each of these cases, waste is emplaced at least $0.6 \mathrm{~m}$ above the highest known water table to reduce the possibility of contaminant migration. However, the disturbed soil around auger holes and in trenches around silos is more permeable than surrounding soil. Water accumulates in this more permeable soil because infiltrating rainwater flows in faster than it can flow out. This "bathtubbing" effect results in a perched water table, which presents a potential pathway for contaminant migration if the silos or the auger hole linings arc ireached. The silos and the auger holes will be monitored by installing wells in the silo trenches and in the area immediately surrounding the auger holes. These wells will permit sampling of the perched water table and early detection of any contamination that leaches from the waste.

The tumulus-type facilities consist of the Tumulus Disposal Demonstration Facility, Tumulus II, and the Interim Waste Management Facility. These facilities are monitored by sampling pad runoff and runoff from beneath the pad to detect any containment failure in the concrete boxes or concrete pad. Groundwater elevation is monitored continuously in a system of wells around the pads to determine the effects of the tumulus on local hydrology, and water from these wells is sampled to detect any contaminant migration that reaches the watcr table.

Initially, the monitoring of TRU waste facilities will focus on gathering information about the hydrology and water quality in the area. Water levels will be monitored in existing grotindwater piezometers and intratrench wells, and these wells will be sampled, as will small streams that drain SWSA 5 North. Once the area is characterized, additional monitoring wells may be installed.

A statistical analysis of the background data was performed to establish action levels that will serve as a basis for identifying potential problems and the need for further investigation or corrective action. The action levels will be reviewed annually, and revised if necessary. Sampling results from LLW and TRU monitoring will be published monthly. Semiannual and annual reports wil'. provide a rigorous examination of the data. 


\section{5}

Hydrochemical Data Quality of Groundwater Samples from the Oak Ridge Y-12 Plant Is Evaluated

J. Switek and T. O. Early
The Oak Ridge Y-12 Plant Environmental Man agement Department has coordinated activities associated with the collection and chemical analysis of groundwater samples from monitoring wells in order to maintain compliance with federal and state environmental regulations. Data from field and laboratory measurements are entered into a SAS ${ }^{*}$ data base that has been maintained for the Y-12 Plant by H\&R Technical Associates. There is a recognized need for timely evaluation of these analyses to ascertain their quality and

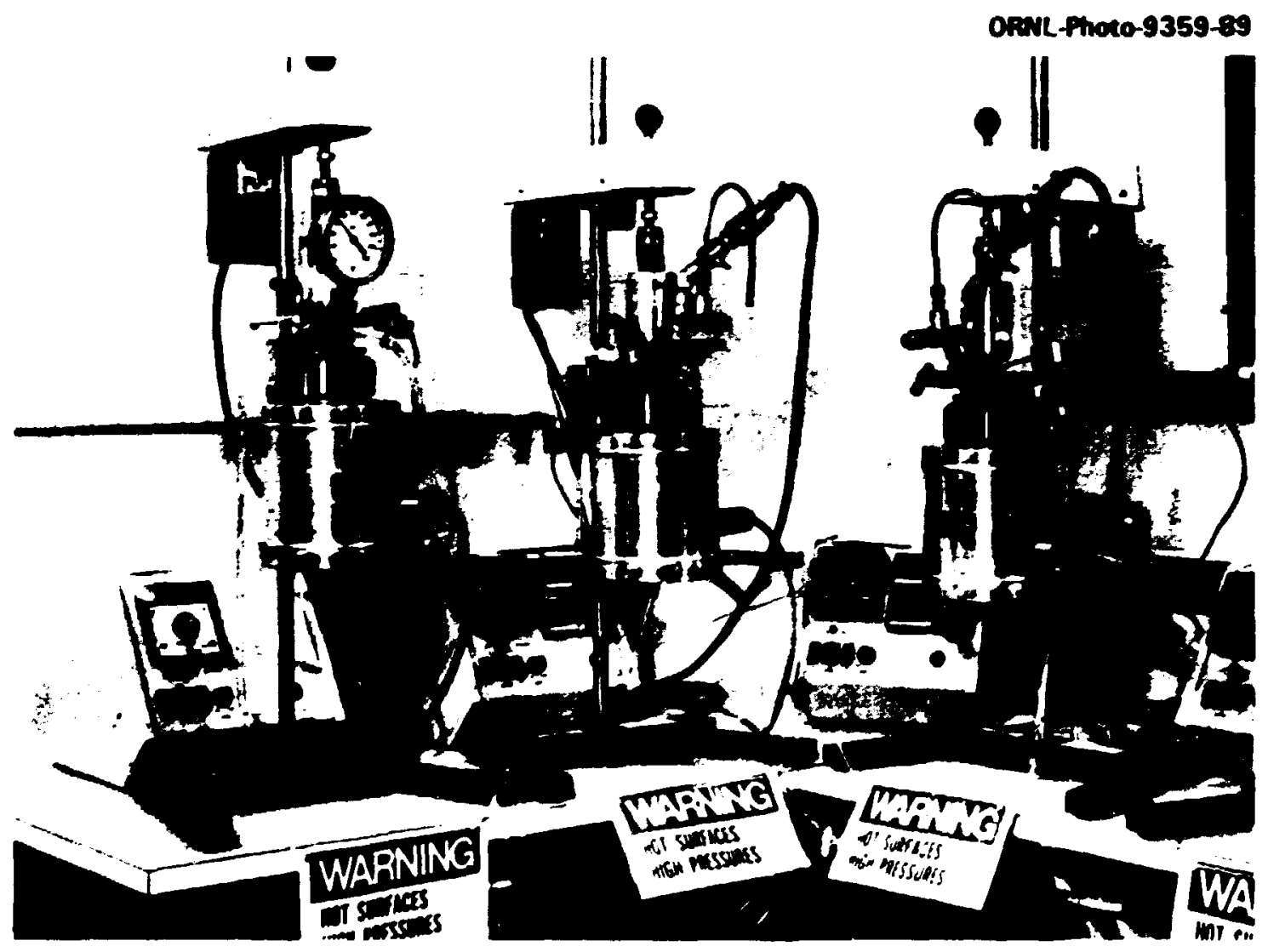

Experimental studies of mineral solubility and water-rock interactions are conducted through the use of Parr Stirred Reaction Vessels (shown here). Karen Von Damm used these vessels to study renctions at temperatures up to $300^{\circ} \mathrm{C}$ at pressures along the liquid-vapor curve. Such vessels allow researchers to withdraw fluid at various time intervals without disturbing the experimental conditions or terminating the experiment. 
for developing a methodology to assess how representative the samples are of the formations from which they are collected.

For this initial investigation, we limited our evaluation to the major cations and anions for water samples collected and analyzed by the Quality and Technical Services Division (Q\&TSD) of the Oak Ridge Gaseous Diffusion Plant. This enabled evaluation of a portion of the data set that was consistent with regard to sampling and analytical technique and representative of the current compliance monitoring activities at the Y-12 Plant. To test for internal consistency, charge balance and total cations and anions vs specific conductance were evaluated for individual samples, and the results of analysis of field duplicate samples were compared. A brief review of the Q\&TSD Quality Assurance (QA) program for interlaboratory analysis was also undertaken. A subjective visual examination of data sets from individual wells over time was performed to address the more subtle, but perhaps more critical, question of sample representativeness.

Both charge balance analysis and comparison of total anions and cations vs specific conductance point out the very large range of groundwater compositions encountered. Much of this variability is generated by samples heavily contaminated by nitrate leachates from the former S-3 Ponds. Comparisons of duplicate analyses generally show an acceptable level of reproducibility though nitrate analyses are shown to be somewhat less reproducible than those for other constituents. The results of these evaluations suggest that nitrate is being systematically overestimated when it is present in large concentrations.

The Q\&TSD interlaboratory QA program is extensive because of its involvement in regulatory compliance activities. However, the above cvaluations point out the desirability for development of a set of internal control samples tailored to the range of groundwater compositions found at the Y-12 Plant.

In evaluating the data for representativencss, time series data from individual wells that had been sampled more than once were inspected visually. This analysis was useful in pointing out the more obvious suspect analyses but is less effective when more subile crrors are encountered. The review process is also labor intensive with such a large and growing data set. There is a clear need to develop and implement computer softwarc capable of analyzing time scrics data to provide an 
estimate of representativeness. We also recognize the need for determining the effect of contamination by drilling fluid through use of tracers during drilling and the need to study the effects of decompression, aeration, and te.mperature changes on water chemistry associated with bringing water samples to the surface environment from depth.

"SAS is the registered trademart of SAS Institute, Inc., Cary, North Carolina.

\section{(5)}

Subsurface Storm Flow Is Measured near ORNL

G. K. Moore' and R. B. Clapp

'The University of

Tennessee, Knawille.
The storm-flow zone approximately corresponds to the root zone of vegetation and is $\mathbf{1 0}$ to $\mathbf{1 0 0 0}$ times more permeable than the underlying vadose zone. Because of this large difference in permeability, many precipitation events produce a transient perched water table in the storm-flow zone, and water is then transmitted downslope, above the water table, toward nearby streams. The stormflow zone may thus prove to be an important pathway for the subsurface flow of water beneath clay caps and into waste trenches.

Monitoring tubes consisting of $1.9-\mathrm{cm}$ plastic pipe, sealed at the bottom and slotied from land surface to depths of $79 \mathrm{~cm}$, were: installed at 17 locations in proposed SWSA 7. All tubes had some water inflows, indicating saturated soils and downslope flows of water. Tubes on steep slopes and in gullies generally had water inflows during small precipitation events, whereas larger or more intense events were required to produce inflows on smooth and shallow slopes. During periods of intense precipitation, overland flow was observed near some monitoring tubes in gullies and swales, but overland flow apparently occurs only after the storm-flow zone fills to overflowing. All water samples obtained from the monitoring tubes were cloudy to muddy, and the suspended sediment was mostly colloidal. Subsurface crosion and sediment transport in colloidal form may be a significant geomorphic process in proposed SWSA 7.

The recession rates of water levels in storm-flow monitoring tubes and in wells were related to discharge from these zones and were used to calculate streamflow components in proposed SWSA 7 for February 15-25, 1990 (sce figure). During this period, measured strcamnow was $71 \%$ of precipitation and consisted of $40 \%$ 


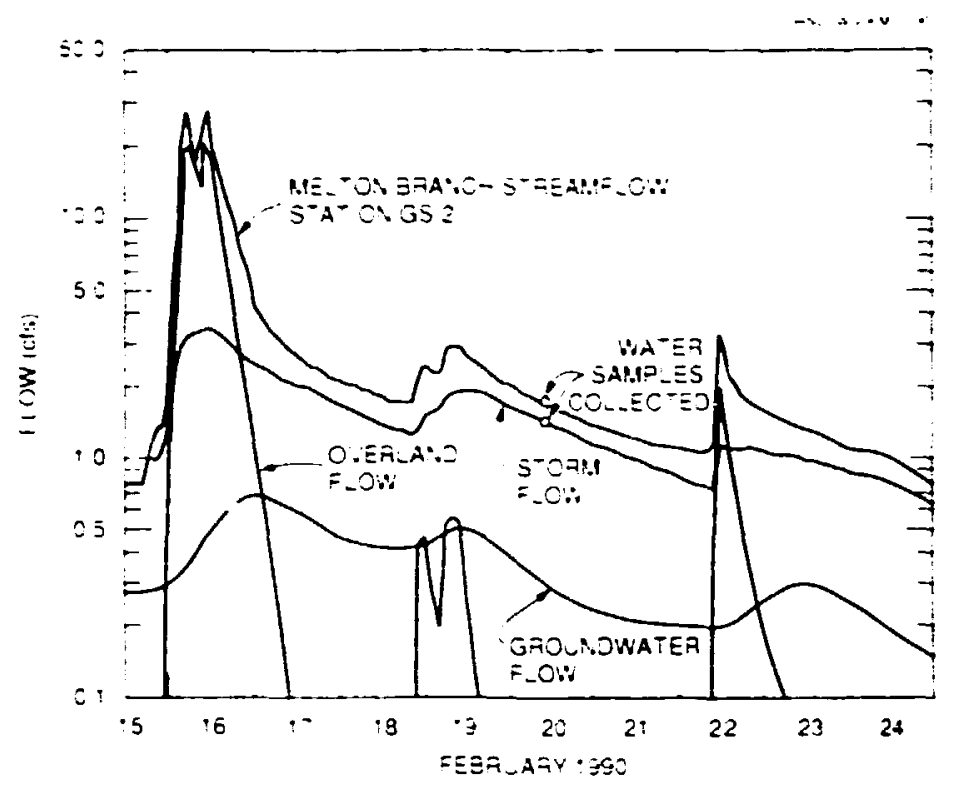

overland flow, $48 \%$ subsurface storm flow, and $11 \%$ groundwater flow. Storm-flow discharge is a larger percentage of streamflow during events when overland flow is minimal. From $1800 \mathrm{~h}$ on February 18 to $0800 \mathrm{~h}$ on February 22, for example, streamflow consisted of 5\% overland flow, $77 \%$ storm flow, and $18 \%$ groundwater flow. Subsurface storm flow is a major part of the water budget during a part of each year.

\section{(5)}

Long-Term Rescarch Plan for Environmental Restoration Identifics More Than 140 Basic Research Noeds

D. K. Solomon, R. L Jollcy,' J. R. Trabalka, S. H. Stow, R. J.

Luxmoorc, B. A. Benen,? C. H. Brown,' G. K. Jacobs, and C. E. Eastcrly²
DOE has begun a major environmental restoration effort to reduce the health and environmental risks resulting from past waste management and disposal practices at DOE sites. In recognition of the complexities associated with environmental restoration and the need for increased understanding of fundamental processes, the DOE Office of Energy Rescarch (OER) began a planning effort to identify long-term basic rescarch needs that will contribute to environmental restoration. DOE/OER requested that ESD take the lead in preparing a comprehensive long-term rescarch plan for environmental restoration.

In September 1989, DOE published the document "Evaluation of Mid-to-Long Term Basic Research for Environmental Restoration." This report is an analysis of 
'Chemical Technology

Division, ORNL.

${ }^{2}$ Health and Safety

Research Division, ORNL.
DOE waste problems and a preliminary identification of research needs. To update and focus the preliminary research needs, staff at ORNL organized a series of workshops involving more than 100 scientists and engineers from 10 national laboratories and 15 universities and subsequently compiled a planning document.

Long-term basic research needs for environmental restoration are divided into five general areas:

(1) environmental transport and transformations;

(2) advanced sampling, characterization, and monitoring methods; (3) new remediation technologies;

(4) performance assessment; and (5) health and environmental effects. Research needs in environmental transport and transformation are directed toward fundamental processes occurring in both natural (undisturbed) and slightly contaminated systems. Advanced sampling, characterization, and monitoring methods research needs are aimed at obtaining representative samples, with an emphasis on high resolution using near real-time analyses. Research needs in new remediation technologies are directed toward understanding fundamental processes for developing remediation methods in highly contaminated areas both near and at sources, as well as contaminated environments. The performance assessment area involves research to develop theory and methods necessary to select remedial action alternatives, predict performance, and confirm the success of remedial action. Research needs in health and elivironmental effects emphasize an understanding of fundamental processes required to assess the risk to human health and ecosystems associated with DOE sites. Each research area is divided into more-detailed categories in which specific research tasks are identified for each category. A total 26 research categories and 141 specific research tasks are included.

Public awareness of issues associated with waste cleanup, such as the magnitude of tax-dollar expenditures and the real health and environmental risks associated with disposal and cleanup activities, is an important part of environmental restoration. Thus, in addition to basic research, this document also deals with cducation and training needs for environmental restoration. 


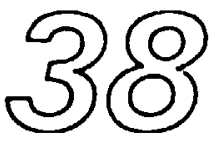

Pumping Tests and Modeling Are Conducted to Assess Performance of an Interceptor Well Sjotem

P. M. Kearl, ${ }^{1}$ J. E. Peterson, ${ }^{2}$ and N. E. Korte $^{1}$

${ }^{1} E S D, O R N L$, Grand Junction Office, Grand Junction, Colorado. ${ }^{2}$ Health and Safety Research Division, ORNL.
The former Tank Farm site at the DOE Kansas City Plant is contaminated with trichloroethene, cis-1,2-dichloroethen, and chloroethene. The contaminated groundwater is being treated on-site with an ultraviolet light/hydrogen peroxide/ozone treatment system. The contaminated groundwater is delivered to the treatment system by three interceptor wells. The system has undergone nearly a year of pilot operation and has been in routine service for approximately 9 months. The interceptor well locations were selected based on the results of field testing and computer modeling. Once the system was operating routinely, regulatory requirements mandated a determination of the accuracy of the original predictive modeling. To assess the reliability of the modeling predictions, the interceptor wells were used to conduct two pump tests to obtain drawdown data, determine aquifer permeability, and evaluate interceptor well performance. The resulting data were then used to repeat the model run used in the design phase to determine whether the results of the updated model accurately represented the physical system. For system design, the model employed a hydraulic conductivity of $2.16 \mathrm{ft} / \mathrm{d}$. Pump tests using the interceptor wells yielded a hydraulic conductivity of $2.3 \mathrm{ft} / \mathrm{d}$. Likewise, the modeling performed for system design predicted $0.44 \mathrm{ft}$ of drawdown in well KC85-32, a well downgradient of the source area and interceptor wells. Field measurements during the pump test demonstrated that the actual drawdown was $0.36 \mathrm{ft}$. These comparisons are excellent, considering the highly disturbed nature of the study area. As the final part of the process, the original computer model was recalibrated and verified with the new data. This updated model will be used for the future assessments required for long-term operation of the treatment system.

DOE has made a commitment to complete environmental restoration at its field sites by 2019 and to modernize waste opcrations at these sites to avoid the need for future cleanup. To address the tasks of

\author{
ESD Staff Axsiet DOE in \\ Major Plans for \\ Environmental Restoration \\ and Wate Operations \\ (5)
}


N. H. Cutshall, R. B.

Fitts, ${ }^{l}$ D. D. Huff, and

C. W. Francis

'Hazandous Waste

Remedial Actions Program

Division, Martin Marietta

Energy Systems, Inc. environmental restoration and waste operations in a comprehensive and coordinated manner, DOE formed a new Headquarters office in November 1989. Within this new Office of Environmental Restoration and Waste Management, the Office of Technology Development (OTD) is charged with pursuing an aggressive program in research, development, demonstration, testing, and evaluation to satisfy needs generated by DOE environmental restoration and waste management missions. Planning and organization of OTD activities was initially defined in the Draft Applied Research, Development, Demonstration, Testing, and Evaluation (RDDT\&E) Plan completed in November 1989. A condensed version of the RDDT\&E Plan was updated and published as a section of the DOE Five-Year Plan for Environmental Restoration and Waste Management, FY 1992-1996 (DOES-0078P), in June 1990.

Staff from ESD, other ORNL Divisions, and other DOE/Oak Ridge organizations participated significantly in the task forces that prepared these major program documents. In addition, Oak Ridge programs also support the goals of OTD. Among the OTD goals is the acceleration of technology development through formation of collaborative teams from DOE laboratories, U.S. universities, and industry to draw on the principal strengths represented by these different sectors. Concordantly, ORNL activities within OTD include this "teaming" approach. Another OTD goal is to assist the DOE Office of Encrgy Research in identifying and supporting basic research that may lead to applications in environmental restoration and waste management. To address this goal, a Basic/Applied Research Working Group has been formed, drawing on the support of ESD and ORNL as well as other organizations.

Participation in these planning efforts by staff from DOE laboratories ensures that the DOE environmental restoration and waste management strategy is based on current and direct field experience and state-of-the-art technologies. Field technical personnel also look ahead to future technologies that will make possible safer, faster, better, and cheaper restoration. At the same time, participants acquire a broadened perspective of DOE system-wide needs, which enables them to compare and contrast both the specific contaminant problems and the controlling environmental conditions at the various DOE sites. As a result, ORNL activities performed for OTD can be made applicable not only to Oak Ridge but also to other sites in the DOE complex. 


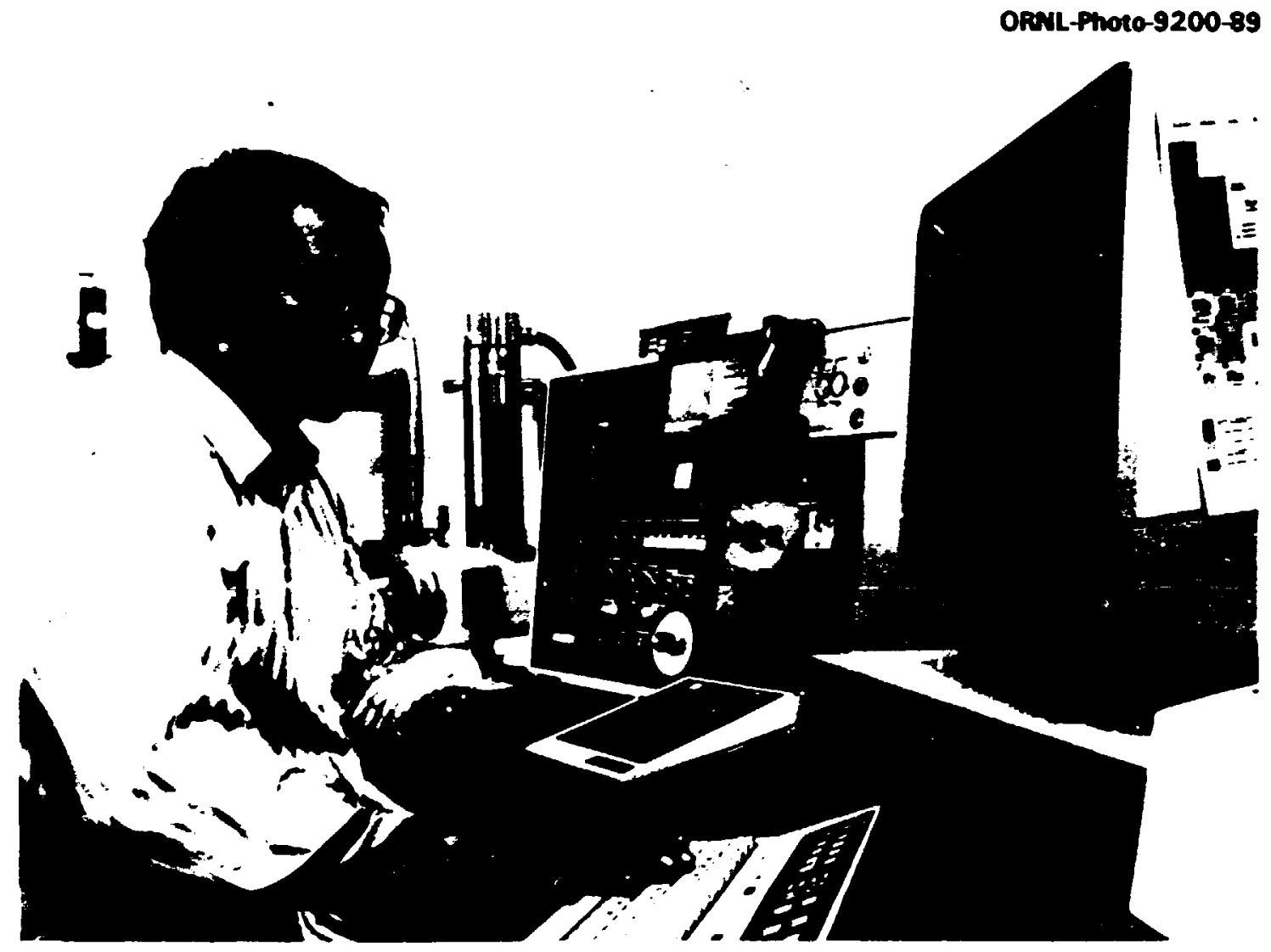

Using a scanning electron microscope and an energy dispersive $X$-ray analyzer, $S . Y$. Lee acquires spectroscopic data and conducts image analyses of sedimentary rock from a potential site for the disposal of hazardous waste. The microstructural and mineralogical information derived from the analyses will be used in evaluating the geochemical, geophysical, and hydrological performance of the site.

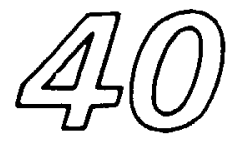

Groundwater Flow Across Ridges Is Likely on the Oak Ridge Reservation

L. E. Toran
A groundwater flow model to examine regional flow patterns was constructed along a cross section in Bear Creek Valley where multilevel monitoring ports were recently installed. Although the area near the S3 Ponds has been modeled before, this is the first time that calibration data were available beneath one of the ridges and at regular intervals below a 100-ft depth. The head data available from the multilevel monitoring ports are preliminary because the wells may not yet have reached 
steady state after installation. Taking into account this precaution, a preliminary cross-sectional model was constructed using MODFLOW, the U.S. Geological Survey finite-difference groundwater flow model. The cross section is only two dimensional, and it extends from Pine Ridge to Chestnut Ridge, adjacent to the S3 Ponds. The recharge to the upper surface was approximated by fuing the water table surface at the top of the model. Additional data are needed to establish this boundary, but the resulting recharge was consistent with other flow models constructed in the area (up to 2 is fyear).

In the initial model, groundwater was ssumed to enter at the ridgetops and discharge in the valley. This conceptual model has been used in virtually all of the groundwater modeling on the Oak Ridge Reservation. Permeability values were selected from previously compiled geostatistical data from measurements grouped by geologic formation, with a drop to a uniform low value below $650 \mathrm{ft}$ deep. The model reproduced measured heads within 10 to $20 \mathrm{ft}$ in the valley and at shallow depths on the ridge slope. However, the ridgetop and deeper monitoring points were off by about $50 \mathrm{ft}$. This mismatch raises questions about the assumption that flow does not cross the ridges at depth.

In another model run, flow was allowed under the ridges below $450 \mathrm{ft}$. The modeled heads improved significantly, drawing within $20 \mathrm{ft}$ of the currently measured values. The amount of underflow was the same order of magnitude as recharge. Further calibration to obtain the depth of underflow and a better approximation of the amount of underflow will be delayed until steady-state head values are obtained in the multilevel monitoring ports. Some additional model runs included cases with anisotropy, greater permeability at depth, low permeability lenses, and underflow beneath the entire depth of the ridge. None of these runs produced a suitable match to measured heads. It may be that some combination of these factors will nonetheless be important in later calibration.

Future work will include comparison of a particle-tracking code with estimates of advection rates from geochemical data and construction of a model including fracture flow. 


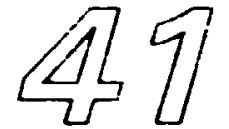

An Integratod Hydrologic and Goologic Study Will

Support Monitoring, Compliance, and

Environmental Restoration Activities on the DOE Oał Ridge Rescivation

C. S. Haasc, R. D. Hatcher, ${ }^{1}$ W. M. McMastcr,' and S. H. Stow

'The Univeritg of Tennessee, Knarville.
Sitc investigation, charactcrization, and remediation activities in progress at the DGE facilities on the Oak Ridge Reservation (ORR) focus largely on groundwater contamination problems identified at multiple sites within each facility. Typically, such investigations deal only with individual contamination occurrences related to specific sites within each facility. Before 1989, there was no integrated effort to determine the larger-scale hydrologic setting of the individual sites or to determine the overall hydrogeologic characteristics of the ORR.

The Oak Ridge Reservation Hydrologic and Geologic Study (ORRHAGS) project began in October 1989. Its objectives are (1) eiucidation and characterization of the groundwater flow systems throughout the ORR and (2) definition of baseline hydrologic and geologic conditions throughout the ORR. The study will provide reservation-wide geologic and hydrologic data for use in a variety of ongoing and future studie:- Additionally, ORRHAGS will provide state-of-the-art technical support to adciress regulatory concerns related to contaminant migration via groundwater. For example, response to inclusion of the ORR on the U.S. Environmental Protection Agency's National Priority List and implementation of DOE Order 5400.1 require sophisticated understanding of the hydrologic systems of the ORR.

Hydrologic studies are the major focus of ORRHAGS. The objectives of these studies are to identify and evaluate the statistical distribution of values for key hydrologic flow and chemical parameters, define the character of hydrologic flow systems operative on the ORR, and evaluate numerical techniques used to model groundwater and associated contaminant movement on the ORR. During the initial year, available hydrologic data were compiled and analyzed, and conceptual models of ORR flow groundwater flow systems were developed for use in subsequent investigations.

Geologic and soil studics support the hydrologic investigations conducted by ORRHAGS. Activities in these areas focus on production of s:ate-of-the-art maps of the ORR that illustrate bedrock geology and structural features and soil types and properties. Additional activities will include development of a finalized stratigraphic nomenclature for geologic units throughout the ORR, an cvaluation of the hydrologic significance of 
various structural features throughout the reservation, and characterization of the statistical distribution of chemical and physical soil properties throughout the ORR. During the first year, a draft bedrock geologic map has been prepared, and a provisional stratigraphic nomenclature scheme has been developed for review and comment.

Data management activities within ORRHAGS support the hydrologic and geologic studies and center on development of a data base containing subsurface hydrogeologic data for the ORR. This data base will be constructed by transferring data from existing facility-spccific data bases. Data to be transferred include well construction, groundwater chemistry, hydraulic head, and aquifer property information. Currently, development of the structure of the data base and protocols to transfer data from facility-specific data bases is complete, and transfer of data to the ORRHAGS data base is under way.

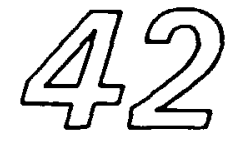

Dense Nonaqueous Phase Liquids Are Characterized in Bear Creck Valley Near Oak Ridge, Tennesuce
C. S. Haase and H. L. King ${ }^{1}$
'Environmental
Management Department, Oak Ridge Y.12 Plant.

In January 1990, accumulations of dense nonaqueous phase liquids (DNAPLs) were discovered in a newly installed monitoring well (GW-625) at depths of $\sim 274 \mathrm{ft}$ below ground surface aiong the southern border of Burial Ground A-South within the Bear Creck Burial Grounds Hazardous Waste Disposal Unit (BCBG) at the DOE Oak Ridge Y-12 Plant. Subsequent to this discovery, a preliminary investigation was initiated to obtain information on the mode of occurrence and distribution of the DNAPLs in fractured rock, such as that underlying $B C B G$. The investigation included installation and sampling of two additional groundwater monitoring wells (GW-628 and GW-629), resampling of existing wells in the vicinity of the discovery well, evaluation of existing groundwater quality data, and revicw of available information and site conditions.

Because of the complex bchavior of DNAPLs in fractured rocks, only rarcly are accumulations of DNAPLs encountered in the subsurface. Samples obtained from wells GW-625 and GW-628, however, provide direct evidence for the occurrence of DNAPLs at depths of at least 270 ft below ground surfacc. Groundwater samples from these two wells consist of an upper, aqueous phase containing 930 to $2500 \mathrm{mg} /$ of tetrachlorocthenc (PCE), 70 to $110 \mathrm{mg} / \mathrm{L}$ of trichlorocthenc (TCE), and 2.8 to 


\section{OPALPhoto-6787-90}

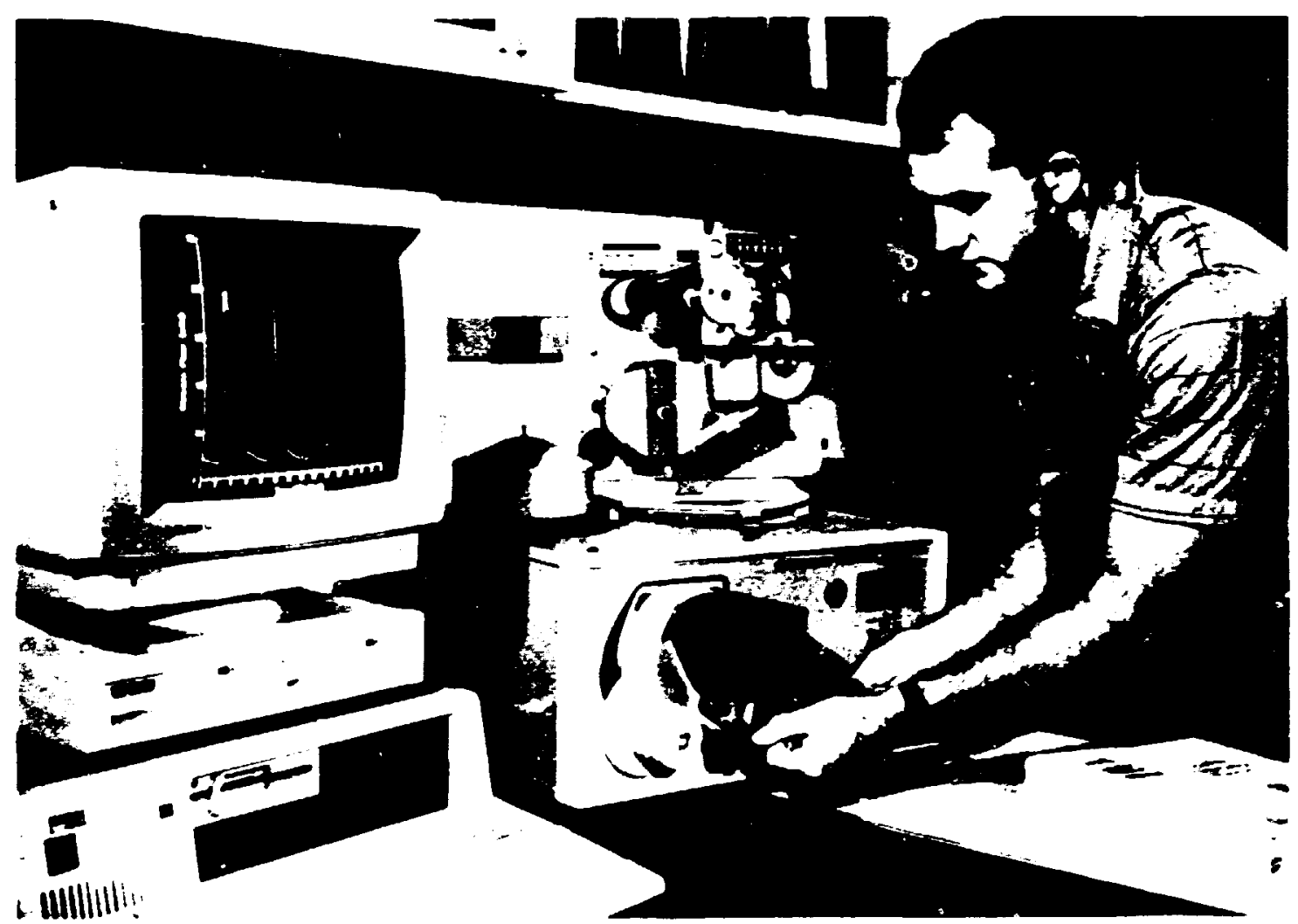

Scott Gregory transfers streamflow data from paper tape to the computer, where the data will be processed into dischange records (shown on the screen). Such data are required for projects involving sile characterization or documentution of environmental compliance, as well as for ecological and hydrologic studies.

$11 \mathrm{mg} / \mathrm{L}$ of polychlorinated biphenyls (PCBs) and a lower, oil-like phase containing PCE $\left(4.5 \times 10^{5}\right.$ to $5.3 \times$ $\left.10^{5} \mathrm{mg} / \mathrm{L}\right)$, TCE $\left(1.1 \times 10^{4}\right.$ to $\left.1.9 \times 10^{4} \mathrm{mg} / \mathrm{L}\right)$, and PCBs $\left(1.4 \times 10^{4}\right.$ to $\left.2.7 \times 1 \mathrm{n}^{4} \mathrm{mg} / \mathrm{L}\right)$.

Accumulations of DNAPLs in the subsurface generate dissolved contaminant plumes within groundwater.

Detcetion and characterization of such plumes typically provide the only reliable means of determining the extent of DNAPL contamination at a sitc. The predominance of PCE and TCE among volatile organic compounds in groundwaters from two existing monitoring wells (GW-71 and (jW-117) and the occurrence of low concentrations of $P C B s$ in onc of them (GW-117) indicatc that these wells may sample dissolved plumes assoxiatcd with subsurface 
DNAPL occurrences. Such groundwater chemical data, together with the existence of an upward vertical hydraulic gradient at the site and the locations of these wells, suggest that DNAPL occurrences may extend to $-500 \mathrm{ft}$ below ground surface at the BCEG site.

Migration of DNAPLs occurs immediatcly on their release into the environment. However, given the history of BCBG, where DNAPLs were disposed of a number of years ago, DNAPL migration is not likely to be occurring currently. Such a static situation will remain as long as the hydrogenlogic system in the immediate vicinity of the DNAPL occurrences is not hydraulically disturbed. If the system is disturbed, DNAPL accumulations could become remobilized. The occurrence of $\sim 10 \mathrm{ft}$ of DNAPL within well GW-625 indicates that substantial accumulaiions of DNAPLS do exist in the subsurface. The static nature of the system and the occurrence of DNAPL pools in the subsurface, combined with the complex hydrogeology of the site, require that future characterization and remediation activities be undertaken with care and understanding of all factors that can influence DNAPL migration.

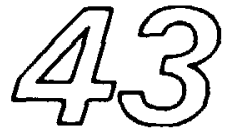

Evidence from Fluid Inclusions and Stable Isotopes in Calcite Veins Suggests that the Nolichucky Shake Experienced Two Contrasting Types of Water-Rock Interactions During Burial and Fracturing, Respectively
J. L. Foreman, ${ }^{1}$ G. K. Jacobs, K. R. Walker,' and W. M. Dunne'
'The University of Tennessee, Knoxville.

Research to elucidate historical water-rock interactions within the Nolichucky Shale is being conducted to help understand processes that may be active today. Such an understanding will aid interpretations of complex hydrogeochemical interactions that may be controlling the release and transport of elements within deep subsurface groundwater systems in the vicinity of contaminated sites on the Oak Ridge Resar ation. Interbedded limestones, calcareous siltstones, and calcarcous shales of the Upper Cambi ian Nolichucky Shale in the southern Appalachian Forcland fold and thrust belt are cut by bed-normal, bed-parallel, and bed-oblique veins filled with calcite.

Crosscutting relationships within the White Oak Mountain thrust sheet suggest that the bed-normal veins are the oldest, followed by bed-parallel and hed-oblique veins, respectively. The bed-normal and bed-parallel veins are extension veins filled with calcitc that contain fluid inclusions having pressurc-corrected trapping temperatures of 80 to $110^{\circ} \mathrm{C}$. Bed-oblique veins are tectonic shear veins, and pressure-corrected trapping temperatures for 
fluid inclusions in a single calcite-filled vein ranged from 200 to $280^{\circ} \mathrm{C}$. Freezing temperatures of fluid inclusions from all veins indicate that calcite precipitated from $\mathrm{Na}-\mathrm{Ca}-\mathrm{Cl}$ brines with $\sim 27$ wt \% $\mathrm{NaCl}$ equivalent salinities; Na:Ca mole ratios are estimated to be 0.61 . The major element chemistry of these brines is strikingly similar to oil-field brines from the Jurassic Norphlet Formation (Mississippi Gulf Coast) and some calcium-rich brines from the Oligocene Frio Formation (Texas Gulf Coast).

Trends of decreasing $\delta^{18} \mathrm{O}$ and $\delta^{13} \mathrm{C}$ with depth for whole-rock limestones and authigenic carbonates in shales are similar, indicating extensive water-rock interaction (i.e., rock-dominated system) between the interbedded limestones and shales during the precipitation of the authigenic carbonate phases. Isotopic compositions $\left(\delta^{18} \mathrm{O}\right.$ and $\delta^{13} \mathrm{C}$ ) of vein calcites do not mimic the trends found in whole-rock limestones or authigenic carbonates in shales, indicating that veining occurred in a water-dominated system. The $\delta^{13} \mathrm{C}$ values in vein calcites are constant with depth and are similar to average values for the Nolichucky, suggesting the source of carbon was limestones having $\delta^{13} \mathrm{C}$ compositions similar to those within the Nolichucky Formation. The fluid inclusion and isotopic evidence illustrate the contrast between fracture and matrix water-rock systems. Preveining episodes of water-rock interaction were characterized by rock-dominated, stratified systems. Fluids trapped within the authigenic carbonates during burial in the interbedded limestones and shales have isotopic signatures, suggesting control by lithologic characteristics in which lateral flow of fluids dominated. Calcite precipitation during vein formation occurred within a watcr-dominated system, with little interaction with the local host formation. The calculated $5^{18} \mathrm{O}$ values for fluids in equilibrium with calcite in both bed-normal and bed-parallel veins have characteristics suggesting a siliciclastic source of oxygen, which is consistent with either a Nolichucky source or some external source of oxygen. The uniquely higher trapping temperatures and corresponding $\delta^{18} \mathrm{O}$ fluid values for the later tectonic bed-oblique shear veins suggest these fluids had a hydrothermal source decper within the Conasauga Group that was activated during thrusting. 


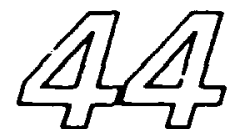

Contaminant Transport Sccnario Is Developed for the South Valley Superfund Site

P. M. Kearl, ${ }^{1}$ N. E Korte, and $K . S$. Dickerson?

'ESD, ORNL, Grand Junction Office, Grand Junction, Colorado. ${ }^{2}$ Health and Safety Research Division, ORNL, Grand Junction Office, Grand Junction, Colorado.
Organic compounds werc detected in SJ-6, an Albuquerque municipal well, in 1980 . Based on these findings, the U.S. Environmental Protection Agency established a 1-mile ${ }^{2}$ radius around $\mathrm{SJ}-6$ as the South Valley Superfund Site. Plant 83, an industrial facility that was operated by the Atomic Energy Commission from 1951 to 1967 and by the U.S. Air Force from 1967 to 1984, is one of six potentially responsible parties.

Controversy had arisen concerning the magnitude and timing of improvements in waste management practices and on the time required for contaminants to travel from Plant 83 to SJ-6. A review of previous investigations revealed that waste management practices were not significantly improved until 1982 , some 15 years later than previous claims. Moreover, new calculations of contaminant transport demonstrated that previous estimates of 6 to 13 years seriously undereitimated the time of travel.

Several issues not considered in previous, investigations greatly affect the potential for contaminan: transport: the relative importance of equilibrium vs nonequilibrium processes, the questionable effectiveness of a silty-clay aquitard, and the effect of pumping $\mathbf{S J}-6$.

Previous calculations assumed that the contaminant transport was governed by equilibrium processes and could be described by means of retardation factors.

Unfortunately, retardation factors describe the total plume mass and not the leading edge of a plume. In addition, site geologic investigations revealed that the subsurface soils are not uniform but consist of interbedded sands, silts, clays, and gravel. Indeed, it had been assumed that a silty-clay aquitard greatly reduced contaminant transport to the groundwater. A review of boring logs, however, revealed silt and sand stringers, root holes, and blocky structures that may provide preferential flow paths for Aluid migration through the aquitard. Finally, several reports noted that the direction of groundwater flow changed from southwesterly to easterly due to the pumping of SJ-6. Transport calculations performed by other investigators did not consider the effect of pumping SJ 6. Assuming noncquilibrium processes such as rapid transport of contaminants through the vadose zone and the effects of pumping SJ.6, we revised the flow calculations, which yiclded travel times of 6 months to 5 ycars for the contaminants to reach SJ-6 from Plant 83. 


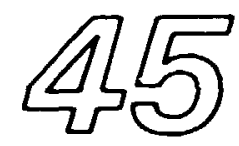

Litholojic Changes and

Porosity Differences Are

Distinguished at the

Paducah Gascous

Diffusion Plant

R. B. Dreier, R. O.

Kennard, and R. J.

Selfridge ${ }^{1}$

'Automated Sciences Group, Inc., Oak Ridge,

Tennessee.
Workers at the Paducah Gaseous Diffusion Plant (PGDP), located in Paducah, Kentucky, and operated by Martin Marietta Energy Systems, Inc, for the U.S. Department of Energy (DOE), discovered in August 1988 that several private wells, generally north of the plant, were contaminated with trichloroethylene (TCE) and/or 97. Presumably, PGDP is the source of both contaminants, and the most likely pathway for contaminant transport is within a regional aquifer that underlies the site. However, it is not possible to characterize potential flow paths and remediate the contamination until the geologic setting of the site is determined and additional well construction information is obtained.

As a result, it was decided to conduct a geophysical logging froject on 25 wells/piezometers on and off the PGDP site to determine the stratigraphic characteristics of the region. Four types of geophysical logs were obtained from each well: caliper, natural gamma ray, thermal neutron, and gamma-gamma density.

Geophysical log interpretation shows that the gravel and clay facies of the Continental Deposits in the vicinity of PGDP can be divided into five lithologic units. These are, in ascending order, (1) gravel unit, (2) sand/silt transition zone, (3) clay unit, (4) silt/sand unit, and (5) sand unit. These units are locally covered with loess and have subsequently been covered with fill in places. The gravel unit and the overlying sand units have the greatest potential for transmitting fluids. The sand units are thickest and most continuous in the immediate plant area. However, the sands thin considerably and locally pinch out to the north in the direction of the Ohio River. Cobble beds within the gravel show either enhanced or reduced porosity characteristics, and, without the geophysical data, it would be difficult to differentiate between these porosity changes.

This study shows that geophysical logging can be very uscful for determining lithologic sequences in the vicinity of PGDP. The logs can differentiate gravels, sand, silt, clay, loess, and fill; they can indicate a gradational or abrupt transition between lithologic types; they provide a continuous downhole record of the geology; they can delincate zones of high and low porosity within the regional gravel aquifer; and they can substantiate or provide some well construction data. If additional lithologic information is required from areas not covered 
by this study, follow-on geophysical logging in wells located in these arcas would be appropriate.

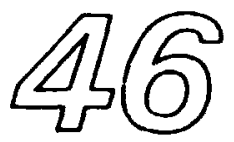

Atmaspheric Chemistry and Deposition Differ Significantly Betwoen U.S. and West German Forests

S. E Lindberg and

M. Bredemeier ${ }^{1}$

'University of Gottingen, Gortingen, Federal Republic of Germany.
Significant forest decline symptoms linked to air follution occur more frequently in Europe than in North America. Emission densities of air pollutants, especially nitrogen compounds, are higher in Europe than in the United States. These differences and climatic characteristics, which influence deposition, suggest that the fluxes of air pollutants may be substantially higher to European than to North American forests.

We performed the first direct comparison of total atmospheric deposition and canopy interactions of major ions in forest stands in the United States and West Germany by using comparable methods at conifer forests in Göttingen, West Germany, and Oak Ridge, Tennessee.* Atmospheric and precipitation concentrations of nearly all ions were higher at the German site, most significantly for the nitrogen species. The much higher levels of $\mathrm{NH}_{4}{ }^{+}$and $\mathrm{NO}_{3}{ }^{-}$reflect higher emissions of $\mathrm{NH}_{3}$ from agricultural sources and of $\mathrm{NO}_{z}$ from industrial sources. Airborne nitrate was dominated in Oak Ridge by $\mathrm{HNO}_{3}$, but in Grttingen by $\mathrm{HNO}_{3}$ and aerosol $\mathrm{NH}_{4} \mathrm{NO}_{3}$, which formed from reactions between $\mathrm{HNO}_{3}$ and $\mathrm{NH}_{3}$.

Total deposition of all major ions was much higher at the German site by up to a factor of 6 for the nitrogen spccies. The importance of dry deposition was confirmed by a strong positive gradient in net throughfall tluxes of $\mathrm{NH}_{4}{ }^{+}$and $\mathrm{NO}_{3}{ }^{-}$near the border of the Gortingen stand where edge effects enhance dry deposition. These forest canopies absorbed 40 to $50 \%$ of the deposited nitrogen, primarily from dry deposition.

The much higher levels of nitrogen input in the Göttingen forest and proven cariopy assimilation of deposited nitrogen support a hypothesis regarding the role of elevated deposition of airborne nitrogen compounds in forest decline in Europe.

\footnotetext{
-This work was also supported by the Alexander Von Ilumboldt Foundation through an Alexander Von Humboldt Fellowship Award to S. I. I Indberg.
} 


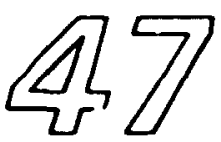

Engincering-Scale In Situ Vitrification Test Confirms Reduced Cesium

Volatilization and

Demonstrates the

Usefulness of Temperature

Sensors in Melis

G. K. Jacobs, B. P.

Spalding, M. T. Naney,'

C. L. Timmerman, ${ }^{2}$ and

T. Powell ${ }^{2}$

'Chemistry Division, ORNL.

${ }^{2}$ Pacific Northwest

Laboratories, Richland, Washington.
In situ vitrification (ISV) involves melting contaminated soik in place to form a glassy-tomicrocrystalline waste form. Off-gases generated during melting are collected through an off-gas hood and treated in an off-gas processing trailer to remove particulates that may carry contaminants. A previous pilot-scale (3/8-scale) ISV test at ORNL in July 1987 illustrated the potential success of this technique in remediating pits and trenches at ORNL. Although the results from the test suggested that at least $99.88 \%$ of the ${ }^{137} \mathrm{C}$ s in a trench would be retaincd in the melted soil, a significant amount of radioactivity would still accumulate in the off-gas system. Thus, we are conducting additional testing to evaluate methods to reduce ${ }^{137} \mathrm{Cs}$ volatilizaticn. The two most promising methods are (1) direct filtering of particulates before they enter the off-gas processing trailer (preferably within the hood itself) and (2) real-time monitoring of ${ }^{137} \mathrm{Cs}$ volatilization and/or melt temperature to provide feedback so that the power control can reduce the melt temperature, as needed, and thus reduce volatility.

An engineering-scale (1/12-scale) ISV test wots performed at Pacific Northwest Laboratories (PNL) jointly by staff from PNL and ORNL during January 1990 to evaluate (1) the effectiveness of an in-line high-efficiency particulate air (HEPA) filter for removing particles before they enter the off-gas system and (2) the performance of type-C thermocouples and optical-based temperature sensors. The 20 -h test created approximately $0.75 \mathrm{~m}^{3}$ of glass. Total volatilization of cesium was estimated to be 0.1 wt \%. When the off-gis was routed through a HEPA filter located immediately outside the melt zone, no cesium was detected past the filter. Thus, a full-scale design with a HEPA filter within the hood to collect contaminated offgas should provide the needed isolation of ${ }^{137} \mathrm{Cs}$ from the off-gis process system. In preparation for the test, several type-C thermocouples, enclosed in protective sleeves of alumina and/or graphite, were placed within the melt zone. As the melt reached the thermocouples, temperature readings were consistent among the thermocouples at $\sim 1300$ to $1400^{\circ} \mathrm{C}$. Two optical-based temperature sensnrs were included in the test; however, the optical-fiber sensor was not contacted by the melt, but the pyrometer sensor was. Furthermore, the temperature readings from the pyrometer sensor were consistent with the values from the 
thermocouples. The optical sensors are being considered for longer-term applications in the melt because they are less susceptible to decalibration and to interference by the electrical equipment associated with ISV. Toward the end of the test, the power level was fuctuated .J determine if slower melting could be used to help reduce the volatilization of ${ }^{137} \mathrm{Cs}$. All the sensors recorded shifts in melt temperature as power to the melt was varied. This

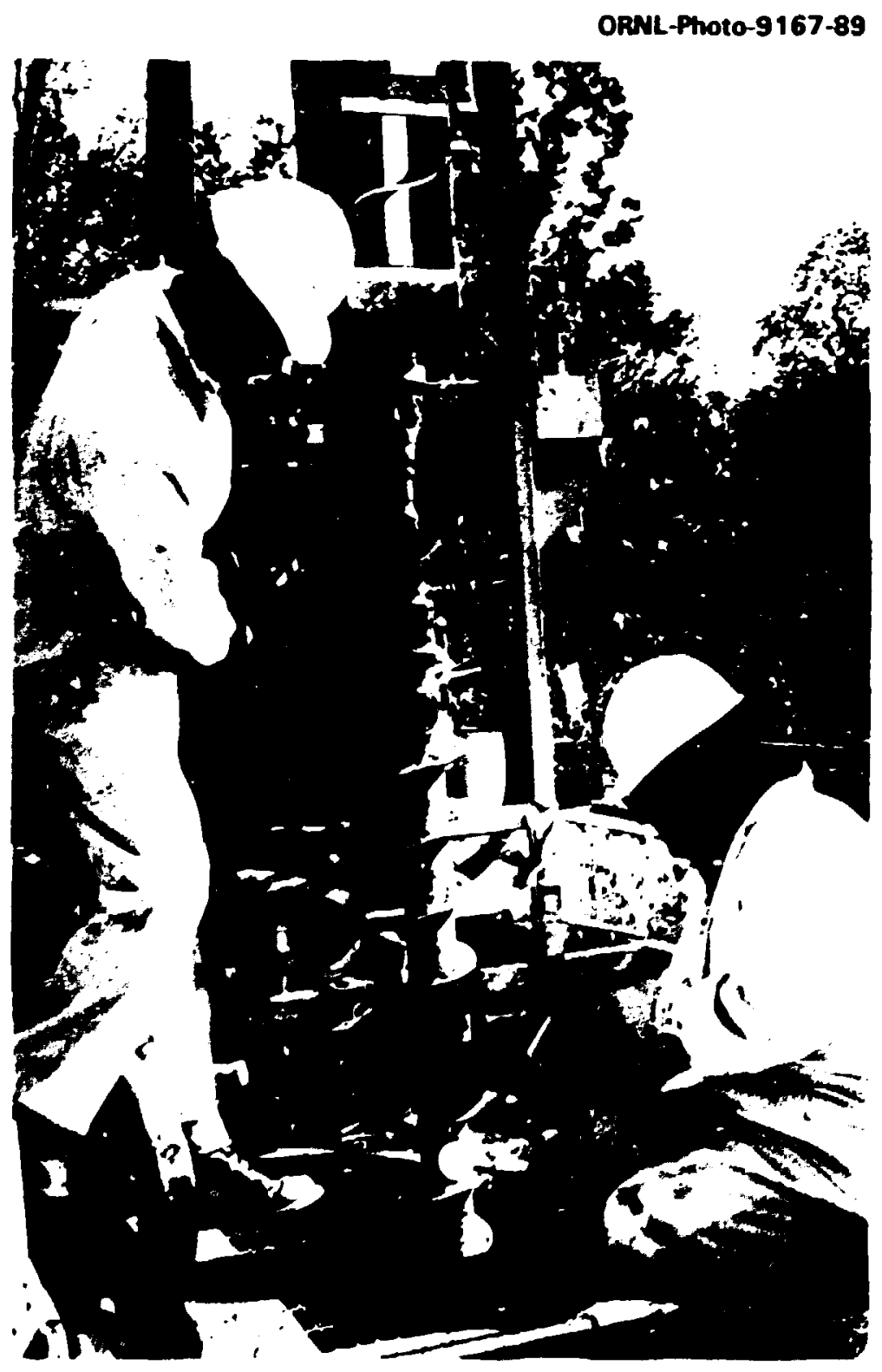

David Farmer (left) augers a hole for the placement of a groundwater-monitoring well while Milo Ward checks the soil cuttings for potential radioactive contaminants. Such monitoring wells in ORNL Solid Waste Storage Area 6 will help ESD researchers both determine the distribution of contaminants and assess the effectiveness of corrective actions. 
direct response of melt temperature to the reduction in power level suggests that the technique has some merit. The results concerning cesium volatility, the effectiveness of the HEPA filters, the performance of the thermal sensors, and the response of melt temperature to power fluctuations will be used to nlan additional tests of these tcchniques and equipment at a larger scale during another piiot-scale ISV test, which will be performed at ORNL during September $\$ 90$.

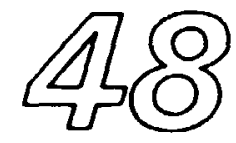

Leachability of Uranium from Oak Ridge Y-12 Plant Wastes Is Investigated

C. W. Francis, L K Hyder, S. C. Howard, J. E Cline, ${ }^{2}$ and

R. B. Clapp

'Waste Management
Division, Oak Ridge Y-12
Plant.
'Development Division,
Oak Ricige Y-12 Plant.
Disposal of Oak Ridge Y-12 Plant wastes contaminated with depleted uranium in unlined landfills may lead to the leaching and subsequent transport of unacceptable levels of uranium to groundwater. To investigate the extent of uranium leaching from Y-12 Plant wastes, a field lysimeter test facility is being constructed. The facility design involves the construction of nine standaid 8-ft-diam and 10-ft-deep column lysimeters that will be used to leach a variety of Y-12 Plant wastes under natural conditions.

To understand more clearly the mechanisms responsible for the leaching of uranium from these wastes, sampling of in situ leachate at varying depths along the lysimeter side wall is planned. Prior to the construction of the field lysimeters, a pilot-scale lysimeter was used to test scveral design concepts of the in situ leachate collection devices.

A Y-12 Plant production waste containing $2 \mathrm{~kg}$ of depleted uranium was loaded into a waste dumpster and leached with demincralized water for $194 \mathrm{~d}$. Three devices were tested to collect in situ leachate froin this waste: conventional ceramic-tipped suction candles (to collect unsaturated flow), V-shaped trays constructed with stainless steel, and 4-L stainless steel beakers. (Th.e latter two devices were filled with fine-grained sand to collect saturatco flow.)

Suction candles proved to be the most effective device to coliect in situ leachatc. Uranium concentrations were monitored in bottom leachatc as well as in in situ leachate. The highest uranium cuncentration $(\sim 0.2 \mathrm{mg} / \mathrm{L})$ observed in the bottom leachate occurred during the first month of leaching, before the active hiolugical decomposition prucesses became dominant, making the lysimeter anoxic. Uranium concentrations in the bottom leachate after this 
initial oxic flushing became very low, averaging $0.021 \mathrm{mg} / \mathrm{L}$ which was in the same range as the uranium concentration in the water used for leaching. Uranium concentrations measured in the in situ leachate collected by the suction candles averaged $0.36 \mathrm{mg} / \mathrm{L}$ over the same period. Leaching data obtained from this study revealed that uranium t:ansfer coefficients from the solid phase of uranium-contaminated waste to the solution phase ranged between 0.001 and 0.0001 . Data of this type will be used in the development of leaching/transport models and pathway analyses of uranium moving off-site.

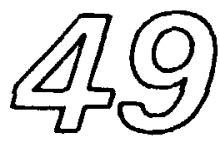

Natural Lsotopic Tracers Are Used to Study Snowmelt Proceses in the Arctic

L. W. Cooper,' C. R. Olsen, D. K. Solomon, I. L. Larsen, R. B. Cook. and J. M. Grebmeier'

'The University of Tennessee, Knawille.
The dominant annual hydrnlogical event in arctic watersheds is the onset of snowmelt. At this time, particles and dissolved solutes stored over the course of many months of snowfall are released into watersheds over shor periods of time. The combination of long cbemical accumulation and short episodic release periods makes it particularly important to understand the fate of chemical constituents stored in the snowpacks of arctic watersheds.

Twc cosmogenically derived radioisotopes, ${ }^{7} \mathrm{Be}$ (with a 53-d half-life) and ${ }^{35} S$ (with a 87-d half-life), were employed as natural tracers of hydrological flow through watersheds and into streams during snowmelt and after rainfall events at Imnavait Creek, Alaska $\left(68^{\circ} 37^{\prime} \mathrm{N}\right.$, $149^{\circ} 17^{\prime} \mathrm{W}$ ). The use of these particle-reactive radioisotopes proved to be a significant improvement over conventional comparisons of the chemical content of precipitation and stream water because the latter methods cannot distinguish the direct contributions of precipitation from the indirect contributions of leachates released from soils or vegetation. Because of the short half-lives of ${ }^{7} \mathrm{Be}$ and ${ }^{35} \mathrm{~S}$, essentially the entire inventory of both radioisotopes is present only in the snowpack at the time of snowmelt, and all contributions from the previous year's rain or snow have decayed to insignificant levels.

Monitoring of ${ }^{18} \mathrm{O}:{ }^{16} \mathrm{O}$ ratios of water in the sr. owpack and stream during the peak of s.3owmelt showed only a small contribution ( $\sim 14 \%$ or less) to the stream from soil water sources. Within a month of snowmelt, however, ${ }^{18} \mathrm{O}:{ }^{16} \mathrm{O}$ ratios in the strcam indicated only negligible amounts of water derived from snow. In contrast to the small centribution of soil water to the snowmelt 
Dave O'Dell acquires a soil water sample to study the movement of a tracer through an undisturbed soil block at ORNL Solid Waste Storage Area 7. The soil block is $2 \times 2 \times$ $3 \mathrm{~m}$ deep and is designed to collect water and solutes from three different soil pore domains through the use of fritted glass solution samplers. The information acquired from the study will be used to calibrate a three-dimensional, multidomain transport model describing the subsurface migration of contaminants.

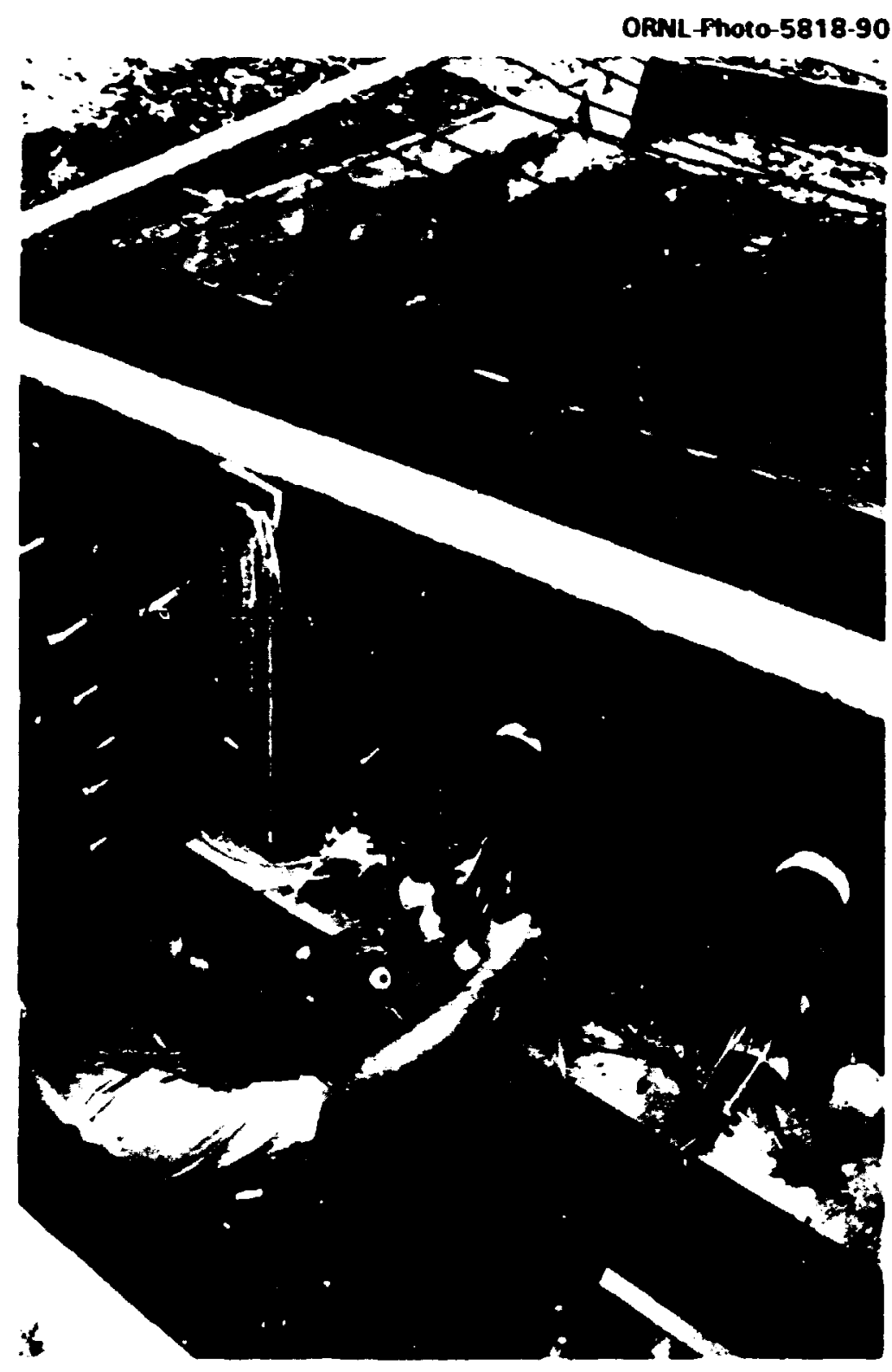

hydrograph, greater than $90 \%$ of the ${ }^{7} \mathrm{Be}$ inventory depositcd both in snow and in rainfali was uniformly sorbed onto the top 2 to $3 \mathrm{~cm}$ of surface organic soils and vegeiation throughout the entire watershed. Similar results were observed for "S. Downslope relocation of ${ }^{7} \mathrm{Be}$ during snowmelt was inferred from the differences in inventory between a riparian zoric soil site $\left(5.5 \mathrm{mBq} / \mathrm{cm}^{2}\right)$ and (wo) upland soil sites (0.7 mBq, $\left.\mathrm{cm}^{2}\right)$. These data 
suggest that particle-reactive materials and contaminants will have larger-than-expected mobility during the peak of snowmelt and that such increased mobility leads to larger inventories of particle-reactive chemicals and contaminants contributed by precipitation in riparian zones. Future work will focus on defining the scale and localization of chemical concentration and on obtaining a better understanding of the ways in which snow, soil, and stream water interact during snowmelt.

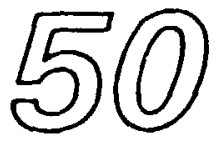

Sedimeni Sources and Short-Tem Sediment Remobitication in the Savannah River Estuary Are Identified with 'Be, ${ }^{137} \mathrm{C}$, and ${ }^{210} \mathrm{~Pb}$

K L Von Damm, J. M. Grebmeier,' I. L. Larsen, and C. R. Olsen

${ }^{1}$ The University of

Tennessee, Knarville.
As part of the study of the southeast Atlantic coastal zone conducted for the DOE Office of Health and Environmental Research, we have been using the natural radionuclides ${ }^{7} \mathrm{Be}\left(53-\mathrm{d}\right.$ half-life) and ${ }^{210} \mathrm{~Pb}(22$-year half-life) and the artificial radionuclide ${ }^{137} \mathrm{Cs}$ (30-year half-life) to study the processes of sediment remobilization and deposition in the Savannah River Estuary in Georgia. Previous results have suggested that much of the sediment deposited in the estuary is from a marine, rather than from a river, source. In September 1989 we collected cores and water samples from four stations in the estuary, ranging in salinity from 10 to $26 \%$. The objective was to compare the changing inventories and distributions of ${ }^{210} \mathrm{~Pb}$ (as a marker of marine-derived material) with those of ${ }^{137} \mathrm{Cs}$ (as a marker of river-derived material) as a function of salinity and depth in order to evaluate changing sediment source terms in space and time. Fortuitously, we sampled just 1 week before Hurricane Hugo hit this area and therefore returned to our stations in early October to collect a second set of cores, including those from a new station (Station 5) on the shelf. This shelf station had been occupied in June 1986 but could not be sampled in September 1989 due to poor weather conditions. The comparison between the two time samplings is being used to understand the effects of storm events on sediment remobilization in the estuary, as indicated primarily by ${ }^{7} \mathrm{Be}$.

Results based on ${ }^{7} \mathrm{Be}$ suggest that, at our lowest-salinity station (Station 2), $8 \mathrm{~cm}$ of new sediment deposition had occurred within 1 month. The change in ${ }^{7} \mathrm{Be}$ inventory is so large that it implies that sediment was not just stirred into the water column and then redeposited but that much new material was added. The next station (Station 3) also shows cvidence of additional sediment deposition, whereas 
the station closest to the mouth of the river (Station 4) suggests that sediment has been lost at this site.

In the core collected on the shelf in 1986, it appeared that the ${ }^{210} \mathrm{~Pb}$ and ${ }^{137} \mathrm{Cs}$ concentrations were anticorrelated, a finding which suggested that we might be observing changes in sediment source. High ${ }^{210} \mathrm{~Pb}$ and low ${ }^{137} \mathrm{Cs}$ would suggest a marine source, whereas low ${ }^{210} \mathrm{~Pb}$ and high ${ }^{17} \mathrm{Cs}$ would suggest a river source. In the cores counted to date (both of the Station 2 cores and the Station 5 core), this anticorrelation does not appear to be a strong signal. However, a large down-core variation in unsupported ${ }^{210} \mathrm{~Pb}$ is ooserved in these three cores. In an ideal case, unsupported ${ }^{210} \mathrm{Pt}$ would decrease exponentially with depth (i.e., with increasing time since deposition). The variance from this ideal case that we are observing reinforces a model of estuarine sediment deposition in which episodic events and possible changes in sediment sources are dominant features of long-term ( $\sim 100$ years) sediment deposition. The analysis of the cores collected at Stations 3 and 4 is in progress to provide better understanding of sedimentation processes for the Savannah River Estuary as a whole.

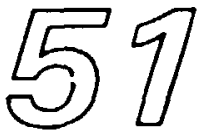

Radioactive Strontium in Contaminated Soits Is Immobilized by Phosphatc Treatment

K H. Kim. ${ }^{1}$ and S. Y. Lec

${ }^{1}$ The University of Tennessep, Knowille.
Radioactive strontium $\left({ }^{90} \mathrm{Sr}\right.$ ) has been recognized as one of the most abundant radionuclides in the contaminated arcas on the Oak Ridge Reservation (ORR) and at other DOE facilities involved in the reprocessing of spent fuel. Strontium- 90 has a relatively short half-life (29 years), but it has relatively high mobility under neutral-to-acidic soil conditicns. Most of the well-developed soils on the ORR have weak acidic reactivity (pH 6.5 to 4.5 ) although they were developed from the residua of dolostone or limestone. The favorable soil conditions resulted in the appearance of several seepages containing ${ }^{90} \mathrm{Sr}$ near solid waste storage areas on the ORR. Therefore, the Environmental Restoration Program at ORNL has supported the development and demonstration of in situ ${ }^{90} \mathrm{Sr}$ immobilization technologies.

In situ phosphatc solution treatment was selected for a fcasibility study as a technology for ${ }^{\text {NS }} \mathrm{Sr}$ immobilization. Both batch and column experiments were performed to find optimum conditions for coprecipitation of ${ }^{\text {on }} \mathrm{Sr}$ with $\mathrm{Ca}, \mathrm{Al}$, and Fe as a phosphatc compound in contaminated 
soils. The results showed that $>99 \%$ of very diluted radiostrontium $\left(<10^{-8} M\right.$ ) was coprecipitated with metal ( $\mathrm{Ca}, \mathrm{Al}$, and $\mathrm{Fe}$ ) phosphate compounds. The optimum concertration of phosphate and metals was above $0.1 M$ with a 1:1 molar ratio, and the coprecipitation was favored at a $\mathrm{pH}$ between 6 and 8 in batch experiments conducted with and without soil. Column leaching experiments revealed a noticeable reduction of "Sr leachability in soil columns treated with metal and phosphate. The reduction was more pronounced with increasing residence time between metal-phosphate treatment and successive leaching. For the calcium-phosphate treatment, the

ORNL-Photo-6261-90

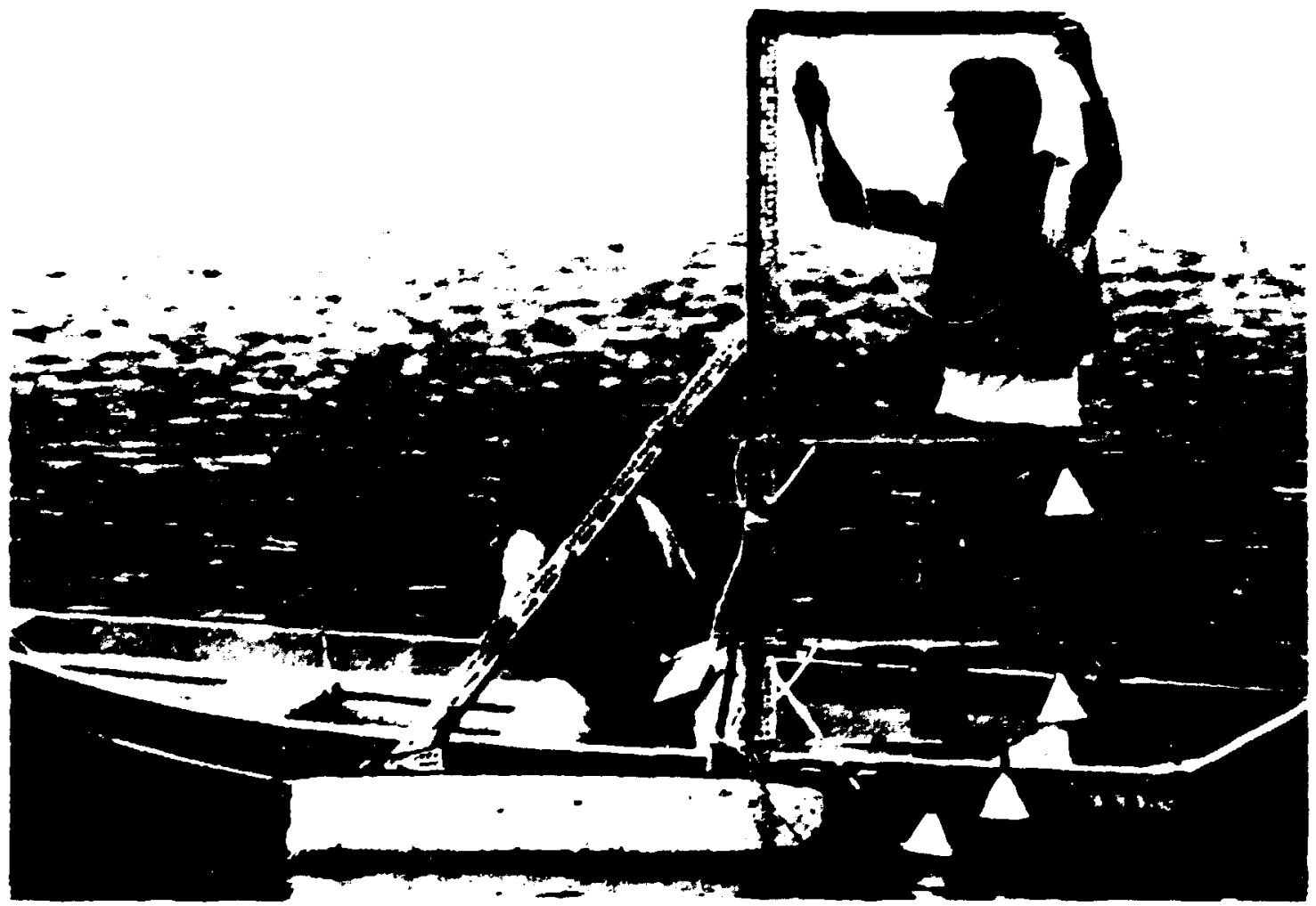

Ralph Tumer and Kristine Willett, an undengraduate chemistry student from the University of North Carolina, check air flow rates on a special air-monitoring buoy installed in Reality Lake at the Oak Ridge Y-12 Plant. The equipment is used to estimate the flux of mercury vapor from the pond surface. Researchers are gatihering the data in efforts to characterize contamination and evaluate remedial altematives for East Fork Poplar Creek. 
reduction was more noticeable when calcium was introduced first than when phosphate was introduced first. The opposite result was observed for other metal-phosphate treatments. Although the amount of ${ }^{90} \mathrm{Sr}$ reduction did not differ much between the metal phosphates, calcium phosphate would be less stable at a lower pH. However, selection of a metal as a coprecipitator is dependent upon site characteristics. For cxample, if contamination has extended to the organic-rich zone of the soil profile, treatment with both phosphate and iron or aluminum would not be an acceptable choice.

Although many detailed aspects of the technology need to be investigated before field demonstration, the laboratory results indicated that phosphate-based in situ treatment would be an attractive option for the sites contaminated mainly by "Sr. The in situ containment of ${ }^{90} \mathrm{Sr}$ would prevent groundwater contamination and lead to eventual decommissioning of the sites through the natural decay process of the radionuclides. The in situ treatment reduces the remediation cost and obviates the need for the further treatment, excavation, transportation, and storage associated with other remediation technologies.

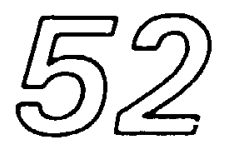

Goology and Goophysics Group Develops IDEM Computer Code to Determine In Situ Dynamic Elastic Moduli Values of Subsurface Soils

R. J. Selfridge,' B. Lewis,' J. Switek, and R. O. Kennard

'Automated Sciences Group, Inc., Oak Ridge, Tennessee.
The response of subsurface soiis beneath facilities during earthquakes is often the most critical factor in determining whether a facility suffers structural failure or escapes serious damage. The geotechnical parameters of interest include Poisson's ratio, Young's modulus, the shear modulus, and the bulk modulus-collectively known as dynamic elastic moduli. These moduli values can be calculated if the in situ density and the in situ compressional and shear wave velocities of the soil layers are known. These values and facility structural data are incorporated in an analysis of soil structure interaction to model the response of a facility to earthquake motion.

The in situ values of density and compressional and shear velocities are measured by downhole and cross-borehole geophysical testing. Typically, three collinear polyvinyl chloride (PVC)-encased boreholes are installed and geophysically logged with a density and borchole-deviation probe. A borchole sparker is then lowered into one borehole, while hydrophones are lowered into the other borcholes. The sparker source and the hydrophone receivers are kept at the same relative 
elevation while the three units are lowered into the bole and the compressional wave arrival time is recorded. This information is interactively entered into the new computer program IDEM, deveioped by Automated Sciences Group, Inc., which concurrently plots arrival time vs depth for each borehole being tested. This method aierts the field geophysicist to possible errors or irregularities in the data and allows immediate retesting of suspect zones. When the probes reach the bottom of the borehole, a clamping mechanism is activated on two triaxial geophones that are attached to the bottom of the hydrophone lines, and the downhole sparker is replaced by a downhole shear-hammer source. The shear-hammer source and each of the clamped triaxial geophones are then collectively raised, and the recorded data are once again interactively entered into the computer program to plot the arrival time vs depth. After the fir compressional and shea. velocities corrected for borehole deviation are calculated automatically. In addition, the density information is used $t u$ calculate the in situ dynamic elastic moduli values for each tested interval. All data tables and plots can then be printed for immediate analysis.

The newly developed computer program and operating procedures will dramatically decrease field and office time and associated costs for the surveys. Mc re importantly, use of the program will improve data quality by alerting the field geophysicist to potential data inaccuracies at a time when the soil zones can be immediately retested. Creation of a simple electronic data base for long-term data storage and faster turnaround time for report publication are additional benefits of the program.

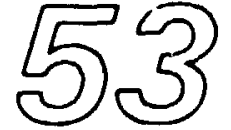

Chemical Form and Concentration of Mercury Determine Performance of Mercury-Dosed Soils on Standard Leaching Tests

R. R. Turner, K. L. Willett,' and J. J. Bcauchamp ${ }^{2}$
The need for, and nature of, any corrective measures for mercury-contaminated soils will depend on a variety of factors, including the total concentration of mercury and the performance of the soils in one or more standard leaching tests. These tests have been designed to evaluate the potential mobility of mercury for transfer to other media such as groundwater. Two such tests are currently in use to classify solid wastes, including contaminated soils. The tests, the Extsaction Procedure Toxicity (EPTOX) and Toxicity Characteristic Leaching Procedure (TCI,P) 
'Universiy of North

Carolina, Chapel Hill.

'Engineering Physics and

Mathematics Division, ORNL. were developed in response to the Resource Conservation and Recovery Act (RCRA). Application of these tests to a variety of contaminated soils from the DOE facilities in Oak Ridge, Tennessee, has not shown any consistent relationship between test results and total mercury concentrations. Low yields of leachable mercury (less than the RCRA limit of $0.2 \mathrm{mg} / \mathrm{L}$ ) have not been uncommon for soils containing several thousand parts per riillion of mercury and even for those exhibiting visible beads of mercury. Conversely, some soils having relatively low concentrations of total mercury have sometimes exhibited high leachability of mercury ( $>0.2 \mathrm{mg} / \mathrm{L}$ ) and been classified as hazardous under RCRA.

The experimental results described here address several issues: (1) Can sample headspace mercury vapor measurements be used to predict the performance of a soil sample on the EPTOX or TCLP tests? (2) What forms of mercury are sufficiently soluble in a soil matrix to yield leachate concentrations exceeding the RCRA limit of $0.2 \mathrm{mg} / \mathrm{L}$ ? (3) How does the total concentration of mercury in a given form relate to the performance of a soil on the standard leaching tests? (4) How does the effectiveness of TCLP, which will replace the EPTOX beginning September 25, 1990, compare with EPTOX?

Samples of uncontaminated soil írom Bear Creek Valley were dosed in triplicate with four different forms of mercury $\left(\mathrm{Hg}^{\circ}, \mathrm{HgS}, \mathrm{HgO}\right.$, and $\left.\mathrm{Hg}_{2} \mathrm{O}\right)$ at three concentration levels $(100,1000$, and $10,000 \mathrm{mg} / \mathrm{kg})$ and then subjected to the two tests. The headspace of each dosed sample was sampled for mercury vapor prior to leaching. Results of the lcaching tests and headspace vapor measurements were evaluated statistically using SAS."

Sample headspace vapor concentrations were generally proportional to the dosed concentration of mercury and were related to the relative volatility of the dosed form of mercury. However, no correlation was observed between leaching test results and vapor concentrations. None of the leaching test results for soil dosed with $\mathrm{Hg}^{\circ}$ or $\mathrm{HgS}$ exiceded the RCRA limit, even at the highest dosing level $(10,000 \mathrm{mg} / \mathrm{kg})$. For both mercury oxide forms, only the higher soil concentrations (1000) and $10,000 \mathrm{mg} / \mathrm{kg}$ ) yiclded leachate concentrations exceeding the RCRA limit. In general, the TCLP yielded higher leachate concentrations of mercury than the EPTOX. These results are consistent with the reported solubilities of the pure mercury compounds, except for $\mathrm{Hg}_{2} \mathrm{O}$, which is reported to be insoluble. Dis?roportionation of mercurous mercury to 
eleunental and merc'uric mercury may have enhanced the solubility of the mercurous oxide in the soil. This study verified that, where the chemical form of mercury is unknown, total mercury concentrations in soil and headspace vapor measurements provide no clue about the performance of a soil in the leaching tests.

-SAS is the registered trademark of SAS Institute, Inc., Cary, North Carolina.

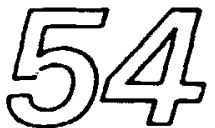

Joint ORNL-IST

Seismic-Reflectur Survey

Provides a

Three-Dimensional Map of

Groundwater Aquifers at

Paducah Gascous

Diffusion Plant

J. Switek, M. A. Speece,

R. T. Williams, ${ }^{\text {' }}$ and J. A.

Hanson'

'The University of

Tennessee, Knarville.
To facilitate a successful groundwater monitoring plan for the Paducah Gaseous Diffusion Plant (PGDP) in western Kentucky, a high-resolution seismic-reflection survey is being conducted in and around the plant. This project is teing carried out jointly by ORNL and The University of Tennessee (UT). The principal aim of this survey is to provide data for PGDP. This information will consist of a three-dimensional map of the main groundwater aquifers and estimates of porosity and permeability from seismic-wave velocities and frequency attenuation. Currently, -12 miles of normal-incidence profile data have been collected in the area, with several additional miles still to be collected before the survey is concluded. Also, a down-hole tomographic experiment will be inmpleted soon on the PGDP site to obtain important three-dimensional information about a possible site of groundwater contaminant release.

After these data are collected, they will be computer processed and interpreted. Initial data processing of some of these data shows strong reflectors within the upper $200 \mathrm{ft}$ for the area north of the PGDP. One especially strong reflector, present at depths of between 25 and $100 \mathrm{ft}$, reveals a complex, irregular surface. A preliminary interpretation places this reflector at the top of the regional gravel aquifer. Other less-prominent reflections are observed both above and below this stronger reflection; these probably arise from variations in the shallow groundwater system and the basement rocks, respectively. Further processing and the incorporation of well-log data should provide a detailed structural interpretation of the groundwater system for the region. These data will provide crucial information for later groundwater modeling studies. 
ORNL-Photo-7283-90

Lauren Larsen places a sediment sample in a radiation detector for low-level gamma-ray analysis. A shield of lead bricks prevents background levels of radioactivity from interfering with signals emitted by the samples.

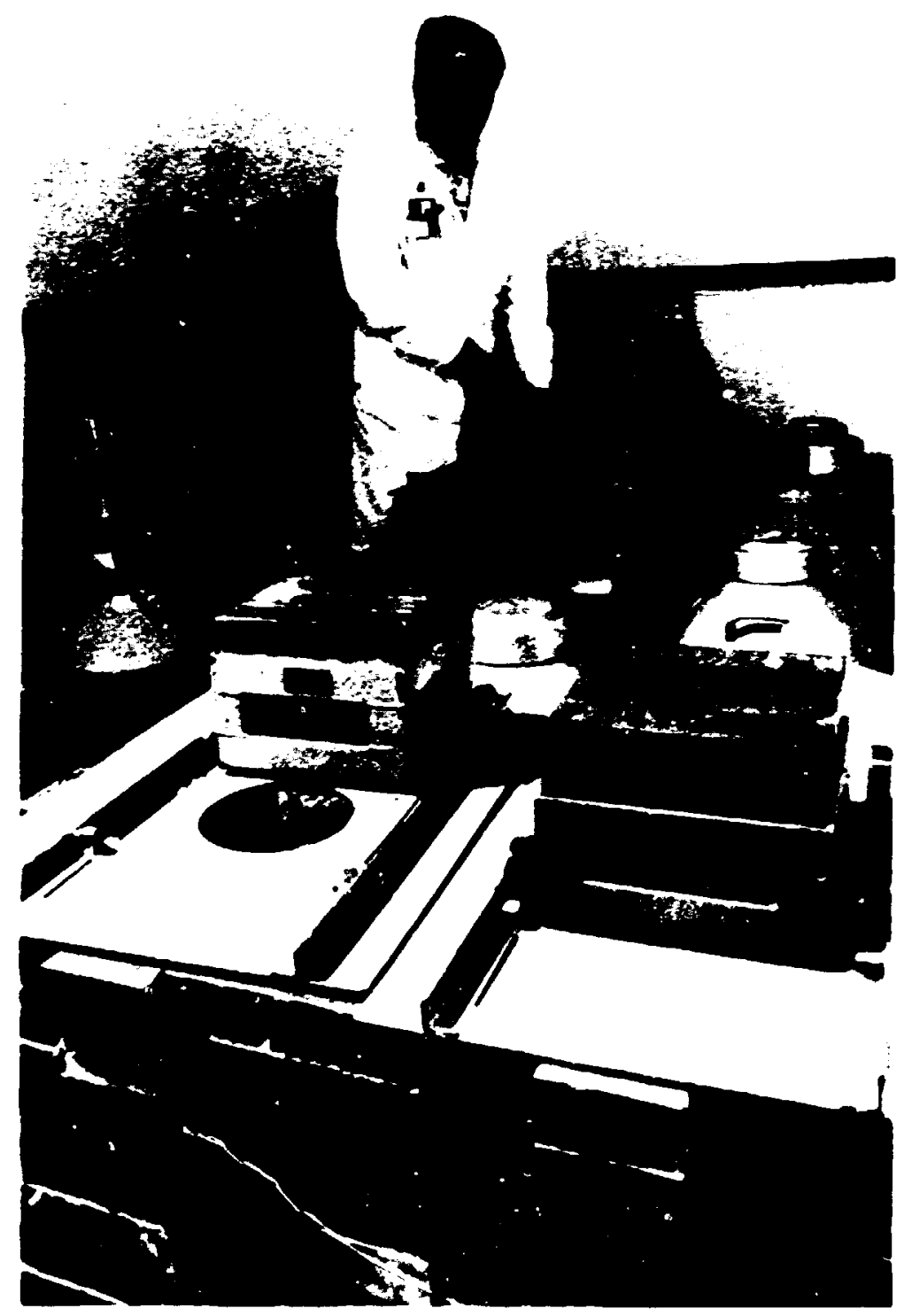

The collection of these data will be an important step in building a successful groundwater monitoring plan for the PGDP. The initial success of this survey bodes well for development of large-scale high-resolution scismicreflection surveys to aid in building a successful groundwater monitoring plan for DOE facilitics. Potentially, these surveys could provide important information needed in a remedial program at any site at which groundwater contamination is a problem. 


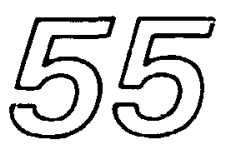

\section{In Situ Soil Venting Demonstration at Air Force Base Is Successfully Completed}

S. E Herbes, D. W. DePaoli, ${ }^{1}$ J. H. Wilson, ${ }^{1}$ D. K. Solomon, J. E. Nyquist, ${ }^{2}$ and N. G. Conklin ${ }^{3}$

'Chemical Technology Division, ORNL. ${ }^{2}$ Health and Safety Research Division, ORNL. ${ }^{3}$ Oak Ridge Associated Universities, Grand Junction, Colorado.
The technology of in situ soi! venting (vacuum extraction) holds great promise for remediation of petroleum hydrocarbon contamination in soil. Because spilled JP -4 jet fuel constitutes a major contamination problem at many air bases, in 1987 the Air Force Engineering and Services Center (AFESC) funded ORNL to demonstrate the effectiveness of the technology at the site of a 25,000-gal jet fuel spili at Hill Air Force Base, Ogden, Utalı. In October 1989 the field test was completed; subsequent soil analysis has demonstrated the near-complete removal of fuel from the vented zone.

The spill occurred in 1986 when a subsurface tank overflowed, allowing much of the spilled JP-4 to penetrate the sandy scils adjacent to and downgradient from the tank. To assist in design of the venting system, soil stratigraphy and the residual fuel distribution were determined by logging of 54 boreholes and collection and analysis of 338 soil samples; soil permeability was measured by air injection tests. Following operation of a 1-month pilot vent test in January 1988, an array of 15 vertical vent wells $50 \mathrm{ft}$ deep were installed throughout the spill zone. Six laterai vents were instal.ed beneath the excavated fuel tanks, and additional lateral vents were installed through the 160-ft-long excavated soil pile. Polyethylene sheeting was installed over half the vertical vent area to evaluate the effect of a surface barrier.

The venting system consisted of the vent wells and piping, two rotary-lobe blowers, two catalytic converters for air emissions control, and associated monitoring and control instrumentation. The system was operated from Ducember 16, 1989, through October 9, 1989; tests conducted during that period included evaluation of different venting rates, various configurations of air-withdrawal wells, and the effect of heated air injection. During this period, more than 170 million $\mathrm{ft}^{3}$ of air was drawn through the vent zone. Following the vent test, residual fuel was determined by collection and analysis of 127 soil samples from 21 borcholes.

During the test, the concentration of hydrocarbons in the vented air stream declined from 45,000 ppmv (as hexane) to $350 \mathrm{ppmv}$. A total of $105,000 \mathrm{lb}$ of hydrocarbons was remo ed in the vented air during the 10-month test; an additional 16,000 to $21,000 \mathrm{lb}$ was estimated to have been biodegraded by microbial action. 
The maximum soil hydrocarbon concentration measured was reduced from $6400 \mathrm{mg} / \mathrm{kg}$ before the test to $424 \mathrm{mg} / \mathrm{kg}$ afterward; gas chromatographic analyses confirmed complete removal of benzene, toluene, xylene, and other more volatile compounds. Based on soil analyses, hydrocarbon removal efficiency was $-94 \%$. Pressure measurements from monitoring points demonstrated effective air flow throughout the vent zone; computer modeling indicated that the surface barrier had little influence on air flow.

A draft final technical report, literature summary, and user's manual have been submitted to the AFESC. The test has demonstrated conclusively the effectiveness of in situ soil venting for jet fuel removal in soils.

Recommendations to the AFESC for additional studies include optimizing biodegradation during venting, evaluating the validity of coupled flow/contaminant removal models, and conducting field tests at sites having less-optimal soil characteristics.

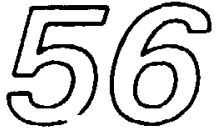

Shallow Grouudwater in SWSA 4 Has a Distinct Deuterium Isotope Signaiure

I. E. Toran and J. D. Marsh, Jr.
Stable isotopes of water, ${ }^{18} \mathrm{O}$ and $\mathrm{D}$ (dcuterium), have been measureo for 17 shallow and dcep groundwater samples on the Oak Ridge Reservation. In addition, waier samples from five rainfall events were collected. These data can provide information on recharge and groundwater now paths. As previously reported, the samples from depths of 30 to $60 \mathrm{~m}$ fall on the typical meteoric water line, representing local arca recharge. New data points [U.S. Geological Survey wells (U wells)] confirm this trend. Deeper samples have a heavier ${ }^{18} \mathrm{O}$ signature, indicating older recharge or water/rock interactions.

The data from rainfall collected from a site in Bethel Valley show greater variability in both ${ }^{18} \mathrm{O}$ and $\mathrm{D}$ than do data from the groundwater sample, as expected. Rainfall temperarure and source can vary during storms. By the time the storm flow reaches the groundwater, the isotope signature has been integrated to a value characterized by the meteoric water line, which describes the relationship between $\mathrm{D}$ and ${ }^{18} \mathrm{O}$.

The new data from shallow depths $(<10 \mathrm{~m})$ in Solid Waste Disposal Arca (SWSA) 4 also have a distinct isotope signature (sec figure). The ${ }^{18} \mathrm{O}$ values are similar to the data that fell on the meteoric water line, but the $D$ values are heavicr than expected. Two different 


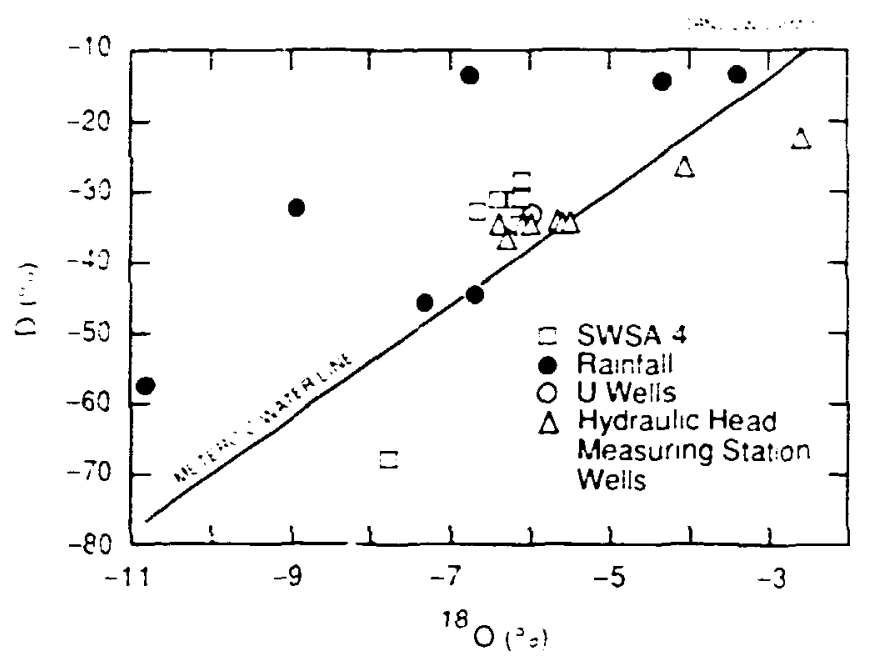

hypotheses are suggested to explain the data. The heavier $\mathrm{D}$ may be caused by some waste-related activity. If so, D would be an additional conservative tracer of contaminant movement. The second hypothesis is that integration of the rainfall did not occur in this shallow groundwater zone because of the presence of highly fractured and heterogenous rock. To test this hypothesis, shallow samples should be collected away from the disposal areas.

Additional $\mathrm{D}$ and ${ }^{18} \mathrm{O}$ data from deep and shallow zones and from rainfall should help in elucidating groundwater flow paths on the Oak Ridge Reservation.

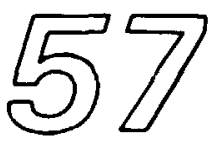

Extent of PCB

Contamination in Upper Tributary 8 Sediments at the Bear Crock Burial Grounds Has Bcen Characterizod

M. A. Boglc and R. R. Turner
A major focus of the Oak Ridge Y-12 Plant Remedial Action Program (RAP) is the identification and remediation of soils and sediments contaminated with polychlorinated biphenyls (PCBs). As part of a recent study to document the extent of PCB contamination in and near the former Oil Retention Ponds and two tributary streams (Tributaries 6 and 7) which adjoin the Oak Ridge Y-12 Plant Burial Ground A in Bear Creek Valley, several soil and sediment samples were collected from the upper reaches of Tributary $\mathbf{8}$ of Bear Creck. Some of the samples from Tributary 8 were found to be contaminated with PCBs, contrary to historical records, which indicated that PCB-contaminated oils were not disposed of in Burial Ground $C$. Additional information on the extent and kevels of PCB contamination along 
upper Tributary 8 was required to determine whether remedial activities are needed.

To delineate the horizontal and vertical boundaries for areas with PCB contamination that exceeds regulatory action limits $(25 \mu \mathrm{g} / \mathrm{g})$, a sampling plan was designed and implemented ior the upper reaches of Tributary 8 . We collected samples from sites located in zones of seepage from Burial Ground $C$ and sites in areas of high sediment deposition along the tributary, thus increasing the probability of locating PCB contamination that equaled or exceeded the action level. In addition, three samples were collected at floodplain locations that were expected to be free of contamination. During the survey, we collected a total of 10 surface soil/sediment samples (0 to 6 in.), plus 1 duplicate, and 23 soil/sediment cores, plus duplicates, for contaminant depth profiles. A hand-operated bucket auger was used for collecting the cores, generally along transects across seepage zones and the adjacent floudplain. The bucket-auger samples were collected at depths of 0 to 6 in. (0 to $15 \mathrm{~cm}), 6$ to 12 in. (15 to $30 \mathrm{~cm}$ ), and 12 to 18 in. (30 to $45 \mathrm{~cm}$ ). Three cores were also taken from a depth of 18 to 24 in. ( 45 to $60 \mathrm{~cm}$ ).

Results of the soil and sediment analysis for PCBs agree with data collected previously for upper Tributary 8: concentrations of PCBs approaching or exceeding $25 \mu \mathrm{g} / \mathrm{g}$ dry weight occurred only in samples collected from Seeps 3 and 4, which drain into Tributary 8 from the base of a steep slope that forms the southern boundary of Burial Ground C. Both seeps showed similar vertical distribution of PCBs: concentrations of PCBs decreased with depth, and concentrations exceeding the action level were limited to the upper 12 in. of sores. The highest concentration of PCBs $(80 \mu \mathrm{g} / \mathrm{g})$ was found in the top section of a core collected at Seep 3. The maximum concentration measured at Seep $4(51 \mu \mathrm{g} / \mathrm{g})$ also occurred in the top section of a core. Concentrations in samples collected upstream of Seep 3 generally showed PCB levils either below or slightly above the detection limit. P'CB levels in samples collected downstream of Seeps 3 and 4 were detectable but well below the action level.

The survey results indicate that $\sim 1200 \mathrm{ft}^{3}$ of sediment/soil in upper Tributary 8 exceeds the action level. Theit results will be used by RAP managers in designing corrective measures, possibly including excavation, as part of the ongoing closure activities for the Burial Grounds. 
50

Westbay Multi-Port Systems Are Installed in Core Holes at the Oal Ridge Y-12 Plant

T. O. Early
During 1985 a series of deep core holes forming several transects act. ss Bear Creek 'alley was dniled in an effort to characterize the subsurface geology in this region. These core holes range in depth from 599 to $1275 \mathrm{ft}$ and, with the exception of surface casing, were completed as open toles. Not only did these core holes yicld valıable geologic data (information sbout lithology and fracture characteristics), but packer testing in selected holes allowed researchers to obtain hydrogeologic information for the region.

The increased emphasis by DOE on characterization of waste disposal sites and the extent of groundwater contamination in Bear Creek Valley has made it essential to obtain a more detailed picture of groundwater how regimes in this region. Identification of the interaction between the local and regional flcw systems will provide insight into the potential flow pathways for contaminants migrating from waste sites. As an important step toward obtaining the required hydrologic data, five of the deep core holes within Bear Creek Valley were chosen to be completed with Westbay Multi-Port (MP) systems. The MP system utilizes a polyvinyl chloride casing with inflatable packers distriouted along its length to define a series of monitoring zones. Once the MP system is inserted into the core hole and the packers are inflated, the zones become hydraulically isolated from one another. The primary advantage of the MP system is that a single well can provide hydraulic and hydrocinemical data from many different monitoring zones. The MP casing within each zone contains one port that can be used to purg? the aquifer and a second port that is used to measure formation temperature and hydraulic pressure and to obtain water samples under in situ conditions. Tools used to prepare a zone for purging, to measure fluid pressures and temperatures, and to collect samples are suspended in the MP by cable and are raised and lowered by winch. The tools are designed to mate with the ports by means of special couplings in the MP casing.

In March 1990, MP systems were installed in four holes forming a transect across Bear Creck Valley near the S-3 Ponds site at the western end of the Oak Ridge Y.12 Plant and in the first of two core holes forming a sccond transict adjacent to Scarboro Road at the cast end of the plant. Results from a preliminary set of pressure 
measurements at the five MPs are qualitatively similar to those obtained earlier by activities associated with packer testing. The earlier investigation suggested that there may be a "floor" to the shallow hydrologic system and th?t the floor limits the extent to which contaminants in the shallow sys'em can migrate downward.

Currently, a team from ESD and the Oak Ridge Y-12 Plant is purging the measurement zones to repare them for hydrochemical sampiing. We anticipate that once preliminary testing is completed, these MP systems will be available for a variety of special sampling and testing activities. For example, collection of groundwater samples for age dating and for stable isotope and rare gas analyses will be possible. In addition, we can determine hydraulic conductivity values for the measurement zones by using rising- and falling-head techniques adapted to the MP system.

\section{Section Staff}

S. H. Stow

\begin{tabular}{|c|c|c|}
\hline L. M. Aplcy & S. B. Garland & A D. Laase \\
\hline T. L Ashwood & C. E. Gilliam & I. L Larsen \\
\hline W. J. Bocgly & M. J. Giorgis & S. Y. Lee \\
\hline M. A. Bogle & J. M. Grebmcier ${ }^{1}$ & A. C. $\operatorname{Lin}^{10}$ \\
\hline E. A. Bondictti & S. M. Grcgory & S. E. Lindahl ${ }^{3}$ \\
\hline D. M. Borders' & O. J. Grooms & S. E. Lindberg \\
\hline C. C. Broders & T. D. Hall ${ }^{6}$ & J. D. Marsh \\
\hline P. A. Buntrock & V. L Harless ${ }^{1}$ & D. S. Marshall \\
\hline R. B. Clapp & B. K Harrington' & R. M. Martino" \\
\hline N.H. Cutshall & R. D. Hatcher ${ }^{7}$ & T. L McGchce ${ }^{\prime \prime}$ \\
\hline M. B. Donohuc 2 & M. S. Hendricks & T. P. McKenzic \\
\hline R. B. Drcicr & S. E. Herbes & W. M. McMaster' \\
\hline T. O. Early & F. M. Hoffman" & M. J. Miller \\
\hline J. A. Ehrfurth ${ }^{3}$ & A. A. Hood & G. K Moore' \\
\hline C. H. Fairfax & L. K Hyder & C. M. Morrisscy \\
\hline C. D. Farmer & G. K. Jacohs & J. D. O'Dell' \\
\hline N. D. Farrow & P. M. Jardinc & C. R. Olsen \\
\hline r. A Fontainc & P. M. Kcarl & J. G. Owcns \\
\hline J. M. Forstrom & N. E. Kortc & T. H. Peng \\
\hline J. E. Foxs' & R. O. Kcnnard & R. R. Ricn \\
\hline C. W. Francis & K. H. Kim' & M. N. Saraıi" \\
\hline B. J. Frederick' & Z. S. Koxner' & L. S. Schilling's \\
\hline
\end{tabular}

R. J. Sclfridge

B. V. Shelton

R. L. Siegrist

M. A. Sipc ${ }^{\text {I4 }}$

D. K. Solomon

B. P. Spalding

M. A. Spcece'

S. H. Stow

L E. Stratton

W. J. Stratton's

J. Switek

A. L. Thomas

L. E. Toran

V. S. Tripathi

R. R. Turner

K. L. Von Damm

D. S. Wickliff

K L. Willett ${ }^{16}$

G. V. Wilson'

Y.-L. $\mathrm{Wu}^{17}$

Z. S. Koxuner

M. N. Sara i"

S. Schilling" 
1. The University of Tennessee Knowvile.

2 Michigan State University, East Lansing.

3. University of Wisconsin, Stevens Point.

4. Oak Ridge High School, Oak Ridge, Temnessee.

5. Le Moyne College, Syracuse, New York

6. Rule High School, Knoxville, Tennessee.

7. ORNLתT Dstinguished Scientivi Program

8. Automated Sciences Group, Inc., Oak Ridge; Tennessere.

9. Pembroke State College, Pembroke, North Carolina.
10. Princeton University. Princetu!1, New Jersey.

11. Texas A\&I, Kingsville.

12 Comell University, Ithaca, New York

13. Virginia Polytechnic Institute and State University, Blactsburg.

14. Roane State Community College, Oak Ridge, Tennessec.

15. Eariham College, Rictimond, Indiana

16. University of North Carolina, Chapel Hill

17. Carnegie-Mellon University, Pitusburgh, Pennsytuania. 


\section{Technical and Administrative Support}

\section{Introduction}

The Technical and Administrative Support (TAS) Organization of the Environmental Sciences Division (ESD) provides operatior.a', information-related, and administrative support for FSD. During FY 1989 this support was provided to about 200 employees and over 300 guests who were housed in ESD's five ORNL buildings, which contain offices, research equipment facilities, and 40 research laboratories. Other ESD facilities include two field installations and several other field locations on the Oak Ridge Reservation.

Operational support activities encompass safety, quality assurance (QA), general operations (including engineering and craf services), and computer operations. TAS staff made significant progress toward mecting the increasing requirements, particularly in the areas of safety, QA, and materials inventory and tracking. Safety-related activities include training (both general and task-specific), quarterly inspections of all ESD facilities and periodic site-specific inspections. advising on project safety plans, and safety documentation. Other activities related to operational safety in ESD include radiation control; environmental protection monitoring; gencration, tracking, disposal, and reduction of wastes; tracking of precious metals; environmental safety and health inspections; and safety checks on rescarch and operations equipment. In the arca of quality, a QA specialist from the Quality Department continued his full. time assistance to ESD staff in providing a QA framework for the division and specific plans for individual projects. Bascd on NQA.1 quality requirements, the
ESD QA Manual provides the framework ior a program that is designed to fill the QA needs of the division. General operations activities include overseeing division maintenance and construction projects (with engineering support staff) and maintaining the ESD grounds.

The Computing and Geographic Information Facility Group operates a central computing facility for ESD. The facility has a remote batch station for printing and plotting, geographic information systems (GISs), and a personal computer (PC) network. A major function of the group is the operation of a remote batch station that provides printed and plotted output generated on the central ORNL computers. The ESD computing facility complements the ORNL computers by providing software and hardware for GISs and for CPU-intensive environmental modeling. Its support staff also provide general support for PC users, office automation, computer communications, and computer security.

Information- and publications-related support included library services, document preparation, editing, and graphic arts. The Information Services Division maintained an ESD branch library that contains $\sim 20,000$ documents. The library staff provided ESD a full range of information services, such as literature searches, biographical information on visitors, the full text of Congressional bills, and document translations. Both internal and external sources were used to provide information and information-rclated services in support of the work of the division. Document preparation staff provided a range of services, from word processing and editing to the creation of publication-quality drawings. In addition to these activities, technical information support is provided (o) ESD management 
in preparing briefing matcrials, descriptions of accomplishments for inclusion in award fee reports, and special write-ups for division and ORNL management.

Administrative support activities include processing information concerning the hiring of new staff and guests, tracking purchase requisitions, and tracking the

\section{Section Staff}

D. E. Fowler

C. H. Abner'

R. R. Adams ${ }^{2}$

P. G. Epperson

K. N. Gibson

A. G. Arp

A. M. Ayres ${ }^{3}$

R. E. Booker ${ }^{2}$

R. K. Bracher'

S. D. Bridges ${ }^{1}$

P. V. Carson

L. S. Corrill ${ }^{4}$

M. S. Denton
N. A. Griffith

A. L. Harkey"

J. B. Harper'

M. S. Hendricks

J. E. Holbrook ${ }^{2}$

G. F. Houser ${ }^{6}$

L. J. Jennings

C. A. Kappelmann
- \$38 million ESD budget. TAS staff also coordinated educational activities within the division, including recruiting students for internships, conducting a DOE high school honors summer program, and convening various classes and programs at the Oak Ridge National Environmental Research Park.
L. W. Littleton

G. M. Logsdon ${ }^{4}$

R. K. McConathy

A. B. $\Lambda^{*}$ =Daniel

G. S. McFarland ${ }^{3}$

T. C. Minton'

J. M. Odom, Jr.'

D. D. Ogle

S. Y. Porter

D. D. Rhew
D. L. Rich ${ }^{2}$

L. E Roberson ${ }^{7}$

M. K. Savage

J. L. Seiber

W. J. Selvidge

T. T. Vann

M. Williamson ${ }^{2}$

K. T. Wilson ${ }^{3}$

I. Ptant and Equipment Division, ORNL.

2 Graphica Division, Martin Marietta Energy Systems, Inc.

3. Information Services Division, Mari in Marielta Energy Systems, Inc.

4. Publications Division, Martin Marielta Fnergy Systerns, Inc.

5. Computing and Telecommunications Division, Martin Marietta Encrgy Systems, Inc.

6. Office of Environmental and Health Protection, ORNL.

7. Quality Department, ORNL.

8. Finance and Materials Division, ORNL. 


\section{Biofuels Feedstock Development Program}

\section{Introduction}

The Environmental Scicnces Division (ESD) Biomass Production Program was reorganized in 1990. The program. which manages rescarch on biofucls feedstock production for the l.. - epartment of Energy (DOE). had included two national research programs. the Short Rotation Wondy Crops Program and the Herbaceous Energy Crops Program. Both herbaccous and woody crop research uill continue. but uill be managed as a single national program called the Biofucls Fecdstock Development Program (BFDP). The program's major sponsor is the Biofucls System Division in DOE's Oftice of Transportation Technologies. In 1990 the U.S. Environmental Protection Agency provided additional support for assessment of hiomass encrgy technologies and major constraints to deployment of biomass encrgy systcms.

The objective of the BFDP is the development of cost-effective production systems for dedicated energy crops. The DOE Bufucl Systcms Division emphasizes technologies for producing liquid and gasecous fue's from lignocellulosic biomass. To complemint that rescarch, the encrgy crops under development in the BFDP are primarily wored and grass species whose whlal aboveground biomass would become the encrgy feedstock. The crop development rescarch is closely coxordinated with rescarch programs at the Solar Encrgy Resciarch Institulc, whirh was designed an develop the kechnologies for converting $u(x) d$ and grass biomass 10 transpertation fucls. The BFDP also participales in International Encrgy Agency activitice related lo biomass producluin
Rescarch and analysis for the BFDP are performed within ESD. other Oak Ridge National Laboratory (ORNL) divisions, and at cooperating institutions. In FY 1990 the program supported rescarch at 16 universities, 3 U.S. Department of Agriculture research stations. and 2 private institutions. Major efforts included genetic improvement rescarch for woody and herbaceous species; related studies on physiology, nutrient cycling. sylviculture, and agionomics; cnvironmental research and analysis; and cconomic analysis. The genetic improvement, silvicultural, agronomic, and physiologic studies were performed primarily at cooperating institutions, supported by subcontracts and interagency agreements. Supprting environmental studies, including tiutrient cycling research, were performed in ESD. Other work performed primarily by ESD or ORNL staff included resource assessment, studies on $\mathrm{CO}_{2}$ cycling in biomass-based energy systems, and cconomic analysis.

In 1990 the BFDP had four major research components-Model Wood Energy Species, Model Herbaceous Energy Species, Environmental Rescarch and Analysis, and Economic Anaiysis and Integration. Other program efforts included International Encrgy Agency (IEA) activities. The current status of each of these arcas is deicribed briclly in the following.

\section{Model Woxd Encrgy Specics}

The goral of this program element is 10 develop word encrgy crops for U.S. regions where land avaiiability and climatc are favorable for the establishment of hiomass hased conergy systems. Model 
species have been selected based on their potentia! to be highly productive on a broad range of sites under environmentally sound management practices.

The primary area of research under this element is the genetic improvement of Populus species. PC-'ilus research subcontracts have been strategically placed within the United States based on the natural range for the species and potential productivity levels. Activities currently include $a$ central and regionally interactive Populus breeding program in the Midwest/Lake States and a program for early selection for resistance to Septoria canker. A breeding plan for Populus in the Midwest in being finalized. An initial version of a Populus growth model (E:COPHYS) is now being validated. New and innovative root research found genetic variation in the growth of roots that strongly affects aboveground growth. Greenhouse testing of herbicide-tolerant poplars has been completed, and promising individuals are being established in the field. For two poplar clones the relationship between growth and the spacing at which the clones were planted was more significant than anticipated, and the physiological and morphological traits accounting for this phenomenon are being studied.

Other model species include silver maple, sycamorc, and black locust. Ficld trials and laboratory experiments are examining the genetic variability in silver maple seed sources collected over the species' natural gengraphic range. Sycamore research concentrates on developing effective clonal propagation techniques, improving rooting success, and improving breeding and genctic selection techniques. Rescarch on black lncust is designed to improve its productivity. nitrogen fixation, and pest resistance. Clonal propagation techniques are also heing developed.
Model Herbacous Encrgy Spocics

The goal of this program element is to develop herbaceous energy crops that are attractive (1) to both growers and processors and (2) from an environmental standpoint. The main emphasis is on grass and legume crops. Switchgrass, reed canarygrass, and sorghum have been chosen as model species for the Midwest/Lake States. Model species for the Southeast include switchgrass and scricea lespedeza (Lespedeza cunea:a). Species still under consideration include flatpea in the Midwest/Lake States and weeping lovegrass and napiergrass in the Southeast. Limited genetic studies were begun for suitchgrass and sericea lespedeza in 1990. Breeding programs fo: the Southeast and Midwest/Lake States are expected to expand in 1991. Specics screening is still under way in the Great Plains.

\section{Environmental Rescarch and Analysis}

The goal of this program element is to ensure that the environmental impacts of energy crop production are understood and accepiable. Environmental issues first became a separate program element in 1990 , although a range of environmental concerns had been addressed under other clements. The scope and direction of this program element is still under development; this 3- to 5-year plan is scheduled for completion in 1991. It is expected to include regional resource analysis, ficld research, and environmental impact assessment. In 1990 a national assessment of land availability, including land quality, location, and current use, was begun. 
Economic Analysis and Integration

The goal of this program element is to ensure that all linkages affecting the overall viability of biomass-based fuel cycles are understood and considered in program research and planning. This element includes the translation of research results to projections of estimated biomass production costs. Because low per-ton production costs alone will not ensure the economic viability of energy crops, this element also includes studies designed to investigate the economic consequences of growing energy crops, both for the producing farmer and the agricultural sector as a whole. Economic Analysis and Integration is also responsible for coordinating the input on biomass production systems needed in DOE and Solar Energy Research Institute planning and analysis efforts.

\section{International Energy Agency Activitics}

The International Energy Agency (IEA) biofuels activities are designed primarily for information exchange among participating countries. The BFDP provides technical support to DOE for IEA tasks on energy crop production. In 1990 the United States participated in eight such tasks-Energy Forestry Production Systems, Energy Forestry Ecophysiology, Dedicated Agricultural/Herbaceous Crop Systems, Pest/Disease Management, Wood Feedstock Qualities, Trce Ideotypes, Exchange of Genetic Materials, and Joint Trials. Activities included the direct involvement of ESD staff and BFDP subcontractors in cooperative evaluations and joint efforts to summarize and synthesize research results.

\section{Technical Summaries}

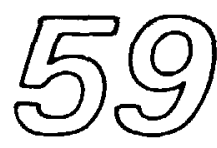

A Methodology Is Developed for Asecsaing the Implications that Aternative Land Use Strategies Have for Carbon Emissions on a Contincental Scale

R. L Graham, J. W. Ranncy, A M. G. Prasad, and R. D. Perlack'

'Energy Division, ORNL.
Changes in land use, in particular, the conversion of forests with high carbon storage to agriculture with low carbon storagc, can relcasc significant amounts of carbon to the atmosphere. Because land use policies in developing countrics affect global carbon emissions, agencies and institutions assisting devcloping countries in recognizing their need to understand the implications of different land use policies or strategies. The objective of this project was to develop a methodology for cvaluating the impact that alternative land use policies in sub-Saharan Africa would have on carbon emissions on a continental scalc.

The methodology was shaped by three goals: (1) to capture coarse-scale geographical variation in carbon inventory and emissions; (2) to link carbon inventory with those factors controlling cursent and pertential land 
use-vegetation, climate, soil fertility, political identity, and agricultural systems; and (3) to link carbon ennissions with land use change. To capture the vast geographical differences within and between countries of sub-Saharan Africa, we modeled carbon inventory and emissions on a yearty basis at $\mathbf{9 0 0 0}$ regularly spaced points across the continent ( $\sim 1$ point per $\left.2000 \mathrm{~cm}^{2}\right)$. Carbon inventory at a point (megagrams of carbon per hectare) was a function of local climate, soil fertility, vegetation type, land use, and likelihood of vegetation degradation. Initial point values for these characteristics were derived from continental maps of soil, climate, vegetation, and political units through the use of a geographic information system. We

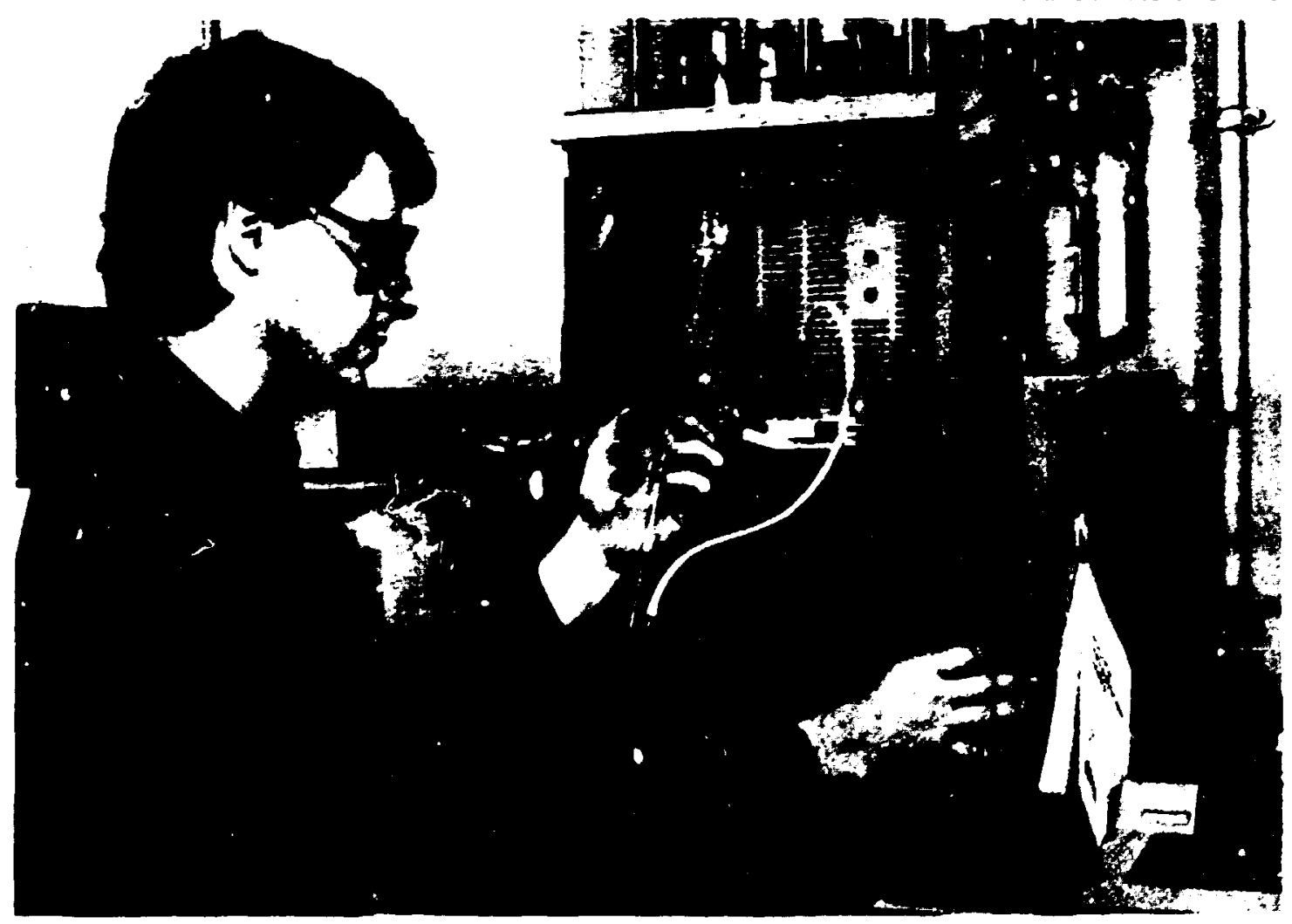

Tim Tschaplinsti analyzes derivativer of soluble carbohydrates and phenolic compounds of plant extracts with a Hewlett Packard 5890A Capillany Gas Chromatograph. Analyses of carbon and nitrogen metabolites by gas chromatography and high-performance liquid chromatography characterize species-specific responses 10 stress. 
calculated carbon emissions as the difference in inventory between succeeding years. Inventory changed as a function of land use change; however, cause of land use change was not modeled. To develop estimates of carbon inventory and emissions for a given country, we averaged the point values within the country and multiplied the average by the country's land area. This approach can be likened to collecting many point samples of soil in order to characterize the fertility of a field.

The modeling methodology was validated by: assuming current deforestation rates (current rates of land use change), calculating the resultant carbon emissions for each country, and comparing the predictions with other predictions of current carbon emissions. The model was then used to predict the carbon emissions that would result from the adoption of three alternative land use strategies: (1) increased conservation of existing forests, (2) widespread adoption of agroforestry, and (3) increased plantation forestry. Because the methodology allowed consideration of geographic variation in land quality, political identity, and current land use, it was possible to implement these strategies selectively (i.e., only at points for which the sirategy was both biologically and socially suitable). Thus, a more realistic evaluation could be made of the possible impact that adopting these strategies would have on both the continental inventory of carbon and carbon emissions.

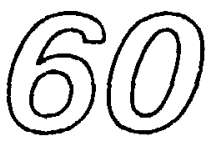

Increased Private-Sector Production of ShortRotation Woody Crops Is Linked to DOE Rescarch Developments

L. L. Wright
The private sector in the United States has been slow to adopt and use short-rotation woody crop (SRWC) technology. This reticence can be attributed primarily to the fact that the use of short-rotation wood as an energy feedstock has been limited by the low prices of competing fuels during the latter half of the 1980s and by the perception that SRWC technology is not yet ready for wide-scale implementation. Both advances in SRWC research and the initiation of cost-shared resesrch with industry are beginning to change the latter perception.

The first commercial plantings in the United States were initiated by the Packaging Corporation of America (PCA) in 1975 with considerable assistance from the North Central Station of the U.S. Department of Agriculture Forest Service. However, because of the lack 
of technical information available at that time, the PCA plantings were not successful. Since the initiation of the DOE Short Rotation Woody Crops Program (SRWCP) in 1978, at least 15 different private-sector groups in the United States have established SRWC plantings of 20 or more hectares, representing a total of over 4500 ha. The largest and the first successful large SRWC planting in the United States is the $\sim 3000$-ha planting in the Columbia River Valley owned by the James River Corporation. The first plots were cstablished in 1982 by using selected hybrid poplar clones and silviculture techniques developed by an SRWCP-funded program at the University of Washington and Washington State University. Although the James River Corporation has an active in-house research program, the rapid improvement in its techniques has been related to the continuing interaction with SRWCP-funded researchers in the region. Eight of the 15 private-sector SRWC plantings in the United States have heen initiated since 1987. Three of these eight began as a result of efforts by the SRWCP to initiate cost-shared research with industry; an additional four have employed SRWCP. funded researchers as consultants to assist in designing and establishing the plantations. The SRWCP projects that appear to be contributing most to the private sector thus far are those with integrated programs of genetic improvement and silviculture research.

Recent contacts have indicated that the acreage in private-sector SRWC can be expected to expand rapidly over the next few years. Although much of this material will likely be used for pulp or other wood products, the plantings will demonstrate the feasibility of SRWC for energy. SRWCP contractors are expected to continue to play a major role in expanding the use of SRWC technology through direct interactions with industry.

\section{Program Staff}

\section{J. W. Ranney}
J. H. Cushman
D. H. Dawson ${ }^{1}$
P. L. Henry
A. M. G. Prasad
H. Van Micgroct?
A. R. Ehrenshaft ${ }^{2}$
J. W. Johnston
G. A. Tuskan
C. R. Wenzel ${ }^{8}$
R. L. Graham ${ }^{3}$
W. A. McNabb
T. J. Tschaplinski ${ }^{4}$
A. F. Turhollow
L. L. Wright
R. J. Norby 
1. Consultan.

2. Health and Safery Research Division, ORNL

3. Environmental Anabses Stetion, ESD.

4. Environmental Touicology Section, ESD.

5. Graduate student, Miami University, Oxford, Ohio.
6. Energy Division, ORNL

7. Ecosystems Studies Section, ESD.

8. Science Applications International Corporation, Oak Ridge, Tennessee. 


\section{Carbon Dioxide Information Analysis and Research Program}

\section{Introduction}

The Carbon Dioxide Information Analysis and Research Program (CDIARP) is operated at Oak Ridge National Laboratory (ORNL) for the U.S. Department of Energy (DOE) Carbon Dioxide Research Division, Office of Basic Energy Sciences. CDIARP consists of three comporents: (1) the Carbon Dioxide Information Analysis Center, (2) Resource Effects, and (3) the Global Carbon Cycle Research Program.

\section{Carbon Dioxide Information Analysis Center}

The objective of the Carbon Dioxide Information Analysis Center (CDIAC) is to acquire, compile, evaluate, archive, document, and distribute $\mathrm{CO}_{2}$-related data and information in support of the DOE Carbon Dioxide Rescarch Program (CDRP). CDIAC is a fully integrated information analysis center that supports CDRP's rescarch program and provides $\mathrm{CO}_{2}$-related data and information frec of charge to an international audience of researchers, policy makers, and students.

CDIAC has two primary types of functions: (1) performing data activitics and (2) distributing $\mathrm{CO}_{2}$-related information. In fulfilling the first function, the Center obtains, compiles, evaluates, documents, and archives many types of information, including numeric data and computer models. Many of these data sets and computer models are fully documented and distributed as numeric data packages (NDPs) and computer model packages (CMPs). These products undergo extensive quality assurance and are assembled in full coordination with the original supplier of the information. CDIAC identifies users' data needs by working closely with researchers, CDRP, consultants, and legislators; attending workshops and conferences; reviewing the literature; and sending questionnaires to users of CDLAC data services. The Center's data activities and approaches are evolving to accommodate changes in research needs and technology, emphasis is placed on new methods of communication (e.g., electronic bulletin boards), new media for data archiving and distribution (e.g., CD ROMs), and new data products (geographic information systems and fully registered and projected cartographic data packages).

In fulfilling its second function, CDIAC serves as the CDRP information distribution center. Activities include performing bibliographic searches for users; compiling and publishing large bibliographies in critica! program areas; producing the semiannual newsletter CDLAC Communications; working with other data centers, individual researchers, and students to promote and facilitate the compilation and exchange of data; froducing and distributing NDPs and CMPs; and collecting and distributing $\mathrm{CO}_{2}$-related reports and articles. In 1990, CDIAC received 6384 requests for different types of information (an increase of $34 \%$ over FY 1989). In filling these requests, 2383 reports and 405 NDPs and CMPs were distributed. Since 1985, the Center has filled 20,250 requests from users in 81 countries. As an additional 
service for CDRP. CDIAC maintains a directory that lists -5500 researchers and policy makers from 148 countrics.

Data activities

CDIAC increased its NDPs to 36 during FY 1990 and updated 3 existing NDPs. The NCP documentation consists of an abstract. a data listing (either in tabular form or on microfiche). FORTRAN and SAS data retrieval programs, graphical displays of the data, and reprints of pertinent literature. CDIAC distributes the NDP-associated data files on magnetic tape or, when feasible, on floppy diskette.

CDIAC's must visible contribution in FY 1990 was the publication of the first in the series of TRENDS reports, to present greenhouse gas related data in a concise. reference-style format. The inaugural issue, TRENDS 90: A Compendium of Data on Global Change (ORNL/CDIAC. 36), was published in FY 1990 and provides atmospheric $\mathrm{CO}_{2}$ concentrations, atmospheric $\mathrm{CH}_{4}$ concentrations, global and national estimates of $\mathrm{CO}_{2}$ emissions, and long-term temperature records. To ensure that the integrity of the data has been maintained, CDIAC has worked closely with the rescarchers and agencies that compile the various recurds. The scope of the data in future issues of Trends will expand as more data are collected.

Also in FY 16x), CDIAC updated and expanded the NDP that provides global and national estimates of annual $\mathrm{CO}_{2}$ cmissions from fossil fucl hurning and cement manufacturing. This product provides onc of the key components to understanding the global greenhousc issuc and represents the best $(O)$ emission estimates available in the world. During Fy $1(x)$, the Center gencrated global and national estimates of annual cmissions for 1950 $\mathrm{xW}$, including estimates of emissions from gas flared in oil ficlds. These emission estimates are the result of an ongoing effort between CDIAC and the United Nations. As an integral part of the effort, CDIAC assures the quality of the United Nations energy statistics before calculating the cmission estimates.

\section{Information distribution}

Communications. The Center publishes the semiannual newsletter CDLAC Communications, which is distributed to all persons listed in the CDIAC directory. (The number of persons listed in the directory increased from 4637 to $\sim 5500$ by the end of FY 1990.) CDIAC Communications informs readers of current $\mathrm{CO}_{2}$ research, CDIAC services, and new $\mathrm{CO}_{2}$-rclated publications and mectings.

Networking. One of the CDIAC objectives is to work with data centers, universities, and individual researchers to promote and facilitate the exchange of data. During FY 1990, CDIAC staff engaged in several activities toward this end, including both organizing and attending symposia and workshops, presenting papers at conferences, and working with rescarchers to obtain and distribute important $\mathrm{CO}_{2}$ data sets.

\section{Resource Eflects}

Changes in climate and vegetation that result from increasing concentrations of atmospheric $\mathrm{CO}_{2}$ may have significant consequences for human health and w :rarc. Many important resources, such as agriculture, forcsts, fisherics, human populations, and water resources, could be affected by the interactive effects of changes in almospheric $\left(\mathrm{C}_{2}\right.$ and climatc. Some of these resources will be affected primatily hy climate: for others, the direct eflect of $\mathrm{C}^{\circ} \mathrm{O}_{2}$ may he significant. 
Additionally, coastal resources may be sensitive to rising sea level (caused by global warming) and related factors, such as changes in tidal regime. Effects on such resources could have important implications for industrial productivity, land use, and encrgy use. The Resource Effects Group within CDLARP has managed and carried out the appropriate research and analytical tasks to address these issues.

The objective of the Resource Effects Group has been to participate in integrated quantitative analyses of the regional effects that changes in $\mathrm{CO}_{2}$ and climate have on key resources. The effects of both $\mathrm{CO}_{2}$ and climate are considered, and important connections between key resources are accounted for.

To fulfill these objectives, the following types of questions must be answered: What are the most important resource areas and resource issues for analysis? What are the most important connections between resources? What definitions of regions are best to use in these analyses? What analytical approaches are best for these analyses? How satisfactory is our understanding of the response of resources to changes in both $\mathrm{CO}_{2}$ and climate and to other important factors, such as technology or government/economic actions, and what additional models need to be developed? How much of the required data base is available, and what additional data need to be developed for the analyses?

\section{Global Carbon Cycle Research Program}

Although fossil fuel use increases the concentration of atmospheric $\mathrm{CO}_{2}$, such changes do not depend on the amount of fossil fucl usc in any simple way.

Exchanges with other carbon rescruoirs-primarily the occans, land vegetation, and soil-further distribute carbon as it is added to the atmosphere; thus, the accumulation in the atmosphere is less than the total fossil fuel release.

We are working to understand the processes and perturbations behind observed changes in atmospheric $\mathrm{CO}_{2}$ levels in order to estimate the $\mathrm{CO}_{2}$ increases that can result from future fossil fuel use. We use mathematiral models that describe the earth systems controlling $\mathrm{CO}_{2}$ levels in order to interpret atmospheric measurements and related data and to project $\mathrm{CO}_{2}$ concentrations. Iterative model refinements and model experiments aimed at understanding newly available data continue to yield substantial progress.

Models of carbon turnover in the oceans can be derived from observed distributions of tracers such as radiocarbon or tritium. These tracer models have helped establish the potential for atmospheric $\mathrm{CO}_{2}$ increase, but they cannot be used to project changes outside the environmental conditions that constrained the observed distributions on which the models are based. General circulation models of the oceans, derived from fundamental physical principles, are now being modified for use in carbon cycle research. These can be used to test the sensitivity of the carbon dynamics associated with both ocean circulation and mixing to the climatic change that is expected to accompany rising concentrations of greenhouse gases. This connection between the carbon cycle and climate has been ignored in assessments of the $\mathrm{CO}_{2}$ issue.

Land use and other similar human activities tend to release carbon from vegetation and soil. Such releases may very well have added about as much carbon dioxide to the atmosphere during the past several centuries as fossil fucl use has. We cannot reconcile this additional source with observed changes in the concentration of atmospheric $\mathrm{CO}_{2}$ or with cstimates of occanic uptake. The 
performances of a number of models, incorporating a wide range of structural assumptions and calibrated against various data. suggest that this inconsistency will not be resolved by straightforward changes in ocean models.

Estimates of past transfers of carbon into the atmosphere from land pools may drop when models that treat a larger range of iesponses are used to analyze more detailed historical land use data. We are also analyzing ways in which terrestrial storage in some regions might have increased in response to changing ellvironmental conditions, including increasing levels of atmospheric $\mathrm{CO}_{2}$.

Highlights of this year's work track our progress toward understanding atmospheric $\mathrm{CO}_{2}$ responses to fossil ? :el emissions. Extensive model compari: uns confirm a systematic inconsistency be ween observed changes in atmospheric $\mathrm{CO}_{2}$ and estimates of oceanic uptake and past relcases of carbon from fossil fuels and from vegetation and soil as a result of land use. Further studies of oceanic carbon dynamics conducted with the use of a lateral transport model derived from radiocarbon distribution indicate that the oceans may take carbon from the atmosphere more readily than conventional, one-dimensional models suggest, but the lateral transport model cannot fully accommodate the past releases implied by land use data. A new model of terrestrial carbon cycling is being used to test for partial compensation of past decreases in terrestrial storage by responses to environmental changes. We continued our analysis of historic fossil fuel and land use data to improve estimates of past emissions and to develop relationships between emissions and human activities that can be used to estimate future emissions. We analyzed mitigation strategies involving carbon cycle manipulation, including fertilization of the marine biota by adding iron to the oceans and large-scale establishment of forests managed for carbon storage. Selected technical summaries of these rescarch activities follow.

\section{Technical Summaries}

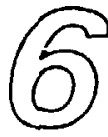<smiles>C=C</smiles>

Model Reconstructions of $\mathrm{CO}_{2}$ Released to the Atmosphere from Past Changes in Land Usc Are Incompatible with Observed Changes in Atmospheric $\mathrm{CO}_{2}$

A. W. King
Estimates of future changes in atmospheric $\mathrm{CO}_{2}$ as projected from global carbon cycle models and time series of future $\mathrm{CO}_{2}$ cmissions from. fossil fucls and land use changes are uscful only if the simulations agrec reasonably well with the observed history of changes in atmospheric $\mathrm{CO}_{2}$. However, simulations with a collection of widely applicd atmospheric and oceanic carbon models affirm that carly (1983) reconstruction of past $\mathrm{CO}_{2}$ cmissions by using the most commonly applied model of land use change and the associated carbon dynamics is incompatible with the changes in atmospheric $\mathrm{CO}_{2}$ recorded in ice core data and 


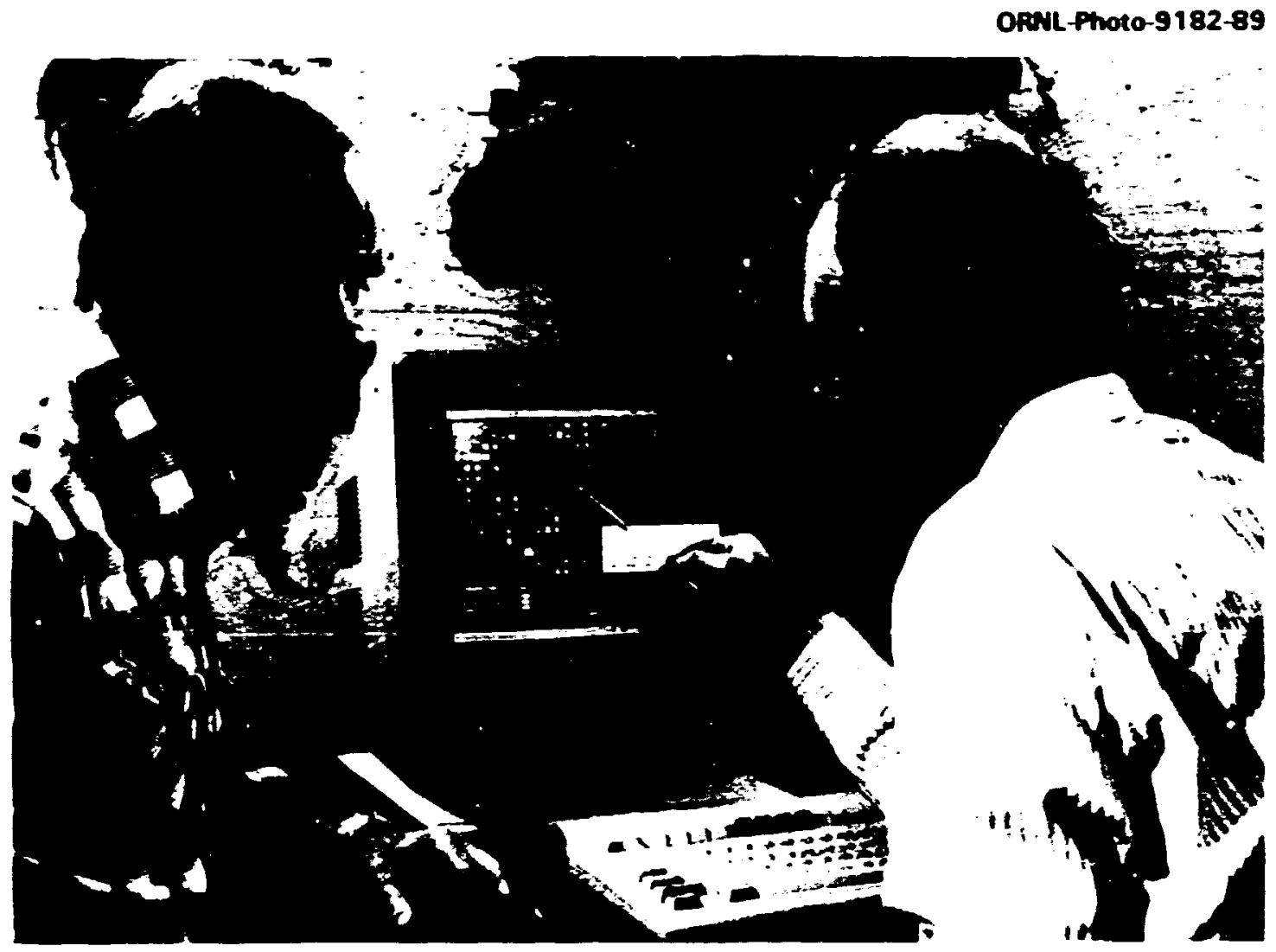

Mac Post (left) and Wilfried Wolf, visining scientist from the Julich Nuclear Research Center in West Germany, discuss details of an individual-based model of an ecosystem.
Such computer simulation models help researchers predict the changes in terrestrial systems that might occur as a result of greenhouse warming of the earth.

measurements of $\mathrm{CO}_{2}$ from Mauna $\mathrm{Loa}$ and other extant monitoring stations. When this historical-ecological reconstruction of past land use emissions is combined with the standard history of fossil fuel emissions as model input, conventional carbon cycle models simulate much higher $\mathrm{CO}_{2}$ concentrations and faster rates of increase than those observed during the Mauna Loa period (1958-present). More recent estimates of past land use emissions from the same model do not significantly reduce this incompatibility despitc a $39-6.3 \%$ reduction in cstimates of the annual $\mathrm{CO}_{2}$ relcase for 1980 .

There are many possible reasons for this incompatibility, including crror in the modeling of the 
oceanic uptake of $\mathrm{CO}_{2}$ However. the models used in the simulations span the existing range of most probable uncertainty in oceanic uptake of $\mathrm{CO}_{3}$ : thus. error in the estimate of land use emissions is a likely cause for the discrepancy between simulation and observation.

Estimates of past $\mathrm{CO}_{2}$ emissions from terrestrial ecosystems as derived by deconvolution of the atmospheric $\mathrm{CO}_{2}$ record [i.e., by (1) calculating the additional atmospheric input or output required to reproduce observed changes in atmospheric $\mathrm{CO}_{2}$ in simulations with a specified $\mathrm{CO}_{2}$ input from fossil fuels and (2) assuming the estimated flux is equivalent to the exchange between terrestrial vegetation/soils and the atmosphere] differ qualitatively from the historical-ecological reconstructions. For the period ca. 1930-1970, the historical-ecological reconstructions extimate an increase in $\mathrm{CO}_{2}$ release from land use change. For the same period, the deconvolution estimates suggest a declining $\mathrm{CO}_{2}$ release and even a small-to-moderate net uptake since 1950. These results suggest either a considerable error in the estimates of land use change and $\mathrm{CO}_{2}$ release or the existence of global terrestrial carbon dynamics that have not been factored into the historical-ecological reconstructions.

Continued investigation and modeling of the global terrestrial ecosystem and its response to changes in land use are needed to resolve these differences and to clarify the historical contribution of terrestrial soils and vegetation to observed changes in atmospheric $\mathrm{CO}_{2}$ In the interim, caution is needed in interpreting $\mathrm{CO}_{2}$ projections made with models that have not yet resolved these fundamental inconsistencies.

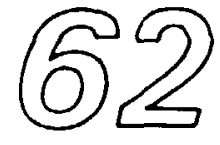

Why Should Developing Tropical Countrics Plant Troes? (A Look to Biomass Fucks to Approach Zero $\mathrm{Net} \mathrm{CO}_{2}$ Emissions)

G. Marland
We have addressed the "what's in it for me?" aspect of tropical forest protection/reforestation. Why should developing tropical countries be interested in maintaining vast expanses of forest, perhaps to their perceived detriment in terms of aspirations for cconomic development and certainly counter to current trends? Beyond achicving watershed protection and providing commercial timber and wondlots at the local level, forest protection has ramifications for global concerns such as hiodiversity and the effects of sca level risc. Howcver, aside from being goxd global citizens, what doxes forest protection/reforestation offer the peoples of Brazil. 
Colombia, Indonesia, and Zaire? (Note that mos: climate models predict that temperature changes will be smallest in the tropics but that changes in the amount and timing of precipitation could be important.) It has been observed that in developing countries the results of plantation efforts to date have been almost uniformly discouraging. Poor results have been due to unrealistic expectations, inadequate planning, low tree survival rates, and failure to capture the interest and support of local peoples. Is it possible to design forestry plans that not only are of a scale to have a meaningful impact on the global $\mathrm{CO}_{2}$ issue but also serve local interests and development goak?

Is it conceivable that developing, tropical nations could confront the concerns of global climate thange by developing energy systems fully based on sustainable biomass plantations? If the developing countries need to play a major role in controlling atmospheric $\mathrm{CO}_{3}$ becoming internally $\mathrm{CO}_{2}$ neutral would certainly be a major step. Also, we need to concede that if forest plantations cannot play a major role in developing tropical nations, it is unlikely they could play a major role anywhere. We have taken a look at the physical possibilities without addressing the social and institutional realities.

We examined data for the 15 tropical countries having the highest current rates of $\mathrm{CO}_{2}$ emissions. Given the set of assumptions made here, 11 of the 15 countries examined could meet the current energy demand with forest plantations occupying less than $30 \%$ of the area of existing closed forests, and 7 of the 15 could accomplish the per capita level of energy use of Spain with plantations occupying less than $30 \%$ of the area of existing closed forest. For only two countries (Indonesia and Vietnam) is the area of forest required for the "Spain scenario" notably larger than the area currently in agricultural crops. For Vietnam, the Philippines, and India, over one-third of the total land area of the country would be required under the Spain scenario, although mceting current energy needs does not look impossible. The numbers, taken cumulatively, suggest that to meet current energy demand would require energy plantations on the order of $25 \%$ of the area of current cropland, whereas mecting the Spain scenario would require energy cropland roughly equivalent to current agricultural cropland. The task appears apprriachable in some countries, outragcous in others, and of huge dimensions in all. However, these 15 countrics arc responsible for only $6.5 \%$ of current global $\mathrm{CO}_{2}$ cmissions from fossil fucls. These statements should he 
taken as indicative rather than demonstrative, but they do suggest that, at current population kevels. the plantation approach is not an outrageous idea for many countries and that, given the impetus of global climate change, many countries might contribute to both global and self-interests through tropical forest plantations.

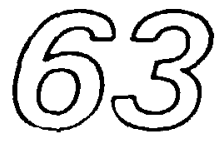

Emissions of $\mathrm{CO}_{2}$ to the Atmosphere from Global Energy Use Are Monilored

\section{T. A. Boden}

With increasing concern about the effect of rising concentrations of greenhouse gases in the global atmosphere, there is a corresponding increase in interest in what might be done to limit or minimize these concentrations. $\mathrm{CO}_{2}$ is of particular concern, not only because of the magnitude of its postulated contribution to climate change but because of its essential linkage to the global energy-supply system.

If we are to understand what is happening in the atmosphere, if we are to appreciate why it is happening. and if we are serious about trying to limit future atmospheric concentrations of $\mathrm{CO}_{3}$ we must understand the magnitude and locations of sources of $\mathrm{CO}_{2}$ emissions.

The Carbon Dioxide Information Analysis Center at ORNL maintains a data base of $\mathrm{CO}_{2}$ emissions from fossilfuel use and cement manufacture. This data set is organized by country and fuel and is continuous from 1950. With recent receipt of the annual global-energyproduction data update from the United Nations statistical office, we have updated the $\mathrm{CO}_{2}$ emissions file to include 1988. Global total $\mathrm{CO}_{2}$ emissions reached $5.893 \times 10^{9}$ metric tons in 1988, an increase of $3.77 \%$ over 1987 , which continues an increasing trend that has prevailed since 1983. Decreases that followed the oil price shocks of the 1970. have now been erased, and a new upward trend secms well established. Growth is most prominent in some developed countries, and emissions from the centrally planned economies of Asia, for example, are now $45 \%$ higher than in 1979. By contrast, emissions from Western Europe are still 19\% below the 1979 maximum and are virtually unchanged since 1982. African $\mathrm{CO}_{2}$ emissions are up 28\% from 1979, and those from Latin America are up $14 \%$ over the same time interval.

U.S. emissions reached $1.310 \times 10^{9}$ tons in 1988 ( 5.39 tons per capita and $22 \%$ of the global total). excecding the 1979 value for the first time but continuing 
an increasing trend that began in 1983. U.S. emissions grew by $4.13 \%$ in 1988 , and for the second year this growth rate was higher than the global average growth rate.

Currently, we are attempting to break down both U.S. and global emissions by economic sector. This will belp to identify those areas, both economically and globally, that might be the most appropriate targets for emissions controk. Initial calculations show, for cxample, that in 1985, 32.5\% of U.S. $\mathrm{CO}_{2}$ emissions came from electric utilities, with another $31.0 \%$ from the transportation sector and 24.7\% from the industrial sector. The

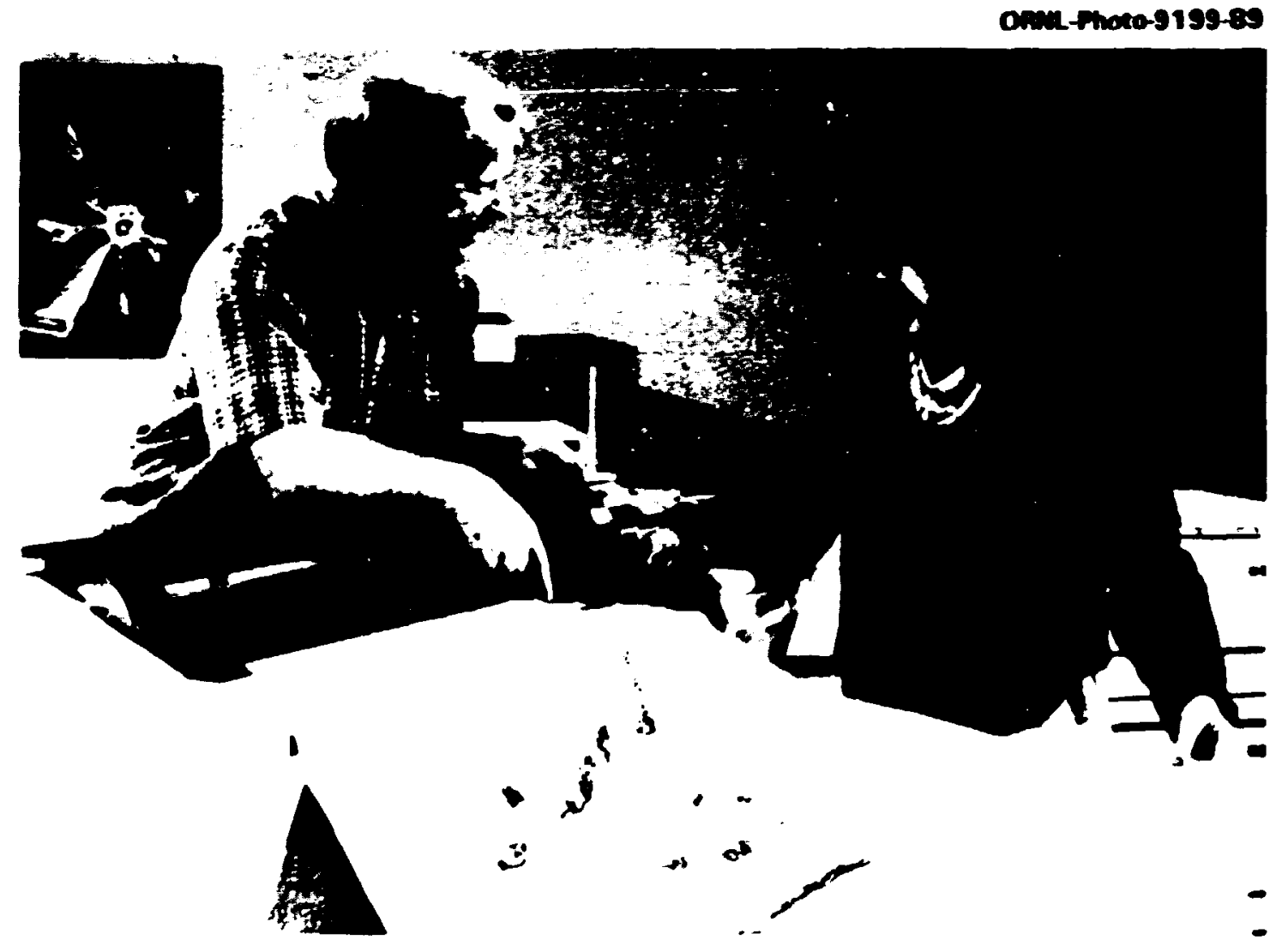

Tammy While and Raymond McCord discuss the highlighting of areas in Chesapeake Bay that are susceptible to sea level rise. ESD's pecographic information system allows researchen to analyze and display the features of geology, geomorphology, elevation, and erosion that indicate sensirivity to coastal flooding as a result of global waming. 
residential commercial sector is responsible for only $11.8 \%$ of direct $\mathrm{CO}_{2}$ emissions. but this rises to $32.6 \%$ when the electric utility emissions are allocated to the appropriate end-use sector.

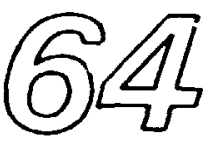

Gbbal Climate Data Base Is Developed for Use in Global-Change Studics

T. A Boden. R. T. Vose, and P. M. Steurer'

${ }^{1}$ The Universing of Tennessee, Knoxille.

-National Climatic Data Center, National Oceanic and Armospheric Administration.
A series of unusually warm and dry years during the past decade has increased interest in climatic change resulting from industrial and deforestation emissions of $\mathrm{CO}_{2}$ and other gases-the so-called "greenhouse effect." In particular, thn question is being asked: Is the earth's climate actually warming, and, if so, is the pattern of warming consistent with what computer models of a greenhouse warming predict? Unfortunately, there does not exist a long-term global climate record that has been quality assured and that climatologists agree can be used to answer such questions.

The Carbon Dioxide Information Analysis Center (CDIAC) and the National Climate Data Center (NCDC), which have in the past produced a quality-assured longterm climate data base for the United States, began during the past year to produce a data set suitable for the study of long-term global climate trends. The data set consists of monthly surface air temperature, sea level and station pressure, and total precipitation recorded in thousands of stations worldwide. The data set is derived largely from NCDC's World Weather Records and the National Center for Atmospheric Research's Monthly Climatic Data for the World, supplemented by additional data sets to enhance spatial coverage. Checks have been made to investigate the integrity of station numbers, names, latitudes, longitudes, and clevations; and numerous checks have been applied to eliminate or correct erroneous data.

The data set, to be completed in its first phase during FY 1991, will be documented, packaged, and distributed hy CDIAC as a numeric data package with all applicable information (c.g., Jata sources and adjustment techniques). It is hoped that further work on this data base will allow further corrections to the data based on station histories and the inclusion of additional data sets to erhance the global coverage. The availability of this data should enable climate rescarchers to address more definitively the question of whether the carth's climate is indecd changing. 


\section{Program Staff}

M. P. Farrell

\begin{tabular}{|c|c|c|c|}
\hline $\begin{array}{l}\text { T. A. Boden } \\
\text { M. D. Burtis } \\
\text { R. M. Cushman } \\
\text { V. H. Dale } \\
\text { W. R. Emanuel' } \\
\text { D. E. Fowler } \\
\text { J. B. Harper }\end{array}$ & $\begin{array}{l}\text { A. M. Heridricks } \\
\text { B. L. Jackson }{ }^{3} \\
\text { H. I. Jager' } \\
\text { S. B. Jones } \\
\text { V. N. Joyce } \\
\text { P. Kanciruk } \\
\text { A. W. King? }\end{array}$ & $\begin{array}{l}\text { G. Marland' } \\
\text { R. E. Millemann } \\
\text { L. J. Morris } \\
\text { T. R. Nelson }{ }^{3} \\
\text { T.-H. Peng } \\
\text { W. M. Post } \\
\text { M. J. Sale }\end{array}$ & $\begin{array}{l}\text { J. S. Sanford } \\
\text { D. E. Shepherd } \\
\text { X. B. Wang } \\
\text { K. L. Warren } \\
\text { T. W. White }\end{array}$ \\
\hline
\end{tabular}

1. Environmental Analyses Section, ESD.

2. Ecosystem Studies Section, ESD.

3. Computing and Telecommunications Division, Martin Marietta Energy Systems, Ixc.

4. The University of Tennessee, Knowville.

5. Geosciences Section, ESD.

6. Visitor from the People's Republic of China Academy of Sciencer, Beijing. 


\section{Environmental Waste Program}

\section{Introduction}

The Environmental Waste Program (EWP) was formed to help ensure the technical consistency and scientific validity of environmental restoration project work across all Martin Marietta Energy Systems, Inc., sites. The scope includes site characterization and cleanup projects at the three Oak Ridge facilities, the Portsmouth Gaseous Diffusion Plant, and the Paducah Gaseous Diffusion Plant. In addition, the Ock Ridge Off-Site Program, which is investigating contamination of the Clinch River and Tennessee River systems, is also included in the oversight charter. The strategy involves technical discipline leaders, who have lead responsibility in their areas of expertise to provide technical assistance to program managers for resolving site-specific issues and to identify critical generic technical issues that are relevant to all sites. The discipline leaders work with technical experts within and external to Energy Systems in the resolution of specific issues.

The majority of site-specific assistance lies in the technical review of remedial investigation planning and documentation. Members of the Technical Review and Oversight Committee (TORC) for the EWP participate in technical integration committees that are involved in the carly stages of planning for remedial facility investigations (RFIs) or remedial investigation/[casibility studies (RI/FSs) to help set the framework and goals for the study. TORC later follows up with reviews of formal RFI or RI/FS plans and subsequent reports. Although the individual details of plans vary from site to sitc, the underlying strategy and technical approach are revicwed to ensure an underlying consistency and technical validity. In many cases, a significant amount of technical information from past scientific investigations at various waste sites is transmitted to subcontractor teams conducting RFI projects. Where appropriate, investigators with specialized knowledge and expertise are identified and integrated into site-characterization teams through the TORC mission.

For issues that have been identified as common to all sites involved in environmental restoration activities, the TORC clarifies the specific technical questions and recommends ways to resolve them. For example, identification of applicable or relevant and appropriate requirements (ARARs) has a common basis and methodology regardless of the specific site. One activity of a TORC subgroup has been to develop a generic document for ARARs that serves as the basis for tiering project-specific ARAR listings. The potential for conflicting objectives between site construction and development planning and environmental restoration projects, where control of contaminated areas is important, is very real. Members of the TORC have played an active role in identifying the sharing of information and notification procedures that is needed to avoid conflict between site, regulatory, and restoration interests. For instances in which remediation of fuclcontaminated soils has been needed, several methods have been used. The TORC conducted a study of the approaches that have been cmployed and developed a generic framework for comparing alternative methods so that a consistent selection methodology could be developed.

Because of the matrix organization and function of the TORC and its subgroups, technical summaries of EWP participants 
are located in the parts of this report describing the various ESD line management sections to which the EWP investigators belong.

\section{Program Staff}

D. D. Huff

J. S. Cox

S. B. Garland ${ }^{1}$

F. O. Hoffman ${ }^{2}$
P. Y. $\mathrm{Lu}^{3}$

A. U. Sheard

J. R. Trabalka
L. D. Voorhees

B. T. Walton ${ }^{2}$

R. K. White ${ }^{3}$
1. Geosciences Section, ESD.

2 Environmental Toxicology Section, ESD.
3. Health and Safety Research Division, ORNL

4. Environmental Arabses Section, ESD. 


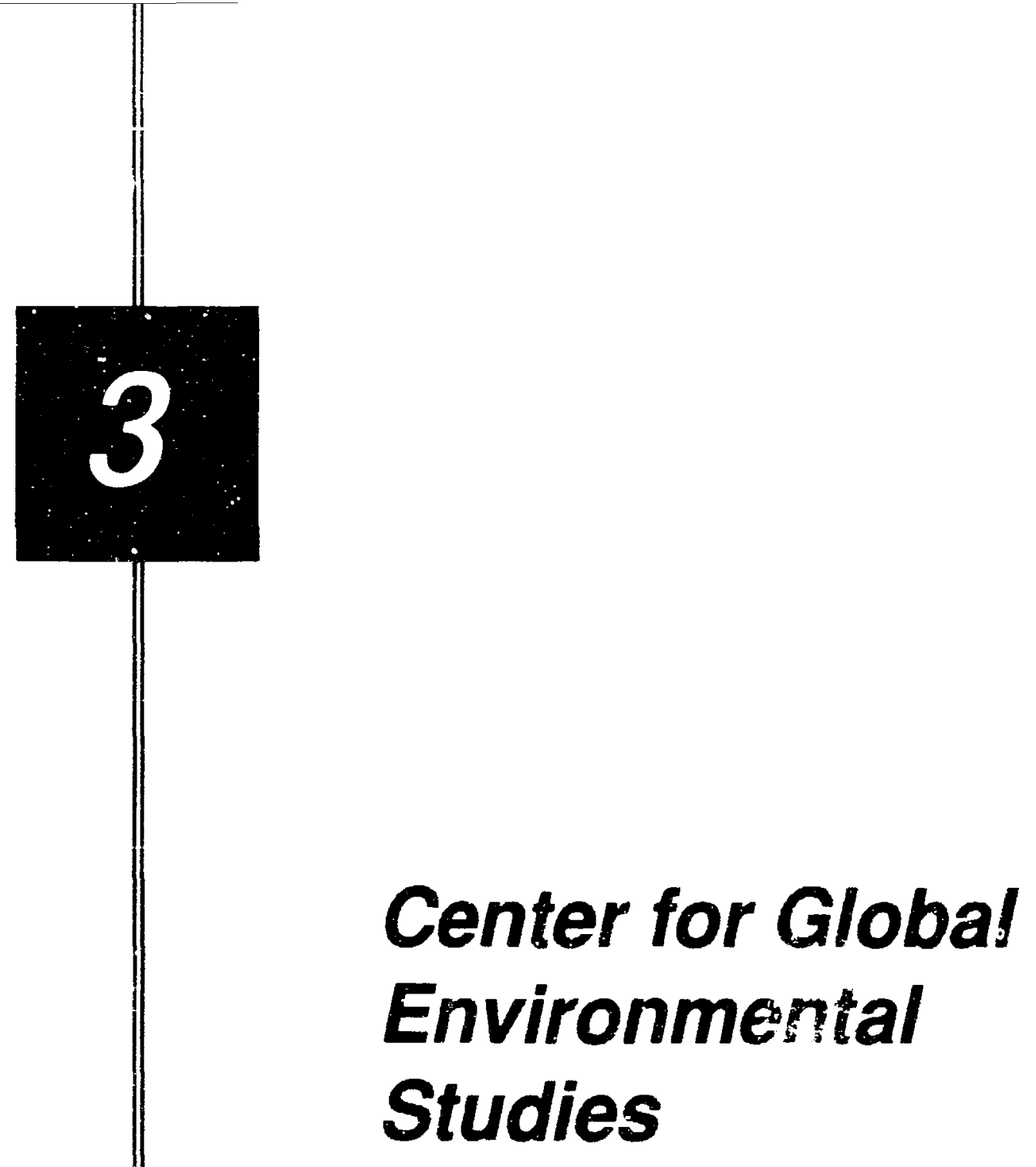




\section{Center for Global Environmental Studies}

\section{Introduction}

Many of the decisions that will determine our direction in the next millennium hinge on issues that are complex, interwoven, and global in scale: greenhouse gases, climate change, ozone breakdown, deforestation and desertification, resource depletion, and spread of pollution. These and other global environmental issues must now be explored far more comprehensively than ever before.

ORNL's Center for Global Environmental Studies, established in 1989, provides a unique, interdisciplinary base for such explorations. The Center has three main goals:

1. to improve the understanding of the global-scale workings of environments in air, on land, and in water;

2. to develop capabilities to anticipate the long-term, large-scale effects that human actions have on the biosphere; and

3. to identify appropriate options for technological and socictal responses.

Like the U.S. Global Research Program - the crosscutting national initiative to which the ORNL Center corresponds-the Center for Global Environmental Studies takes a new view of the kinds of rescarch needed in this formidahic hut exciting field. The Center's work is hased on scveral assumptions that sct it apart from ORNL's traditional approach to research and analyscs:
- The processes and problems we are exploring are far greater both in scake and in time than those addressed in traditional rescarch projects. Problems such as ozone depletion, the greenhouse effect, and global change do not respect nationa! borders; they affect the entire planet. Our responses, therefore, must be equally broad. Similarly, processes such as climate change and dwindling biodiversity may become clearly evident only when viewed over decades or even centuries. We must, therefore, envision and develop programs that can serve as foundations on which to build for many years.

- Intcrdisciplinary collaboration among traditionally competitive institutions is essential for the development of meaningful undersianding. The global environment responds to the interactions of many systems, factors, and processes: air circulation, ocean currents, land use changes, economic incentives for development (or nondevelopment), migration of smokestack industries, national energy practices and policies, and even political turmoil. Narrow, singlediscipline approaches give us only detailed analyses of individual aspects of the biosphere (individual trees, so to speak) when what we need now is an overall vicw of the global environmental forcst.

- Economically and politically practical policy must be a prime driver of global cnvironmental rescarch. We must consider not only what should ideally be done to protece the biosphere but also what can be done given economic, technological, and political constraints. 
These are the principles that guide the Center's organization and work: a largescale, long-term view; a commitment to collaboration; and a continual assessment of what constitutes realistic policy.

\section{Areas of Focus}

The central and unifying framework for our work is global systems analysis, which seeks to develop increasingly sophisticated models that reflect the dynamic interactions of numerous subsystems-global vegetation; human cultures and behaviors; and earth systems such as atmospheric chemistry, ocean composition and circulation, and the links between air, land, and sca. Our long-term goal is to develop models that reflect the interplay of demographics, land use patterns, economics, ecological relationships, and other facters that influence the global environment.

Co.nplementing our central focus on global systems are four areas of more specific concentration:

\section{Measurement science and} instrumentation seck to ensure better monitoring of the state of the environment. ORNL has a long history of excellence in instrumentation in high-energy physics, health physics, pollution monitoring, nuclear reactor technology, and nuclear and chemical waste. We are now directing this expertise toward instrumentation for atmospheric, terrestrial, and aquatic rescarch. Areas of strength that can immediately benefit the Center include laser-based instrumentation, which we expect will play an increasingly vital role in global-change rescarch; mass spectrometry and isotopic analysis; remote sensing and fiber optics, another key technology for climate studics; and automation. miniaturization, and portability.

Logical applications of this expertise include laser-based devices to measure trace gases, temperature, and pressure; low-cost, air-droppable packages for reading atmospheric or ocean conditions; and instruments for studying cloud formation and propertics in support of the U.S. Atmospheric Radiation Measurement Program.

2. Data systems are key to making sense of the global environment, now and for decades to come. The amount of data collected in the course of global environmental research is already staggering and will grow even more rapidly as newer, more sophisticated instruments and monitoring projects emerge. For example, in a few years NASA's Earth Observing System will begin transmitting enough data to fill all the books in the Library of Congress ... every three weeks. In addition to handling massive quantities of data, information systems must present the data in a form that will also ensure its usability over decades since the importance of some data may not become clear for many years.

3. Large-scale environmental studies examine the cnvironment from a longer perspective than traditional ecological research. Global-scale studies cannot be based on mere extrapolations of traditional detailed studies; many of the subtle ecological processes on which traditional research thrives are less meaningful for these purposes than are aggregate processes that are invisible at close range. The Center is developing tools and techniques to enable us to scale rescarch to the global level that is now necded. 
4. Policy, energy, and human-systems analysis recognizes that mankind is inextricably linked with the physical systems of the earth. In the past two centuries, our species has emerged as a primary agent of global environmental change. Therefore, questions of human activity and policy-including the effects of technology, energy conversion, land use, population growth, and political and cultural patterns-must play a key role in global environmental studies. The Center brings together anthropologists, economists, political scientists, sociologists, planners, geographers, climatologists, and ecologists to examine the decision processes involved in global management of risks and resources. Building on extensive work aiready under way at ORNL and elsewhere, we are developing the theoretical underpinnings of a practical approach to the problems of decision making involving many players and many complex technical issues.

Ultimately, this approach will produce a blend of theory and practice to

\section{Center Staff}

M. P. Farrell
L. S. Conper
B. G. Eads'
W. R. Emanucl?

1. Instrumentatuon and Controls DIvision, ORNI..

2. Carbon Dioxide Information Analysis and Resarch Program and Fcosystem Studics Section, Fisi). eliminate the barrier that for so lung has separated the "thinkers" from the "doers."

\section{Summar;}

The range and depth of ORNL's scientific expertise uniquely qualify the Laboratory to take up the challenges of the Global Change Program. By establishing the Center for Global Environmental Studies, ORNL is drawing on its proven expertise and worldwide scientific connections while also laying the foundation for expanded, focused research into the problems of global change.

The Center for Global Environmental Studies is dedicated to an earth system-centered, interdisciplinary approach to scientific research. It views human interaction with the environment as one of the driving forces of global environmental change. The Center stands in a unique position to serve the needs of federal agencies and international efforts and to make a significant contribution to our understanding of the delicately balanced biosphere we call home.
P. Kanciruk ${ }^{3}$

S. Rayner ${ }^{4}$

M. G. Turner'

3. Carbon Dioxide Information Analysis and Rescarch Program, I:Si).

4. Iincrgy Division, ORNI.

5. Fenvironmenial Anatyscs Sccion, IST). 


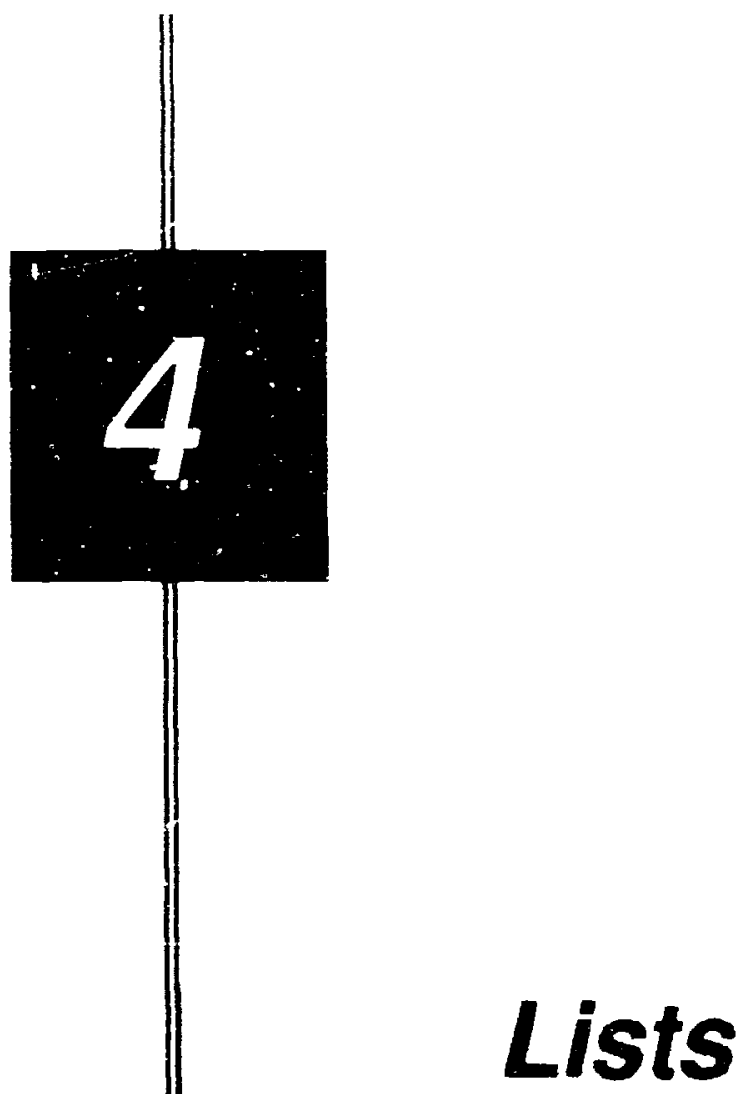




\section{Awards and Honors}

The following ESD personnel received professional, corporate, or organizational awards during this reporting period.

BARNTHOUSE, L W. Appointment to the Committee on Risk Assessment Methodology, National Research Council

BLAYLOCK, B. G.

Election to the National Council on Radiation Protection and Measurements

BORDERS, D. M.

Registered Professional Engineer, Tennessee State Board of Architectural and Engineering Examiners

CADA, G. F.

Fellow, American Institute of Fishery

Research Biologists

CUSHMAN, J. H.

Distinguished Service to the East

Tennessee Chapter of the Association for Women in Science

CUTSHALL, N. H.

Significant Accomplishment Award. Martin Marietta Energy Systems. Inc.; Technical Achievement Award, Martin Marietta Energy Systems, Inc.

DeANGELIS, D. L First Place, 1990 International Technical Publications Competition, sponsored by the Socicty for Technical Communication; First Place, 1990 Technical Publication Compctition, sponsored by the East Tennessec Chapter of the Socicty for Technical Communication

GARLAND, S. B., II

Opcration and Support Team Award. Martin Maricila Encrgy Systems. Inc.
GARTEN, C T., Jr.

Annual Award for Scientific Achievement, Environmental Sciences Division

GRAHAM, R. L

Better Letter Award from the Remote Sensing Society for article published in the International Joumal of Remote Sensing

HATCHER, R. D., Jr.

Nomination, Vice President, Geological

Society of America

HUFF, D. D.

ORNL Director's Award. Environmental, Safety, and Health Upgrade Team

HUNSAKER, C. T.

Consultant, Ecoregions Subcommittee.

Science Advisory Board, U.S.

Environmental Protection Agency

HUSTON, M. A.

First Place, 1990 International Technical

Publications Competition, sponsored by the Society for Technical Communication; First Place, 1990 Technical Publication Competition, sponsored by the East Tennessee Chapter of the Society for Technical Communication

JOHNSTON, J. W.

ORNL Director's Award, Environmental, Safety, and Health Upgrade Team

KANCIRUK, P.

DOE Representative, Committec on Earth Scicnce Task Group on Earth Systcm Measurements and Data Management

KELLY, J. M.

Certificd Professional Soil Scientist, American Registry of Certified Profcssionals in Agronomy, Crops, and Soils 
LARSEN. I. L

Technical Achicvement Award. Martin Marietta Encrgy Systems, Inc.; Certificate of Recognition for Patent Filing. Office of Technology Transfer, Martin Marietta Energy Systems, Inc.

McCARTHY, J. F. Award of Achievement, 1990 Technical Publication Competition, sponsored by the East Tennessee Chapter of the Society for Technical Communication

McCORD, R. A

PIP Award, Martin Marictta Energy

Systems, Inc.

McDONALD, L K

Operations and Support Award. Martin

Marietta Energy Systems. Inc.

OLSEN, C. R.

Author of the Year, Martin Marietta

Encrgy Systems, Inc.; Jefferson Cup for Excellence, Martin Marictta Corporation; Technical Merit Award, Martin Marictta Encrgy Systems, Inc.

OWENS, J. G.

Distinguished Technical Achicvement Award. Environmental Sciences Division

POST, W. M., III

First Place, 1990 International Technical Publications Competition, sponsored by the Society for Technical Communication: First Place, 1990 Technical Publication Competition, sponsored by the East Tennessec Chapter of the Socicty for Technical Communication; PIP Award. Martin Marictta Encrgy Systems, Inr.

SHARPLES, F. E.

Appointment to the Commitlec on

Science, Enginecring, and Public Policy.

Amcrican Association for the

Advancement of Science
SHRINER. D. S.

Certificate for Outstanding Contribution to the National Acid Precipitation

Assessment Program

SUTER, G. W.. II

Election to Board of Directors, Society of Environmental Toxicology and Chemistry

TURNER, M. G.

Editorial Advisor. Climate Research;

Directorate for Temperate Ecosystems, U.S. Man and the Biosphere Program

TURNER, R. S.

Certificate for Outstanding Contribution to the National Acid Precipitation

Assessment Program; Director's Technical Contribution Award, U.S. Environmental

Protection Agency, Environmental

Research Laboratory, Corvallis, Oregon

VAN WINKLE, W.

Fellow. American Institute of Fishery

Rescarch Biologists

VON DAMM, K L

Distinguished Scientific Achicvement

Award. Association for Women in Science

WALTON, B. T.

Award of Merit, 1990 Technical

Publication Competition, sponsored by the East Tennessec Chapter of the Society for Technical Communication

WRIGHT, L. L.

Award of Achievement, 1990 Technical Publication Competition, sponsored by the East Tennessec Chapter of the Soncicty for Technical Communication 


\section{Significant Accomplishments}

During FY 1990 ESD reported numerous technical accomplishments, the most significant of which are listed here.

- The division initiated a major project to study the hydrologic and geologic characteristics of the entire Oak Ridge Reservation (ORR). This project is of prime importance for waste management and ensironmental restoration issues because ORR is hydrogeologically the most complex of DOE sites.

- The Draft Basic Research Plan in Support of Environmental Restoration was completed for the Office of Energy Research. This plan details the midterm to long-term research needs and parallels the DOE Five-Ycar Plan for Environmental Restoration and Waste Management.

- Members of the division assisted DOE in implementing part of Admiral Watkins' ten-point plan by presenting to top-level field office managers scventecn 2-day and five 4-day training courses covering compliance with major environmental laus.

- ESD hosted the DOE High School Science Honors Workshop in Environmeital Sciences. This 2-wcek program allous 57 top-quality high school science students to work on rescarch projects with ESD staff. ORNL is unc of six DOE laboratorics involved in the program.

- Rescarchers in the division demonstrated that a multiple-resistance model for quantifying dry deposition of mercury can he developed. Data show that dry deposition could he greater than wet deposition in the Walker Branch Watershed forest, an important issue in biogeochemical cycling.

- Fifteen ESD staff members contributed to the completion of 7 of 28 Statc-ofScience chapters in the National Acid Precipitation Assessment Program (NAPAP). Two members of the division presented the results of two of these chapters at a major international NAPAP peer-review meeting in February 1990.

- ESD researchers supported EPA Headquarters program staff in the development of an analysis of ecological indicators to be used in the new EPA long-term environmental monitoring program. ESD staff have also contributed to this program by developing landscape indices of disturbance that are of potential use in interpreting the ecological significance of future change in landscape pattern.

- By documenting that inputs of occanic materials into coastal bays and estuaries can grcatly exceed inputs from land-derived sources, ESD researchers made a significant discovery concerning land-sea interactions. This research, performed with the use of carbon isotopes and other radionuclides (plutonium and cesium) in the Savannah River estuary, has implications for the disposal of wastes in the occans as well as for models assessing the sediment dynamics associated with nuvial-marine systems.

- The role of natural colloidal organic matter in facilitating the subsurface mobility of organic and inorganic contaminants has heen demonstrated in 
laboratory soil columns. The results are oxing modeled to improve capibilitiss to include colbid-facilitated transport processies in predictions of contaminant movement in groundwater.

- A light element stable isotope ratio laboratory has been extablished in ESD for quantifying the transport and behavior of ecologically important ekments in Walker Branch Watershed. These measurements are critical to quantifying physiological. biogeochemical, and hydrologic processes in ecological systems.

- Analysis of $\mathrm{CO}_{2}$ cmissions in 15 developing countries suggests that preserving existing forests, planting new forest areas, and developing energy systems based on forest plantations could lead to zero net $\mathrm{CO}_{2}$ emissions. Eleven of the 15 countries could meet current energy demand with forest plantations by using less than $30 \%$ of their existing closed forest.

- The Carbon Dioxide Information Analysis Center has produced Trends 90. the first in an annual series documenting environmental trends important to the U.S. global change research community. Topics include workwide atmospheric $\mathrm{CO}_{2}$ emissions from the burning of fossil fuek, historical atmospheric $\mathrm{CO}_{2}$ concentraicions reported at over 20 monitoring stations, and worldwide temperature data.

- ORNL coordinated the ORNLTVAVT Research Consortium presentation on global studies to congressional staffers and federal agency sponsors in Washington, D.C. on Novembe: 1, 1989. The event was hosted by the Tennessee congressional delegation. 


\section{Conferences Organized or Chaired}

During the past year, ESD staff members actively participated in numerous conferences. Listed below are conferences organized or chaired ty members of the division.

Worlshop on Fish Health Assessment. Tennessee Valley Authority, Muscle Shoak, Alabama, October 1989.

Organizer: S. M. Adams.

Assessing the Ecological Healih of Hartwell Reservoir, U.S. Army Corps of Engineers, Hartwell. South Carolina, March 1990. Organizer: S. M. Adams.

National Environmental Research Park Data Synthesis Workshop, U.S.

Department of Energy, Oak Ridge. Tennessee, October 1989. Chairman and organizer: M. Cunningham.

Basic/Applied Research Working Group, U.S. Department of Energy, Chicago, November 1989 and March 1990.

Chairman and organizer: $\mathbf{N}$. $H$. Cutshall.

Everglades Symposium: Spatial and Temporal Patterns as Guidance for Restoration, U.S. National Park Service and the South Florida Watcr Management Board, Key Largo, Forida, October 1989. Organizer: D. L DeAngelis.

Individual-Based Modeling of Populations, Communities, and Ecosystems, Electric Power Rescarch Institute/UT-ORNL Science Alliance, Knoxville. Tennessec, May 1990. Organizer: D. L. DeAngelis.

OJI International Scminar, Japan Socicty for Promotion of Science and the Fujiwara Foundation of Science, Gifu, Japan, August 1990. Chairman: D. L. DeAngclis.
Symposium on Food Webs: Regularities and Their Causes, International Association for Ecology, Yokohama, Japan, August 1990. Chairman and organizer: D. L DeAngelis.

The Scientific Challenges of NEPA: Future Directions Based on 20 Years of Experience, Oal Ridge National Laboratory and others, Knoxville, Tenressec, October 1989. Session chair. G. $K$ Eddkmon.

Giobal Change: A Southern Perspective, U.S. Department of Energy and others, Charleston, South Carolina,

February 1990. Chairman: M. P. Farrell.

The Scientific Challenges of NEPA:

Future Directions Based on 20 Years of Experiemie, Oak Ridge National Laboratory and others, October 1989. Chairman and organizer: S. G. Hildebrand.

IAEAVAMP (Multiple Pathways Assessments), International Atomic Energy Agency, Vienna, Dicember 1989.

Chairman and organizer: F. O. Hoffman.

Annual Meeting of the National Council on Radiation Protection and Measurements, Washing!on, D.C., April 1990. Organizer: D. D. Huff.

Third Tennessee Water Resources Symposium, American Water Resources Association, Nashville, Tennessee, August 1990. Chairman: D. D. Huff.

62nd Annual Conference of the Water Pollution Control Federation, San Francisco, October 1989. Chairman and organizer: C. T. Hunsaker. 
Fifth Annual Landscape Ecology Symposium, International Association of Landscape Ecology, Oxford, Ohio, March 1990. Chairman: C T. Hunsaker.

Wildlife Workshop for Ecological Indicators, Environmental Monitoring and Assessment Program, U.S. Environmental Protection Agency, Las Vegas, March 1990. Organizer: C. T. Hunsaker.

Riparian and Wetland Ecotones, U.S. Man and the Biosphere Program, Oak Ridge, Tennessee, September 1990. Organizer: C. T. Hunsaker.

Walker Branch Watershed Risearch Symposium, U.S. Department of Energy, Oak Ridge, Tennessee, March 1990. Chairman and organizer: $\mathbf{M}$. A. Huston.

Advancing Toward Closure of the Carbon, Nitrogen, and Hydrologic Cycles, National Science Foundation and the USDA Forest Service, Grunby, Colorado, June 1990. Chairman: M. A. Huston.

Basic Research Needs in Performance Assessment for Environmental Restoration, U.S. Department of Energy, Oak Ridgc, Tennessee, February 1990. Chairman and organizer: G. $K$ Jacobs.

Revicw Panel for Atmospheric Chemistry, Swedish Environmental Protection Board Project on Mercury in the Swedish Environment, June 1990. Chairman: S. E. Lindberg.

Special Session on Solar Conversion Efficiency of Forests, International Union of Forest Research Organizations World Congress, Montreal, August 1990.

Chairman and organizer: R. J. Luxmcore.

Organics in Water and SedimentsBiological Processes, American Chemical
Society, Boston, April 1990. Chairman and organizer: J. F. McCarthy.

Transect Workshop, U.S. Department of Energy. Office of Health and Environmental Research, Las Cruces, New Mexico, March 1990. Organizer: R. V. O'Neill.

Ocean Margins Workshop, U.S. Department of Energy, Office of Health and Emvirunmental Research, Virginia Beach, Virginia, June 1990. Co-organizer: C. R. Olsen.

Annual Meeting of the American Chemical Society, Boston, April 1990.

Session chair: A. V. Palumbo.

Individual-Based Modeling of Populations, Communities, and Ecosystems, Electric Power Research Institute/UT-ORNL Science Aliance, Knoxville, Tennessee, May 1990. Chairman and organizer: W. M. Post.

Annual Conference on Water Resources, American Society of Civil Engineers, Fort Worth, Texas, April 1990. Chairman and organizer: S. F. Railsback.

Assessing Impacts of Ecological Resources, The Scientific Challenge of NEPA: Future Directions Based on 20 Years of Experience, Knoxville, Tennessee, October 1989. Session chair: R. M. Reed.

The Scientific Challenges of NEPA: Future Directions Based on 20 Years of Experience, Oak Ridge National Laboratory and others, Knoxville, Tennessec, October 1989. Session chair: M. J. Salc.

Third Tennessec Water Resources Symposium, American Water Resources Association, Nashville, Tennessce, August 
1990. Chairman and organizer: M. J.

Sale.

The Scientific Challenges of NEPA: Future Directions Based on 20 Years of Experience Oak Ridge National Laboratory and others, Knoxville, Tennessee, October 1989. Session chair: F. E Sharples.

14th Symposium on Aquatic Toxicology and Risk Assessment, American Society for Testing and Materials, San Francisco, April 1990. Chairman: L R. Shugart.

Long-Term Base Research in Environmental Restoration, U.S.

Department of Energy, Office of Health and Environmental Research, Waterloo,
Ontario, Ca'sada, February 1990.

Chairman: D. K. Solomon.

International Conference on High-Level Nuclear Waste, U.S. Department of Energy and the American Nuclear Society, Las Vegas, April 1990. Chairman and organizer: S. H. Stow.

Symposium on Methodology in Landscape Ecology, Fifth International Congress of Ecology, Yokohama, Japan, August 1990. Chairman and organizer: M. G. Turner.

COMPMECH Workshop on Smallmouth Bass, Oak Ridge National Laboratory and the University of Wisconsin, Madison, Wisconsin, September 1990. Chairman and organizer: W. Van Winkle. 


\title{
Research and Development Subcontracts and Interagency Agreements
}

\author{
A. B. McDaniel
}

Presented here are the parties with whom ESD had a subcontract or an interagency agreement during this reporting period. The ESD researcher who served as technical contact is given in parentheses after the title of the project.

\section{Advanced Sciences Group}

Evaluation of chronic stress on the dynamics of fish populations in contaminated streams (S. M. Adams)

Validate the use of biomarkers in animals as indicators of exposure to contaminants (J. F. McCarthy)

Assist in characterization of natu.al organic matter in water and aquifer material from different geologic formations sampled in the DOE Subsurface Microbiology Deep Probe Program (J. F. McCarthy)

Determine mobility of colloidal particles in groundwater and their effect on subsurface transport of other hazardous waste elements (J. F. McCarthy)

Manipulation of aquatic organisms in local streams (H. L. Boston)

Assist in limnological and sedimentological studies (B. L. Kimmel)

Provide biologist to assist with collection and processing of envirenmental samples
(A. J. Stewart)

\author{
Alaska, University of \\ Support in collection of cores of tundra \\ soils and mcasurement of radiocarbon \\ concentration (M. P. Farrell) \\ Amana Society, Inc. \\ Establishment and maintenance of \\ silver maple monoculture viability trials \\ (L. L. Wright)
}

\section{Analysas Corporation}

Technical support in development, implementation, and analysis of models pertaining to several areas of research (S. M. Bartell)

Technical support in geographic information and analysis of effects of acidic deposition on aquatic resources (C. T. Hunsaker)

Assistance in Walker Branch Watershed Research Program fol DOE (S. M. Bartell)

Technical support in the Biomass Production Program (J. W. Ranney)

Argonne National Laboratory

Environmental restoration research planning (D. K. Solomon)

\section{Aubum University}

Research on selection of lignocellulosic species for energy crops (J. H.

Cushman)

Examine variability for biomass production and plant composition in Sericea lespediza gcrmplasm (J. H. Cushman) 
Automated Sciences Group, Inc.

Technical support characterizing plant physiological processes (S. B.

McLaughlin)

Support to physiologist/endocrinologist in evaluating contaminant-related stress in aquatic systems (S. M. Adams)

Geophysical mapping (T. O. Early)

QA support for the Waste

Management Research and

Development Programs (S. H. Stow)

Support in administration of large data bases used for research and assessment of regional environmental problems (D. S. Shriner)

Technical support in the analysis of the effects of air pollution on forest ecosystems (D. S. Shriner)

Ecological studies in environmental biomonitoring (M. G. Ryon)

Technical support in the NPDESmandated Biological Monitoring and Abatement programs at the Oak Ridge Y-12 Plant and ORNL (G. R. Southworth)

Support in software development for contaminant transport modeling (V. S. Tripathi)

Technical support of a physiological ecologist for analysis of effects of stress on aquatic organisms (S. M. Adarns)

Technical support of a laboratory biochemist in assays and measurement of biological and sediment samples (S. M. Adams)

Technical support on collcction reduction and analysis of geophysica! well logging and cross-hole and downhole studies related to the Hazardous Wastc Remedial Actions Program (T. O. Early)
Battelle Pacific Northwest Laboratory

Research and development in application of in situ vitrification technology for low-level wastes (B. P. Spalding)

Support in the application of in situ vitrification at ORNL (G. K. Jacobs)

Workshop for preparation of long-term research plan in the area of environmertal restoration requested by the Office of Energy Research (D. K. Solomon)

Review of data related to the ongoing fish kill at the Oak Ridge Y-12 Plant (J. M. Loar)

Bern, University of Develop three-dimensional model of the carbon cycle in the oceans (M. P. Fartell)

\section{Brools Rand Lid.}

Chemical analysis of methylmercury water samples (R. R. Turner)

\section{California, University of}

Development of a three-dimensional transport model of the carbon cycle in the ocean (M. P. Fartell)

Monitor atmospheric $\mathrm{CO}_{2}$ levels (M. P. Farrell)

Quantitative histopathological analysis of tissue of fish from East Fork Poplar Creek, White Oak Creek, and reference streams (S. M. Adams)

Workshop for preparation and review of a drafi document concerning midterm to long-term rescarch necds in the arca of environmental restoration (D. K. Solomon)

Continuation of precise measurement of atmospheric carbon dioxide at Mauna Loa Observatory, Hawaii (M. P. Farrell) 
Support in laboratory studies on the permeability of fractured rocks (L E Toranj

\section{Calvin College}

Geostatistical analysis and modeling

(R. B. Clapp)

Center for Environmental Information, Inc.

Preparation of a data base compendium of global change centers in the United States (M. P. Farrell)

\section{CER}

Furnish earth scientist assistance for environmental research and assessment (R. I. Van Hook)

Provide support for compliance assessments of Air Force bases (C. F. Sigmon)

Provide well-drilling services (R. B. Clapp)

Provide support for compliance assessments of FDA facilities (C. F. Sigmon)

Development of C \& X-based user interfaces and graphics displays for geologic and geochemical data (V. S. Tripathi)

\section{Clemson University}

Technical support on the study of natural organic colloids on the subsurface transport of contaminants (J. F. McCarthy)

\section{Colgate University}

Rescarch on weathering characteristics of soil mincrals at sites associated with the EPRI Integrated Forest Study

(S. E. Lindberg)

\section{Colorado Statc University}

Involvement with the National Atmosphcric Deposition Program that requires sample analysis by a central analytical laboratory for comparability of data on atmospheric deposition on a national scale (S. E. Lindberg)

Summarize and compare short-rotation woody crop systems (L L W Wright)

Columbia University Development of global coastal hazard data base (R. M. Cushman)

\section{Cornell University}

Screening and selection of herbaceous species for biomass production in the Midwest Lake States (J. H. Cushman)

\section{Dartmouth College}

Evaluate atmospheric deposition and nutrient cycling in the Integrated Forest Study (S. E. Lindberg)

\section{Desert Research Institute}

Provide scientific and technical management support to the Integrated Forest Study (S. E. Lindherg)

Provide scientific and technical management support to the study of acid deposition and red spruce nutrition in the Great Smoky Mountains National Park (H. Van Miegroet)

Provide technical expertise in reviewing theory, equipinent, and methodology for the borehole telescope project (P. M. Kearl)

\section{Duke University}

Ficld nutrient cycling research at the loblolly pine plantation in Duke Forest (S. E. Lindberg)

Support in evaluating exchanges of carbon between the atmosphere and terrestrial ccosystems as a result of land-use change (M. P. Farrell)

\section{Fimory University}

Integrated Forest Study of cffects of atmospheric deposition (S. E.

Lindberg) 
Energy Performance Systems

Analysis and reviews on how to match the objectives of the Short Rotation Woody Crops Program with the needs of potential utility users of wood ( $L$ L Wright)

Environmental Chemistry, Inc

Preparation of sections of the National Acid Precipitation Assessment Program 1990 report (R. S. Turner)

\section{Environmental Systems Research}

Create climate, soils, population, and land-use data sets for Africa (R. L Graham)

\section{E. R. Johnson Associates}

Provide off-site Office for Technical Assistance for the Office of Civilian Radioactive Waste Management (N. H. Cutshall)

\section{Geophyta}

Selection of lignocellulosic species for energy crops (J. H. Cushman)

\section{Goorgia, University of}

Development of winter rapeseed production practices for the southeastern United States (J. H. Cushman)

Optimizing energy yields in black locust through genetic selection ( $\mathrm{L}$ L Wright)

Perform specialized studies on incorporation of sul'ser into soil organic matter (S. E. Lindberg)

Support of Integrated Forest Siudy of atmospheric deposition (S. E. Lindberg)

H\&R Technical Associatcs, Inc.

Provide data base development of hydrogeological data (C. S. Haasc)
Hudson River Foundation

Measuring changes in the forests of the Amazon basin (M. P. Farrell)

ICF Technology, Inc Technical support in reviewing environmental documents (R. M. Reed)

Idaho, University of

Development of broadly adapted cultivars of winter rapeseed as a source of diesel fuel (J. H. Cushman)

\section{Illinois, University of}

The role of tropical forests in the global carbon cycle (M. P. Farrell)

Provide graduate student to support ESD projects (C. W. Gehrs)

Indiana State University

Vegetation classification maps produced from computer-assisted analysis of spectral data for the continent of Africa for assessment of deforestation and climate change (R. L. Graham)

\section{Indiana University}

Provide graduate students to support Environmental Analyses Section projects (S. G. Hildebrand)

\section{Institute of Oceanographic Sciences} Develop three-dimensional models of the carbon cycle in the oceans (M. P. Farrell)

\section{Iowa State University}

Support in selection of forage species for energy crops in the Great Plains (J. H. Cushman)

Brecding clones for intensive culture of biomass for encrgy (part of DOE's Short Rotation Wondy Crops Program) (G. A. Tuskan) 


\section{JAYCOR}

Technical support in the ORGDP macrobenthos analyses (J. M. Loar)

Technical support in the ORNL macrobenthos analyses (J. M. Loar)

Technical assistance in the benthos support study (J. M. Loar)

Technical support in the Oak Ridge Y-12 Plant macrobenthos analyses (J. M. Loar)

Technical support in climate change, deforestation, afforestation, soils, and land availability (J. W. Ranney)

Assistance in assessing the feasibility of developing biomass-based alternative fuels (J. W. Ranney)

Support of environmental biologist for monthly reports of NEPA compliance assessments and environmental compliance assessments and review of NEPA documents (L L L Sigal)

John M. Cockerbam \& Aswociater, Inc. Provide support in the program management of the Remedial Action Program (S. B. Garland)

Kaneas State University Determination of the best species and management techniques for short-rotation production of fuel wood in the Great Plains (L. L. Wright)

\section{Keko-Regen Aceociates}

Engineering support in developing and constructing devices for dispensing and monitoring $\mathrm{CO}_{2}$ and pollutant gases and apparatuses for exposing plants to ultraviolet light in the field (J. W. Johnston)

Kentucky, University of Conduct field study on biomass production by fescue and switchgrass alone and in mixed swards with legumes (J. H. Cushman)

Plan and implement a biological monitoring research program at the Paducah Gaseous Diffusion Plant (B. T. Walton)

\section{Knorvilte College}

Technical support for studies of biological communities and in-stream toxicity in East Fork Poplar Creek (H. L. Boston)

Support in studies of the biodegradation of polychlorinated biphenyls (H. L. Boston)

\section{Lamont-Doherty Geological Obeervatory.} Columbia University Comparison of prebomb and postbomb radiocarbon in soils and soil fractions (M. P. Farrell)

Assessment of carbon dioxide sinks and sources in oceanic areas (M. P. Farrell)

Assemble and evaluate oceanographic data in support of ocean model development (M. P. Farrell)

Research designed to identify and quantify principal sources and sinks of atmospheric $\mathrm{CO}_{2}$ on a global scale (M. P. Farrell)

\section{Maryland, Univerzity of}

Support in scquiring and analyzing existing data on the feeding success of individual striped bass larvae at ambient zooplankton concentrations (W. Van Winkle)

Preparation of digital map of current native vegetation of the continent of Africa, including Madagascar, and location of forest cover change between 1980 and 1988 in Cameroon (R. L. Graham) 
Massachusctts Institute of Technology Technical support in the processes regulating streamflow generation on Walker Branch Watershed (P. J. Mulholland)

\section{Miami, University of}

Provide graduate students to participate in multidisciplinary activities and become trained in the functions of an information analysis center for the international carbon dioxide research community (M. P. Farrell)

\section{Michigan State University}

Tree species and management strategies for biomass production in the Great Lakes states (L, L. Wright)

Minnesota, University of

Use of wetlands for production of woody plants for fuels and petrochemical substitutes (J. W. Johnston)

Support in determining the response of peatlands, tundra, and boreal ecosystems in the global carbon cycle (W. M. Post)

\section{Missiesippi State University}

Technical support in early selection criteria and clonal propagation systems (J. W. Jchnston)

National Acronautics and Space

Administration

Computer support to run models $c$ er the atmosphere (M. P. Farrell)

\section{National Occanic and Almospheric Administration}

Temperature and precipitation in the United States (M. P. Farrell)

Global historical climate network (M. P. Farrell)
New Hampshire, University of A study of the role of the oceans in the global carbon cycle through modeling exercises (M. P. Farrell)

\section{New Merico, University of}

Provide support for a postdoctoral student to test theoretical predictions made by staff of ESD (R. V. O'Neill)

\section{New York Botanical Garden:}

Atmospheric deposition and canopy interactions studies (S. E Lindberg)

\section{New Yort, State University of}

Exchanges of carbon betwcen the atmosphere and terrestrial ecosystems as a result of land-use change (M. P. Farrell)

\section{North Carolina Agricultural and Technical} State University

Technical support in determining range of rare plants (P. D. Parr)

\section{North Carolina State University}

Monoculture viability trials of woody crops for energy production (L. L Wright)

\section{North Dakota State University}

Support on the selection of forage species for energy crops in the Great Plains (J. H. Cushman)

Norwegian Forcst Rescarch Institute Integrated Forest Study on atmospheric deposition (S. E. Lindberg)

Nova Scotia, University of Lipid biochemistry of fish from East Fork Poplar Creck (S. M. Adams)

Oak Ridge Research Institute Technical support in the conduct of aquatic bioassays (A. J. Stcwart) 
Otlahoma State University

Evaluate Populus selection for fuel wood (L L Wright)

\section{Oregon State University}

Continued collection of oceanic carbonate data to verify ocean penetration of anthropogenic $\mathrm{CO}_{2}$ (M. P. Farrell)

Support for production and publication of North Atlantic Treaty Organization Advanced Research Workshop on climate-ocean interaction (M. P. Farrell)

\section{Pennsytvania State University}

Net energy and economic analysis for producing Populus hybrid under four management strategies (L L Wright)

\section{Princeton University}

Development of a three-dimensional model for predicting the distribution of dissolved carbon species in the oceans (M. P. Farrell)

\section{Puerto Rico, University of}

The role of tropical forests in the global carbon cycle (M. P. Farrell)

\section{Pundue University}

Evaluation of the agronomic and economic feasibility of different systems for producing herbaceous biomass on marginal lands (J. H. Cushman)

\section{Roarse State Community College}

Student support for field work (N. T. Edwards)

\section{Science \& Technology}

Implementing Phase II of

environmental training (F. E. Sharples)

\section{Science Applications Intemational}

\section{Corporation}

Provide control of incoming analysce

(status of sample analyses and detection of errors) as well as available access to existing data and associated statistical analyses (L D. Voorhees)

Provide scientific programmer to assist ESD coologists in data management and analysis (L D. Voorhees)

Assist in ecological data management, data representation, and data analysis for ESD (L D. Voorhees)

Identification and evaluation of legal-regulatory aspects of remedial action activities at ORNL (L. D. Voorhees)

On-site junior-level data management support (M. A. Huston)

Provide technical expertise in planning and implementation (R. M. Reed)

Provide on-site data management support in soil characteristics, deposition chemistry, surface water chemistry, land use, runoff, and precipitation (R. S. Tumer)

Preparation of data documents regarding the DOE Environmental Survey (R. B. Fitts)

\section{Selma University}

Provide research personnel responsible for the isolation of toluene-degrading microorganisms and for preliminary sceenning of these organisms for the abiiity' to degrade trichloroethylene (A. V. Palumbo)

\section{Sticway Institute of Oceanography}

Collect and analyze surface water and interstitial water from the Clinch River and Watts Bar Reservoir for inorganic forms of arsenic (R. B. Cook)

\section{Southern Illinois University}

Genetic biomass and grown analysis of clonal silver maple in scveral locations (L. L. Wright) 
Stanford University

Isolate cultures capable of degrading recalcitrant organic compounds and clone a set of biodegradation genes into a "starvation promoter" ( $A$ V. Palumbo)

Tennesee Technological University Investigations in the transportation and fate of contaminants (B. L Kimmel) Combined plant off-site RCRA facility (S. F. Railsback)

Support on NSF-sponsored study on nutrient cycling and ecosystems stability (P. J. Mulholland)

\section{Tennesce, The University of}

Study role of natural organic macromolecules on the subsurface transpont of organic contaminants (J. F. McCarthy)

Perform specified hydrologic support for waste management and research tasks (D. D. Huff)

Scientific support in geohydrologic characterization at ORNL (D. D. Huff)

Support in identifying and propagation of rare and endangered plant species (P. D. Parr)

Performance of light stable isotope ratio analysis on gaseous samples to determine spatial and temporal variability in biogeochemical cycling in watersheds (P. J. Mulholland)

Hydrologic sharacterization and subsurfacc transport (S. H. Stow)

Short-term and exploratory programmatic nceds in areas where staff capability and/or funding uncertainty preclude ORNL staff commitments (S. E. Herbes)

Staff members of the Department of Civil Engincering are to provide assistance in waste management-related programs (S. H. Stow)

A cooperative venture between ESD and The University of Tennessee Graduate Program in Geological Sciences (S. H. Stow)

Life Sciences Distinguished Scientist, David White (C. W. Gehrs)

Life Sciences Distinguished Scientist, Robert Hatcher (S. H. Stow)

Study on use of biological markers as indicators of environmental pollutants (J. F. McCarthy)

Investigation of soil characteristics in Walker Branch Watershed (S. Y. Lee)

Technical support on long-term effects of soil erosion on crop production and economics of energy crop production (J. H. Cushman)

National Environmental Research Park workshop on data syntheses (P. D.

Parr)

Provide monitoring and maintenance of biodegradation experiments (A V. Palumbo)

Provide assistance in limnological, sedimentological, and water quality-related data collection ( $K$ L $\mathbf{L}$ Von Damm)

Study of natural variation in stable isotope ratios of $\mathrm{D} / \mathrm{H}, \mathrm{O}, \mathrm{C}$, and $\mathrm{N}$ in watersheds (P. J. Mulholland)

Support in data base management in the $\mathrm{CO}_{2}$ program (M. P. Farrell)

Support in study on nutrient cycling and ecosystem stability (A. V.

Palumbo)

Investigations of the absorption of heavy metals and radioelements on minerals and rocks from aqueous solutions (V.S. Tripathi) 
Provide blood samples from dairy and beef cattle needed to establish baseline cholinesterase activity (R. S. Halbrook)

Perform seismic imaging of the in situ vitrification melt (G. K. Jacobs)

Workshop from the EPRI-funded program on Compensatory Mechanisms in Fish Populations (W. Van Winkle)

Economic and technical analyses of issues related to herbaceous energy crop production (J. H. Cushman)

Technical support in identification and review of basic research needs for environmental restoration and waste management (N. H. Cutshall)

Provide high-resolution seismic survey for the purpose of imaging the shallow subsurface geologic features in the vicinity of the Paducah Gaseous Diffusion Plant (T. O. Early)

Data management support in the RCRA Facility Investigations for the Clinch River (L. D. Voorhees)

Groundwater monitoring compliance at ORNL and support to the Oak Ridge Reservation Hydrologic and Geologic Studies project (R. B. Clapp)

Support for DOE project on groundwater colloids (J. F. McCarthy)

Perform X-ray fluorescence and diffraction analyses on sediment samples collected from the Clinch River and Watts Bar Reservoir (R. B. Cook)

Technical support on groundwater monitoring compliance at the Oak Ridge Y.12 Plant and the Oak Ridge Reservation (C. S. Haasc)

Suppon for EPRI-funded program on Compensatory Mechanisms in Fish Populations (W. Van Winklc)
Develop DNA and RNA probes for measurement of methanotrophic bacterial populations (A. V. Palumbo)

Support in the use of signature biomarker techniques for identification of individual organisms and characterization of microbial consortia known to degrade PCBs (A. V. Palumbo)

Continued development of basinwide spill forecasting model and training of ORNL emergency response staff ( $R$. B. Clapp)

\section{Tennesce Valley Authority}

Geophysical data acquisition: and reduction services (S. H. Stow)

ORNL spill forecasting (M. J. Sale)

Southern Appalachian Man and the Biosphere Cooperative (P. D. Parr)

Water-bearing fractures in selected wells (S. H. Stow)

Tetra Tech, Inc Code and test nutrient cycling model (S. E Lindberg)

Tecos A\&M Research Foundation Application of ecological field theory to landscape ecology development of computer simulation methods for predicting landscape effects and responses to natural and man-made disturbances (D. S. Shriner)

Toronto, University of Determine influence of weather and population (L. W. Barnthouse)

Tuskegee Institute

Strengthen programs in biomass and carbon dioxide research at Tuskegee Institute and ESD at ORNL (J. H. Cushman) 
U.S Department of Agriculture

Establishment of biomass energy farms

(J. W. Ranney)

Eucalyptus plantations for energy production in Hawaii (J. W. Ranney)

Research on atmospheric deposition (S. E Lindberg)

Oilseed crops for diesel fuel substitutes (J. H. Cushman)

Identify risks of cultural treatments, coppice productivity, and improved productivity for energy through genetic research and selection (J. W. Ranney)

Increasing the biomass production of alder plantations in the Pacific Northwest (J. W. Ranney)

Short-rotation woody crop triak for energy production (L L Wright)

Carbon metabolism and ozone stress in loblolly pine (G. E. Taylor)

Genetic variation between switchgrasses for agronomic traits, forage quality, and biomass fuel production (J. H. Cushman)

U.S. Department of the Interior Collect surface water discharge data (D. D. Huff)

Geological survey (S. H. Stow)

Effects of atmospheric deposition on canopy and soil processes (S. E. Lindberg)

ORNL access to water quality and quantity data (S. G. Hildebrand)

\section{U.S. Environmental Protection Agency}

Continued access to the Environmental Protection Agency's
STORET/BIOSTORET data base

(C. T. Hunsaker)

Collaborative research on

bioremediation of contaminated sites

(R. R. Turner)

US Fith and Widlife Service

Data base development for simulation modeling in detection of forest responses ( $R . J$. Lummoore)

\section{US Ceological Survey}

Geologic and hydrologic characterization of the Oak Ridge Reservation (S. H. Stow)

Utah, University of Sampling and analysis of groundwater helium (D. K. Solomon)

Vanderbilt University Experimental field studies on Walker Branch Watershed (J. W. Elwood)

Virginia Polytechnic Institute Conduct research on the selection of lignocellulosic species for energy crops (J. H. Cushman)

Washington, University of Effects of acid rain on forest nutrient status (S. E. Lindberg)

Evaluation and genetic improvement of black coltonwood for short-rotation coppice culture (L L Wright)

Chemical analysis of soil solutions and soil extracts for ammonium and nitrate (H. Van Miegroct)

\section{Yale University}

Conduct stable isotope investigation of Oak Ridge Reservation hydrology systems (C. S. Haase) 


\section{Technology Transfer}

\section{L Larsen}

Martin Marietta Energy Systems, Inc., has established the Office of Technology Transfer to promote the transfer of technology from the national facilities in Oak Ridge to industries in the private sector. Recently, several federal laws have been initiated or revised to facilitate technology transfer to private industry as well as to protect the rights of inventors. Energy Systems employees working at DOE facilities have a responsibility to record and report to the Patent Section (prior to public disclosure) any discovery that might constitute an invention.

During the past year, a patent application was submitted to the U.S.
Patent and Trademark Ofice for an instrument developed by L. L Lassen of ESD and M. M. Chiles and C. V. Miller of the Instrumentation and Controls Division. The development of this instrument, an in situ radiation detector, was transferred through the Office of Technology Transfer to a vendor of nuclear instrumentation for manufacturing and marketing. When interfaced to a computer, this device allows continuous real-time in situ remote sensing of radioactivity in groundwater, along with data processing and archiving and documentation of data. 


\title{
Education Programs
}

\author{
S. E Herbes
}

ESD traditionally maintains strong relationships with universities and other research institutions. and through these interactions we are able to augment staff capabilities in key scientific areas. Universities also provide valuabin assistance by supplying summer sta.T and interns for short-term positions and by assisting us in our search for highly qualified persons to fill permanent staffing needs. Guests, ranging from high school students to university faculty, are appointed through a wide variety of programs administered by the ORNL University and Educational Programs Office (UEP) and by Oak Ridge Associated Universities (ORAU), as well as through subcontracts with individual universities. Program diversity provides fexibility in identifying appointments for widely warying educational levels, purposes, and durations. ESD education programs are coordinated through the Education Committee, whose role is to advise division management on questions of education policy and to ensure that these programs continue to provide exceptional opportunities for student involvement while mee'ing ESD's programmatic objectives.

During the past several years, national concern has focused on the steadily decreasing number of college students who choose carcers in science and engincering. DOE's response to these trends has becn to underscore the importanice of both strengthening and supporting existing precollege science education curricula and to actively promote involvement of underrepresented minorities in carcer-track science and cngincering cducation programs. In kecping with DOE's and
UEP's renewed emphasis in these areas, the ESD education program during the past several years has expanded research opportunities for high school students and teachers, as well as for minority students and faculty. In FY 1990 these initiatives have been reflected in the continuously increasing level of activities of the Ecological and Physical Sciences Study Center, jointly administered by ESD and UEP; the expansion of the American Chemical Society High School Study Program (SEED) to provide summer-long research opportunities for high school students; the successful completion in July 1990 of the third annual DOE High School Honors Workshop in the Environmental Sciences; the expanded involvement of high school teachers in research; the increased involvement of Hispanic students and facility in research programs; and the appointment of a Minority Education Liaison within the division to assist in developing and ensuring high-quality research experiences for minorities in ESD.

\section{DOE Higi School Honors Wortahop in the Environmental Sciences}

\section{T. L. Ashwood and J. A Watts}

DOE sponsors science education workshops for exceptional high school students at scven national laboratories each suminer. The workshop at ORNL focuses on the environmental sciences. Fifty-scven students from 48 states, the District of Columbia, Puerto Rico, and 7 forcign countries participated in the 2-'veck ORNL program this year. Just 
under $50 \%$ of the students were female. and $15 \%$ of the American students represented ethnic minorities.

Each student was assigned to 1 of 15 research projects. These projects (led by 30 scientists from ESD and the Health and Safety Research Division) provicied the students with hands-on research opportunities in such areas as geochemistry, environmental toxicology, conservation biology, molecular biology, botany, wildife ecology, and soil physics, as well as instruction in the use of large computerized models, data bases, and geographical information systems. The members of each research group prepared a written report and gave an oral presentation to their peers.

In addition. students were placed in one of four groups, each working on a major environmental theme: global warming, hazardous waste incineration, radioaclive waste disposal, and radon. The theme groups (led by six staff members from ESD, Health and Safety Research Division, Energy Division, and the Hazardous Waste Remedial Actions Program) studied all sides of the issuc, and their work culminated in a series of public hearings during which students roleplayed opposing factions.

Throughout the program, students also participated in seminars and special programs at the Oak Ridge National Environmental Rescarch Park and at the Great Smoky Mountains National Park. At the end of the workshop, each student and each rescarch leader were asked to evaluate the program. Students unanimously agreed that their perceptions of science had been positively changed or rcinforced. Rescarch leaders typically felt that the program had challenged and refreshed their own perceptions of science.
Eoological and Physical Sciences Study Center

T. L Lashley, P. D. Parr, and E D. Aebischer

The Ecological and Physical Sciences Study Center, now in its seventh year, has grown rapidly as a precollege science education program. From 125 students in 1984 , the study center served some 16,800 students and teachers representing 9 East Tennessee counties during the 1989-90 school year. Study center staff now include a director and eight instructors, all of whom serve on a part-time basis under subcontract.

The primary purpose of the study center is to enhance environmental and science education for precollege students (kindergarten through high school). Halfday field or laboratory activity units at the Oak Ridge National Environmental Research Park (mainly using the Freels Bend cabin area and the Graphite Reactor site) em.phasize a hands-on approach to learning about ecological relationships and physical science concepts. Currently, 32 activity units are offered. Objectives also include furnishing informational and instructional materials for teachers to use in developing their own study units, providing special presentations and programs for teachers and the public, and adapting units so that disabled students can participate. Special study center events (in addition to the regular study units) included National Science and Technology Week (Flight Day and Environmental Education Youth Day), the "Science Is..." Posier Contest, Spring Science Experience for Girls, Spring Science Experience for Minoritics, Summer Science Experiences (weck-long programs and a family day program), and Martin Marictla Encrgy Systems Employment Disability Awareness Weck (programs for cmployecs and the public). 
In addition, study center staff made special presentations at regional conferences sponsored by the National Science Teachers Association, at the annual meeting of the Tennessee Science Teachers Association, and at the fall conference of the Tennessee Environmental Education Association.

The program is jointly administered by UEP and the Oak Ridge National Environmental Research Park, which is managed by ESD.

\section{Secondary School Science Education Programs}

\section{G. J. Haynes and S. E. Herbes}

This year six high school students participated in ESD research projects through the American Chemical Society's SEED program. The goal of SEED is to encourage outstanding juniors and seniors to consider careers in science and mathematics by providing an 8 - to 10 -week summer research experience. Although the students spend most of their time with their research advisors, they also participate in seminars, write papers, and receive career guidance from UEP and ESD staff. The hands-on research experience that the students gain can often motivate them to pursue carecrs in science or mathematics.

During the past several years, ORNL has initiated numerous programs to strengthen science education on the secondary school level by providing opportunities for teachers and students to participate directly in ORNL research projects. During summer 1990, eight high school teachers from Tennessee, Connecticut, Nebraska, and Puerto Ricn worked for 8 wecks in ESD through the Science Teachers Research Involvement for Vital Education and the Teacher Research Associates programs. Several
ESD staff also contributed to area secondary science education by participat . ing as speakers in high schools through the UEP Visiting Scientist Program.

\section{Minority Educational Institution Initiatives}

\section{H. L. Boston and M. S. Hendricks}

ESD efforts associated with minorities have primarily addressed three areas: (1) increasing the participation of minority students in ESD education programs;

(2) encouraging minority faculty to collaborate with ESD researchers and to participate in faculty research programs in ESD; and (3) providing opportunities for minority students at the undergraduate and graduate levels to work with ESD researchers, with the goal of eventually recruiting some of these students as Martin Marietta Energy Systems employees. The two focal areas for Minority Educational Institution (MEI) activities have been Historically Black Colleges and Universities (HBCUs) and Hispanic educational institutions.

During FY 1990 an ad hoc committee met to review minority educational opportunities provided by the division. On the committee's recommendation, a brochure describing ESD research activities and ORNL education programs was developed to assist in recruiting highly qualified students. Also on committee recommendation, M. S. Hendricks was appointed Minority Education Liaison, a new position created to enhance ESD communications with UEP in the area of minority programs and to assist in ensuring positive experiences for minority education guests in ESD.

In FY 1990, ESD staff strengthened ties with faculty at several MEIs through continuing participation in the Urban Lcague's Black Exccutive Exchange Program and through contacts made at 
national meetings. These ties are a useful means for contacting and recruiting students for education programs and employment opportunities. Because students often are not aware of the many opportunities available and often are hesitant to venture into unfamiliar areas (such as programs at national laboratories), first-hand knowledge of a faculty member is important to potential applicants. These faculty ties also provide a means of disseminating information about research opportunities at ORNL and of encouraging collaborative research between ESD staff and faculty at MEIs.

A blanket subcontract was established with Knoxville College, a local HBCU, to allow students to work part-time with researchers in ESD. Three students participated under this arrangement in FY 1990. Although students' responsibilities are to provide technical support rather than to develop independent research projects, staff advisors are expected to involve the stude.its in ongoing research activities as mich as possible. This program is designed to encourage subsequent participation in various ORNL education programs as well as to provide a unique spportunity for students to expand their career options through exposure to the world of environmental research.

During the past 4 years, UEP and ESD have established strong connections with several Puerto Rican educational institutions, largely through the efforts of a former ESD staff member, B. D. Jimenez, $v^{\prime} . v$ is now on the faculty of the University of Pucrio Rico at Mayaguez. During this period the number of Puerto Rican students and faculty participating in summer-or semester-long rescarch internships in ESD has stcadily increased, from 5 in FY 1987, 7 in FY 1988, 9 in FY 1989, to a total of 13 individuals in FY 1990). Two high school students, six undergraduates, three graduate students, a high school teacher, and a university faculty member participated in research assignments this past year.

\section{Undergraduate Education Frogram}

\section{G. J. Haynes}

Several ORNL and ORAU programs for undergraduate student participation in ESD research and assessment projects provide a continuing opportunity for interaction between students and staff. In FY 1990 a total of 56 undergraduates, representing 25 different institutions, participated in divisional research activities.

Highly qualified undergraduates are selected from colleges and universities throughout the United States (see table) on the basis of academic performance, references, future research interests, and availability of appropriate positions in ESD. Students are assigned to ESD advisors, who guide them through a summer- or semester-long experiment or project associated with one of the ESD programs. The research experience is supplemented through seminars, workshops, oral and poster presentations, course work, and preparation of a research paper. Participants also become familiar with sophistizated, state-of-the-art scientific research equipment. Students gain experience that can lead to success in graduate studies and to an expanded understanding of carcer opportunities in environmental rescarch.

\section{Graduatc and Postgraduatc Education Programs}

\section{S. E. Herbes}

ESD provides the opportunity for gi aduatc and postdoctoral rescarch consistent with the mission of ORNL. 
During this reporting period, a total of 48 students participated in graduate research in ESD (see table). While maintaining the traditionally strong participation of The University of Tennessee Graduate Program in Ecology, ESD hosted graduate students from 18 other universities. In addition, 16 postdoctoral interns and two Hollaender Fellows pursued research studies as part of divisional programs.

Graduate research opportunities vary in length, from internships of several months' duration to multiyear Ph.D. dissertation projects. Student research is guided by selected ESD staff members, one of whom serves on the student's university academic guidance committee. Tuition, fees, and stipends for some of the graduate students are provided through DOE educational assistance programs administered through ORAU and UEP. Many students are supported through ESD programmatic funds, and several are selfsupported.

In addition to students in residence, ESD programs support graduate research at many of the universities with which subcontractual arrangements are maintained (see section of this report entitled Research and Development Subcontracts and Interagency Agreements).

\section{Faculty Program}

\section{S. E Herbes}

ESD provides opportunities for professional educators to participate in collaborative research with division staff. During this reporting period, five university faculty participated in summer or sabbatical research at ESD through the ORAU Faculty Research Participation and sabbatical programs. In addition, many faculty members visited ESD for workshops, seminars, or subcontract consultations.

\begin{tabular}{|c|c|c|c|c|c|c|c|}
\hline \multicolumn{8}{|c|}{ 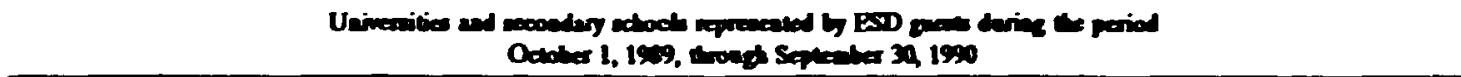 } \\
\hline \multirow[b]{2}{*}{ Instivition } & \multicolumn{3}{|c|}{ Sudent } & \multirow{2}{*}{$\begin{array}{l}\text { Posidocioral } \\
\text { eppointees }\end{array}$} & \multicolumn{2}{|c|}{ Faculy } & \multirow[b]{2}{*}{ Progan } \\
\hline & $\underset{\text { sight }}{\text { Higol }}$ & $\begin{array}{l}\text { Lader- } \\
\text { gradusle }\end{array}$ & Gradule & & $\underset{\text { sithol }}{\text { High }}$ & $\begin{array}{l}\text { Colkegl } \\
\text { eninerity }\end{array}$ & \\
\hline Artanes Sule Cinnenity & & $\mathfrak{l}$ & & & & & SRP \\
\hline Akstiz-Ean High Schood (Tensence) & & & & & 1 & & STRIVE \\
\hline Berufsakaderaie (Gerwany) & & & 2 & & & & Precticun \\
\hline Cartewas College & & 1 & & & & & ORSERS \\
\hline Chimen Liveniny of Techuology (Sueden & & & 1 & & & & Practicus \\
\hline Colorado Sule Linivenity & & & 1 & & & & Precticun \\
\hline Conell Linversity & & 1 & & & & & PIP \\
\hline Dr. Acuotin Sully Sctionl (Puerto Rico) & & & & & 1 & & IRA \\
\hline Luke Liamersiny & & & & 1 & & & PRTP \\
\hline Farthe College & & 1 & & & & 1 & GILCAACM \\
\hline Faut Tenouce Sule L'orvernity & & & 1 & & & & SRI \\
\hline Fon lews College & & & & & & 1 & PSP \\
\hline Henuge Hingh Sctwool (Tennewere) & 1 & & & & & & SFF.D \\
\hline Holswe High sxwool (Tenserme) & 1 & & & & & & SEFE \\
\hline
\end{tabular}




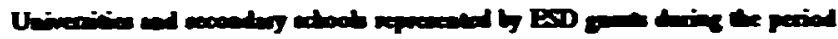

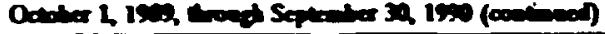

\begin{tabular}{|c|c|c|c|c|c|c|c|}
\hline \multirow[b]{2}{*}{ Lestitution } & \multicolumn{3}{|c|}{ Sndenes: } & \multirow{2}{*}{$\begin{array}{l}\text { Poatioctorai } \\
\text { appoiatees }\end{array}$} & \multicolumn{2}{|c|}{ Facaly } & \multirow[b]{2}{*}{ Propene } \\
\hline & $\begin{array}{l}\text { High } \\
\text { sciool }\end{array}$ & $\begin{array}{l}\text { Uader. } \\
\text { ondure }\end{array}$ & Gradeate & & Hidh & $\begin{array}{l}\text { Collegel } \\
\text { waiverily }\end{array}$ & \\
\hline Indinan Ulimeniey & & 1 & 2 & & & & SRP. Sub \\
\hline Kenville College & & 3 & & & & & $\operatorname{sab}$ \\
\hline LeMogre Colleg: & & 1 & & & & & SRP \\
\hline Loniviana Sule Veriversity & & & & 1 & & & PRTP \\
\hline 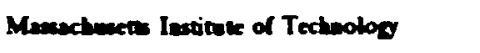 & & & 1 & & & & LGP \\
\hline MoGill University (Canda) & & & & I & & & PRTP \\
\hline Mieni Viniverity (Otio) & & & 2 & & & & $\operatorname{seb}$ \\
\hline Michion Save Uaivarity & & 1 & & & & & PIF \\
\hline Murmy Sule Univernily & & & 2 & & & & GSRP \\
\hline Sem Brituin Hipl Sebool (Cossecticat) & & & & & $\mathbf{1}$ & & TRA \\
\hline Norris Jweior High Sclood (Nebrastu) & & & & & 1 & & TRA \\
\hline Oak Ridpe High Scibool (Tennesere) & 1 & & & & & & SEED \\
\hline Onblaed High School (Tenenewer) & & & & & 1 & & TRA \\
\hline Ohio Laiversity & & 1 & & & & & SRP \\
\hline Oliner Spriug High Sclool (Tensemex) & 1 & & & & 1 & & SEED, TRA \\
\hline Orepon Suk Univensiy & & & & 1 & & & PRTP \\
\hline Peabrote Suk Colleg: & & $\mathbf{I}$ & & & & & ORSERS \\
\hline Peangytraia Suk Laiversily & & 1 & 1 & & & & $\begin{array}{l}\text { ORSERS } \\
\text { GSRP }\end{array}$ \\
\hline Priacetoe Lainerity & & 1 & & & & & PIP \\
\hline Pusdue Linversing & & 1 & & & & & SRP \\
\hline Resen Powey Giralt School ('tuerno Rico) & 1 & & & & & & SEED \\
\hline Rudes College & & 1 & & & & & PIP \\
\hline Rauve Suk Connusiry Colkge & & 21 & & & & & Sab, IIP \\
\hline Rule High Sclood (Teasceree) & & & & & 1 & & STRUE \\
\hline Sontweat Miscouri Sule Uaivenity & & 1 & 1 & & & & SRP, GSRP \\
\hline Se Fraecis Sclool (Keatucly) & & & & & $\mathfrak{l}$ & & TRA \\
\hline Se Louis Uaiversily & & 1 & & & & & ORSERS \\
\hline Teas Aal lainenity & & 1 & & & & 1 & SRP. FRP \\
\hline Ciniverided Ceetral de Ceribe (Pwerto Rico) & & & 1 & & & & GSRP \\
\hline Cinivenided Metropoliuns (Pueno Rico) & & & & & & 1 & FRP \\
\hline Cinenity of Colifornis-Davis & & & & 1 & & & PRTP \\
\hline Cineriby of Deloware & & & & 1 & & & PRTP \\
\hline Conivenity of Florid. & & & 1 & & & & Practicuen \\
\hline Linenily of Georps & & 1 & & 1 & & & PIP, PRTP \\
\hline \multirow[t]{2}{*}{ Cainersity of Mictioss } & & 2 & 1 & & & & ORSERS, \\
\hline & & & & & & & SRP, SRI \\
\hline liniversity of New Haepolure & & 1 & & & & & PIP \\
\hline Cismersiny of Nionb Coroties & & 1 & 1 & & & & PIP. GSRP \\
\hline Vervenity of Otiskons & & & & & & 1 & FRP \\
\hline
\end{tabular}




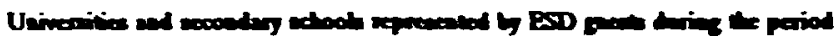

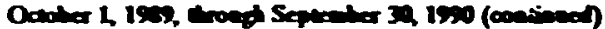

\begin{tabular}{|c|c|c|c|c|c|c|c|}
\hline \multirow[b]{2}{*}{ Institution } & \multicolumn{3}{|c|}{ Srudeat: } & \multirow{2}{*}{$\begin{array}{l}\text { Posidoctional } \\
\text { appointed }\end{array}$} & \multicolumn{2}{|c|}{ Faculy } & \multirow[b]{2}{*}{ Progene } \\
\hline & $\begin{array}{l}\text { Hiefl } \\
\text { scirod }\end{array}$ & $\begin{array}{l}\text { Ueder- } \\
\text { Jroderite }\end{array}$ & Grodule & & Hiel & $\begin{array}{l}\text { Colleged } \\
\text { univeniyy }\end{array}$ & \\
\hline Liviverxity of Pwerto Rico & & 6 & 2 & & & & $\begin{array}{l}\text { ORSERS } \\
\text { PIP. SRP. } \\
\text { GSRP }\end{array}$ \\
\hline Linve. city of Pwerso Rico High School & 1 & & & & & & SEED \\
\hline University of Rochester & & & & 1 & & & PRTP \\
\hline University of Siene (Italy) & & & $\mathbf{I}$ & & & & Practicue \\
\hline Seiversity of Tenscanee & & & 20 & 3 & & & $\begin{array}{l}\text { PRIP, SCP. } \\
\text { SA, PIP. } \\
\text { UP, LGP }\end{array}$ \\
\hline Univernity of Tomonso (Canada) & & & & $\mathbf{I}$ & & & PRIP \\
\hline Uaiversily of Vurginis & & & 1 & & & & Practicale \\
\hline University of Wrscomsin & & 3 & & $\mathbf{I}$ & & & $\begin{array}{l}\text { ORSERS, } \\
\text { PRTP }\end{array}$ \\
\hline Universily of Wyoming & & & & 2 & & & Sin \\
\hline U.S. Noval Acadery & & & 1 & & & & SARA \\
\hline Vacderbilt Usivetrity & & & $\mathbf{I}$ & & & & LGP \\
\hline Virginia Potyrecheic lestitule & & 2 & & 1 & & & SRL, PRTP \\
\hline & 一 & - & -- & - & - & - & \\
\hline Toul & 6 & $\$ 6$ & 48 & 16 & 8 & $\mathbf{s}$ & \\
\hline
\end{tabular}

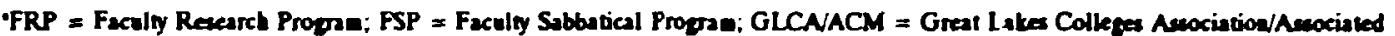

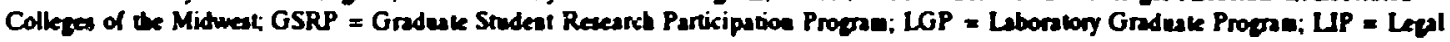

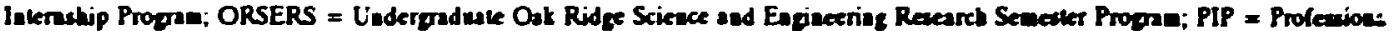

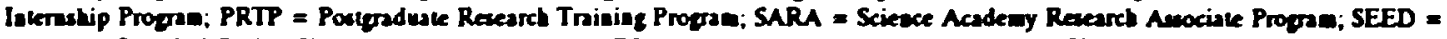

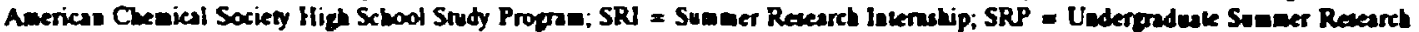
Propras; STAR = Science Teachers as Resources Propose; STRIVE = Scieace Teachen Research lavolvewent for Vilal Edecation: Sub =

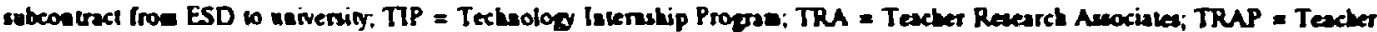
Recearch Aseocisle Progan.

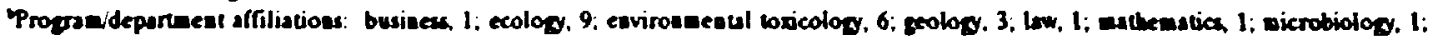
wildlife. 1; zoolon. 1 


\title{
Affirmative Action
}

\author{
V. R. Tolbert and A. U. Sheard
}

ESD strongly supports the Martin Marietta Energy Systems Equal Employment Opportunity and ORNL Affirmative Action programs. The division has made concerted efforts to ensure job equality for all employees regardless of race, color, religion, sex, or national origin. In addition, ESD has taken steps to expand employment opportunities for minorities, women, and the disabled. During FY 1990, ESD continued to support affirmative action principles in four main areas: hiring and staffing, promotions, career development, and education programs. ESD has also continued to build on the groundwork laid in the past and to expand efforts to identify and recruit minority staff for positions throughout the division. The following summarizes ESD's progress in affirmative action during this reporting period.

- ESD has a sincere commitment to develop closer relationships with minority educational institutions (MEIs). These relationships allow identification and development of potential minority employees and offer opportunitics for subcontract interactions and the further development of MEI capabilities.

- The interactions begun last year between the Oak Ridge Environmental Research Park and North Carolina Agricultural and Technical Statc University have proved very bencficial to both the Research Park and the university. SAS Graph (SAS is the registered trademark of SAS Institutc. Inc.,
Cary, North Carolina) and a computer modem were purchased for the university to fulfill its contractual obligations and will be used for a number of other projects. Staff from North Carolina Agricultural and Technical State University participated in SAS instructional courses in conjunction with the subcontract work, and several students have learned skills that they have been able to apply to other jobs. Opportunities for further interactions botween ESD and university students and staff have been identified.

- An ad hoc education committee was formed within the division. The committee developed informational brochures for ESD to use in recruiting at minority institutions and at job fairs. $A$ member of the committee attended the minority job fair in New Orlcans.

- Interactions between ESD staff and the senior seminar at Knoxville College continue. At least two Knoxville College students work in ESD part-time during the school ycar and full-time in the summer, and an ESD staff member serves as mentor for one of the students.

- Opportunities for rescarch collaboration betwecn ESD and Metropolitan University in Pucrto Rico and the University of Pucrto Rico were explored. As a result of these interactions, a faculty member 
from Metropolitan University participated in research sponsored by the Biomass Production Program this summer.

- ESD continues to have a strong commitment to increasing opportunities for disabled individuals.

- A hearing-impaired employee in ESD has been named secretary for the Quality Improvement Program for Deaf and Hearing-Impaired Individuals.

- ESD explored the possibility of hiring a disabled female mathematical modeler (to work out of her home) and a disabled female veterinarian. Although the modeler moved to Colorado and the veterinariait decided to pursue her student education workshops independently, ESD will continue its efforts to employ qualified disabled individuals.

- Female professional staff members continue to be actively involved as officers and members of the local chapter of the Association for Women in Science (AWIS). ESD female staff were the recipients of the Outstanding Scientific Achievement and the Outstanding AWIS Service awards for 1990. The division recognized the award recipients at a luncheon with the Director of ORNL

- The division has pursued affirmative action efforts through hiring and staffing during the year.

- ESD recruited two professional females during FY 1990 and has pursued the hiring of a minority female as a Wigner Fellow. (The minorily female has since accepted the Wigner Fellowship.) A minority female was hired as a post-M.S. employee through Oak Ridge Associated Universities.

- A minority female staff member at The University of Tennessee is working on a research project with ESD staff to characterize subsurface transport.

- ESD has actively recruited a number of minority secretarial candidates for potential job openings in the division and at the laboratory.

- ESD has promoted affirmative action objectives by extending its employees further opportunities for professional development and skilts training. Female professional staft members attended a variety of national and international conferences and workshops, as well as participated in training opportunities as either leaders or participants. A minority secretary received an associate degree in computer science.

- With the knowledge that minorities and women will become the majority in the work force by the year 2000, ESD has taken steps to include more women and minorities in the various training and educational programs that are open to visiting students, faculty, and scientists. These efforts will help ESD to identify additional potential employecs from these groups.

- ESD hosted the 2-wcek DOE High School Honors Workshop that cnabled outstanding high school students from each of the 50 states and from several foreign countries to learn more about science and to 
participate in hands-on risearch while visiting ESD.

- During the summer of 1990 , five minority students worked in ESD in various programs (the American Chemical Society High School Study Program, the Professional Internship Program, and the Undergraduate Summer Research Program). The division has maintained contact with these students and is encouraging them to return next summer. Two Puerto Rican teachers also participated in ESD summer programs.

- An ESD minority research staff member delivered four lectures at Prairie View A \& M. University on research, opportunities in science, and opportunities at ORNL. Requests for applications for employment and education programs have resulted from these interactions.

- A visiting Mexican female researcher is currently working in ESD.

- ESD management was actively involved in discussions to encourage a minority female to remain at ORNL Although the employee will remain in her home division, she will work half-time on research in ESD.

- An ESD minority research staff member represented ORNL at the National Minority Environmental Career Conference at Howard University. As a result of this interaction, division management has established a relationship with a company to identify minority interns to participate in division programs. 


\title{
Seminar Program
}

\author{
R. J. Norby
}

During the past year, the ESD Seminar Committee coordinated a diverse program of guest speakers (listed here) to inform ESD staff and other interested members of the local scientific community about topics of general interest in the environmental sciences. The Seminar Committee relies largely on suggestions from ESD staff members concerning the selection of outstanding speakers.

K. K. Turekian, Department of Geology and Geophysics, Yale University, New Haven, Connecticut: The Detection of Changes in Oceanic Upwelling History Using $\delta^{13} \mathrm{C}$ and $\Delta^{14} \mathrm{C}$ in Calcareous Tests and Varied Sediments," October 12, 1989.

F. Führ, Institute of Radioagronomy, Jülich Research Laboratory, Germany: "Long Term Fate of ${ }^{14} \mathrm{C}$-Labelled Pesticides in Agroecosystems," October 26, 1989.

M. Lewis, National Aeronautics and Space Administration, Washington, D.C.:

"Equatorial Fluxes of Heat, Nitrate, and Carbon in the Pacific Ocean,"

November 16, 1989.

W. L. Chamcides, School of Earth and Atmospheric Sciences, Georgia Institute of Technology, Atlanta: Tropospheric Gzonc, Biospheric-Atmospheric Intcractions, and Global Change," January 25, 1990.

R. P. Niclson, Oregon State University and U.S. Environmental Procection Agency, Corvallis: Regional-Scale Biome Responses to Global Climatc Change," February 13, 1990 .
J. Meagher, Atmospheric Science Department, Tennessee Valley Authority, Muscle Shoak, Alabama: "Poliutant Production and Exposure in a Montane Ecosystem," March 28, 1990.

W. T. Swank, Coweeta Hydrologic Laboratory, U.S. Department of Agriculture Forest Service, Otto, North Carolina: "Research Activities at the Coweeta Hydrologic Laboratory," April 10, 1990.

R. V. Smythe, Forest Environment

Research, U.S. Department of Agriculture Forest Service, Washington, D.C.: "Challenges for Forest Service Environment Research," April 19, 1990.

P. Tans, Climate Modeling and Diagnostics Labotatory, National Oceanic and Atmospheric Administration, Boulder, Colorado: "Do Terrestrial Ecosystems Take Up More Fossil Fuel $\mathrm{CO}_{2}$ than the Oceans?" April 20, 1990.

J. F. Splettstoesser, Polar Consulting, Inc., Rockland, Maine: "Antarctic Geology, Minerals, and Politics: Implications for Treaty Review in 1991," June S, 1990.

B. Mandula, U.S. Environmental Protection Agency, Washington, D.C.: "Time Trends in Science and Engineering," June 19, 1990.

J. W. Elwood, Committec on Earth Sciences, Washington, D.C., and ESD: The Committec on Earth Sciences and the Global Change Research Program," July 20,1990 . 


\section{Visitors Hosted}

\section{G. J. Haynes}

During FY 1990 a total of 1672 persons visited the ESD facilities as part of tour groups. This number includes the groups listed in the table below as well as an additional $\mathbf{4 2 6}$ persons, many of them high school students and undergraduates, who toured the division as part of
Saturday educational tours hosted by

Public Relations personnel trained by the ESD tour coordinator. The diversity of visitors reflects interest in the many areas of environmental research conducted in the division.

Tour group botad from October 1, 1989, to September 30, 1990

\begin{tabular}{|c|c|c|c|}
\hline Institution & Date & $\begin{array}{l}\text { Number } \\
\text { in tour }\end{array}$ & ESD host(s) \\
\hline Containment Experiments Wortashop & $10 / 19 / 89$ & 54 & H. L Boston \\
\hline Science class, Rockwood High School & $10 / 26 / 89$ & 30 & C. J. Ford, J. M. Cushman \\
\hline Participants, National Chemisery Week & $10 / 31 / 89$ & 23 & G. J. Haynes \\
\hline Participants, National Chemistry Week & $11 / 289$ & 23 & G. J. Haynes \\
\hline $\begin{array}{l}\text { Environmental problems class, } \\
\text { Middle Tennessee State University }\end{array}$ & $11 / 17 / 89$ & 11 & H. L Bosion, C. R. Wenzel \\
\hline $\begin{array}{l}\text { Biology and physics students, } \\
\text { Lenoir City Fligh School }\end{array}$ & $12 / 6 / 89$ & 17 & G. J. Haynes \\
\hline $\begin{array}{l}\text { Students, Oak Ridge Science and } \\
\text { Engineering Research Semester }\end{array}$ & $11 / 8 / 90$ & 30 & G. J. Haynes, C. R. Wenzel \\
\hline DOE Emvironmental Clean Up Group & $1 / 10 / 90$ & 5 & S. M. Adams \\
\hline Science majors, ORAU Science Minimesier & $1 / 17 / 90$ & 25 & G. J. Haynes, C. R. Wenzel \\
\hline Dr. and Mrs. Siegrist & $2 / 2 / 90$ & 2 & G. J. Haynes, S. H. Stow \\
\hline Japanese Nuclear Advocacy Team & 228190 & 7 & C. J. Ford \\
\hline $\begin{array}{l}\text { Science, Technology, and Public } \\
\text { Policy Seminar }\end{array}$ & $3 / 14,90$ & 30 & N. T. Edwards, A J. Stewart \\
\hline $\begin{array}{l}\text { Representatives, Chung Shan Institule } \\
\text { of Science }\end{array}$ & $3 / 16 / 90$ & 5 & B. L. Kimmel, A J. Stewart, S. H. Stow \\
\hline Department of Botany, Rutgers University & $3 / 19,90$ & 9 & $\begin{array}{l}\text { M. A. Huston, P. J. Muholland, R. J. } \\
\text { Norby }\end{array}$ \\
\hline $\begin{array}{l}\text { Phiysics, chemisiry, and biology students, } \\
\text { Fmory and IIenry Colkge }\end{array}$ & $3 / 20 / 90$ & 37 & M. S. Adams, C. R. Wenzel \\
\hline Soviet delegation & $3 / 28,90$ & 30 & A J. Stewan, J. W. Ranney \\
\hline $\begin{array}{l}\text { Finvironmental problems class, The University } \\
\text { of Tennessee, Chattanooga }\end{array}$ & $3 / 29 / 90$ & $\mathbf{2 0}$ & C. J. Ford, J. W. Ranney \\
\hline $\begin{array}{l}\text { Science and mathematics students, } \\
\text { Lincoln Memorial Universily }\end{array}$ & $4 / 4 / 90$ & 25 & C. J. Ford \\
\hline $\begin{array}{l}\text { American Chemical Sockety, } \\
\text { Cumberland College }\end{array}$ & $4 / 10 / 90$ & 25 & A. Turhollow \\
\hline $\begin{array}{l}\text { Representatives, Unversidad Metropolitana, } \\
\text { Puerto Rico }\end{array}$ & $4 / 17 / 90$ & 3 & G. J. Haynes, J. W. Ranncy \\
\hline $\begin{array}{l}\text { Past Tennessec Chaper, American Women } \\
\text { in Science }\end{array}$ & $4 / 20, \times 10$ & 25 & V. R. Tolbert \\
\hline
\end{tabular}


Tour group hoted from Ocsober 1, 1989, wo September 30, $19 \% 0$ (continued)

\begin{tabular}{|c|c|c|c|}
\hline Institution & Dare & $\begin{array}{l}\text { Number } \\
\text { in rour }\end{array}$ & ESD host(s) \\
\hline Science CJub, Nortwwest High School & $4 / 27 / 90$ & 35 & T. Grizard, N. T. Edwards \\
\hline $\begin{array}{l}\text { ORAU-sponsored group from Northeastern } \\
\text { Alabama Junior College }\end{array}$ & $5 / 3,90$ & $\boldsymbol{w}$ & M. S. Adams, T. Grieard \\
\hline $\begin{array}{l}\text { Representatives, Chemical Tech, } \\
\text { Mitsuhishi, Japan }\end{array}$ & $5 / 7 / 90$ & 6 & R. J. Norby \\
\hline $\begin{array}{l}\text { Biocechnology for Fuets and } \\
\text { Chemizals Symposium }\end{array}$ & $5 / 9 / 90$ & 40 & H. L Boston, A V. Palumbo \\
\hline $\begin{array}{l}\text { Scudents and faculty, Waterdomn } \\
\text { High School, Canada }\end{array}$ & $5,9 / 90$ & 37 & V. R. Tolbert, C. R. Wenzel \\
\hline $\begin{array}{l}\text { Biology and nursing sludents, } \\
\text { Dabney S. Lancaster Community College }\end{array}$ & $5 / 15 / 30$ & 10 & C. J. Ford, C. R. Wenzed \\
\hline MBA students, The University of Tennescee & $5 / 16 / 90$ & 8 & G. J. Haynes \\
\hline $\begin{array}{l}\text { Environmental problems clase, } \\
\text { Middle Tennessee State University }\end{array}$ & $3 / 29 / 90$ & 12 & C. J. Ford, C. R. Weozel, T. Grizond \\
\hline Science majors, ORAU Science Minimester & $5 / 29 / 90$ & 16 & A. D. Steiman, C R Wenzel \\
\hline $\begin{array}{l}\text { Students and faculty, Frank White Academy, } \\
\text { Harrogate, Tennescee }\end{array}$ & $5 / 3090$ & 32 & T. Grizaard, C. R. Wenzel \\
\hline Science majors, ORAU Science Minimestet & $5 / 31 / 90$ & 16 & C. J. Ford, C. R. Wenzed \\
\hline Science majors, ORAU HBCU & $6 / 1 / 90$ & 14 & H. L Bosion \\
\hline $\begin{array}{l}\text { Emironmental problems ctass, Carroll } \\
\text { Colkge, Waukesha, Wisconsin }\end{array}$ & $6 / 1 / 90$ & 7 & $\begin{array}{l}\text { H. L Boston, T. Grimard, C. R. } \\
\text { Wenzel }\end{array}$ \\
\hline Arnold Chiet's group, Energy Systems & $6 / 6 / 90$ & 7 & A. J. Stewart \\
\hline Soutb African delegation & $6 / 8990$ & 17 & G. J. Haynes \\
\hline Oak Ridge Science Camp & $6 / 1290$ & 4 & M. G. Ryan, J. G. Smith \\
\hline DOE new employee orientation & $6 / 1290$ & 35 & M. J. Peterson, C. R. Wenzel \\
\hline $\begin{array}{l}\text { High school workshop, } \\
\text { Tennessee Technological University }\end{array}$ & $6 / 14 / 90$ & 25 & V. R. Tolbert \\
\hline Teachers, TRAC, STRIVE, and SEED & $6 / 18 / 90$ & 35 & C. R. Wenzel \\
\hline DOE Weatherization Ascistance Workchop & $6 / 20 / 90$ & 15 & M. S. Adams \\
\hline Teachers, National Science Foundation & $7 / 2 / 90$ & 46 & L L Wright \\
\hline High School Ilonors Sludents & $7 / 16 / 90$ & 62 & G. J. Maynes, C. R. Wenzel \\
\hline Governor's Scholars & $7 / 23 / 90$ & 17 & T. Grizzard \\
\hline Science Alliance Chemissry Group & $7 / 24 / 90$ & $\mathbf{2 0}$ & H. L Bosion \\
\hline $\begin{array}{l}\text { Environmental problems class, Tennessee } \\
\text { Technological University }\end{array}$ & $8 / 1 / 90$ & 15 & $\begin{array}{l}\text { G. J. Haynes, J. M. Loar, A D. } \\
\text { Steinman }\end{array}$ \\
\hline General Counsel, Marietta Michoud & $8 / 2,90$ & 3 & C. W. Gehrs \\
\hline $\begin{array}{l}\text { ARDNWDR TV, West German } \\
\text { educational TV }\end{array}$ & $8 / 9 / 90$ & 4 & G. J. Haynes \\
\hline $\begin{array}{l}\text { Representatives, Carolina Powet and Ijght } \\
\text { Company, Raleigh, North Carolina }\end{array}$ & $8 / 16 / 90$ & 4 & G. J. Haynes \\
\hline $\begin{array}{l}\text { Students, Oak Ridge Science and } \\
\text { Engineering Rescarch Semester }\end{array}$ & $8 / 20 / 90$ & 30 & G. J. Haynes, C. R. Wenzel \\
\hline $\begin{array}{l}\text { Participants, Semester Student Program, } \\
\text { Great I akes College Association }\end{array}$ & $8 / 28 / 90$ & 25 & C. J. Ford, C. R. Wenzel \\
\hline $\begin{array}{l}\text { Representatives, Tennessee } \\
\text { Wildlife Resources }\end{array}$ & $9 / 14 / 20$ & 60 & J. Evans \\
\hline Wetland and Riparian Zones Workshop & $9 / 17 / 20$ & 3 & C. T. Hunsaker, R. J. Otson \\
\hline Science, Technology, and Public Policy Scminar & $9 / 18 / 90$ & 35 & C. R. Wenzel, A J. Stewart \\
\hline Representatives, Japan Atomic Fnergy & $9 / 20 / 90$ & 15 & A. D. Sieinman \\
\hline
\end{tabular}


Tour goups hated from Odober 1, 1989, to September 39, 1990 (contined)

\begin{tabular}{|c|c|c|c|}
\hline Institution & Date & $\begin{array}{l}\text { Number } \\
\text { in tour }\end{array}$ & ESD bost(s) \\
\hline $\begin{array}{l}\text { Program Assessment and Development, } \\
\text { Energy Systems }\end{array}$ & $9 / 21 / 90$ & $\mathbf{2 0}$ & H. L Boston \\
\hline $\begin{array}{l}\text { Deans and Ascociate Deans, Tennescec } \\
\text { Technological University }\end{array}$ & $9 / 24 / 90$ & 15 & G. J. Haynes \\
\hline $\begin{array}{l}\text { Technolog ches, Jefierson County High, } \\
\text { Jefferson, Tennesce }\end{array}$ & $9 / 26 / 90$ & 25 & C. J. Ford, C. R. Weosed \\
\hline Total & & 1246 & \\
\hline
\end{tabular}

DOE = U.S. Department of Energy, GLCA = Great Lakes Colleges Aecociation; HBCU = historially blact colleges and universities; ORAU = Oak Ridge Associated Universities; SEED = American Chemical Society High School Study Program; STRIVE = Science Teachers Research Involvement for Vital Education;

TRAC = Teacher Research Associates. 


\section{Publications}

Adams, H. S., S. B. McLaughlin, T. J. Blasing. and D. N. Duvick 1990. A survey of radial growth trends in spruce in the Great Smoky Mountains National Park as influenced by topography, age, and stand development. ORNL/TM-11424.

Adams, S. M. 1990. Status and use of biological indicators for evaluating the effects of stress in fish. Am. Fish. Soc. Symp. 8:1-8.

Adanus, S. M., and J. E. Breck 1990. Bioenergetics. pp. 389-415. IN C. B. Schreck and P. B. Moyle (eds.), Methods for Fish Biology. American Fisheries Society, Bethesda, Maryland.

Adams, S. M., M. S. Greeley, B. D. Jimenez, J. F. McCarthy, and L R. Shugart. 1989. Causal relationships between contaminant exposure and cffects in aquatic organisms. Abstract. FOR Symposium on Transboundary Pollution, Society for Environmental Toxicology and Chemistry, Washington, D.C.

Adams, S. M., M. S. Greeley, Jr., and L. R. Shugart. 1990. Assessing the health of fish populations: Application of multi-response indicators of physiological health. Abstract. FOR Annual Meeting of the American Fisheries Socicty, Pittsburgh.

Adams, S. M., M. S. Greclcy, and L. R. Shugart. 1990. Bioindicators of contaminant-related stress: An integrated ficld assessment methodology. Abstract.

FOR 14th Sym; sium on Aquatic Toxicology. Amcrican Socicty for Testing and Matcrials, Philadelphia.

Adams, S. M., K. L. Shcpard, and M. S. Greclcy, Jr. 1989. An integrated bioindicator approach for assessing the effects of fisheries management practices and environmental stress on fish. p. 159. IN Fisheries Management Coniroversies. American Fisheries Society, Bethesda, Maryland.

Adams, S. M., K. L. Shepard, M. S. Greeley, Jr., B. D. Jimenez, M. D. Ryon, L. R. Shugart, J. F. McCarthy, and D. E Hinton. 1989. The use of bioindicators for assessing the effects of pollutant stress on fish. Mar. Environ. Res. 28:459-464.

Adams, S. M., L R. Shugart, G. R. Southworth, and D. E. Hinton. 1990. Application of bioindicators in assessing the heaith of fish populations experiencing contaminant stress. pp. 333-353. IN J. F. McCarthy and L R. Shugart (eds.), Biomarkers of Environmental Contaminants. CFC Press, Boca Raton, Forida.

Allison, L. J., C. T. Hunsaker, R. M. Cushman, T. W. White, and J. D. Draves. 1990. Environmental atlas of the Iowa-Kansas-Missouri-Nebraska climate-change study region. ORNLCDIAC-3.3.

Anderson, T. A, and B. T. Walton. 1989. Microbial degradation of trichlorsethylene in rhizosphere and nonvegetated soils from a contaminated field site. Abstract. FOR Tenth Annual Meeting of the jociety of Environmental Toxicology and Chemistry, Toronto.

Arnalds, O., N. H. Cutshall, and G. A. Niclsen. 1989. Cesium-137 in Montana soils. Hcalth Phys. 57(6):955-958.

Ashwood, T. L., and G. K Eddlemon. 1989. Environmental and sccupational 
safety manual. U.S. Naval Sea Systems Command Detachment, Porsmouth, Virginia.

Baes, C. F., III. 1990. Reporting releases of hazardous substances under CERCLA and EPCRA: Information brief. EH 231/04-90. U.S. Department of Energy, Washington, D.C.

Baker. J. P., D. P. Bernard, S. W. Christensen, M. J. Sale, J. Freda, K Heltcher, D. Marmorek, L Rowe, P. Scanlon, G. Suter. W. Warren-Hicks, and P. Weltoum. 1990. Biological effects of changes in surface water acid-base chemistry. State-of-Science/Technology Report No. 13. National Acid Precipitauion Assexsment Program, Washington, D.C.

Baker, J. P., and S. W. Christensen. 1989. Models of biological response to changes in aquatic systems. Sect. 6. IN D. Renne (ed.), Models Planned for Use in the NAPAP Integrated Assessment. National Acid Precipitation Assessment Program, Washington, D.C.

Baker, J. P., W. Warren-Hicks, J. Gallagher, and S. W. Christensen. 1990. Historical changes in fish communities in Adirondack lakes. pp. 3-105-3-150. IN Adirondack Lakes Survey: An Interpretive Analysis of Fish Communities and Water Chemistry, 1984-1987. Adirondack Lakes Survey Corporation, Ray Brook, New York.

Barnthouse, L. W. 1990. Ecotechnology (book revicw). Ecology 71(2):411-412.

Barnthousc, L. W., G. W. Sutcr, and A. E. Rosen. 1990). Risks of toxic chemicals to exploitcd fish populations. Environ. Toxicol. Chem. 9(2):297-312.
Bittner, E, and R. B. Dreier. 1990. Core fracture analysis applied to groundwater flow systems: Chickamauga Group, Oa's Ridge, Tennessee. pp. 16-29. IN D. N. Bearce and M. J. Neilson (eds.), Case Studies in Applied Geology in the Southeastern United States. Georgia Geolcgic Survey Bulletin 122 . Georgia Department of Natural Resources.

Bogle, M. A 1990. A new species of Cladocarpus (Coelentrata: Hydroida: Plumulariidae) from the Straits of Florida. Proc. Biol. Soc. Wash. 103(1):229-234.

Brandt, C. C., R. S. Turner, D. L. Stevens, and D. D. Schmoyer. 1989. Aggregating pedon data to characterize mapped soils data on a regional scale. Abstract. p. 258. Agron. Abstr. American Society of Agronomy, Madison, Wisconsin.

Burris, J. A. M. S. Bamford, and A. J. Stewart. 1990. Behavioral responses of marked snails as indicators of in situ toxicity. Environ. Toxicol. Chem. 9:69-76.

Cada, G. F. 1990. Assessing fish mortality rates. Hydiro Rev. 9(1):52-60.

Cada, G. F. 1990. Effects of hydrnelectric turbine passage on fish early life stages. Abstract. FOR Annual Mecting of the American Fisheries Society, Pittsburgh.

Cada, G. F. i990. Effects of hydroelectric turbine passage on fish early life stages. Abstract. FOR 78th Annual Meeting of the Ecological Society of America, Snowbird, Utah.

Cada, G. F., and C. T. Hunsaker. 1990. Cumulative impacts of hydropower development: Rescarching a watershed in impact assessment. Environ. Prof. 12(1):2-8. 
Cada, G. F., and R. L Kroodsma (ESD contributors). 1990. Draft environmental assessment of the proposed sale of parcel $\mathbf{2} 2$ of the Oak Ridge Reservation to the City of Oak Ridge, Tennessee. U.S. Department of Energy, Oak Ridge, Tennessee.

Cada, G. F., and J. W. Webb (ESD contributors). 1990. Environmental assessment of the Pine Creek Hydroelectric Project, Rovanna, California. Federal Energy Regulatory Commission, Washington, D.C.

Cerling, T. E, S. J. Morrison, R. W. Sobocinski, and I. L Larsen. 1990. Sediment-water interaction in a small stream: Adsorption of ${ }^{137} \mathrm{Cs}$ by bed load sediment. Water Resour. Res. 26(6):1165-1176.

Cerling, T. E., B. L. Pederson, and K. L. Von Datnm. 1990. Comment and reply on "Sodium-calcium ion exchange in the weathering of shales: Implications for global weathering budgets." Geology 18:190-191.

Chang, L. H., and S. F. Railsback 1990. Predicting effects of global climate change on reservoir water quality and fish habitat. pp. 545-550. IN R. M. Khanbilvardi and T. C. Gooch (cds.), Optimizing the Resources for Water Management, Proceedings of the 17th Annual National Conference, Water Resources Planning and Management Division. American Society of Civil Engincers, Ncw York.

Chason, J. W., and M. A. Huston. 1990. A comparison of direct and indirect methuds for estimating leaf area index. Abstract. Bull. Ecol. Soc. Am. Suppl. 71(2):117.

Christensen, S. W., J. J. Beauchamp, J. A Shaakir-Ali, J. M. Coc, J. P. Baker, E. P.
Smith, and J. Gallagher. 1990. Patterns of fish distribution in relation to lake/watershed characteristics: Regression analyses and diagnostics. Appendix A. IN Adirondack Lakes Survey. An Interpretive Analysis of Fish Communities and Water Chemistry, 1984-1987.

Adirondack Lakes Survey Corporation, Ray Brook, New York

Christensen, S. W., K. H. Reckhow, J. J. Beauchamp, J. A Shaakir-Ali, J. M. Coe, J. P. Baker, E P. Smith, and J. Gallagher. 1990. Patterns of fish distribution in relation to lake/watershed characteristics. pp. 3-72-3-80. IN Adirondack Lakes Survey: An Interpretive Analysis of Fish Communities and Water Chemistry, 1984-1987. Adirondack Lakes Survey Corporation, Ray Brook, New York

Church, M. R., K W. Thornton, P. W. Shaffer, D. L. Stevens, B. P. Rochelle, G. R. Holdren, M. G. Johnson, J. J. Lee, R. S. Turner, D. L. Cassell, D. A Lammers, W. G. Campbell, C. I. Liff, C. C. Brandt, L. H. Liegel, C. D. Bishop, D. C. Mortenson, S. M. Pierson, and D. D. Schmoyer. 1990. Future effects of long-term sulfur deposition on surface water chemistry of the eastern U.S.: Result of the Direct/Delayed Response Project. Abstract. FOR International Conference on Acidic Deposition: Its Nature and Impacts, Glasgow, Scotland.

Clapp, R. B., and A. C. Lin. 1990. A surface-subsurface model applicable to hilly terrain underlaid by weathered shale. Abstract. FOR Third Tennessee Water Resources Symposium, American Water Resources Association, Nashville, Tennessec.

Cook, R. B., R. G. Kreis, Jr., J. C. Kingston, K. E. Camburn, S. A. Norton, M. J. Mitchell, B. Fry, and L. C. K Shane. 1990. Palcolimnology of McNearncy 
Lake: An acidic lake in northern Michigan. J. Paleolimnol. 3:13-34.

Costain, J. K., R. D. Hatcher, Jr., and C. Coruh. 1989. Appalachian ultradeep core hole $(\mathrm{ADCOH})$ project site investigation-Regional seismic lines and geologic interpretation. Plate 8. IN R. D. Hatcher, Jr., W. A Thomas, and G. W. Viele (eds.), The Appalachian-Ouachita Orogen in the United States. Geological Society of America, Boulder, Colorado.

Costain, J. K, R. D. Hatcher, Jr., C. Coruh, T. L. Pratt, S. R. Taylor, J. J. Litehiser, and I. Zietz. i989. Geophysical characteristics of the Appalachian crust. pp. 385-416. IN R. D. Hatcher, Jr., W. A. Thomas, and G. W. Viele (eds.), The Appalachian-Ouachita Orogen in the United States. Geological Society of America, Boulder, Colnrado.

Cowling, E. B., D. S. Shriner, R. J. Olson, and J. H. B. Garner. 1990 Regional variability in the chemical exposure of forests across eastern North America. Abstract. FOR 1990 International Conference, National Acid Precipitation Assessment Program, Acid Deposition: State of Science and Technology, Hilton Head, South Carolina.

Cushman, R. M., D. L. DeAngelis, W. R. Emanuel, M. P. Farrell, C. T. Hunsaker, A.W. King, and G. Marland (ESD contributors). 1990. Energy and Climate Change. Lewis Publishers, Chelsea, Massachusetts.

Cushman, R. M., and P. N. Spring. 1989. Differences among mode! simulations of climate change on tine scale of resoura regions. Environ. Manage. 13(6):789-795.

D.'ं, V.H 1489. Effects of management on plant recovery at Mount St. Helens.
Abstract. FOR 16th Annual Natural Areas Conference, Knoxville, Tennessee.

Dale, V. H. 1989. Potential effects of climate change on forests of western Oregon. Abstract. FOR Sixth Annual Acid Rain Conference for Southern Appalachia, Gatlinburg, Tennessee.

Dale, V. H., R. H. Gardner, and M. G. Turner. 1989. Predicting across scales: Comments of the guest editors of Landscape Ecology. Landscape Ecol. 3:147-151.

Davis, T. L, J. R. Tabor, and R. D. Hatcher, Jr. 1989. Orogen-parallel to orogen-oblique ductile deformation and possible Late Paleozoic(?) ductile deformation of the western Piedmont, southern Appalachians. Abstract. FOR Annual Meeting of the Geological Society of America, Boulder, Colorado.

Davis, T. L., J. R. Tabor, and R. D. Hatcher, Jr. 1990. Geologic mapping in the Columbus Promontory, western Piedmont: Polyphase development of a crystalline thrust complex Abstract. FOR Southeastern Section of the Geological Society of America, Boulder, Colorado.

DeAngelis, D. L 1989. Nutrient cycling. ìnnu. Rev. Ecol. Systemat. 20:71-95.

DeAngelis, D. L., S. M. Bartell, and A. L. Brenkert. 1989. Effects of nutrient recycling and food-chain length on resilience. Am. Nat. 134:778-805.

DeAngelis, D. L., and R. M. Cushman. 1990. Potential application of models in forccasting the effects of climate changes on fisheries. Trans. Am. Fish. Soc. 119:224-239.

Donoghue, J. F., O. P. Bricker, and C. P Olsen. 1989. Particle-rcactive 
radionuclides as tracers for sediment in the Susquehanna River and Chesapeake Bay. Estuarine Coastal Shelf Sci. 29:341-360.

Dreier, R. B., and T. O. Early. 1990. Groundwater flow system studies at the Oak Ridge Y-12 Plant using multiport monitoring systems installed in coreholes. Abstract. pp. 38-41. IN Extended Abstracts from Third Tennessee Water Resources Symposium. American Water Resources Association, Nashville, Tennessee.

Dreier, R. B., R. O. Kennard, and R. J. Selfridge. 1990. Geologic characterization of the Paducah Gaseous Diffusion Plant and surrounding area determined from geophysical logs. ORNL/TM-114j̄1

Dreier, R. B., and S. M. Koerber. 1990. Fault zone identification in the area surrounding the $Y-12$ Plant and its waste management areas: Preliminary investigation. Y/TS-656. Oak Ridge Y-12 Plant, Oak Ridge, Tennessee.

Dreier, R. B., and M. B. Leat. 1990. Fracture zone identification in the Appalachian fold and thrust belt determined from geophysical logs. pp. 355-369. IN R. Arora (ed.), Proceedings of the International Conference on Fluid Flow in Fractured Rocks, May 15-18, 1989. Center for Hydrogeology, Georgia State University, Atlanta.

Dreier, R. B., M. B. Leat, and S. M. Koerber. 1990. Geophysical log digitization: Status report. Y/TS-657. Oak Ridge Y-12 Plant, Oak Ridge, Tennessee.

Dreier, R. B., P. H. Pollard, and M. B. Leat. 1990. Core barn inventory: Status report. Y/TS-655. Oak Ridge Y-12 Plant, Oak Ridgc, Tennessce.
Dunnivant, F. M., P. M. Jardine, D. T. Taylor, and J. F. McCarthy. 1990.

Transport of dissolved crganic matter and polychlorinated biphenyls in soil columns. Abstract. FOR American Chemical Society, Boston.

Early, T. O., and J. W. Douthitt. 1990. Contaminant migration in groundwater at the Paducah Gaseous Diffusion Plant. Abstract. FOR Southeastem Section, Geological Society of America, Boulder, Colorado.

Eckert, J. O., R. D. Hatcher, Jr., ard D. W. Mohr. 1989. The Wayah granulite-facies metamorphic core, southwestem North Carolina: High-grade culmination of Taconic metamorphism in the southern Blue Ridge. Geol. Soc. Am. Bull. 101:1434-1447.

Eddlemon, G. K 1989. Assessing effects of radioactive effluents on a warmwaier fishery. Abstract. FOR The Scientific Challenges of NEPA, Oak Ridge National Laboratory, Cak Ridge, Tennessee.

Eddlemon, G. K 1990. Responding to ecological concerns of defense-related initiatives. Abstract. Bull. Ecol. Soc. Am. Suppl. 71(2):144-145.

Eddlemon, G. K, and V. R. Tolbert (ESD contributors). 1990. Demonstration of coal reburning for cyclone boiler $\mathrm{NO}_{x}$ control, Nelson Dewey Generating Station, Cassville, Wisconsin. DOE/EA-0406. U.S. Department of Energy, Washington, D.C.

Edwards, N. T. 1989. Pine necdle holders in gas exchange measurements. Tree Physiol. 5:507-509.

Edwards, N. T., G. E. Taylor, Jr., M. B. Adams, G. L. Simmons, and J. M. Kelly. 1990. Ozone, acidic rain and soil magncsium effects on growth and foliar 
pigments of Pinus taeda L Tree Physiol. 6:95-104.

Edwards, N. T., G. E Taylor, Jr., and A. L Friend. 19:99. Response of Pinus taeda L seedlings to tropospheric ozone, soil magnesium deficiency and rain chemistry. Abstract. FOR Sixth Annual Acid Rain Conference for the Southem Appalachians, Gatlinburg, Tennessee.

Edwards, N. T., G. E Taylor, Jr., and C. A. Gunderson. 1990. Growth and physiological responses of Pinus teeda $\mathrm{L}$ seedlings to rain chemistry, soil magnesium status, and tropospheric ozone. Abstract. Bull. Ecol. Soc. Am. Suppl. 71(2):145.

Elwood, J. W. 1989. Ecosystem research on Walker Branch watershed. Abstract. FOR International Mitteilungen des Symposiums Konzepte zur Okosystemforschung. Christian-Albrechts Universitat zu Kiel, Federal Republic of Germany.

Elwood, J. W. (contributor). 1990. Concepts and methods for assessing solute dynamics in stream ecosystems: Stream solute workshop. J. North Am. Benthol. Soc. 9(2):95-119.

Elwood, J. W., M. J. Sale, P. R. Kaufmann, and G. F. Cada. 1989. Effects of acidic deposition on the chemistry of streams, lakes, and reservoirs in the Southern Blue Ridge Province. Aostract. FOR Sixth Annual Acid Rain Conference for the Southern Appalachians, Gatlinburg, Tennessee.

Eng, W., and A V. Palumbo. 1990. Methanol suppression of trichlorethylene degradation by Methylosinus trichosporium and cultures. Abstract. FOR Twelfth Symposium on Biotechnology for Fucls and Chemicals, Gatlinburg, Tennessee.
Farrell, M. P., P. Kancinuk, and F. M. O'Hara, Jr. 1990. Global climate change and human health: Information needs and research priorities. pp. 317-334. IN J. C. White, W. Wagner, and C. N. Beal (eds.), Global Climate Change and Public Health. Elsevier Science Publishing, Amsterdam.

Feischhaver, H. L, and N. Korte. 1990. Formulation of cleanup standards for trace elements with probability plots. Environ. Manage. 14(1):95-105.

Foreman, J. L., W. M. Dunne, K R. Walker, and G. K. Jacobs. 1990 . Fluid chemistry and environmental conditions during vein formation in a foreland thrust sheet from the Southern Appalachians. Abstract. FOR Third Biennial Pan-American Conference on Research on Fluid Inclusions, Toronto.

Foreman, J. L, K R. Walker, and G. K. Jacobs. 1930. Deep burial fluid migration in the Upper Cambrian Nolichucky formation: Stable isotope and fluid inclusion evidence írom tectonic calcite veins. Abstract. FOR Southeastern Section of the Geological Society of America, Tuscaloosa, Alabama.

Fritz, W. J., R. D. Hatcher, Jr., and J. L Hopson (eds.). 1989. Geology of the eastern Blue Ridge of northeast Georgia and the adjacent Carolinas. Georgia Geological Society, Georgia State University, Atlanta.

Gardner, R. H., V. H. Dale, and R. V. O'Neill. 1990. Error propagation and uncertainty in process modeling. pp. 208-219. IN R. K. Dixon, R. S. Meldahi, G. A Ruark, and W. G. Warren (eds.), Forest Growth Responses to Environmental Stress. Timber Press, Pr:tland, Oregon. 
Gardner, R. H., J.-P. Hettelingh, J. Kamari, and S. M. Bartell. 1990. Estimating the reliability of regional predictions of aquatic effects of acid deposition. Pp. 185-207. IN J. Kamari (ed.), Impact Models to Assess Regional Acidification. Kluwer Academic Publishers, London.

Gardner, R. H., R. V. O'Neill, M. G. Turner, and V. H. Dale. 1989. Quantifying scale-dependent effects of animal movement with simple percolation models. Landscape Ecol. 3(3):217-227.

Garten, C. T., Jr. 1990. Foliar leaching, translocation, and biogenic emission of ${ }^{35} \mathrm{~S}$ in radiolabeled loblolly pines. Ecology 71(1):239-251.

Garten, C. T., Jr. 1990. Multispecies method of testing for toxicity: Use of the rhizobium-legume symbiosis in nitrogen fixation and correlations between responses by algae and terrestrial plants. pp. 69-84. IN W. Wang, J. W. Gorsuch, and W. R. Lower (eds.), Plants for Toxicity Assessment. ASTM STP 1091. American Society for Testing and Materials, Philadelphia.

GarteI, C. T., Jr., and P. J. Hanson. 1990. Foliar retention of ${ }^{15} \mathrm{~N}$-nitrate and

${ }^{15} \mathrm{~N}$-ammonium by red maple (Acer nubrum) and white oak (Quercus alba) leaves from simulated rain. Environ. Exp. Bot. 30(3):333-342.

Graham, R. L., S. M. Berta, J. A. Harrington, Jr., P. W. Mauscl, and C. O. Justice. 1990. Satellite imagery analysis of deforestation in closed forests of equatorial Africa. Abstract. Bull. Ecol. Soc. Am. Suppl. 71(2):72.

Graham, R. L, M. G. Turner, and V. H. Dalc. 1989. $\mathrm{CO}_{2}$-induced climate change and forest resources. pp. 233-241. IN
R. D. Noble, J. L Martin, and K. F. Jensen (eds.), Air Pollution Effects on Vegetation. USDA Forest Service, Northeastern Forest Experiment Station, Broomall, Pennsylvania.

Graham, R. L. M. G. Turner, and V. H. Dale. 1989. The greenhouse effect and forests: A spatial and temporal perspective. Abstract. FOR Sixth Annual Acid Rain Conference for Southern Appalachia, Gatlinburg, Tennessee.

Graham, R. L., M. G. Turner, and V. H. Dale. 1990. Increasing $\mathrm{CO}_{2}$ and climate change: Effects on forests. BioScience 40(8):575-587.

Greeley, M. S., S. M. Adams, B. D. Jimenez, J. F. McCarthy, and L R. Shugart (ESD contributors). 1989. Assessing effects of chronic exposure to mixed industrial effluents on fish production. Abstract. FOR Annual Meeting of the Society for Environmental Toxicology and Chemistry, Toronto.

Greibmeier, J. M., C. R. Olsen, and I. L. Larsen. 1990. A radionuclide tracer is used to identify potential contamination zones on the Alaskan shelf in response to the Exxon Valdez oil spill. Abstract. EOS Am. Geophys. Union 71:72.

Gunderson, C. A and G. E. Taylor. 1990. Physiolcgical site of ozone effects on $\mathrm{CO}_{2}$ assimilation in Glycine max. Plant Physiol. Suppl. 93:103.

Haase, C. S. 1990. Application of water chemistry to identification of groundwater flow paths in Bear Creek Valley near Oak Ridge, Tennessec. Abstract. FOR Third Tennessee Water Resources Symposium, American Water Resources Association, Nashville, Tennessee. 
Halbert, B. E, D. B. Chambers, V. J. Cassaday, and F. O. Hoffman. 1990. Environmental assessment modelling. pp. 345-390. IN Part 3: Impact on Man, The Environmental Behavior of Radium. IAEASTI/DOC/10/310 ( Vol. 2). International Alomic Energy Agency, Vienna.

Hanson, P. J., and S. B. McLaughlin. 1990. Continuous gas exchange measurements using individual fascicle cuvettes: The "tubule" system. pp. 143-147. IN H. D. Payer, T. Pfirmann, and P. Mathy (eds.), Environmental Research with Plants in Closed Chambers. Air Pollution Reports Series. Commission of the European Community.

Hanson, P. J., S. B. McLaughlin, and C. T. Garten, Jr. 1990. Application of artificial rain in experimental systems: Methods, results of case studies, and future needs. IN H. D. Payer, T. Pfirmann, and P. Mathy (eds.), Environmental Research with Plants in Closed Chambers. Air Pollution Reports Series. Commission of the European Community.

Hanson, P. J., and R. J. Norby. 1990. The impact of early morning elevated $\mathrm{CO}_{2}$ on foliar carbon gain. Abstract. Plant Physiol. Suppl. 93:56.

Hanson, P. J., R. J. Norby, G. E Taylor, and S. E Lindberg. 1989. Deposition and assimilation of reactive nitrogen gases to forest canopies. Abstract. FOR International Congress on Forest Decline Research, Fricdrichshafen, Federal Republic of Germany.

Hanson, P. J., K Rott, G. E. Taylor, Jr., C. A. Gunderson, S. E. Lindberg, and B. M. Ross-Todd. 1989. $\mathrm{NO}_{2}$ deposition to forest landscape surfaces. Atmos. Environ. 23:1783-1794.
Hanson, P. J., and G. E. Taylor, Jr. 1990. Modeling pollutant gas uptake by leaves: An approach based on physicochemical properties. pp. 351-356. IN R. Dixon, R. Meldahl, G. Ruark, and W. G. Warren (eds.), Process Modeling of Forest Growth Responses to Environmental Stress. Timber Press, Portland, Oregon.

Hatcher, R. D., Jr. 1989. Appalachians introduction. pp. 1-6. IN R. D. Hatcher, Jr., W. A. Thomas, and G. W. Viele (eds.), The Appalachian-Ouachita Orogen in the United States. Geological Society of America, Boulder, Colorado.

Hatcher, R. D., Jr. 1989. Ultradeep continental drilling. pp. 89-92 IN D. James (ed.), Encyclopedia of Solid Earth Geophysics. Van Nostrand Reinhold, New York.

Hatcher, R. D., Jr. 1990. The Alleghanian: A diachronous, transpressional collisional event. Abstract. FOR Northeastern Section of the Geological Society of America, Boulder, Colorado.

Hatcher, R. D., Jr. 1990. Structural Geology: Principles, Concepts and Problems. Macmillan, New York.

Hatcher, R. D., Jr., and R. J. Hooper. 1990. Laboratory Manual for Structural Geology. Macmillan, New York

Hatcher, R. D., Jr., P. H. Osberg, A A Drake, Jr., P. Robinson, and W. A Thomas. 1989. Tectonic map of the U.S. Appalachians. Plate 1. IN R. D. Hatcher, Jr., W. A. Thomas, and G. W. Viele (eds.), The Appalachian-Ouachita Orogen in the United States. Geological Society of America, Boulder, Colorado.

Hatcher, R. D., Jr., and J. R. Tabor. 1989. Orogen-parallel coaxial mineral lincations 
and folds-Products of buckling and passive folding in coaxial and noncoaxial flow. Abstract. FOR Annual Meeting of the Geological Society of America, Boulder, Colorado.

Hatcher, R. D., Jr., and W. A Thomas (eds.). 1990. GSA centennial articles from volume 100 of the GSA Bulletin. Special Paper 253. Geological Society of America, Boulder, Colorado.

Hatcher, R. D., Jr., W. A Thomas, P. A. Geiser, A. W. Snoke, S. Mosher, and D. V. Wiltschko. 1989. Alleghanian orogen. pp. 233-318. IN R. D. Hatcher, Jr., W. A Thomas, and G. W. Viele (eds.), The Appalachian-Ouachita Orogen in the United States. Geological Society of America, Boulder, Colorado.

Hatcher, R. D., Jr., W. A Thomas, and J. E. Thyfault. 1990. The Geological Society of America Bulletin: 100 volumes of a scientific journal. Libr. Acquis. Pract. Theory 14:23-30.

Hatcher, R. D., Jr., W. A Thomas, and G. W. Viele (eds.). 1989. The Appalachian-Ouachita orogen in the United States. Geological Society of America, Boulder, Colorado.

Heckman, C. G., G. F. Cada, and K J. Brown. 1990. Evaluation of NEPA appraisal forms and memorandums-to-file: Final report. U.S. Department of Energy, Washington, D.C.

Hettelingh, J.-P., R. H. Gardner, K A Rose, and A. L. Brenkert. 1989.

Broad-scale effects of sulfur deposition: A response surface analysis of a complex model. pp. 266-277. IN J. Kamari, D. F. Brakke, A Jenkins, S. A Norton, and R. F. Wright (edr), Regional Acidification Models: Gcographic Extent and Time Development. Springer-Verlag, Berlin.
Hicks, B. B., D. R. Matt, R. T. McMillen, J. D. Womack, M. L Wesely, R. L Hart, D. R. Cook, S. E Lindberg, R. G. de Pena, and D. W. Thomson. 1989. A field investigation of sulfate fluxes to a deciduous forest. J. Geophys. Res. 94:13003-130011.

Hoffman, F. O., and E Amaral 1989. The use of Chernobyl fallout to test model predictions of the transfer of radioiodine from air to vegetation to milk. pp. 129-153. IN C. Leising and E Wirth (eds.), Experiences with Radioecological Assessment Model, Comparisons Between Predictions and Observations. ISH-Heft 128. Institut fur Strahlenhygiene, Bundesgesundheitsamt, Neuherberg, Federal Republic of Germany.

Hoffman, F. O., and E. Hofer (eds). 1989. Evaluating the reliability of predictions using environmental transfer models. International Atomic Energy Agency, Vienna.

Hoffman, F. O., I. L. Larsen, M. L Frank, B. G. Blaylock, and C. R. Olsen. 1989. The use of Chernobyl fallout to quantify the transfer of submicron aerosols from rain to vegetation and test natural $\mathrm{Be}-7$ as an environmental tracer. pp. 124-128. IN C. Leising and E. Wirth (eds.), Experiences with Radioecological Assessment Models, Comparisons Between Predictions and Observations. ISH-Heft 128. Institut fur Strahlenhygiene, Bundesgesundheitsamt, Neuhcrberg. Federal Republic of Germany.

Hooper, R. J., and R. D. Hatcher, Jr. 1989. Nature and origin of phyllonites from the Dean Crcek fault, Avalon-Piedmont terrane boundary, central Gcorgia. p. 64. Abstract. IN Annual Mecting of the Gcological Society of America, Boulder, Colorado. 
Hooper, R. J., and R. D. Hatcher, Jr. 1989. The origin of ultramafic rocks from the Berner mafic complex, Carolina terrane, central Georgia. Geol. Suc. Am. Bull. 231:87-92.

Hooper, R. J., and R. D. Hatcher, Jr. 1990. The Ocmulgee fault: The Piedmont-Avalon terrane boundary in central Georgia. Geology 18:708-711.

Hopson, J. L., R. D. Hatcher, Jr., and A. L Stieve. 1989. Geology of the eastern Blue Ridge of northeastern Georgia and the adjacent Carolinas. pp. 1-40. IN W. J. Fritz, R. D. Hatcher, $\mathrm{Jr}_{\text {., }}$ and J. L. Hopson (eds.), Geology of the Eastern Blue Ridge of Northeast Georgia and the Adjacent Carolinas. Georgia Geological Society, Georgia State University, Atlanta.

Houlberg, L M., M. E Langston, A. Nikbakht, and M. S. Salk. 1989. Environmental regulatory update table. ORNL-6526/R8-R11.

Houlberg. L M., M. E. Langston, A Nikbakht, and M. S. Salk. 1989.

Environmental regulatory update table. ORNL-6608 and ORNL-6608/R1-R3.

Houlberg, L M., A. Nikbakht, and M. S. Salk. 1990. Environmental regulatory update table. ORNL-6608/R4-R7.

Hunsaker, C. T. 1989. Regional water quality assessment methods for aquatic ecosystems. Abstract. FOR Annual Conference of the Water Pollution Control Feduration, Washington, D.C.

Hunsaker, C. T. 1990. Ecosystem assessment methods for cumulative effects at regional and global scales. Abstract. FOR Ninth Oak Ridge National Laboratory Life Sciences Symposium, Oak Ridge. Truncssce.
Hunsaker, C. T., and D. E Carpenter (eds.). 1990. Ecological indicators for the Envirunmental Monitoring and Assessment Program. EPA-600/3-90-060. U.S. Environmental Protection Agency, Research Triangle Park, North Carolina.

Hunsaker, C. T., and D. E Carpenter. 1990. Indicators of regional ecological health. Abstract. Bull. Ecol. Soc. Am. Suppl. 71(2):195.

Hunsaker, C. T., D. E Carpenter, and J. Messer. 1990. Ecological indicators for regional monitoring. Bull. Ecol. Soc. Am. 71(3):165-172.

Hunsaker, C. T., R. L. Graham, G. W. Suter II, R. V. O'Neill, L W. Barnthouse, and R. H. Gardner. 1990. Assessing ecological risk on a regional scale. Environ. Manage. 14(3):325-332.

Hunsaker, C. T., B. L Jackson, S. Timmins, and D. A. Levine. 1990. Relationships between landscape structure and water quality. Abstract. pp. 36-37. IN The Role of Landscape Ecology in Public-Policy Making. U.S. Association of the International Association of Landscape Ecology and Land Management, Oxford, Ohio.

Hunsaker, D. B., C. R. Boston, E L Hillsman, R. O. Johnson, R. L Kroodsma, R. L. Miller, L W. Rickert, G. O. Rogers, G. M. Schocple, W. P. Staub, V. R. Tolbert, D. C. West, and G. P. Zimmerman. 1990. Disposal of chemical agents and munitions stored at Anniston Army Depot, Anniston, Alabama-Final phase I environmental report.

ORNLTM-11206.

Hunsaker, D. B., Jr., R. B. McLcan, W. M. Willis, G. F. Cada. E. J. Licbsch, R. L. Graham, C. T. Garten, C. T. Hunsaker, and $\mathrm{A}$ W. Campbell. 190. Assessing the 
potential environmental impacts of proposed rules affecting future electric power generation in the United States. ORNL/TM-11301.

Huston, M. A, and J. Chason. 1990. Mortality of tulip poplar saplings during a severe drought on Walker Branch Watershed. Abstract. Bull. Ecol. Soc. Am. Suppl. 71(2):197.

Jacobs, G. K, and P. M. Jardine. 1990. Soil-contaminant-water interactions: Controls on contaminant release and transport. Abstract. IN Subsurface Science Program Overview and Research Abstracts. DOE/ER-0432. U.S. Department of Energy, Washington, D.C.

Jager, H. I., T.-H. Peng, A W. King, and M. J. Sale. 1990. Documentation and analysis of a global $\mathrm{CO}_{2}$ model developed by Peng et al. (1983). ORNL/CDIAC-38.

Jager, H. I., M. J. Sale, and R. L. Schmoyer. 1990. Cokriging to assess regional stream quality in the Southern Blue Ridge Province. Water Resour. Res. 26(7):1401-1412.

Jardine, P. M. 1989. Modeling the kinetics of inorganic reactions in soil. Abstract. p. 201. Agron. Abstr.

American Society of Agronomy, Madison, Wisconsin.

Jardine, P. M., and G. K Jacobs. 1990. Unsaturated transport of inorganic cations in undisturbed soil columns. Abstract. FOR Radionuclide Adsorption Workshop, Los Alamos National Laboratory, Los Alamos, New Mexicc.

Jardine, P. M., G. V. Wilson, and R. J. Luxmox)re. 1990. Unsaturated solute transport through a forest soil during storm events. Geoderma 46:103-118.
Jardine, P. M., G. V. Willson, J. F. McCarthy, R. J. Luemoore, and D. L. Taylor. 1990. Hydrogeochemical processes controlling the transport of dissolved organic carbon through a forested hillslope. J. Contam. Hydrol. $6(1): 3-19$.

Jardine, P. M, G. V. Wilson, J. F. McCarthy, R. J. Luxmoore, D. L Taybor, and L W. Zelazny. 1990.

Hydrogeochemical processes controlling transport of dissolved organic carbon through a forested hillslope. EOS 71:503.

Kearl, P. M., R. J. Zinkl, J. J. Dexter, and T. Cronk 1990. Air permeability measurements of the unsaturated Bandelier Tuff near Los Alamos, New Mexico. J. Hydrol. 117:225-240.

Kennel, S. J., R. G. Epler, T. K. Lankford, L. J. Foote, V. Dickas, M. Canamucio, R. Cavalierie, M. Cosimelli, I. Venturo, R. Falcioni, and A Sacchi. 1990. Second generation monoclonal antibodies to the human integrin $a^{6} \mathrm{~B}_{4}$. Hybridoma 9:243-255.

King, A W., W. R. Emanuel, and W. M. Post. 1990. Terrestrial ecosystems as a historical sink for atmospheric carbon. Abstract. Buil. Ecol. Soc. Am. Suppl. 71(2):212.

King, A W., and M. J. Sale. 1990. A plan for intermodel comparison of atmosnheric $\mathrm{CO}_{2}$ projections with uncertainty analysis. ORNLCDLAC-32.

King, H. L, and C. S. Haase. 1990. The occurrence and characterization of dense nonaqueous phase liquids in Bear Creck Valley near Oak Ridge, Tennessee. Abstract. FOR Third Tennessee Water Resources Symposium, American Watcr Resources Association, Nashville, Tennessee. 
Korte, N. E, and P. M. Kearl. 1990. Plume management-An inexpensive long-term strategy for gmundwater contamination at low-risk sites. Waste Manage Res. 8:246-248.

Korte, N. E, P. M. Kearl, and D. Smuin. 1989. State-o:-the-art approach to hazardous waste site characterizations. Environ. Manage. 13(6):677-684.

Kroodsma, R. L, and G. F. Cada (ESD contributors). 1990. Environmental assessment for the Corrosion Control Facility, Kelly Air Force Base, Texas. Air Force Logistics Command, WrightPatterson Air Force Base, Ohio.

Kroudsma, R. L, G. K. Eddlemon, and V. R. Tolbert (ESD contributors). 1990. Environmental assessment for demonstration of coal rebuming for cyclone boiler $\mathrm{NO}_{z}$ control.

DOE/EA-0440. U.S. Department of Energy, Washington, D.C.

Kszos, L A, and M. L Holtz 1989. Life table evalua!ion of chronic exposure of Ceriadaphnia dubia to calcium and magnesium sulfate. Abstract. FOR Society of Environmental Toxicology and Chcmistry, Toronto.

Layton, P. A, L L Wright, T. W. Doyle, J. W. Ranney, J. H. Cushman, J. W. Johnston, and A. F. Turhollow. 1990. Accelerating energy crop growth via genetic techniques. IN Energy from Diomass and Wastes XIII. Institute of Gas Technology, Chicago.

Lee, S. Y., D. H. Philiips, J. T. Ammons, and D. A Lictzke. 1990. A microscopic study of iron and manganesc oxide distribution in soils from East Tennessec (U.S.A). pp. 511-517. IN L A. Douglas (cd.), Soil Micromorphology: A Basic and Applied Science. Elscvicr, Amsterdam.
Lemiszki, P. J, and R. D. Hatcher, Jr. 1990. Contrasting structural geometries between the Whitcoak Mountain and Copper Creek thrust faults, Bethel Valley quadrangle, East Tennessee. Abstract. Southeastern Section, Geological Society of America, Boulder, Colorado.

Levine, M. B, C. F. Sigmon, G. K Eddlemon, and R. A. Barringer. 1990. Environmental compliance assessment findings for Naval Petroleum Reserve No. 3 and Naval Oil Shale Reserve No. 3. ORNLM-1171.

Levine, M. B, E D. Smith, F. E Sharples, and G. K. Eddlemon. 1990. Integrating NEPA and CERCLA requirements during remedial responses at DOE facilities. ORNL/TM-11564.

Liebert, C., T. Barkay, R. R. Turner, and N. Bloom. 1990. Acclimation to $\mathrm{CH}_{3} \mathrm{Hg}^{+}$ and $\mathrm{Hg}^{2+}$ of aquatic microbial communities from a mercury-polluted pond. Abstract. p. 328. IN Annual Meeting of the American Society for Microbiology, Anaheim, Califomia.

Lindberg, S. E 1990. 1990 annual report of the NADP. U.S. Department of Agriculture, Washington, D.C.

Lindberg, S. E., M. Bredemeier, D. A Schaefer, and L. Qi. 1990. Atmospheric cuncentrations and deposition of nitrogen compounds and major ions during the growing season in conifer forests in the United States and West Germany. Atmos. Environ. 24A:2207-2220.

Lindberg. S. E., D. W. Johnson, G. M. Lovett, G. E. Taylor, H. Van Miegroet, and J. G. Owens. 1989. Sampling and analysis protocols and project description for the Integrated Forest Study. ORNLTM-11214. 
Lindberg, S. E, and J. G. Owens. 1990. Precipitation chemistry and atmospheric deposition in Oak Ridge, Tennessee. IN G. Likens (ed.), MAP3S 10-Year Summary Report. U.S. Department of Energy, Washington, D.C.

Lindberg, S. E, A. L. Page, and S. Norton (eds.). 1990. Acidic Precipitation, Vol. 3: Sources, Deposition, and Canopy Interactions. Advances in Environmental Sciences Series. Springer-Verlag, New York

Liu, A, and R. D. Hatcher, Jr. 1989. Exotic rocks in the Brevard fault zone and Chauga belt. Abstract. FOR Annual Meeting of the Gcological Society of America, Boulder, Colorado.

Loar, J. M., S. M. Adams, L J. Allison, J. M. Giddings, J. F. McCarthy, G. R. Southworth, J. G. Smith, and A. J. Stewart 1989. The Oak Ridge Y-12 Plant Biological Monitoring and Abatement Program for East Fork Poplar Creek. ORNLTM-1M265.

Luxmoore, R. J., P. M. Jardine, G. V. Wilson, J. R. Jones, and L. W. Zelazny. 1990. Physical and chemical controls of prepared path flow through a forested hillslope. Geoderma 46:139-154.

Luxmoore, R. J., and J. G. Saldarriaga. 1989. PAR conversion efficiencies of a tropical rainforest. Ann. Sci. For. 46(Suppl.):523-525.

Luxmoore, R. J., M. L. Tharp, and D. C. West. 1990. Simulating the fhysiological basis of tree ring responses to environmental changes. pp. 393-401. IN R. K. Dixon, R. S. Meldahl, G. A. Ruark, and W. G. Warren (cds.), Process Modeling of Forest Growth Responses (o) Environmental Stress. Timber Press, Portland, Orcgon.
Luxmoore, R. J., G. V. Wilson, P. M. Jardine, and R. H. Gardncr. 1990. Use of percolation theory and Latin hypercube sampling in field-scale solute transport investigations. Pp. 437-439. IN B.-Q. Lin (ed.), Forest Soils and Modem Forest Management. Northeast Forest University, Harbin, China.

Mann, L K, V. H. Dale, R. J. Olson, D. W. Johnson, and K. C. Dearstone. 1989. Spatial patterns of tree mortality and site characteristics on Walker Branch Watershed Abstract. FOR Annual Meeting of the American Society of Agronomy, Madison, Wisconsin.

McCarthy, J. F., S. M. Adams, B. D. Jimene, M. S. Greeley, G. W. Suter, and L. R. Shugart. 1989. Biomarkers on environmental contamination. Abstract. FOR Annual Meeting of the Society for Environmental Toxicology and Chemistry, Toronto.

McCarthy, J. F., F. M. Dunnivant, and P. M. Jardine. 1990. Mobile organic colloids enhance transport of contaminants in porous media. Abstract. EOS 71:503.

McCarthy, J. F., D. N. Jacobson, L R. Shugart, and B. D. Jimenez. 1989. Pre-exposure to 3-methylcholanthrene increases benzo(a)pyrene adducts on DNA of bluegill sunfish. Mar. Environ. Res. 28:323-328.

McCarthy, J. F., B. D. Jimenez, L R. Shugart, F. V. Sloop, and A. Oikari. 1989. Biological markers in animal sentinels: Laboratory studies improve interpretation of field data. IN S. Sandhu (ed.), In Situ Evaluation of Biological Hazards. Plenum Press, New York.

McCarthy, J. F., L. E. Roberson, and L. W. Burns. 1989. Association of benzo(a)pyrene with dissolved organic 
matter: Prediction of $\mathbf{K}_{\text {dom }}$ from structural and chemical properties of the organic matter. Chemosphere 19:1911-1920.

McLaughlin, S. B., C. P. Andersen, N. T. Etwards, W. K. Roy, and P. A. Layton. 1990. Seasonal patterns of photosynthesis and respiration of red spruce saplings from two elevations in declining : Juthem Appalachian stands. Can. J. For. Res. 20:485-495.

McLaughlin, S. B., C. P. Andersen, N. T. Edwards, W. K. Roy, and P. A. Layton. 1990. Seasonal patterns of photosynthesis and respiration of red spruce saplings from two elevations in declining southern Appalachian stands. Poster abstract. FOR International Meeting on Forest Decline, October 2-6, 1989, Friedrickshafen, Federal Republic of Germany.

McLaughlin, S. B., C. P. Andersen, N. T. Edwards, W. K Roy, and P. A. Layton. 1990. Seasonal patterns of photosynthesis and respiration of red spruce saplings from two elevations in declining southern Appalachian stands. Poster abstract. FOR NAPAP International Mecting on Acid Deposition, February 12-16, 1990, Hilton Head, South Carolina.

Meyers-Schome, L., L. R. Shugart, and B. T. Walton. 1989. Comparison of two turtle species as indicators of contamination in freshwater ecosystems at hazardous waste sites. Abstract. FOR Symposium on In Situ Ecological Assessment of Hazardous Waste Sites, Tenth Annual Meeting of the Society for Environmental Toxicolngy and Chemistry, Toronto.

Mulhclland. P. J. 1990. Regulation of stream phosphorus concentration at hasenow: Groundwater inputs versus within-stream processes. Abstract. Bull. North Am. Benthol. Soc. 7:112

Mulholland, P. J., C. N. Dahm, M. B. David, D. M. DiToro, T. R. Fisher, H. F. Hemond, I. Kogel-Krabner, M. H. Meybeck, J. L. Meyer, and J. R. Sedell. 1990. What are the temporal and spatial variations of organic aids at the ecosystem level? pp. 315-329. IN E M. Perdue and E T. Gjessing (eds.), Organic Acids in Aquatic Ecosystems. John Wiley and Sons, Chichester, England.

Mulholland, P. J., C. T. Garten, and L. W. Cooper. 1990. Regulation of nitrogen in Walker Branch: Effects of riparian and within-stream processes. Abstract. Bull. Ecol. Soc. Am. Suppl. 71(2):264.

Niedzielski, J. J., T. J. Phelps, R M. Schram, S. E Herbes, and D. C. White. 1990. Biodegradation of trichloroethylene in continuous-recycle expanded-bed bioreactors. Appl. Environ. Microbiol. 56:1702-1709.

Niedzielski, J. I., R. M. Schram, T. J. Phelps, S. E. Herbes, and D. C. White. 1989. A total-recycle expanded-bed bioreactor design which allows direct headspace sampling of volatile chlorinated aliphatic compounds. J. Microbiol. Methods 10:215-223.

Norby, R. J., M. Cockrill, and E. G. O'Neill. 1990. Elevated $\mathrm{CO}_{2}$ does not delay leaf senescence in white oak or yellow-poplar seedlings in the field. Plant Physiol. Suppl. 93:102.

Norby, R. J., T. J. Tschaplinski, and D. W. Johnson. 1989. Foliar indicators of optimum nitrogen nutrition in shortrotation sycamorc. Abstract. p. 309. Agron. Abstr. American Socicty of Agronomy, Madison, Wisconsin. 
Norton, S., S. E. Lindberg, and A. L Page (eds.). 1990. Acidic Precipitation, Vol. 4: Soils, Aquatic Processes, and Lake Acidification. Advances in Environmental Sciences Series. Springer-Verlag, New York.

Odum, E. P., and M. G. Turner. 1990. The Georgia landscape: A changing resource. pp. 137-164. IN I. S. Zonneveld and R. T. T. Forman (eds.), Changing Landscapes: An Ecological Perspective. Springer-Verlag, New York.

Olsen, C. R., R. B. Cook, D. K. Solomon, I. L Larsen, L W. Cooper, and J. W. Grebmeier. 1990. Use of natural radionuclide and isotopic tracers to quantify the chemical interactions of soils and runoff during storm and snowmelt events. Abstract. EOS Trans. Am. Geophys. Union 70:1126.

Olsen, C. R., I. L Larsen, P. D. Lowry, C. R. Moriones, C. J. Ford, K. C. Dearstone, R. R. Turner, and B. L. Kimmel. 1990. Transpor: and accumulation of cesium-137 and mercury in the Clinch River and Watts Bar Reservoir System. ORNL/ER-7.

Olsen, C. R., M. Thein, I. L Larsen, P. D. Lowry, P. J. Mulholland, N. H. Cutshall, J. T. Byrd, and H. L Windom. 1989. Plutonium, lead-210, and carbon isotopes in the Savannah River. Environ. Sci. Technol. 23(12):1475-1481.

O'Neill, R. V., A R. Johnson, and A W. King. 1989. A hicrarchical framework for analysis of scale. Landscape Ecol. 3:193-205.

Packard, J., A. Brecn, G. S. Sayler, and A. V. Palumbo. 1989. Monitoring populations of 4-chlorobiphenyl-degrading hacteria in soil and lake water microcosm. using colony hybridization. Abstract. FOR Superfund 89, Washington, D.C.

Packard, J., A. Breen, G. S. Sayler, and A. V. Palumbo. 1990. Monitoring populations of 4-chlorobiphenyt-degrading bacteria in soil and lake water microcosms using colony hybridization. IN

Biotreatmeni: The Use of Microorganisms in the Treatment of Hazardous Materials and Hazardous Wastes, Proceedings of the Secona National Conference. Hazardous Materials Control Research Institute, Silver Spring, Maryland.

Palumbo, A. V., W. Eng, and G. W. Strandberg, 1990. Biodegradation kinetics of mixed chlorinated ethenes by Methylosinus trichosporium. Abstract. FOR Annual Meeting of the American Society for Microbiology, Washington, D.C.

Palumbo, A. V., B. R. Zaidi, P. M. Jardine, and J. F. McCarthy. 1990. Characterization and bioavailability of dissolved organic carbon: Comparison of deep subsurface and surface waters. IN Proceedings of the First International Symposium on Microbiology of the Deep Subsurface, Orlando, Florida.

Parr, P. D., F. Au, D. Burns, R. Chesser, W. Conley, M. Cunningham, T. Foxx, J. Jastrow, P. Kennedy, L. Mann, J. Paulk, T. Reynolds, and W. Rickard. 1990. Park Net: A network of National Environmental Research Parks. Bull. Ecol. Sox. Am. 71(2):279.

Parr, P. D., and M. Cunningham. 1990. Habitat manipulation: The effect on a declining rare plant population. Assoc. Southeastern Biol. 37(2):85,

Peng, T.-H., W. M. Post, D. L. DeAngelis, V. H. Daic, and M. P. Farrell. 1990. Atmospheric carbon dioxide and the giobal 
carbon cycle: The key uncertainties. pp. 17-38. IN T. NeJat Veziroglu (ed.), Environmental Problems and Solutions. Hemisphere Publishing Corporation, New York

Post, W. M. 1990. Report of a workshop on climate feedbacks and the role of peatlands, tundra, and boreal ecosystems in the global carbon cycle. ORNL/TM-11457.

Posk, W. M., and L K. Mann. 1990. Changes in soil organic carton and nitrogen as a result of cultivation. pp. 401-406. IN A. F. Bowman (ed.), Soils and the Greenhouse Effect. Wiley, New York.

Post, W. M., and J. Pastor. 1990. Climate change and forest ecosystem response. pp. 61-74. IN L. Wensel and G. Biging (eds.), Forest Simulation Systems:

Proceedings of the IUFRO Conference, Berkeley, California, November 2-5, 1988. University of California, Berkeley.

Post, W. M., T-H. Peng, W. R. Emanuel, A. W. King, V. H. Dale, and D. L DeAngelis. 1990. The global carbon cycle. Am. Sci. 78(4):310-326.

Quinn, M. J., and R. D. Hatcher, Jr. 1990. Structural, stratigraphic, and petrologic dissimilarities across the Hayesville fault in western North Carolina: Preliminary report. Abstract. Southeastern Section of the Geological Society of America, Boulder, Colorado.

Railsback, S. F., J. M. Bownds, M. J. Sale, M. M. Stevens, and G. H. Taylor. 1990. Aeration at navigation dams in the upper Ohio River Basin. J. Envirun. Eng. 116(2):361-375.

Railsback, S. F., C. C. Coutant. and M. J. Sale. 1990. Improving the effectiveness of fisheries agencies in developing hydropowsr mitigation. Fisheries $15(3)=3-8$.

Railsback, S. F., and M. J. Sale. 1990. Application of optimized water quality mitigation to hydropower development in the Ohio River Basin. pp. 413-422 IN S. P. Simonovic et al. (eds.), Water Resource System Application. Universily of Manitoba, Winnipeg, Canada.

Reed, R. M., R. L Kroodsma, and L. D. Voorhees (ESD contributors). 1990. Final environmental impact assessment, Starlab Program. U.S. Air Force, Los Angeles.

Reed, R. M., R. L Kroodsma, and L D. Voorhees (ESD contributors). 1990. Environmental review, Starlab Site on Antigua. U.S. Air Force, Los Angeles.

Reed, R. M., R. L Kroodsma, and L. D. Voorhees (ESD contributors). 1990. Environmental review, Starlab Site on Ascension Island. U.S. Air Force, Los Angeles.

Reed, R. M., G. Marland, S. F. Railsback, M. S. Salk, J. A. Watts, and J. W. Webb (ESD contributors). 1989. Clean Coal Technology Demonstration Program: Final programmatic environmental impact statement. DOE/EIS-0146. U.S. Department of Energy, Washington, D.C.

Rose, K A 1989. Book review: Taxic Contaminants and Ecosystem Health: $A$ Great Lakes Focus. J. Environ. Qual. 18:556.

Rose, K A, R. B. Cook, A L Brenkhert, and R. H. Gardner. 1990. Comparative uncertainty analysis of the ILWAS, MAGIC, and ETD watershed acidification models. Abstract. FOR 1990 International Conference, National Acid 
Precipitation Assessment Program. Hilton Head, South Carolina.

Ryan, P. F., D. S. Schmoyer, C. C. Brandt, and R. S. Turnei. 1990. Parameter uncertainty in predicting regional changes in lake acid neutralizing capacity. How important is weathering rate? International Conference on Acidic Deposition: Its Nature and Impacts, Glasgow, Scotland.

Ryan, P. F., R. S. Turner, T. J. Sullivan, D. L Marmorek, J. P. Baker, K. W.

Thornton, S. W. Christensen, and M. J. Sale. 1990. Integrated Assessment Question 3: Aquatic Effects. National Acid Precipitation Assessment Program, Washington, D.C.

Ryon, M. G., J. M. Loar, G. R. Southworth, A. J. Stewart, S. M. Adams, and L. A. Kszos. 1990. Evaluation of fish kills during November 1986 and July 1987 in upper East Fork Poplar Creek near the Oak Ridge Y-12 Plant. ORNL/TM-11578.

Ryon, M. G., and R. H. Ross. 1990. Water quality criteria for 2, 4, 6-trinitrotoluene. Regulat. Toxicol. Pharmacol. 11:104-113.

Salc, M. J., M. A. Faulkner, and H. I. Jager. 1990. Acidic stress assessment for regional ish resources in streams. Abstract. IN Technical Summary from NAPAP 1990 International Conference. National Acid Precipitation Assessment Program, Washington, D.C.

Sale, M. J., and P. M. Presley (eds.). 1990. Procecdings, Third Tennessee Water Resources Symposium. American Water Res, irces Assnciation, Nashville, Tenncisce.

Salk. M. S. (ESD contributor). 1989. Environmental assessment: Innovative
Clean Coal Technology Program:

Circulating Fluidized Bed Boiler Repowering Demonstration Project. DOE/EA-0415. U.S. Department of Energy, Washington, D.C.

Salk, M. S. (ESD contributor). 1989. Environmental assessment: Innovative Clean Coal Training Program: Advanced Flue Gas Desulfurization Demonstration Project. DOE/EA-G420. U.S. Department of Energy, Washington, D.C.

Salk, M. S., and G. F. Cada (ESD contributors). 1989. Envirnnmental assessment: Innovative Clean Coal Technology Program-Coke Oven Gas Cleaning Demonstration Program. DOE/EA-0404. U.S. Department of Energy, Washington, D.C.

Saylor, R. E, D. G. Jernigan, B. D. Lasley, M. A. Mitckes, L K. Mann, S. M. Schexnayder, M. Schweitzer, W. P. Staub, : V. R. Tolbert, J. W. Van Dyke, J. P. Witherspoon, and A. K. Wolfe. 1990. Data package for the Atomic Vapor Laser Isotope Separation (AVLIS) Plant environmental impact statement. ORNL/TM-11482

Schultz, T. W., J. N. Dumont, and R. G. Elper. 198y. The embryotoxic and ostcolathyrogenic effects of semicarbazide. Toxicology 36:183-198.

Sharples, F. E. 1989. Review of In:migront Killers: Introduced Predators and the Conservation of Birds in New Zealand, by Carolyn King. Environ. Manage. 13(6):808-809.

Sharples, F. E 1990). Review of Ecology of Biological Irvvasions of North America and Hawaii, ed. by Mooncy and Drake. Environ. Manage. 14(2):279-280. 
Shriner, D. S., W. W'. Heck, S. B. McLaughlin, D. W. Johnson, P. M. Irving, J. D. Joslin, and C. E. Peterson. 1990. Responses of vegetation to atmospheric deposition and air pollution. pp. 181-363. IN P. M. Irving, J. D. Joslin, and C. E. Patterson (eds.), National Acid Precipitation Program State of Science/Technology Report No. 18 U.S. Government Printing Office, Washington, D.C.

Shugart, L R. 1990. Biological monitoring: Testing for genotoxicity. pp. 211-223. IN J. F. McCarthy and L. R. Shugart (eds), Biumarkers of Environmental Contamination. Lewis Publishers, Chelsea, Michigan.

Shugart, L R. 1990. DNA damage as an indicator of pollutant-induced genotoxicity. Am. Soc. Test. Mater. 13:348-355.

Shugart, L. R. 1990. 5-Methyl deoxycytidine content of DNA from bluegill sunfish (Lepomis macrochirus) exposed $\omega$ benzo[a]pyrene. Environ. Toxicol. Chem. 9(2):205-228.

Shugart, L. R., M. K Gustin, D. M. Laird, and D. A. Dean. 1989. Susceptibility of DNA in aquatic organisms to strand breakage: Effect of $x$-rays and gamma radiation. Mar. Environ. Res. 28:339-343.

Siegrist, R. L 1990. Development and implementation of soil quality and cleanup criteria for contaminated sites. pp. 149-156. IN Proceedings, Third International KRKTNO Conference on Contaminated Soils, Karlruhe, Federal Republic of Germany. Kluwer Publishers, Dordrecht. The Netherlands.

Sicgrist, R. L. 1990. Methods development for sampling contaminated soils and sediments for volatile organic compound measurement. Abstract. pp. 761-763. IN Proceedings, Third International KFKTNO Conference on Contaminated Soik, Karlruhe, Federal Republic of Germany. Kluwer Publishers, Dordrecin!, The Netherlands.

Siegrist, R. L, and P. D. Jenssen. 1990. Evaluation of sampling method effects on volatile organic compound measurements in contaminated soils. Environ. Sci. Technol. 24(9):1387-1392.

Sigal, L L, and G. F. Cada. 1990. NEPA compliance auditing. Abstract. FOR 1990 Conference of the National Association of Environmental Professionals, San Antonio, Texas.

Sigal, L. L, and G. W. Suter II. 1989. Potential effects of chemical agents on terrestrial resources. Environ. Prof. 11:376-384.

Sigal, L. L, and G. W. Suter II. 1990. Analysis of the effects of chemical agents on wildlife. Abstract. pp. 44-45. IN The Scientific Challenges of NEPA: Future Directions Based on 20 Years of Experience, Oak Ridge National Laboratory, Oak Ridge, Tennessee.

Smith, J. G., and J. M. Loar. 1990. Secondary production of the benthic macroinvertebrate community in a polluted stream. Bull. North Am. Benthol. Soc. $7(1): 121$.

Smith, T., and M. Huston. 1989. A theory of the spatial and temporal dynamics of plant communities. Vegetatio 83:49-69.

Sobocinski, R. W., T. E. Cerling, S. J. Morrison, and I. L. Larsen. 1990.

Scdiment transport in a small stream based on ${ }^{137} \mathrm{Cs}$ inventories of the bed-load fraction. Water Resour. Res. 26(6):1177-1187. 
Southworth, G. R., R. R. Tumer, and M. J. Peterson. 1989. Response of mercury contamination in fish to source remediation. Abstract. FOR Annual Meeting of the Society for Environmental Toxicology and Chemistry, Toronto.

Spalding, B. P, and G. K Jacobs. 1990. Oak Rivige National Laboratory in situ vitrification needs and plans. Abstract. FOR U.S. Department of Energy Thermal Treatment of Soils Workshop, Richland, Washington.

Steinman, A. D., P. J. Mulholland, A V. Palumbo, T. F. Flum, and D. L DeAngelis. 1990. Resistance of lotic ecosystems to a light elimination disturbance: A laboratory stream study. Oikos 58:80-90.

Stewart, A. J. 1990. Ammonia excretion rates and movement patterns of lotic snails. Abstract. Bull. North Am.

Benthol. Soc. 7(1):80.

Stewart, A. J. 1990. Book review: Ecology and Our Endangered Life-Support Systems, by E. P. Odum, 1989. Environ. Manage. 14:283-284.

Stewart, A. J., L A. Kszos, B. C. Harvey, L. F. Wicker, G. J. Haynes, and R. D. Bailey. 1990. Ambient toxicity dynamics: Assessments using Ceriodaphnia dubia and fathead minnow larvae (Pimephalis promelas) in short-term tests. Environ. Toxicol. Chem. 9:367-379.

Stieve, A. L., and R. D. Hatcher, Jr. 1989. Two sequential shear zones overprinting the Tallulah Falls dome in northeast Georgia. pp. 111-132. IN W. J. Fitz, R. D. Hatcher, Jr., and J. L. Hopson (eds.), Geology of the Eastern Blue Ridge of Northeast Gcorgia and the Adjacent Carolinas. Gcorgia Gcological Society, Gcorgia State University, Allanta.
Stow, S. H. 1989. The U.S. Department of Energy and geoscience education: What's the relationship? Abstract. FOR Annual Meeting of the Geological Society of America, St. Louis.

Stow, S. H, and T. O. Earty. 1990. Hydrologic and geologic studies on the Oak Ridge Reservation and their relationship to radioactive waste management. Abstract. FOR 28th Interuational Geological Congress, Washington, D.C.

Strandberg, G. W., T. L Donaldson, A. V. Palumbo, W. Eng, and J. Cosgrove. 1990. Biodegradation of chlorinated aliphatics in a fixed-film methanotrophic bioreactor. Abstract. FOR Annual Meeting of the Society for Industrial Microbiology, Orlando, Florida.

Strauss, C. H., and L. L. Wright. 1990. Woody biomass production costs in the United States: An economic summary of commercial Populus plantation systems. Sol. Energy 45(2):105-110.

Suter, G. W., II. 1990. Endpoints for regional risk assessments. Environ. Manage. 14:9-23.

Suter, G. W., II. 1990. Environmental risk assessment/environmental hazard assessment. IN W. G. Landis (ed.), Aquatic Toxicology and Risk Assessment: 13th Symposium. American Society for Testing and Materials, Philadelphia.

Suter, G. W., II. 1990. Risk assessment models for terrestrial effects of pesticides. pp. 335-345. IN L Somerville and C. $H$. Walker (eds.), Pesticide Effects on Terrestrial Wildlife. Taylor and Francis, London.

Suter, G. W., II. 1990. Screening level risk assessment for off-site ecological 
effects in surface waters downstream from the U.S. Department of Energy Oak Ridge Reservation. ORNL/ER-8.

Suter, G. W., II, and L. W. Barnthouse. 1989. Impact, hazard, and risk assessments of toxic effects on nonhuman organism. pp. 47-48. IN The Scientific Challenges of NEPA: Future Directions Based on 20 Years of Experience: Abstracts of Papers and Posters. Oak Ridge National Laboratory, Oak Ridge, Tennessee.

Tabor, J. R., T. L Davis, and R. D. Hatcher, Jr. 1990. Implications of late deformation in the Columbus Promontory, southern Appalachians, for regional deformation and metamorphism in the Piedmont. Abstract. FOR Southeastern Section of the Geological Society of America, Boulder, Colorado.

Taylor, G. E., C. A. Gunderson, M. G. Tjoelker, and H. B. Adams. 1989 Ozone and drought stress in Pinus taeda $\mathrm{L}$. (loblolly pine): Recognition of a significant interaction under field conditions using stable carbon isotopes $\left(\delta^{13} \mathrm{C}\right)$. Abstract. pp. 465-466. IN International Congress on Forest Decline Research: State of Knowledge and Perspectives, Vol. I. Forschungsbeirat Walschaden/Luftverunreiningungen, Federal Republic of Germany.

Taylor, G. E., Jr., P. J. Hanson, and S. E Lindberg. 1990. Deposition and emission of trace gases in controlled environments: Conceptual models, methodologies, and application of results. In $H$. D. Payer, $T$. Pfirmann, and P. Mathy (eds.),

Environmental Rescarch with Plants in Closed Chambers. Air Pollution Reports Series. Commission of the European Community.

Tolbert, V. R. 1990. Usc of an aquatic spill model in the EIS process to predict impacts from destruction of chemical nerve agents. Abstract. Bull North Am. Benthol Soc. 7(1):163.

Tolbert, V. R, and J. E Breck 1989. Effects of chemical agent destruction on aquatic resources. Environ. Prof. 11(4):267-375.

Tolbert, V. R, and P. M. Kotila 1990. Environmental requirements. IN Current and Selected Bibliographies on Benthic Biology. Allen Press, Lawrence, Kansas.

Tolber, V. R, G. P. Zimmerman, and D. B. Hunsaker, Jr. 1990. Along the aquatic resources pathway from programmatic to site-specific: The U.S. Army Chemical Stockpile Disposal Program. Abstract. p. 41. IN Abstracts: 1990 Conference of the National Association of Environmental Professionaks. National Association of Environmental Professionak, Alexandria, Virginia.

Toran, L E 1990. Carbon isolope mass transfer as evidence for contaminant dilution. pp. 190-201. IN R. L. Bassett and D. C. Melchior (eds.), Chemical Modeling in Aqueous Systems II. Symposium Series 416. American Chemical Society, Washington, D.C.

Tschaplinski, T. J., and T. J. Blake. 1989. Water relations, photosynthetic capacity, and root/shoot partitioning of photosynthate as determinants of productivity in hybrid poplar. Can. J. Bot. 67:1689-1697.

Tschaplinskj, T. J., and T. J. Blake. 1989. Water-stress tolcrance and late-scason organic solute accumulation in hybrid poplar. Can. J. Bot. 67:1681-1688.

Tschaplinski, T. J., and T. J. Blakc. 1990. Corrclation between carly root production, 
carbohydrate metabolism, and subsequent biomass production in bybrid poplar. Can J. Bot. 67:2168-2174.

Tschaplinski, T. J., and T. J. Blake. 1990. Photosynthetic reinvigoration of leaves following shoot decapitation and accelerated growth of coppice shoots. Physiol. Plant. 75:157-165.

Tschaplinski, T. J., and R. J. Norby. 1990. Elevated $\mathrm{CO}_{2}$ increases soluble sugar concentrations in roots of loblolly pine seedlings. Abstract. pp. 96-97. IN 11th North American Forest Biology Workshop, University of Georgia, Athens.

Tschaplinski, T. J., R. J. Norby, D. E Johnson, and D. E Todd. 1990. Nitrogen fertilization and drought resistance in sycamore planiations. Abstract. FOR First Annual Walker Branch Watershed Rescarch Symposium, Environmental Sciences Division, Oak Ridge National Laboratory, Oak Ridge, Ten.essee.

Turner, M. G. 1990. Landscape changes in nine rural counties in Georgia, JSA. Photogram. Eng. Remote Sens. 56:379-38i.

Turner, M. G. 1990. Spatial and temporal anabysis of landscape patterns. Landscape Ecol. 4:21-30.

Tumer, M. G., R. Costanza, and F. H. SkJar. 1989. Methods to evaluate the performance of spatial simulation models. Ecol. Modell. 48:1-18.

Turner, M. G., and V. H. Dale. 1990. Modeling landscape disturbance. pp. 323-351. IN M. G. Turner and R. H. Gardner (eds.), Quantitative Methods in Landscape Ecology. Springer-Verlag, Ncw York.
Tumer, M. G., V. H. Dake, and R. H. Gardner. 1989. Predicting across scales: Theory development and testing. Landscape Ecol. 3(3/4):245-252.

Turner, M. G., R. V. O'Neill, R. H. Gardner, and B. T. Milne 1989. Effects of changing spatial scale on the analysis of landscape pattern. Landscape Ecol. 3(3/4):153-162.

Turner, R. R., T. Barkay, and A. J. VandenBrook 1990. Biotransformations of mercury in contaminated and control streams in relation to the abundance of microbial gene sequences encoding mercury resistance. Abstract. FOR National Swedish Environmental Protection Board, Gavle, Sweden.

Tumer, R. R, and G. A. Southworth. 1990. Volatilization, methylation, and demethylation of mercury in a mercury-contaminated stream. Abstract. FOR 41th Southeast Regional Meeting of the American Chemical Society, Washington, D.C.

Turner, R. S., C. C. Brandt, D. D. Schmoyer, P. W. Shaffer, M. G. Johnson, and M. B. Adams. 1989. Regional soil characteristics of statistically selected watersheds in the Northeast and Southern Blue Ridge Province. Abstract. p. 312. Agron. Abstr. American Society of Agronomy, Madison, Wisconsin.

Turner, R. S., R. B. Cook, H. Van Miegroet, D. W. Johnson, J. W. Elwood, O. P. Bricker, S. E Lindberg, and G. M. Hornberger. 1990. Watershed and lake processes affecting surface water acid-base chemistry. State-of-Science/Technology Report No. 10. National Acid Precipitation Assessment Program, Washington D.C. 
Turner, R. S., P. F. Ryan, J. P. Baker, D. L Marmorek, K W. Thornton, S. W. Christensen, and M. J. Sale 1990. Integrated Assessment Question 4: Aquatic Effects. National Acid Precipitation Assessment Program. Washington, D.C.

Tumer, R. S., P. F. Ryan, D. R. Marmorek, K W. Thornton, J. P. Baker, S. W. Christensen, and M. J. Sale. 1990. Sensitivity to change for low-ANC eastern U.S. lakes and streams and their associated biota under altemative sulfate deposition scenarios. Abstract. International Conference on Acid Deposition: Its Nature and Impacts, Glasgow, Scotland.

Van Hook, R. I. 1990. Establishment of a National Ecological Research Program and Institute. pp. 63-70. IN Ecological Research Public Meetings, U.S. Environmental Protection Agency, Office of Research and Development, Washington, D.C.

Van Miegroet, H. 1990. Book review: Forest Hydrology at Coweeta. ed. by W. T. Swank and D. A Crossley. Environ. Manage. 14(2):284-285.

Van Miegroet, H., H. L Boston, and D. W. Johnson. 1989. Environmental and plant effects of sludge application to forests and pastures. Pp. 329-352 IN Proceedings. Twelfth Annual Madison Waste Conference. University of Wisconsin, Madison.

Van Miegroct, H., D. W. Cole, D. Binkley, and P. Sullins. 1989. The effect of nitrogen accumulation and nitrification on soil chemical propertics in alder forests. pp. 515-528. IN R. K Olson and A. S. Lefohn (eds.), Effects of Air Pollution on Western Forests. Air and Waste Management Association, Pittshurgh.
Van Miegroet, H., D. W. Cole, and P. S. Homann. 1990. The effect of alder forest cover and alder forest conversion on site fertility and productivity. pp. 333-354. IN S. P. Gessel, D. S. Lacate, G. F. Weetman, and R. F. Powers (eds.), Sustained Productivity of Forest Soik: Proceedings of the Seventh North American Forest Soils Conference. University of British Columbia, Vancouver, British Columbia, Canada.

Van Miegroet, H., C. S. Duncan, and D. W. Johnson. 1989. Changes in soil N availability and site $\mathbf{N}$ fertility following application of municipal sludge. Abstract. p. 312 Agron. Abstr. American Society of Agronomy, Madison, Wisconsin.

Van Miegroet, H., D. W. Johnson, and D. W. Cole. 1990. Soil nitrification as affected by $\mathbf{N}$ fertility and changes in forest floor $\mathrm{CN}$ ratio in four forest soils. Can. J. For. Res. 29(8):1012

Van Miegroet, H., D. W. Johnson, and D. E Todd. 1989. Soil solution chemistry in two spruce-fir stands located at different elevations near Clingman's Dome, Great Smoky Mountains National Park. Abstract. p. 71. IN Proceedings of the Sixth Annual Gatlinburg Acid Rain Conference. Tennessee Valley Authority, Knoxville, Tennessec.

Von Damm, K L 1990. Scafloor hydrothermal activity: Black smoker chemistry and chimneys. Annu. Rev. Earth Planet. Sci. 18:173-204.

Von Damm, K L., B. E. Beynon, and J. A. Biddle. 1989. Quartz solubility in salt solutions: Applications to hydrothermal systems. Abstract. EOS 70:1396.

Walker, D., S. G. Dricsc, and R. D. Hatcher, Jr. 1989. Palcotectonic significance of the quartzite of the 
Sauratown Mountains window, North Carolina. Geology 17:913-917.

Walton, B. T, and T. A. Anderson. 1990. Microbial degradation of trichlorethylene in the rhizosphere: Potential application to biological remediation of waste sites. Appl Environ. Microbiol. 56(4):1012-1016.

Walton, B. T, and S. S. Talmage. 1990. Small mammals as indicators of radionuclides, heavy metaks, and persistent organic chemicals at hazardous waste sites. Abstract. FOR Symposium on In Situ Ecological Assessment of Hazardous Waste Sites, Tenth Annual Meeting of the Society for Environmental Toxicology and Chemistry, Toronto.

Wanninkhof, R, P. J. Mulholland, and J. W. Ehwood. 1990. Gas exchange rates for a first-order stream determined with deliberate and natural tracers. Water Resour. Res. 26:1621-1630.

Webb, J. W. 1989. Book review of Saving the Tropical Rain Forests. Environ. Prof. 11:454-464.

White, T. W., R. M. Cushman, and V. Gornitz 1990. The global coastal hazards data base. Abstract. FOR Tenth Annual Environmental Systems Research Institute User Conference, Palm Springs, California. metal amendment on the fecundity of Ceriodaphria dubia. Abstract. FOR Tenth Annual Meeting of the Society for Environmental Toricology and Chemistry, Toronto.

Wilson, G. V, P. M. Jardine, R. J. Luxmoore, and J. R. Jones. 1990. Hydrology of a forested hillsbope during storm events. Geoderma 46:119-38.

Wiman, B., M. Unsworth, S. E Lindberg. B. Bergqvist, R. Jeanicke, and H.-C. Hansson. 1990. Perspectives on zerosol deposition to natural surfaces:

Interactions between aerosol residence times, removal processes, the biosphere, and global environmental change. J. Aerosol Sci. 21:313-338.

Wright, L L 1990. Commercialization of short-rotation intensive culture tree production in North America.

pp. 309-328. IN D. L. Klass (ed.), Energy from Biomass and Wastes XII. Institute of Gas Technology, Chicago.

Zimmerman, G. P., C. R. Boston, E L Hillsman, R. O. Johnson, R. L Kroodsma, R. L Miller, L W. Rickert, G. O. Rogers, W. P. Staub, and V. R. Tolbert. 1990. Disposal of chemical agents and munitions stored at Tooele Army Depot, Tooele, Utah-Final phase I environmental report. ORNLIM-11211.

Wicker, L F., and J. Richmond. 1990.

The effects of Perrier water and trace 


\section{Presentations}

Adams, S. M., G. F. Cada, M. S. Greeley, and $L$ R. Shugart

Evaluating Effects of Environmental

Stress on Fish Communities Using

Multi-response Indicators, " The

Scientific Challenges of NEPA: Future

Directions Based on 20 Years of

Experience, Knoxville, Tennessee,

October 1989.

Adams, S. M., M. S. Greeley, Jr., and

L. R. Shugart

"Bioindicators of Contaminant-Related

Stress: An Integrated Field

Assessment Methodology," 14th

Symposium on Aquatic Toxicology, San

Francisco, April 1990.

"Assessing the Health of Fish

Populations: Application of

Multi-response Indicators of

Physiological Health," Annual Meeting

of the American Fisheries Society,

Pittsburgh, September 1990.

Ashwood, T. L, D. S. Wiclulif, C. M.

Morrissey, and $\mathrm{H}$. L. Adair

"Active Sites Monitoring at Oak Ridge

National Laboratory," Spectrum 90:

Nuclear and Hazardous Waste

Management International Topical

Meeting, Knoxville, Tennessee,

September 1990.

Baes, C. F., III

The Safe Drinking Water Act,"

Presentations at DOE Oak Ridge

Operations, Oak Ridge National

Laboratory, and Oak Ridge Associated

Universitics, Oak Ridge, Tennessce,

November 1989 and May 1990.

The Comprehensive Environmental

Response, Compensation, and Liability

Act," Presentations at DOE Oak Ridgc
Operations, Oak Ridge National Laboratory, and Oak Ridge Associated Universities, Oak Ridge, Tennessee, December 1989 and May 1990.

"CERCLA, SARA, CWA, and EPCRA," Hazardous Materials/Waste Manager Review Course, Oak Ridge, Tennessee, March 1990.

Baker, J. P., S. W. Christensen, J. Gallagher, C. L Schofield, and K. H. Reckhow

Status of Fish Communities in Adirondack Lakes in Relation to Potential Effects from Acidic Deposition," 1990 International Conference, National Acid

Precipitation Assessment Program, Acid Deposition: State of Science and Technology, Hilton Head, South Carolina, February 1990.

Baker, J. P., S. W. Christensen, and M. J. Sale

"Difficulties in Relating Fisheries

Status to Water Quality Changes: The Acidification Example," Annual Meeting of the American Fisheries Society, Pittsburgh, August 1990.

"Assessment of the Effects of Changes in Surface Water Acid-Base Chemistry on Fish Populations in the United States," Third International Symposium on Acidic Deposition: Its Nature and Impacts, Glasgow, Scotland, September 1990.

Bartell, S. M.

"Considerations of Scale and

Aggregation in Modeling Chemical

Fate in the Environment," Ninth Oak

Ridge National Laboratory Life 
Sciences Symposium," Knoxville, Tennessee, October 1989.

TJsing Ecosystem Rate Structure for Predicting Ecological Rist,"

Engineering Foundation Conference, Santa Barbara, California, October 1989.

"Ecological and Environmental Risk Analysis: A Framework for Data Analysis and Interpretation," Conference on Data Analysis and Interpretation for Environmental Surveillance, Lexington, Kentucky, February 1990.

Bartell, S. M., and F. O. Hoffman

-An Overview of Environmental Transport Models," Meeting of the American Statistical Association, Copper Mountain, Colorado, July 1990.

Beauchamp, J. J., S. W. Christensen, and E. P. Smith

Selection of Factors Affecting the Presence of Fish in Adirondack Lakes," Second International Conference on Statistical Methods for the Environmental Sciences, Como, Italy, September 1990.

Boston, H. L, and W. R. Hill Disparate Effects of Grazing on Stream Periphyton Photosynthesis," Annual Meeting of the Ecological Society of America, Snowbird, Utah, July 1990.

Boston, H. L, W. R. Hill, and A J. Stewart

"Evaluating Direct Toxicity and Food Chain Effects in Aquatic Systems Using Natural Periphyton Communities," Second Amcrican Socicty for Testing and Matcrials Symposium on the Use of Plants for Toxicity Assessment, San Francisco, April 1990.
Brandt, C C, R. S. Turner, D. L Stevens, and D. D. Schmoyer

"Aggregating Pedon Data to Characterize Mapped Soik Data on a Regional Scale," Annual Meeting of the Soil Science Society of America, Las Vegas, October 1989.

Cada, G. F.

"Approach to the Acsessment of Aquatic Resources Impacts from Relicensing Actions," Nuclear Regulatory Commission Advisory Team, Oak Ridge, Tennessee, March $19: 00$.

"Numarc Survey of Nuclear Utilities," Annual Progress Report to Numarc, the Nuclear Regulatory Commissiou, and utility representatives, Washington, D.C., April 1990.

"Assessment of Ecological Impacts of Nuclcar Power Plant Relicensing," U.S. Department of the Interior, Washington, D.C., June 1990.

Effects of Hydroelectric Turbine Passage on Fish Early Life Stages," Annual Meeting of the Ecological Society of America, Snowbird, Utah, July 1990.

"Effects of Hydroelectric Turbine Passage on Fish Early Life Stages," Annual Meeting of the American Fisheries Society, Pittsburgh, August 1990.

"Status of the Aquatic Resources Ascessment for the NRC Relicensing GEIS," Nuclear Regulatory Commission Advisory Team, Washington, D.C., August 1990.

Cada, G. F., and L. L. Sigal "NEPA Compliance Auditing," Annual Meeting of the National Association of 
Environmental Professionak, Sain Antonio, Texas, June 1990.

Christensen, S. W.

'Patterns of Distribution of Brook

Trout, Creek Chub, and Lakes Containing Fish in Relation to Adirondack Lake/Watershed Characteristics: Results of Regression Analyses," Adirondack Lakes Survey Corporation, Third Workshop, Project on Evaluation of Surface Water Chemistry and Fish Communities in Adirondack Lakes, Albany, New York, October 1989.

"Current and Future Applications of the Lake Acidification and Fisheries Framework in the NAPAP

Assessment," Electric Power Research Institute Briefing on the Lake Acidification and Fisheries Project: Results and Conclusions, Arlington, Virginia, December 1989.

Tish Population Dynamics: The Lake Acidification and Fisheries

Framework," Electric Power Research Institute Briefing o: the Lake Acidification and Fisheries Project: Results and Conclusions, Arlington, Virginia, December 1989.

"Lake Acidification and Fisheries Project: Conclusions About Fish Populations," Electric Power Research Institute Briefing on the Lake Acidification and Fisheries Project: Results and Conclusions, Arlington, Virginia, December 1989.

Fish Population Response to Acidification: Integrating Bascline and Acidification Models," 1990 International Conference, National Acid Precipitation Assessment Program, Acid Deposition: State of
Science and Technology, Hilton Head, South Carolina, February 1990.

Clapp, R. B.

Evaluation of Hydrograph Predictions from a Topographically Based H,drologic Model of Two Watersheds with Contrasting Geology," Fall Meeting of the American Geophysical Union, San Francisco, December 1989.

"Chemical and Graphical Hydrograph Separation Techniques," First Annual Walker Branch Watershed Symposium, Oak Ridge National Laboratory, Oak Ridge, Tennessee, March 1990.

Clapp, R. B, and A. C. Lin

"A Surface-Subsurface Hydrologic Model," Workshop on Mathematics and Environmental Problems, Oak Ridge National Laboratory, Oak Ridge, Tennessee, July 1990.

Cook, R. B.

"Controk of pH in Natural Waters," Chemical Ocearography class, University of North Carolina, Chapel Hill, March 1990.

Cook, R. B., and C. A Kelly

"Sulfur Cycling and Fluxes in Lakes," Joint Seminar Program: Marine Sciences Program, Geology Department, and Environmental Science and Engineering. University of North Carolina, Chapel Hill, March 1990.

Cook, R. B., K A Rose, A L Brenkert, and R. H. Gardner

"Comparison of the ILWAS, MAGIC, and ETD Watershed Acidification Models," Fall Scminar Program. Institute of Ecosystems Studies, The Cary Arboretum, Millbrook, New York, November 1989. 
Systematic Comparison of the ILWAS, MAGIC, and ETD Watershed Acidification Modek," Third International Conference on Acidic Deposition: Its Nature and Impacts, Glasgow, Scotland, September 1990.

Cunningham, $\mathbf{M}$.

"Cedar Barrens of the Oak Ridge

Area: Their History, Plant

Communities, and Rare Species," The University of Tennessee Arboretum Society, Oak Ridge, Tennessee, May 1990.

Species Richness and Biotic Similarity Related to Physiography and Climate at the Department of Energy's National Environmental Research Parks," poster presentation, Annual Meeting of the Ecological Society of America, Snowbird, Utah, August 1990.

Cunningham, M., and P. D. Part "Successful Culture of the Rare Annual Hemiparasite Tomanthera auriculata (Michx) Raf. Scrophulariaceae," Natural Areas Conference, Knoxville, Tennessee, October 1989.

Cushman, J. H.

"Herbaceous Energy Crops Program, April 1989," Department of Energy Biofuels Management Review, Washington, D.C., April 1990.

"Herbaceous Energy Crops Research," Board of Directors, National Wood Energy Association, Oak Ridge, Tennessee, May 1990.

Cushman, J. H., and A. F. Turhollow "Selecting Herbaceous Energy Crops for the Southeast and Midwest/Lake Siates." 14ih Annual Conference on Energy from Biomass and Wastcs. Lake Buena Vista, Florida, January 1990.
Cushman, R. M., D. B. Hunsaker, Jr., M. S. Salt, and R. M. Reed "Global Climate Change and NEPA Analyses," The Scientific Challenges of NEPA: Future Directions Based on 20 Years of Experience, Knoxville, Iinnessee, October 1989.

Dale, V. H.

Integrating Socioeconomic and Ecologic Models to Assess Patterns of Deforestation in Rondonia, Brazil," Sixth Annual Acid Rain Conference for Southern Appalachia, Gatlinburg. Tennessee, October 1989.

"Effects of Management on Plant Recovery at Mount St. Helens," Arnual Natural Areas Conference, Knoxville, Tennessee, November 1989.

"Integrating Socioeconomic and Ecologic Models to Assess Patterns of Deforestation in Rondonia, Brazil," Seminar for Brazilian Environmental and Agro-forestry Specialists, The University of Tennessee, Knoxville, November 1999.

"Modeling the Effects of Air Pollution on Forest Ecosystems: Considerations for Applying a Modei to Southeast Asia," Workshop on Designing an Acid Deposition Policy Model for Southeast Asia, Bangkok, Thailand, November 1989.

"Plant Recovery at Mount St. Helens: Ten Years Later," High School Honurs Program, Oak Ridge National Laborato y, Oak Ridge, Tennessee, July 1990.

Daniels, R. C. The Effecls of Training Field Size on Image Classification Accuracy," Annual Mecting of the Association of 
American Geographers, Toronto, April 1990.

DeAngelis, D. L

"What Food Web Anabysis Can

Contribute to Widlife Toxicology,"

International Conference: The

Population Ecology and Widlife

Toxicology of Agricultural Pesticide

Use: A Modeling Initiative for Avian

Species, Annual Meeting of the Society

for Environmental Toxicology and

Chemistry, Toronto, November 1989.

Model Investigations of Where

Density-Dependent Regulation Occurs

in Fisn Life Cycles," Futuoka

Symposium on Theoretical Ecology,

Fukuoke, Japan, August 1990.

The Role of Size Variations Within

Fish Cohorts in Competition, Response

to Predation, and Apparent

Mutualism," OJI International Seminar, Gifu, Japan, August 1990.

DeAngelis, D. L., W. M. Post, P. J.

Mulholland, A. D. Steinman, and A. V.

Palumbo

"Nutrient Limitation and the Structure of Food Webs," Fifth International Congress of Ecology, Yokohama, Japan, August 1990.

Dreier, R. B., T. O. Early, and H. L King "Groundwater Flow System Studies at the Oak Ridge Y-12 Plant Using Multiport Monitoring Systcms Installed in Coreholes," Third Tennessee Water Resources Symposium, Nashville, Tennessee, August 1990.

Early, T. O., and J. W. Douthitt "Contaminant Migration in Groundwater at the Paducah Gascous Diffusion Plant," Southeastern Section Meeting of the Geological Socicty of
America, Birmingham, Alabama, April 1990.

Eddlemon, G. $\mathbf{K}$

"Assessing Effects of Radioactive Effluents on a Warmwater Fishery," The Scientific Challenges of NEPA: Future Directions Based on 20 Years of Experience, Knorville, Tennessee, October 1989.

Decosion Making and NEPA

Follow-up," DOE Mid-kevel Management Training Course on Environmental Laws and Regulations, Albuquerque, New Mexioo, June 1990, Oatland, California, June 1990.

"Preparing NEPA Documentation," DOE Mid-level Management Training Course, Oakland, California, June 1990.

"Responding to Ecological Concerns of Defense-Related Initiatives," Annual Meeting of the Ecological Society of America, Snowbird, Utah, July 1990.

"Preparing NEPA Documentation," NEPA Compliance Training Course, Oak Ridge, Tennessee, Sept imber 1990.

Edwards, N. T., G. E. Taylor, Jr., and A L Friend

"Response of Pinus taeda L. Seedlings to Tropospheric Ozone, Soil Magnesium Deficiency, and Rain Chemistry," Sixth Annual Acid Rain Conference for Southern Appalachia, Gatlinburg, Tennessee, October 1989.

Edwards, N. T., G. E. Taylor, Jr., and C. A. Gunderson

"Growth and Physiological Responses

of Pinus taeda L. Scedlings to Rain

Chemistry, Soil Magnessium Status, and

Tropospheric Ozone," Annual Meeting 
of the Ecological Society of America, Snowbird, Utah, August 1990.

Ehwood, J. W.

"Ecosystem Research on Walter

Branch Watershed,"

Symposium/WGikhop on Concepts in

Ecosystem Research, Kiel, Federal

Republic of Germany, October 1989.

Elwood, J. W, M. J. Sale, P. R.

Kaufmann, and G. F. Cada

Effects of Acidic Deposition on the

Chemistry of Streams, Lakes, and

Reservoirs in the Southern Blue Ridge

Province," Sixth Annual Acid Rain

Conference for Southern Appalachia,

Gatlinburg. Tennessee, October 1989.

Elwood, J. W., and M. J. Turner

"Oak Ridge/ESD Site Capabilities and

Perspectives on Global Change

Research in the Southwest, "Long-

Term Ecological Reserve Workshop on

Global Change Research, Denver, November 1989.

Emanuel, w. R

"Atmospheric $\mathrm{CO}_{2}$ and the Global

Carbon Cycle," Conference on the

Photosynthetic Carbon Metabolism and

Regulation of Atmospheric $\mathrm{CO}_{2}$ and

$\mathrm{O}_{2}$ Lansing, Michigan, March 1990.

"Atmospheric $\mathrm{CO}_{2}$ Increases and the Global Carbon Cycle," Oak Ridge

National Laboratory Advisory

Committee, Oak Ridge, Tennessee,

April 1990.

Terrestrial Ecosystems and Climatir. Change," Global Change Feedback Workshop, Brookhaven National Laboratory, Long Island, New York, June 1990.

"Atmospheric $\mathrm{CO}_{2}$ Increase and the Global Carbon Cycle," Seminar for the
Oak Ridge National Laboratory Fusion Energy Division, Oak Ridge,

Tennessee, August 1990.

Eng, W, and A. V. Palumbo

Methanol Suppression of

Triciloroethylene Degradation by

Methylasinus trichaporium and Mixed

Cultures;" 12th Symposium on

Biotechnology for Fuek and Chemicak,

Gatlinburg, Tennessee, April 1990.

Faulkner, M. A, and L D. Voorbees

Management of Groundwater

Hydrology Data at Oak Ridge National Laboratory," Conference on Data

Analysis and Interpretation for

Environmental Surveillance, Lexington, Kentucky, February 1990.

Gardner, R. H.

"Environmental Pradictions and

Anałysis of Uncertainties," Invited

Lecture, Institute of Environmental

Studies, Free University, Amsterdam, November 1969.

Theoretical Methods for Linking

Pattern with Process at Broad Spatial

Scales," Invited Lecture, The National

Institute of Public Health and

Environmental Protection, Bilthoven,

The Netherlands, November 1989.

"Relationships Between Pattern, Process and Predictability," Invited Presentation, Environmental Sciences Division Annual Iniormation Mecting, May 1990.

Gardner, R. H., M. G. Tumer, and R. V. O'Neill

"Quantifying Length Scales of

Disturbance Effects in Structured

Landscapes," Annual Meeting of the

Ecological Society of America,

Snowbird, Utah, July 1990. 
Garten, C. T., Jr.

The Effect of Chemical

Transformations on Terrestrial

Element Cycling and Food-Chain

Transport of Technetium-99,"

Symposium on the Chemical Behavior

of Radinactive Substances in the

Environment, 1989 International

Chemical Congress of the Pacific Basin

Society, Honolulu, December 1989.

Garten, C. T., Jr., P. J. Hanson, and S. E.

Lindberg

"Isotopic Studies of Sulfur and

Nitrogen Deposition to and Leaching

from Deciduous and Coniferous Trees,"

International Conference on Acidic

Deposition: Its Nature and Impacts, Glasgow, Scotland, September 1990.

Garten, C. T., Jr., P. J. Mulholland, P. J. Hanson, and $H$. Van Miegroet

Nitrogen-15 Abundance in a Forest

Watershed Reflects Spatial Variation

in N Cycling," Annual Meeting of the

Ecological Society of America,

Snowbird, Utah, July 1990.

Graham, R. L., S. M. Berta, J. A.

Harrington, Jr., P. W. Mausel, and C. O.

Justice

"Satellite Imagery Analysis of

Deforestation in a Closed Forest of

Equatorial Africa," Annual Meeting of the Ecological Society of America,

Snowbird, Utah, July 1990.

Graham, R. L., M. G. Turner, and V. H. Dale

The Greenhouse Effect and Forests: A Spatial and Temporal Perspective," Sixth Annual Acid Rain Conference for Southern Appalachia, Gatlinburg, Tennessec, October 1989.

Grebmeier, J. M., C. R. Olsen, and I. L. Larsen
"A Radionuclide Tracer Is Used to Identify Potential Contanination Zones on the Alastan Shelf in Response to the Exoron Valdez Oil Spill," Ocean Series Meeiing, New Orleans, February 1990.

Gunderson, C. A, and G. E Taylor "Physiological Site of Orone Effects on $\mathrm{CO}_{2}$ Assimilation in Glycine max," Annual Meeting of the American Society of Plant Physiologists, Indianapolis, August 1990.

Fianson, P. I., and C. T. Garten "Anthropogenic Nitrogen Sources from the Atmosphere: Quantifying Forest Inputs," 13th North American Forest Biology Workshop, Athens, Georgia, June 1990.

Hanson, P. J., and S. B. McLaughlin "Continuous $\mathrm{CO}_{2} \mathrm{H}_{2} \mathrm{O}$, and Trace Gas Exchange Measurements Within Forest Canopies," First Annual Walker Branch Watershed Research Symposium, Oak Ridge, Tennessec, March 1990.

Hanson, P. J., and R. J. Niorby

The Impact of Early Morning Elevated $\mathrm{CO}_{2}$ on Foliar Carbon Gain," Annual Meeting of the American Society of Plant Physiologists, Indianapolis, August 1990.

Hanson, P. J., R. J. Norby, G. E. Taytor, and S. E Lindberg

"Deposition and Assimilation of

Reactive Nitrogen Gases to Forest

Canopies," International Congress on

Forest Decline Research,

Friedrichshaften, Federal Republic of

Germany, October 1989.

Hanson, P. J., G. E. Taylor, Jr., and C. A Gunderson

"Dynamics of Nitrogen Deposition to Forest Canopy Surfaces," First Annual 
Walker Branch Watershed Research Symposium, Oak Ridge, Tennessee, March 1990.

Hatcher, R. D., Jr.

"Geologic Overview of the Southern Appalachians," 16th Annual Natural Areas Conference, Knoxville, Tennessee, October 1989.

Seismicity Related to Old Structural Boundaries," New Madrid Seismic Zone Workshop, Memphis, November 1989.

"Crustal Structure of the Southeastern United States," Savannah River Site Seismicity Workshop, December 1989.

Hatcher, R. D., W. M. McMaster, G. K. Moore, and P. J. Lemiszke

-Oak Ridge Reservation Hydrologic and Geologic Study-Evolving Concepts in a Fractured Reservoir System," Third Tennessee Hydrology Symposium, Nashville, Tennessee, August 1990.

Hoeksema, R. J., and R. B. Clapp "Calibration of Groundwater Flow Models Using Monte Carlo Simulations and Geostatistics," Proceedings of the International Conference on Calibration and Reliability in Groundwater Modeling, The Hague, September 1990.

Hoffman, F. O.

The Use of Globally Dispersed Radionuclides from 'se Chernobyl Accident to Tast Food Chain Transport Models," DOE Office of Health and Environmental Research, Germantown, Maryland, November 1989.

"Final Conclusions of BIOMOVS," Ninth Worksnop of the International
Biospheric Model Validation Study, Ottawa, January 1990.

"Preliminary Results from the International Biospheric Model Validation Study (BIOMOVS) Where Data from the Chernobyl Accident Has Been Used to Test Model Predictions," Technical Steering Panel, Hanford, Washington, January $\mathbf{9 9 0 .}$

-A Progress Report on the Multiple Pathways Scenario of VAMP," International Atomic Energy Agency, Vienna, January 1990.

The Role of Uncertainty Analysis in Environmental Risk Assessment," Oak Ridge Associated Universities, Oak Ridge, Tennessee, January 1990.

Hoffman, F. O., S. M. Bartell, R. A Young, and P. Hovatter

-A Preliminary Screening Analysis for Dioxin in Sediment at the Paducah Gaseous Diffusion Plant, Kentucky Division of Waste Management, Frankfort, Kentucky, January 1990.

Hoffman, F. O., and B. L Kimmel

"A Preliminary Evaluation of Contaminants in the Clinch River/Watts Bar System," Roane/Anderson County Economic Commissiou, Oak Ridge, Tennessee, January 1990.

Hunsaker, C. T.

"Ecosystem Assessment Methods for Cumulative Effects at Regional and Global Scales," Ninth Oak Ridge National Laboratory Life Sciences Sympusium, Oak Ridge, Tennessee, October 1989.

"Regional Water Quality Assessment Methods for Aquatic Ecosystems," Annual Conference of the Water 
Pollution Control Federation, San Francisco, October 1989.

Landscape Ecology and Environmental Management," Geography Department Seminar, Pennsytvania State University, University Park, January 1990.

Ecosystem Assessment Methods for Cumulative Effects at Regional and Global Scales," Geography and Geology Department Seminar, Indi-na State University, Terre Haute, February 1990.

"Regional Ecological Risk Assessment: Examples of Air Pollution," Geography Department Seminar, University of California, Santa Barbara, February 1990.

"Ecosystem Assessment Methods for Cumulative Effects at Regional and Global Scales," Zoology Department Seminar, The University of Tennessee, Knoxville, March 1990.

"Indicators of Ecological Conditions," Office of Research and Development Seminar, U.S. Environmental Protection Agency, Washington, D.C., June 1990.

Hunsaker, C. T., and D. E Carpenter "Indicators of Regional Ecological Health," Annual Meeting of the Ecological Society of America, Snowbird, Utah, July 1990.

Iunsaker, C. T., B. L Jackson, S. Timmins, and D. A Levine

"Relationships Between Landscape Structure and Water Quality," Fifth Annual Landscape Ecology Symposium, Miami University, Oxford, Ohio, March 1990.
Huston, M. A

Linking Plant Physiology and

Ecosystem Dynamics on Waiker

Branch Watershed," Clemson

University Ecology Program, Clemson,

South Carolina, November 1989.

Ecosystem Research on Walker Branch Watershed: Issues and Opportunities," Geography

Department, The I'niversity of

Tennessee, Knoxville, September 1990.

Jacobs, G. K

In Situ Vitrification for Remediation of Contaminated Soil Sites," Workshop on Mathematics and Environmental Waste Problems, Oak Ridge, Tennessee, July 1990.

Jacobs, G. K, and P. M. Jardine "Soil-Contaminant-Water Interactions: Controls on Contaminant Release and Transport," Subsurface Science Program Overview and Research Abstracts, Washington, D.C., January 1990.

Jardine, P. M.

Modeling the Kinetics of Inorganic Reactions in Soil," Annual Meeting of the American Society of Agronomy, Las Vegas, October 1989.

Jarcine, P. M., and G. K. Jacobs "Unsaturated Transport of Inorganic Cations in Undisturbed Soil Columns," Radionuclide Adsorption Workshop, Los Alamos, New Mexico, September 1990.

Jardine, P. M., G. V. Wilson, J. F. McCarthy, D. L. Taylor, R. J. Luxmoore, and L. W. Zclazny

"Hydrogeochemical Processes Controlling the Transport of Dissolved Organic Carbon Through a Forested Hillslope," Spring Meeting of the 
American Geophysical Union, Baltimore, May 1990.

Johnston, J. W.

Biomass Production Program: A Program Overview," Woody Biomass Committee, U.S. Department of Agriculture, Ames, Iowa, March 1990.

Kancinut, P.

The Carbon Dioxide Information Analysis Center," International Symposium on Climate Change, Beijing, China, August 1990.

Kelly, J. M., G. S. Edwards, and N. T. Edwards

"Growth and Nutrient Status of Loblolly Pine Seedlings as Impacted by Ozone, Rainfail Acidity, and Soil Magnesium Status," International Conference on Acidic Deposition: Its Nature and Impacts, Glasgow, Scotland, September 1990.

Kimmel, B. L.

"Clinch River-Watts Bar Remedial Investigation," Report to the Roane County Environmental Advisory Committee, Kingston, Tennessee, May 1990.

"Environmental Restoration Program," Public Meetings, Harriman, Oak Ridge, and Spring City, Tennessee, June 1990.

King, A W., and W. R. Emanuel

The Response of Atmospheric $\mathrm{CO}_{2}$ to Changes in Land Use," Chapman Conference on Global Bicmass Burning, Williamsburg, Virginia, March 1990.

King, A. W., W. R. Emanucl, and W. M. Post

Terrestrial Ecosystcms as a Historic:

Sink for Atmospheric Carbon," Annual
Meeting of the Ecological Society of America, Sncwbird, Utah, July 1990.

Kszos, L A, and M. L Holtz

Life Table Evaluation of Chronic Exposure of Ceriodaphnia dubia to Calcium and Magnesium Sulface," Annual Meeting of the Society of Environmental Toricology and Chemistry, Toronto, October 1989.

Levine, M. B.

The Doctrine of Sovereign Immunity, the Supremacy Clause, and the Unitary Executive Theory," DOE Senior Management Training Course in Environmental Laws anci Regulations, Idaho Falts, Idaho, November 1989 and May 1990; Amarillo, Tecas, May 1990, Largo, Florida, May 1990.

"The Clean Air Act," DOE Senior Management Training Course in Environmental Laws and Regulations, Idaho Falls, Idaho, May 1990.

The Clean Water Act," DOE Training Course in Environmental Laws and Regulations for Mid-level Managers and Technical Staff, Las Vegas, May 1990; Albuquerque, New Mexico, June 1990; San Francisco, June 1990; Idaho Falls, Idaho, June 1990; Oak Ridge, Tennessee, August 1990; Washington, D.C., September 1990.

The Federal Water Pollution Control Act (a.k.a. Clean Water Act)," DOE Senior Management Training Course in Envizonmental Laws and Regulations, Idaho Falls, Idaho, May 1990; Largo, Florida, May 1990.

"Overview of Environmental Law and Regulations," Environment, Safety, and Hcalth Workshop for Division Managers, Argonne National 
Laboratory, Argonne, Illinois, August 1990.

"Rist Assessment and Risk Management," DOE Training Course in Envirunmental Laws and Regulations for Mid-level Managers and Technical Staff, Las Vegas, May 1990; Albuquerque, New Merico, June 1990; Oak Ridge. Tennessee, June 1990, San Francisco, June 1990, Idaho Falls, Idaho, June 1990; Washington, D.C., September 1990.

Levine, D. A, and C. T. Hunsaker "GIS Applications in Regional Water Quality Analysis," Third National Conference and Exposition on Geographic Information Systems-East, Washington, D.C., June 1990.

Lindberg. S. E

"Atmospheric Deposition in North American Forests," International Congress on Forest Decline Research: State of Knowledge and Perspectives, Friedrichshafen, Federal Republic of Germany, October 1989.

"Comparison of Atmospheric Deposition to Conifer Forests in the US and FRG," Annual Technical Mecting of the National Atmospheric Deposition Program. Provincetown, Massachusetts, November 1989.

Important Conclusions on Atmospheric Deposition from the Integrated Forest Study," 1990 International Conference, National Acid Precipitation Assessment Program, Acid Deposition: State of Science and Technology, Hilton Head, South Carolina, February 1990.

The Behaviof of Airbornc Sulfur in Forest Canopics: A Synthesis of Results on Throughfall Studies in the
Integrated Forest Study," Departmeat of Geography, University of Utrecht. The Netherlands, May 1990.

"Canopy Assimilation of Deposited Atmospheric Nitrogen Compounds: Resuits from the Integrated Forest Study," National Institute of Public Health and Environmental Protection, Utroct:h, The Netherlands, June 1990.

The Role of Dry Deposition in the Almosphere/Forest Transfer of Mercury," International Conference on Mercury as an Environmental Pollutant, Gavle, Sweden, June 1990.

- A Changing Climate for Atmosphere/Forest Interactions: Atmospheric Deposition and the Role of Climate Change on Aerosol Sources and Sinks," Department or Environmental and Energy Systems Studies, Lund Institute of Scicnce and Technology, Lund, Sweden, June 1990.

-Atmosphere/Canopy Exchange in the Deposition Process," National Academy of Sciences Review of DOE

Atmospheric Chemistry Program, Washington, D.C., September 1950.

"Deposition and Interactions of Airborne Nitrogen and Metals in Forest Ecosystems: Implications for Global Change," Symposium on Interdissiplinary Environmental Rescarch, 110th Anniversary of the Free University of Amsterdam. The Netherlands, Scptember 1990.

"Atmospheric Chemistry and Deposition of Nitrogen Compounds in the U.S. and Germany," International Conference ois Acid Rain: Its Nature and Impacts, Glasgow, Scotland, September 1990. 
Lumoore. R. J.

-Are Percolation Theory and Fractal

Analysis Useful in Subsurface

Contaminant Transport Investigations?"

Workshop on Mathematics and Environmental Waste Problems, Oak Ridge, Tennessee, July 1990.

Mann, L K., V. H. Dake, R. J. Olson, D. W. Johnson, and K. C. Dearstone Spatial Patterns of Tree Mortality and Site Characteristics on Walker Branch Watershed, Annual Meeting of the American Society of Agronomy, Las Vegas, October 1989.

Marsh, J. D., Jr., and R. B. Clapp "Leachate Characterization a! Bear Creek Burial Ground," Workshop on Mathematics and Environmental Problems, Oak Ridge National Laboratory, Oak Ridge, Tennessee, July 1990.

Mcrarthy, J. F.

'Biomarkers of Environmental Contamination," Pacifichem '89, American Chemical Society, Honolulu, December $1: 89$.

"Subsurface Transport of Contaminants," Environmental Science Program, University of Virginia, Charlottesville, April 1990.

"Biomarker-Based Biomonitoring for Evaluating Health and Ecological Effects of Environmental Contaminants," ORNL Life Sciences Symposium, Gatlinburg, Tennessce, May 1990.

"Mobile Colloids Enhance Transport of Contaminants in Porous Media," Spring Mceting of the American Gcophysical Union, Baltimorc, May 1990.
McCarthy, J. F., L. W. Burrus, and V. R. Tolbert

Bioaccumulation of Benzo(a)pyrene by Fathead Minnows," Annual Meeting of the American chemical Society,

Boston, April 1990.

McCarthy. J. F., P. M. Jardine, L. E

Toran, ami T. $M$. Williams

"Chemical and Hydrologic Controls of

Colbid Transport in Porous Media,"

Subsurface Science Pn sgram Meeting,

U.S. Department of Energy,

Germantown, Maryland, March 1990.

"Geochemical Transport/Colloid

Subprogram Overview," Subsurface

Science Program Meeting, U.S.

Department of Energy, Germantown, Maryland, March 1990.

McCarthy, J. F., and L R. Shugart "DNA Alterations and Enzyme Activities in Japanese Medaka Exposed to DNA, Animal to Human Extrapolation Symposium, San Antonio, Texas, March 1990.

McLaughlin, S. B.

"Growth and Physiology of Red Spruce Saplings in Relationship to Acid Deposition in the Great Smoky Mountains National Park, U.S.A," International Congress on Forest Decline Rescarch: State of Knowledge and Perspectives, Lake Constance, Federal Republic of Germany, October 1989.

"U.S.A. Research on the Role of Air Pollution in Forest Decline," State Laboratory for Natural Environmental and Climate Monitoring, U.S.U.S.S.R. Scientific Exchange to Russia, Moscow, October 1989.

"Growth and Physiology of Red Sprucc Saplings in Relationship to Acid 
Deposition in High-Elevation Southem Appalachian Stands," 1990 International Conference, National Acid Precipitation Assessment Program, Acidic Deposition: Statc of Science and Technology, Hilton Head, Jouth Carolina, February 1990.

"Growth and Physiology of Red Spruce Saplings in Relationship to Acid Deposition in High-Elevation Southern Appalachian Stands," Symposium on Air Pollution and Its Ecological Effects, Appalachian State University, Boone, North Carolina, February 1990.

"Southern Appalachian Red Spruce: Effects of Acid Deposition on Growth and Physiology," Conference on Resourcess at Risk: Effects of Acid Precipitation and Ozone on the Southern Appalachians, Asheville, North Carolina, April 1990.

"An Overview of Terrestrial Research in the Ervironmental Sciences Division," Management Team Meeting, Southeast Region, USDA Forest Service, Dillard, Georgia, May 1990.

"Ecophysiological Perspectives on Effects of Regional Air Pollution and Global Climatic Change on Forests," Institutc of Terrestrial Ecology, Edinburgh, September 1990.

"Growth and Physiology of Red Spruce Saplings in Relationship to Acid Deposition in High-Elevation Southern Appalachian Stands," Third International Symposium on Acid Deposition: Its Nature and Impacts, Glasgow, Scotland, September 1990.

"USA Rescarch on the Role of Air Pollution in Forest Decline,"
U.S/U.S.S.R Scientific Exchange to

Russia, Moscow, Seplember 1990.

McLean, R. B., and R. M. Reed

"Analyses of Complex Siles and

Programmatic Issues: A NEPA Challenge," Annual Meeting of the National Aseociation of Environmental Professionak, San Antonio, Texas, June 1990.

Milne, B. T., M. G. Turner, J. A Wiens, and A. R. Johnson

The Scale Dependence of Animal Foraging on Dynamic Fractal Landscapes," Fifth Annual Landscape Ecology Symposium, Univeraity of Miami, Oxford, Ohio, March 199.

"Interactions Between the Fractal Geometry of Landscapes and Allometric Herbivory," Annual Meeting of the Ecological Society of America, Snowbird, Utah, July 1990.

Mulholland, P. J.

"Nutrient Spiralling in Streams:

Nutrient Cycling and Downstream Transport in Lake Ecosystems," Ecology Program Seminar, University of North Carolina, Chapel Hill, March 1990.

"Regulation of Stream Chemistry in Walker Branch," Walker Branch Watershed Research Symposium, Oak Ridge, Tennessee, March 1990.

"Regulation of Stream Phosphorus Concentrations at Bascllow: Groundwater Inputs Versus Within-Stream Processes," Annual Mecting of the North American Benthological Society, Blacksburg. Virginia, March 1990. 
Mulholland. P. J.. C. T. Garten, and L. W. Cooper

Regulation of Nitrogen in Walker Branch: ElTects of Riparian and Within-Stre am Processes," Annual Meeting of the Ecological Society of Anerica, Suowbird, Utah, July 1990.

Mulholland, P. J., G. V. Wilson, P. M. Jardine, and D. P. Genereux

-Hydrological and Chemical Dynamirs ir. Nested Subcatchments During Storms," Walker Branch Watershed Research Symiposium, Oak Ridge, Tennessee, March 1990.

Norby, R. J.

'Responses of Forest Trees to Carbon Dioxide Enrichment of the Atmosphere: Physiological Studies to Address Ecological Questions," Seminar, Duke University, Durham, North Carolina, November 1989.

Norby, R. J., M. Ccckrill, and E G. O'Neill

"Elevated $\mathrm{CO}_{2}$ Does Not Delay Leaf Scnescence in White Oak or Yellow-Poplar Seedlings in the Field," Annual Mecting of the American Socicty of Plant Physiologists, Indianapolis, August 1990.

Norby, R. J., and E. G. O'Neill "Aboveground Growth and Gas Exchange of White Oak and Yellow-Poplar Seedlings Exposed to Elevated $\mathrm{CO}_{2}$ in the Field," 11th North American Forest Biology Workshop. Athens, Gcorgia, June 1990.

Norby, R. J., E. G. O'Ncill, C. A. Gunderson, and R. J. Luxmoore "Responses of Trec Scedlings to Elevated $\mathrm{CO}_{2}$ in Growth Chambers and in the Ficld," 19th World Congress, Internatirnal Union of Forest
Research Organizations, Montreal, August 1990.

Norby, R. J., T. J. Tschaplinski, and D. W. Johnson

"Foliar Indicators of Optimum Nitroge n Nutrition in Short-Rotation Sycamore," Annual Merting of the Soil Science Society of America, Las Yegas, October 1989.

Olsen, C R, R. B. Cook, D. K. Solomon, I. L Larsen, L W. Cooper, and J. M. Grebmeier

"Use of Natural Radionuclide and Isotopic Tracers to Quantify the Chemical Interaction of Soils and Runoff During Storm and Snowmelt Events," Fall Meeting of the American Geophysical Union, San Francisco, December 1989.

Olson, R. J., R. A McCord, and K. C. Dearstone

"Using ARC/INFO to Produce Effective Graphical Displays for Research Presentations," Tenth Annual ESRI User Conference, Palm Springs, California, May 1990.

O'Neill, E. G., R. J. Norby, and R. V. O'Neill

"Hierarchy Theory as a Suide to Mycorrhizal Research on Large-Scale Problems," Eighth North American Coniercnce on Mycorrhizae, Jackson, Wyoming, September 1990.

Packard, J., A. Breen, G. S. Sayler, and A. V. Palumbo

"Monitoring Populations of 4-Chlorobiphenyl-Degrading Bacteria in Soil and Lake Water Microcosms Using Colony Hybridization," Conference on Superfund '89. Washington, D.C., November 1989. 
Palumbo, A V, W. Eng, and G. W.

Strandberg

The Effects of Groundwater

Chemistry on Co-metabolism of

Chlorinated Solvents by

Methanotrophic Bacteria," Annual

Meeting of the American Chemical

Society, Boston, April 1990.

Biodegradation Kinetics of Mixed Chlorinated Ethenes by Methylosinus trichosporium," Annual Meeting of the American Society for Microbiology, Anabeim, California, May 1990.

Palumbo, A V, B. R. Zaidi, and J. F. McCarthy

"Characterization and Bioavailability of

Dissolved Organic Carbon:

Comparison of Deep Subsurface and

Surface Waters," First International

Symposium on Microbiobgy of the

Deep Subsurface, Orlande, Florida, January 1990.

Parr, P. D., F. Au, D. Burns, R. Chesser, W. Conky, M. Cunningham, T. Foxw, J.

Jastrow, P. Kennedy, L Mann, J. Paulk, T.

Reynolds, and W. Rickard

ParkNet: A Network of National

Environmental Research Parks,"

Annual Meeting of the Ecological

Society of America, Snowbird, Utah, July 1990.

Parr, P. D., and M. Cunningham

Habitat Manipulation: The Effect on

a Declining Rare Plant Population,"

Annual Mecting of the Association of

Southern Biologists, Baltimore, January 1990.

Peng, T.-H.

The Cause of the Glacial to

Interglacial Atmospheric $\mathrm{CO}_{2}$ Change:

A Polar Alkalinity Hypothesis," Third International Conference on Analysis and Evaluation of Atmospheric $\mathrm{CO}_{2}$
Data, Present and Fast, Hinterzarten, Federal Republic of Germany, October 1989.

"Global $\mathrm{Net} \mathrm{CO}_{2}$ Flux Across the Sea-Air Interface Based on the Observed $\mathrm{pCO}_{2}$ in the Surface Water," Third International Conference on Analysis and Evaluation of Almospheric $\mathrm{CO}_{2}$ Data, Present and Past, Hinterzarten, Federal Republic of Germany, October 1989.

"Modeling Changes in Ocean Ventilation Rates in the Past Few Thousand Years Based on " $\mathrm{C}$ Variations in the Atmosphere and Oceans," Second Workshop on Geological Indicators of Climate from Marine Environments, U.S. Geology Survey, St. Petersburg. Florida, January 1990.

Modeling the Seasonality of $\mathrm{CO}_{2}$ in the North Atlantic," International Meeting on Modelin, the Physics, Biology, and Chemistry of the Upper Ocean and Its Interaction with the Almosphere, The Royal Society, London, March 1990.

"Reconstruction of Radiocarbon Distribution in the Glacial Occan," Conference on Four Decades of Radiocarbon Studies: An Interdisciplinary Perspective, University of California Lake Arrowhead Conference Center, Lake Arrowhead, California, June 1990.

"Oceanic $\mathrm{CO}_{2}$ Uptake and Future Almospheric $\mathrm{CO}_{2}$ Concentration Based on a Lateral Transport Model of the World Ocean," Second International Symposium on Gas Transfer at Water Surfaces, Minneapolis, September 1990. 
Peng, T.-H, and W. S. Broecker

The Antarctic Iron Fertilization Strategy: Dynamic Considerations," Workshop on Physical and Chemical Tracers in the Ocean, Friday Harbor, Washington, July 1990.

Post, W. M, and J. Pastor Modeling Forest Response from Tree to Planet," Fifth International Congress of Ecology, Yokohama, Japan, August 1990.

Railsback, S. F.

"A Simple Empirical Model of Aeration at Navigation Dams," Second Intemational Symposium on Gas Transfer at Water Surfaces, Minneapolis, September 1990.

Railsback, S. F, and M. J. Sale "Application of Optimized Water Quality Mitigation to Hydropower Developmeat in the Ohio River Basin," International Symposium on Water Resources Systems Application, Winnipeg, Manitoba, Canada, June 1990.

Reed, R. M.

"NEPA Compliance Planning," Training Course for DOE Middle Management, Pittsburgh, July 1990.

"Special Topics in the NEPA Process: Integrating Other Environmental Review Requirements into NEPA Reviews," Training Course for DOE Middle Management, Pittsburgh, July 1990.

Reed, R. M., M. S. Salk, and J. W. Webb "Wetlands Protection by Federal Agencies," The Scientific Challenges of NEPA: Future Directions Based on 20 Years of Experience, Knoxville. Tennessec, October 1989.
Romme, W. H. M. G. Turner, D. G. Despain, and R. H. Gardner Scale and Heterogeneity of Fire on the Yellowstone Plateau," Annuil Meeting of the Ecological Society of America, Snowbird, Utah, July 1990.

Rose, K A., L W. Barnthouse, G. KleinMacPhee, and D. Danila "Using an Individual-Based Model to Simulate the Influence of E\&g and Larval Size on Recruitment Success in Winter Flounder," Annual Meeting of the American Fisheries Society, Pittsburgh, August 1990.

Rose, K A., L W. Barnthouse, G. KleinMacPhee, B. Sullivan, A. Keller, D. Danila, and D. Miller Winter Flounder Young-of-the-Year Growth and Survival in Mesocosm and Field Ecosystems," Workshop on Winter Flounder Biology, Mystic, Connecticut, December 1989.

Rose, K A, A. L. Brenkhert, R. B. Cook, and R. H. Gardner

"Comparative Uncertainty Analysis of the ILWAS, MAGIC, and ETD Watershed Acidification Modek," NAPAP International Conference, Hilton Head, South Carolina, February 1990.

Rose, K A, D. L. DeAngelis, L. W. Barnthouse, and W. Van Winkle "Individual-Based Modeling, Population Dynamics, and Fisheries Recruitment Success," Fisheries-Oceanography Cooperative Investigation Workshop on Fisheries Recruitment Modelling. Seattle, February 1990.

Rose, K A, and E. P. Smith "Determining the Effectiveness of Pollution Abatement: The Need for Integrated Monitoring and Statistical Analysis," Conference on Data Analysis 
and Interpretation for Environmental Surveillance, Lexington, Kentucky. February 1990.

Ryan, P. F, D. S. Schmoyer, C. C. Brandt, and R. S. Turner

-Parameter Uncertainty in Predicting

Regional Changes in Lake Acid

Neutralizing Capacity: How Important

Is Weathering Rate? Turd

Intcrnational Conference on Acidic

Deposition: Its Nature and Impacts,

Glasgow, Scotland, September 1990.

Sale, M. J.

"Cumulative Impacts, Alternative

Analysex, and Decision-Making in

Environmental Impact Statements,"

The Scientific Challenges of NEPA:

Future Directions Based on 20 Years

of Experience, Knoxville, Tennessee,

October 1989.

Environmental Study Needs for Enhanced Hydropower Development," Seminar at the Waterworks, Washington, D.C., July 1990.

Sale, M. J., M. A. Faulkner, and H. I. Jager

"Acidic Stress Assissment for Regional

Fish Resources in Streams," 1990

International Conference, National

Acid Precipitation Assessment

Program, Acid Deposition: State of

Science and Technology, Hilton Head,

South Carolina, February 1990.

Salk, M. S.

"Environmental Regulatory Update

Table." EPA's Federal Agency

Roundtable, Washington, D.C.,

February 1990.

"Preparing NEPA Documentation," DOE Mid-level Management Training
Course, Las Vegas, May 1990,

Washington, D.C. Sepiember 1990.

Special Topics in the NEPA Process: Integrating Other Environmental Laws into NEPA Reviews," DOE Mid-level Management Training Course, Las Vegas, May 1990; Albuquerque, New Mexico, June 1990, Idaho Falk, Idaho, August 1990, Washington, D.C. Seprember 1990.

"NEPA Compliance Planning, DOE Mid-level Management Training Course, Albuquerque, New Merioo, June 1990; Idabo Falls, Idaho, August 1990.

Sharplex, F. E

The Clean Air Act," Senior

Management Training Course in Environmental Laws and Regulations, Idaho Falls, Idaho, November 1989, Amarillo, Texas, May 1990, Largo, Florida, May 1990.

Regulatory Drivers for the Development of Treatment Technology," WATTec, Knoxville, Tennessee, February 1990.

Sharples, F. E, C. F. Baes, M. B. Levine, and C. F. Sigmon

The Regulatory Context for Waste Management and Environmental Restoration," Environmental Sciences Division Annual Information Meeting. Oak Ridge, Tennessee, May 1990.

Shriner, D. S.

"Our Current Understanding of the

Biological Basis for Air Pollution

Effects un Trees," 19h World Congress, International Union of Forest Rescarch Organizations, Montreal, August 1990. 
Shriner, D. S., W. W. Heck, S. B.

McLaughlin, D. W. Johnson, P. M. Irving.

J. D. Joslin, ard C. E Peterson

Response of Vegetation to

Almospheric Deposition and Air

Pollution," 1990 International

Scnference, National Acid

Precipitation Assessment Program,

Acid Deposition: State of Science and

Technology. Hilton Head, South

Carolina, February 1990.

Shugart, L R.

Detecting Genotoricity in

Environmental Species Using DNA

Alterations," Symposium on Biological

Markers at Pacifichem 89, Honolulu. December 1989.

Shugart, L R, J. F. McCarthy, M.

Greeley, C. Hull, and S. D'Surney

"Biological Markers of Toxicity in

Japanese Medaka," Third Annual

Carcinogenicity Research Review,

Frederick, Marylard, August 1990.

Siegrist, R. L.

International Review of Approaches

for Establishing Cleanup Goals for Hazardous Waste Contaminated Land," Multi-Stakeholder Contaminated Site Consultation Workshop, Toronto, November 1989.

Sampling Methods Effects on VOCs in Sotvent Contaminated Soil and Intemational Perspectives on Cleanup Standards for Contaminated Land," Fourth Intemational Workshop on Demonstration of Remedial Action Technologies for Contaminated Land and Groundwater, Oslo, March 1990.

Volatile Organic Compound Measurements in Contaminated Soils: State of Practice, Methods Development, and Implications for Site Remediation," Annual Mecting of the
American Chemical Society, Washington, D.C., August 1990.

Measurement Error Potential and Control when Quantifying Volatile Hyurocarbon Concentrations in Soik," Fifth National Conference on Hydrocarbon Contaminated Soik, University of Massachusetts, Amherst, September 1990.

Sigal, L L

Decision Making and NEPA

Follow-up," DOE Mid-level

Management Training Course:

Environmental Laws and Regulations,

Las Vegas, May 1990, Washington,

D.C. Sepiember 1990.

"NEPA Compliance Planningo" DOE

Mid-level Manage nent Training

Course: Environmental Laws and

Regulations, Las Vegas, May 1990,

Oakland, California, June 1990,

Washington, D.C., September 1990.

Special Topics in the NEPA Process,

I: Integrating Other Environmental

Review Requirements into NEPA

Reviews," DOE Mid-level Management

Training Course: Environmental Laws and Regulations, Oakland, California, June 1990.

"Overview of the DOE NEPA

Compliance Prog-am," Senior

Management Training Course:

Environmental Laws and Regulations, Oak Ridge, Tennescee, July, August. and September 1990.

Training for NEPA Compliance in the DOE System," TRADE Environmental Management Special Interest Group, Integrating Environmental Training. Knoxville, Tennessee, August 1990. 
Sigal, L L. and C. F. Cada

What About Compliance with

NEPA? American Defense

Preparedness Association, 1?th

Environmental Symposium, Atlanta, April 1990.

Sigmon, C. F.

The Resource Conservation and Recovery Act," DOE Senior Training Course in Environmental Laws and Regulations, Germantown, Maryland, November 1989.

The Toxic Substances Control Act, DOE Senior Training Course in Environmental Laws and Regulations, Germantown, Maryland, November 1989.

-Comprehensive Environmertal Response, Compensation, and Liability Act," FUSRAP Training Course in Environmental Laws and Regulations, Oak Ridge, Tennessee, September 1990.

Spill Reporting Under CERCLA, TSCA, and the Clean Water Act," FUSRAP Training Course in Environmental Laws and Regulations," Oak Riçe, Tennessee, September 1990.

Smith, E D., M. B. Levine, G. K. Eddkemon, and F. E Sharples

"Integrating NEPA and CERCLA

Requirements: What Needs to Go into an RIFS-EIS?" The Scientific Challenges of NEPA: Future Directions Based on 20 Years of Experience, Knoxville, Tennessee, October 1989.

Smith, J. C.

"Secondary Production of the Benthic Macroinvertebratc Coinmunities on the Department of Energy's Oak Ridge
Reservation" First Annual Walker

Branch Watershed Research

Symposium, Oat Ridge, Tennessee, March 1990.

Smith, J. G, and J. M. Loar

Secondary Production of the Benthic Macroinvertebrate Community in a Polluted Stream, Annual Meeting of the North American Benthological Society, Blacksburg, Virginia, May 1990.

Southworth, G. R., and R. R. Turner

Response of Mercury Contamination in Fish to Source Remediation," Annual Meeting of the Society of Envirenmental Toxicology and Chemistry, Toronto, November 1989.

Spalding, B. P.

"Oak Ridge National Laboratory In Situ Vitrification Needs and Plans," DOE Thermal Treatment of Soil Workshop, Richland, Washington, August 1990.

Spalding. B. P., and E C. Davis "Stabilization of Low-Level Waste Burial Trenches by Dynamic Compaction," DOE Model Conference, Oak Ridge, Tennessee, October 1989.

Spalding, B. P., and T. A Fontaine "Field Demonstration of In Situ Grouting of Radioactive Solid Waste Burial Trenches with Polyacrylamide," American Society for Testing and Materials Symposium on Stabilization/Solidification of Hazardous, Radioactive, and Mixed Wastes, Williamsburg. Virginia, May 1990.

Stcinman, A D. "ErTects of Substrate Conditioning. Irradiance, and Grazing on Strcam Pcriphyton Colonization and Growth," 
Walker Branch Watershed Research Symposium, Oak Ridge, Tennessee. March 1990.

Stability of Lotic Periphyton Communities," Third Annual Algal Ecology Consortium, Erlanger, Kentucly, April 1990.

"A Functional-Form Model for Lotic Algae," Annual Meeting of the North American Benthological Society, Blacksburg, Virginia, May 1990.

\section{Stewart, A. J.}

"Ammonia Excretion Rates and Movement Patterns of Lotic Snaik," Annual Meeting of the North American Benthological Society, Blacksburg. Virginia, May 1990.

Stoss, F. W.

'Users' Needs Assessment of the Greenhouse Effect," Executive Board Meeting of the DOE Energy Technical Data Exchange Program, Gatlinburg, Tennessee, April 1990.

Stow, S. H.

The Department of Encrgy and the Demand for Geoscientists," Council on Undergradua:e Research, San Antonio, Texas, June 1990.

Stow, S. H., and T. O. Early

"Hydrologic and Geologi: Studies on the Oak Ridge Reservation and Their Relationship to Radivactive Waste Management," International Geological Congress, Washington, D.C., July 1990.

Strandberg, G. W., T. L Donaldson, A V. Palumbo, W. Eng, and J. Cosgrove "Biodegradation of Chlorinated Aliphatics in a Fixed-Film Methaintrophic Bioreactor," Annual Mecting of the Society for Industrial
Microbiology, Orlando, Florida, July 1990.

Suter, G. W., II

Species and Other Extrapolations in Aquatic and Other Systems,"

Colloquium on Uncertainty Issues in Hazard Assessment, Washington, D.C., April 1990.

Methods for Assessing Toxicological Risks to Populations of Fishes," Joint Meeting of the Pacific Northwest Chapter of SETAC and the Pacific Northwest Chapter of SOT, Corvallis, Oregon, September 1990.

Suter, G. W, II, and L W. Barnthouse Impact, Hazard, and Risk Assessment of Toxic Effects on Nonhuman Organisms," The Scientific Challenges of NEPA: Future Directions Based on 20 Years of Experience, Knoxville, Tennessee, October 1989.

Suter, G. W., II, S. W. Christensen, and Y. I. Jager

"Fitting Exposure-Response Models to Tests of Acidification Effects on Fish," 1990 International Conference, National Acid Precipitation Assessment Program, Acid Deposition: State of Science and Technology, Hilton Head, South Carolina, February 1990.

Tolbert, V. R.

"Use of an Aquatic Spill Model in the EIS Process to Predict Impacts from Destruction of Chemical Nerve Agents," Annual Mecting of the North American Benthological Society, Blacksburg, Virginia, May 1990.

Tolbert, V. R., and J. E. Breck "Predicting Mortality of Fish in Streams as the Result of Chemical Nerve Agent Spills," The Scientific Challenges of NEPA: Future Directions Based on 20 
Years of Experience, Knoxville, Tennessee, October 1989.

Tolbert, V. R, G. P. Zimmerman, and D. B. Hunsaker, Jr.

"Along the Aquatic Resources Pathway from Programmatic to Site-Specific: The U.S. Army Chemical Stockpile Disposal Program," Annual Meeting of the National Association of Environmental Professionals, San Antonio, Texas, June 1990.

Tschaplinski, T. J., and R. J. Norby "Elevated $\mathrm{CO}_{2}$ Increases Soluble Sugar Concentrations in Roots of Loblolly Pine Seedlings," 11th North American Forest Biology Workshop, Athens, Georgia, June 1990.

Turner, M. G.

Interactions Between Landscape Pattern and Ecological Processes," Elroy Rice Lecture Series, Department of Botany and Microbiology, University of OkJahoma, Norman, February 1990.

"Interactions Between Landscape Pattem and Ecological Processes," Seminar, University of Notre Dame, South Bend, Indiana, February 1990.

Turner, M. G., R. H. Gardner, and R. V. O'Neill

"Potential Responses of Landscape Structure to Global Climate Change," First European Symposium on Landscape Ecological Impacts of Climate Change, Lunteren, The Netherlands, December 1989.

The Effects of Landscape Pattem on Ecological Processes: Theory and Testing," Symposium: Methodology in Landscape Ecology, Fifth International Congress of Ecology, Yokohama, Japan, August 1990.
Turner, M. G., W. H. Romme, and R. H. Gardner

Spatial Heterogeneity of Bum Severity and First-Year Plant Responses to Fire on Subalpine Plateaus in Yellowstone National Park," Fifth Annual Landscape Ecology Symposium, University of Miami, Oxford, Ohio, March 1990.

Turner, M. G., W. H. Rommo, and L. L. Wallace

Simulation of Winter Foraging by Large Ungulates in a Heterogeneous Landscape," Annual Meeting of the Ecological Society of America, Snowbird, Utah, July 1990.

Turner, R. R., T. Barkay, and A. J.

VandenBrook

"Biotransformations of Mercury in

Contaminated and Control Streams in

Relation to the Abundance of Microbial Gene Sequences Encoding Mercury Resistance," International Conference on Mercury as an Environmental Pollutant, Gavle, Sweden, June 1990.

Turner, R. R., and G. A. Southworth

"Volatilization, Methylation, and

Demethylation of Mercury in a Mercury-Contaminated Stream," American Chemical Society Symposium-Mercury Mobility in the Environment, Raleigh, North Carolina, October 1989.

Turner, R. S.

"Assessing Global Change,"

Faculty-Alumni Symposium, University of Pennsylvania, Philadelphia, May 1990.

"Key Findings of the Aquatic Effects Research Program, Task Group VI," Final National Acid Precipitation Assessment Program Task Force 
Meeting, Washington, D.C., September 1990.

Turner, R. S., C. C. Brandt, D. D.

Schmoyer, P. W. Shaffer, M. G. Johnson, and M. B. Adams

"Regional Soil Characteristics of Statistically Selected Watersheds in the Northeast and Southern Blue Ridge Province," Annual Meeting of the Soil Science Society of America, Las Vegas, October 1989.

Tumer, R. S., R. B. Cook, H. Van Miegroet, D. W. Johnson, J. W. Elwood, O. P. Bricker, S. E Lindberg, and G. M. Hornberg

"Watershed and Lake Processes Affecting Surface Water Acid-Base Chemistry," 1990 International Conference, National Acid Precipitation Assessment Program, Acid Deposition: State of Science and Technology, Hilton Head, So'th Carolina, February 1990.

Turner, R. S., P. F. Ryan, D. R. Marmorek, K W. Thornton, J. P. Baker, S. W. Christensen, and M. J. Sale "Sensitivity to Change for Low-ANC Eastern U.S. Lakes and Streams and Their Associated Biota Under Alternative Sulfate Deposition Scenarios," Third International Conference on Acidic Deposition: Its Nature and Impacts, Glasgow, Scotland, September 1990.

Tuskan, G. A

"Short Rotation Woody Crops Program Summary," International Energy Agency Ecophysiology Meeting, Toronto, August 1990.

Van Hook, R. I.

"Global Environmental Studies as They Relate to the Southeast," Sixth Annual
Acid Rain Conference, Gatlinburg, Tennessee, October 1989.

"Energy Crop Resources," Industry Panel Committee on Alternative Energy R\&D Strategies, National Research Council, Washington, D.C. November 1989.

"ORNL Center for Global Environmental Studies," Cooperative Studies Unit of the National Part Service, The Unin' rsity of Tennessee, Knoxville, February 1990.

"Global Environmental Issues: ORNL's International Role," Earth Day Ceremonies, Oak Ridge, Tennersee, April 1990.

"Establishment of a National Fcological Research Program and Institute," Regional Public Meeting, Philadelphia, June 1990.

Van Hook, R. I., M. P. Farrell, W. R. Waldrop, S. Rayner, and W. Colglazier "ORNL-TVA-UT Research Consortium Global Studies Overview," Washington, D.C.. November 1989.

Van Miegroet, H., D. W. Cole, G. M. Lovett, and N. W. Foster

The Integrated Forest Study: Nitrogen Flux Patterns and Nitrogen Saturation," 1990 International Conference, National Acid Precipitation Assessment Program, Acid Deposition: State of Science and Technology, Hilton Head, South Carolina, February 1990.

Van Miegroet, H., C. S. Duncan, and D. W. Johnson

"Changes in Soil $\mathbf{N}$ Availability and Site N Fertility Following: Application of Municipal Sludge," Annual Mecting of 
the Soil Science Society of America, Las Vegas, October 1989.

Van Miegroet, H., D. W. Johnson, and D. E Todd

Soil Soluiion Chemistry in Two Spruce-Fir Stands Located at Different Elevations near Clingman's Dome, Great Smoky Mountains National Park," Gatlinburg, Tennessee, October 1989.

Van Winkle, W.

Proposed Three-Site Monitoring Program for Striped Bass," Technical Meeting on Issues Related to the Hudson River Settlement Agreement Monitoring Program, Albany, New York, November 1989.

Implications of the LAF Project: Current Applications and Future Research and EPRI's Program on Compensatory Mechanisms in Fish Populations," Briefing on the Electric Power Research Institute's Lake Acidification and Fisheries Project (LAF): Results and Conclusions, Arlington, Virginia, December 1989.

"Individual-Based Modeling as an Approach for Understanding Dynamics of Fish Populations," Invited Seminar for the Migratory Fish Research Institute and Department of Zoology, University of Maine, Orono, April 1990.

Van Winkle, W., and S. W. Christensen "Individual-Based Striped Bass Modeling as a Tool for Management," Annual Workshop on the Sacramento-San Joaquin Striped Bass Decline, Stockton, California, February 1990.
Von Damm, K L

${ }^{77} \mathrm{Be}$ and ${ }^{137} \mathrm{Cs}$ in Sediments from the Savannah River Estuary," DOE Contractors Meeting, FLEX

Workshop, Savannah, Georgia, December 1989.

"Quartz Solubility in Salt Solutions: Applications to Hydrothermal Systems," Fall Meeting of the American Geophysical Union, San Francisco, December 1989.

"Hot Springs on the Seafloor," East Tennessee Geological Society, Knoxville, Tennessee, January 1990.

"Geochemistry of Shale Groundwaters," Seminar, School of Geophysical Sciences, Georgia Institute of Technology, Atlanta, February 1990.

"Vent Fluid Chemistry on Cleft Segment: Where We Are and Where We Should Go," 1990 VENTS Workshop on the Cleft Segment, Southern Juan de Fuca Ridge, Pacific Marine Environmental Laboratory, National Oceanic and Atmospheric Administration, Seattle, March 1990.

"Seafloor Hydrothermal Systems: Hot Springs, Brines, and Drilling," Seminar, Department of Geological Sciences, The University of Tennessee, Knoxville, September 1990.

Voorhees, L. D.

"Development of a Consolidated Environmental Data Base," Seminar on Data Analysis and Interpretation for Environmental Surveillance, Lexington, Kentucky, February 1990. 
Voorhees, L D., A. E Rosen, L A. Hook, M. J. Gentry, M. A. Faulkner, J. L Bledsoe, and K. A. Newman "Easy Access to Selected ORNL RAP Data Sets," DOE Model Conference. Oak Ridge, Tennessee, October 1989.

Vose, R. S.

"A Regional Synoptic Index for the Delaware River Basin," Annual Meeting of the Association of American Geographers, Toronto, April 1990.

Walton, B. T., and S. S. Talmage Small Mammals as Indicators of Radionuclides, Heavy Metals, and Persistent Organic Chemicals," Symposium on In Situ Ecological Assessment of Hazardous Waste Sites, Annual Meeting of the Society of Environmental Toxicology and Chemistry, Toronto, November 1989.

Webb, J. W.

"Decision Making and NEPA Follow-up," DOE Office of NEPA Oversight Training Course, Pittsburgh, June 1990; Idaho Falls, Idaho, July 1990; Oak Ridge, Tennessee, August 1990.

"Preparing NEPA Dccumentation," DOE Office of NEPA Oversight
Training Course, Oak Ridge, Tennessee, June and August 1990; Idaho Falls, Idaho, July 1990.

Wright, L L

Relevance of Short Rotation Woody Crops Research to the Wood Products Industries," American Forest Council Meeting, Denver, October 1989.

"Biomass Production Program," Seminar for the Royal Forestry Society Tour Group, Norris, Tennessee, November 1589.

"A Program of Short Rotation Woody Crop Research," Seminar for the Brazilian delegation visiting The University of Tennessee, Knoxville, November 1989.

Wright, L. L, R. L. Graham, and A. Turhollow

Short Rotation Woody Crop Opportunities to Mitigate Global Warming," North American Conference on Forestry Responses to Climate Change, Washington, D.C., May 1990.

Wright, L L, and P. A. Layton "Short Rotation Woody Crops Program," DOE Management Review, Washington, D.C., April 1990. 


\section{Professional Activities}

ADAMS, S M

Chaiman: Workshop on Fish Health Assessment, sponsored by TVA, Muscle Shoak, Alabama; Assessing the Ecological Health of Hartwell Reservoir, sponsored by the U.S. Army Corp of Engineers, Hartwell, South Carolina.

Member. Socie' $f$ of the Sigma Xi.

Participant: Annual Meeting of the Society of Environmental Toxicology and Chemistry, Toronto, November 1989, Seminar on Environmental Stress, sponsored by TVA, Chattanooga, Tennessee, March 1990; 14th Symposium on Aquatic Toxicology and Risk Assessment, sponsored by the American Society for Testing and Materials, San Francisco, April 1990, Environmental Monitoring and Assessment Program Workshop, sponsored by EPA, New Orleans, May 1990, National Meeting of the American Fisheries Society, Pittsburgh, August 1990.

Faculty: Adjunct Faculty, Graduate Program in Ecology and Graduate Program in Environmental Toxicology, both The University of Tennessee.

Advisor. Ken Ham, Christine Gettys Hull, Ph.D. candidates, The University of Tennessce; Stan Sharp, M.S. candidate, The University of Tennessee.

Ad hoc reviewer. Transactions of American Fisheries Society; Canadian Joumal Fisheries Aquatic Sciences; Environment International; NSF proposals.

Other: Editor, American Fisheries Society, Symposium Publication No. 8.

\section{ASHWOOD, T. L}

Participan: SPECTRUM 90, sponsored by the American Nuclear Society, Knoxville, Tennessec, September 1990.

Advisor: Susan E. Lindahl, B.S., University of Wisconsin-Stevens Point;
Lisa S. Schilling. B.S. candidate, Virginia

Polytechnic Institute and State University; Marianne B. Donahue, B.S. candidate, Michigan State University, Mindy N.

Sarafi, Oak Ridge High School.

Other. Vice-Chairman, Environmental

Review Board, Roane County.

BARNIHOUSE, L W.

Member. Board on Environmental

Studies and Toxicology, Committee on

Risk Assessment Methodology, National

Research Council; Society of

Environmental Toxicology and Chemistry;

Steering Committee, Individual-Based

Modeling of Populations, Communities, and Ecosystems, sponsored by the Electric Power Research Institute/UT-ORNL Science Alliance, Knoxville, Tennessee. Participant: Workshop on Winter Flounder Biology, sponsored by NOAA, Mystic, Connecticut, December 1989, Public Health Aspects of the National Energy Strategy, sponsored by DOE, Bethesda, Maryland, July 1990; Seventh International Congress of Pesticide Chemistry, sponsored by the International Union of Pure and Applied Chemistry, Hamburg, Federal Republic of Germany, August 1990.

Ad hoc reviewer. Environmental

Toxicology and Chemistry.

Other. Board of Editors, Environmental Taxicology and Chemistry.

BARTEL, S. M

Advisor: Jackie A Cunningham, Ph.D. candidate, The University of Tennessee.

Ad hoc reviewer. Chemosphere; Lewis Publishers; NSF, EPA proposals.

Other: Editorial Board, Ecological Applications. 
BLASING, T. J.

Member: American Meteorological

Society, American Geophysical Union,

Society of the Sigma Xi, Air and Waste

Management Association.

Participant: High School Honors

Workshop, sponsored by DOE, Oak

Ridge, Tennessee, July 1990.

Faculty: Adjunct Associate Professor,

Department of Geography, The University

of Tennessee.

Ad hoc reviewer. Ecology, Ecological

Monographs; Unwin-Hyman Publishing

Company, NSF proposak.

BLAYLOCK, B G.

Member: Genetics Society of America,

Health Physics Society.

Participant: Enviroumental

Surveillance, Data Analysis and

Interpretation, sponsored by ORNL,

Lexington, Kentucky, February 1990;

Workshop on Environmental Screening,

sponsored by the National Council on

Radiation Protection and Measurements,

Sequim, Washington, July 1990.

Faculy: Adjunst Professcr, Graduate

Program in Ecology, The University of

Tennessee.

Advisor: Timothy Ament, B.S.

candidate, University of

Wisconsin-Stevens Point; Martina Renate

Goehringer, Isabel Ghosh, B.S. candidates, Berutsa Kademie Karlsruhe; Deborah A.

Mohrbacher, Richard V. Graham, Ph.D. candidates, The University of Tennessee;

Alicia E. Waters, M.S. candidate, The

University of Tennessee; Jacqueline

Ghiron, M.S. candidate, University of

Florida.

Ad hoc reviewer. Health Physics;

National Council on Radiation Protection and Measurements.

Other. Deputy Secretary, Union of Radioecologists.
BODEN, T. A

Participan: NOAAVGCC Program

Review, Boulder, Colorado, March 1990,

12th International CODATA Conference:

Data for Discovery, sponsored by the International Council of Scientific Unions, Columbus, Ohio, July 1990.

\section{BOGLE, M A}

Member. East Tennessee Chapter of the Health Physics Society, Association for Women in Science.

Other. Science-by-Mail participant, Knox County schook.

BORDERS, D. $M$

Member. American Society of Civil Engineers.

Participan: Third Tennessee Water

Resources Symposium, sponsored by the American Water Resources Association, Nashville, Tennescee, August 1990.

BOSTON, H L

Member. Ecological Society of America.

Participan: DOE RDDT\&E

Prioritization, sponsored by the DOE Orfice of Technology Development, Washington, D.C., February 1990; National Minority Environmental Career Conference, sponsored by CEIP, Washington, D.C., April 1990; Seminar on Waste Water, sponsored by the City of Oak Ridge, Oak Ridge, Tennessee, August 1990.

Faculy: Adjunct Professor, Department of Biology, Knoxville College; Faculty Affiliate, Department of Radiology and Radiation Biology, Colorado State University.

Advisor. Kim Trowbridge, M.S. candidate, University of North Carolina at Chapel Hill; Lisa Stctar, M.S. candidate,

Colorado State University;

Deborah A. Mohrbacher, Ph.D. candidate, The University of Tennessec.

Ad hoc reviewer. Ecology; NSF. 
Other. Urban League Black Executive Exchange Program.

CADA, G. F.

Participant: Annual Meeting of the National Association of Environmental Prefessionals, San Antonio, Texas, June 1990; Annual Meeting of the Ecological Society of America, Snowbird, Utah, July 1990; Annual Meeting of the American Fisheries Society, Pittsburgh, August 1990. Advisar. Lisa Au, B.S. candidate, Cornell University.

Ad hoc reviewer. Canadian Joumal of Fisheries and Aquatic Sciences; Hydro Review.

\section{CHRISTENSEN, $\mathbf{S} \mathbf{w}$.}

Participant: Third Workshop, Adirondack Lakes Survey Corporation Project on Evaluation of Surface Water Chemistry and Fish Communities, Albany, New York, October 1989; Aquatic Effects Research Program Workshop on Integrated Assessment: Question 3, Sensitivity to Change, sponsored by EPA for the National Acid Precipitation Assessment Program, Little Rock, Arkansas, November 1989; Electric Power Research Institute Workshop, Project on Compensatory Mechanisms in Fish Populations, Arlington, Virginia, November 1989; Electric Power Research Institute Briefing on the Lake Acidification and Fisheries Project: Results and Conclusions, Arlington, Virginia, December 1989; International Conference on Acidic Deposition: State of Science and Technology, sponsored by the National Acid Precipitation Assessment Program, Hilton Head, South Carolina, February 1990; Workshop on Populations, Communities, and Ecosystems: An Individual Perspective, sponsored by the Electric Power Research Institute/UT-ORNL Science Alliance, Knoxville, Tennessec, May 1990.
CLAPP, R R

Advisor. Albert C. Lin, B.S. candidate, Princeton University.

Ad hoc reviewer. Hydrological

Processes; Water Resources Research.

Other: Consultant North Carolina

Nature Conservancy on Hydrology.

COOK, R. B.

Participant: International Conference on Acidic Deposition: State of Science and Technology, sponsored by NAPAP, Hilton Head, South Carolina, February 1990; Remedial Action Program Review, sponsored by DOE/EPA, Chattanooga, Tennessee, July 1990; Permit Review Meeting, sponsored by TVA and the U.S. Army Corps of Engineers, Chattanooga, Tennessee, August 1990; International Conference on Acidic Deposition: Its Nature and Impacts, sponsored by the Royal Society of Edinburgh, Glasgow, Scotland, September 1990.

Ad hoc reviewer. Limnology and Oceanography; Biogeochemistry, EPA.

\section{COOPER, L W.}

Participant: R\&D Synthesis, sponsored by DOE/OHER, San Diego, May 1990.

Ad hoc reviewer. DOE proposal.

\section{CUNNINGHAM, M}

Chaiman: National Environmental Research Park Data Synthesis Workshop, sponsored by DOE, Oak Ridge,

Tennessee.

Member: Public Affairs/Involvement Committee.

Participant: Natural Areas Conference, sponsored by the Natural Areas Asscciation, Knoxville, Tennessee, October 1989; Sixth Annual Acid Rain Conference, sponsored by TVA, Gatlinburg, Tennessec, October 1989; National Environmental Research Park Colloquium, sponsored by DOE, Washington, D.C., November 1989; Botanicals and Pharmaceuticals in the Southern Appalachians Werkshop, 
sponsored by SAMAB, Asheville, North Carolina, March 1990, Joint Meeting of the Executive and Working committees, sponsored by SAMAB, Asheville, North Carolina, April 1990.

Other. Science-by-Mail participant, Oak Ridge and Knoxville County schook; Judge, seience fair posters, Lenoir City High Sctípol; Lecturer, Career Day, Oak Ridge High School

\section{CUSHMAN, J. H}

Member. Membership Committce, Society of the Sigma Xi, 1991 Southern Biomass Conference (ad hoc planning committee).

Participant: Energy from Biomass and Wastes XIV, sponsored by the Institute for Gas Technology, Lake Buena Vista, Forida, January 1990, Biofuels and Municipal Waste Technology Management Review, sponsored by DOE/BMWTD, Washington, D.C., April 1990.

Ad hoc reviewer. Biomass.

Other: Editorial Boasd, Biomass.

\section{CUSHMAN, $\mathbf{R} \mathbf{M}$}

Participant: The Scientific Challenges of NEPA, sponsored by DOE and others. Knoxville, Tennessee, October 1989, Earth Day Celebration, sponsored by Harpeth High School, Kingston Springs, Tennessee, April 1990.

Advisor: Kevin R. Birdwell, M.S. candidate, Murray State University, Richard C. Daniels, M.A. candidate, Miami University.

Ad hoc reviewer. Environmental Management.

\section{CUTSHALL, N. H}

Chaiman: Basic/Applied Research

Working Group, sponsored by DOE, Chicago.

Participant: Annual Fall Mecting of the American Gcophysical Union, San Francisco, December 1989; Symposium for RDDT\&E for Environmental Restoration and Waste Managemenh sponsored by DOE, San Francisco, December 1989, State and Tribal Governments Working Group, sponsored by DOE, Kansas City, Missouri, March 1990, Annual Meeting of the American Chemical Society, Boston, April 1990, Annual Meeting of the National Council on Radintion Protection, Washington, D.C. April 1990; Annual Meeting of the National Ascociation of Counties, Miami, July 1990; Annual Meeting of the National Conference of State Legislatures, Nashville, Teanessec, August 1990, National Meeting of the American Chemical Society, Washington, D.C. August 1990; Tennesece Water Resources Symposium, sponsored by the American Water Resources Aseociation, Nashville, Tennessee, August 1990.

\section{DALE V. $\mathbf{H}$}

Chaiman: Citizens for Quality Growth, City of Oak Ridge, Tennessee. Participant: Sixteenth Annual Natural Areas Conference, Knoxvilke, Tennessee, October 1989, Sixth Annual Acid Rain Conference, sponsored by TVA, Gatlinburg, Tennessee, October 1989; Seminar for Brazilian Environmental and Agro-forestry Specialists, sponsored by AID, Knoxville, Tennessee, November 1989, Workshop on Designing an Acid Deposition Policy Model for Southeast Asia, Bangkok, Thailand, November 1989, Workshop on Land Use Changes in South and Southeast Asia, San Juan, Puerto Rico, December 1989; Workshop on Public Participation in the National Forests, Knoxville, Tennessee, July 1990. Advisor: Robert Frohn, Master's internship candidate, Miami University of Ohio.

Ad hoc reviewer. Canadian Joumal of Forest Resear:h; American Midland Naruralist; Ficology; NSF proposals. Other. Elitor, special issue, Canadian Joumal of Forest Research. 
DANIELS, R C

Member. Association of American

Geographers, American Society for

Photogrammetry and Remote Sensing. Urban and Regional Information Systems Ascociation.

Participant: Annual Mceting of the Association of American Geographers, Toronto, Apri 1990.

DEANGEIS, D. L.

Chaiman: Everglades Symposium: Spatial and Temporal Patterns as Guidance for Restoration, sponsored by the U.S. National Park Service and the South Forida Water Management Board, Key Largo, Florida; Symposium on Individual-Based Modeling, sponsored by the Electric Power Research Institute/UTORNL Science Alliance, Knoxville, Tennessee; Symposium on Food Webs: Regularities and Their Causes, sponsored by the International Association for Ecology, Yokohama, Japan; OJI International Seminar, sponsored by the Japan Society for Promotion of Science, Fujiwara Foundation of Science, Gifu, Japan.

Member. Society for Mathematical Biology.

Participant: Workshop on Smallmouth Bass, sponsored by the Electric Power Research Institute and the Ontario Ministry of Natural Resources, Maple, Ontario, Canada, November 1989; Fisheries Research Assessment Annual Meeting, sponsored by the Ontario Ministry of Natural Resources, Callander, Ontario, Canada, April 1990.

Faculy: Adjunct Professor, Graduate Program in Ecology, The University of Tennessee.

Advisor. Jeffrey B. Hyman, Ph.D. candidate, The University of Tennessee; Anett S. Trebitz, Master's candidate. The University of Tennessee.

Other. Associate Editor, Mathema:ical Biosciences.
DEARSTONE, $\mathbf{K} \mathbf{C}$

Participant: GISILIS 89 Annual Conference and Exposition, sponsored by ACSM and others, Orlando, Florida, November 1989, ESRI Annual User Conference, sponsored by the Environmental Systems Research Institute, Palm Springs, Califomia, May 1990, Southeast ARCINFO User Conference, sponsored by ESRI, Atlanta, September 1990.

\section{DREIER, R R}

Paricipant: Applied Drilling Engincering for Rotary and Auger Methods, sponsored by ihe National Water Well Association, Columbus, Ohio, November 1989, Quantitative Interpretation of Joints and Faults, sponsored by the Geological Society of America, St. Louis, November 1989, Third Tennessee Water Resources Symposium, sponsored by the American Water Resources Association, Nashville, Tennessee, August 1990.

Facully: Assistant Professor, Department of Geological Sciences, The University of Tennessee.

Advisor. P. J. Lemiszki, Ph.D. candidate, The University of Tennessee.

EARLY, T. O.

Participant: Meeting of the Southeastem Section of the Geological Society of America, Tuscaloosa, Alabama, March 1990; Third Tennessee Water Resources Symposium, sponsored by the American Water Resources Association, Nashville, Tennessee, August 1990. Other. Associate Editor, Environmental Effects Section, Nuclear Safery.

EDDLEMON, G. $\mathbf{K}$

Chaiman: Session chair, The

Scientific Challenges of NEPA, sponsored by DOE and others, Knoxville, Tennessec. 
Member: American Fusheries Society, Society of the Sigma $\mathbf{X}_{\mathbf{i}}$. East Tennessee Chapter of the Health Physics Society, Tau Beta Pi National Engineering Society.

Participant: The Scientific Challenges of NEPA, sponsored by DOE and others, Knoxville, Tennessee, October 1989, Annual Meeting of the Ecological Society of America, Snowbird. Utah, July 1990, DOE Tiger Team Environmental Assessments: Hanford, Savannah River, Panter, and Nevada Test Site.

Other. United Way Allocations Panel Liaison Committee, Knox County.

EDWARDS, N. T.

Participant: Sixth Annual Acid Rain Conference, sponsored by TVA, Gatlinburg. Tennessee, October 1989, Annual Meeting of the Ecological Society of America, Snowbird, Utah, July 1990, Fourth International Congress of Systematic and Evolutionary Biology, sponsored by the University of Maryland, College Park, Maryland, July 1990; ROPIS West Reviciw, sponsored by the Electric Power Research Institute, Newport, Oregon.

Ad hoc reviewer. Canadian Joumal of Forest Research; Joumal of Environmental Qualiny, Environmental Science and Technolozy, Soil Science Saciety of America of Joumal; Forest Science; Pedobiologia.

ELWOOD, J. W.

Participant: LTER Global Change Workshop, sponsored by the National Science Foundation, Denver, November 1989.

Faculy: Adjunct Professor, Graduate Program in Ecology, The University of Tennessee; Adjunct Professor, Department of Biology, Vanderbilt University; Adjunct Professor, Institute for Environmental Studies, University of Itlinois.

Advisor. Scung do Kim, Ph.D. candidate, University of Illinois;
Amy D. Rosemond, $\mathrm{Ph}$. candidate, Vanderbilt University.

Ad hoc reviewer. Jowmal of

Environmental Qualing, Canadian Joumal of Fisheries and Aquatic Sciences; Water, $A i r$, and Soil Pollution; Limnology and Oceanography; Nature; Joumal of the North American Benthalogical Socieny, Water Resources Research; Climate Research; Ecolozy, EPA report; NSF proposals.

EMANUEL, W. R. Member: Worting Group on Integrated Global Change Modeling. Committee on Global Change, National Research Council

Faculty: Faculty Associate, Graduate Program in Ecology, The University of Tennessee.

Ad hoc reviewer. Clinatic Change; Joumal of Climate; Science; Tellus; Ecology, DOE, NSF proposals; Intergovernmental Panel on Climate Change report.

\section{FARREL, M P.} Chaiman: Global Change: A Southern Perspective, sponsored by DOE and others, Charleston, South Carolina; Technologies for a Greenhouse-Constructed Society, sponsored by DOE, Oak Ridge, Tennessee.

Participant: UT-TVA-ORNL Consortium, sponsored by DOE and others, Washington, D.C., February 1990; NSF EPSCOR Conference, Washington, D.C., August 1990.

\section{FAULKNER, $M$ A}

Participant: Conference on Data Analysis and Interpretation for Environmental Surveillance, sponsored by DOE, Lexington, Kentucky, February 1990; SAS Uscrs Group International Conference Proceedings, sponsored by Statistical Analysis Systems, Inc., Nashville, 
Tennessee, April 1990, Environmental Systems Research Institute User Conference, Palm Springs, California, May 1990.

Advisor. Pat A. Scarbrough, MS. candidate, Murray State University.

FONTANE, T. A

Member. American Geophysical

Unicn, American Society of Civil

Engineers.

Participant: Clay Liners and Cov:"rs for Waste Disposal Facilities, sponsored by The University of Texas, Austin, Teses, February 1990, Solidification/

Stabilization-Mechanisms and Applications, sponsored by the Gulf Coast Hazardous Substance Research Center, Beaumont, Texas, February 1990; HELP Modeling Workshop, sponsored by the University of Wisconsin, Milwaukee. March 1990.

Ad hoc reviewer. Water Resources Bulletin.

\section{FORSTROM, J. M}

Paicicipan: Third Tennessee Water Kesources Sympusium, sponsored by the American Water Resouras Association, Nashville, Tennessee. August 1990.

Ad hoc reviewer. NRC environmental impact statement.

Other: Councillor (elected), East Tennessee Gcological Society.

FRANCTS, C. W.

Participant: Soil Washizg Workshop, sponsored by DOE, Las Vegas, August 1990.

Ad hoc reviewer. Soil Science Society of America Joumal; Water, Air, and Soil Pollution; Environmental Science and Technology: American Socicty for Testing and Matcrials symposium publication.

FRANK, M. L.

Participant: Symposium on Access and Usc of Information Resources in Assessing
Health Rists from Chemical Exposure, sponsored by EPA, Oal Ridge, Tennessee, June 1990.

GARDNER, R H

Chairman: Session chair, 1990 U.S. Landscape Ecology Symposium, Oxford. Chio.

Participant: Invited Participant, NSF

Wortshop on Mathematics and Biology. The Interface, Challenges and Opportunitiex, Washington, D.C., April 1990; Annual Meeting of the Ecological Society of America, Snowbird, Utah, July 1990; U.S. Landscape Ecology Society Annual Meeting, Oxford, Ohio, July 1990.

Facully: Adjunct Prolessor, Graduate Program in Ecology, The University of Tennessee.

Ad hoc reviewer. Ecology;

Environnental Management; Landscape Ecology, Ecological Society of America symposium volume; NSF proposal

GARLAND, S. B, I

Member. Water Pollution Control Federation, Hazardous Waste Committee, American Society of Civil Engineers, American Water Well Association.

Participant: Laboratory Services, sponsored by NUS, Houston, October 1989; Invited speaker, WATTec 90, Knoxville, Tennexsee, February 1990; Mixed Waste Regulation Conference, sponsored by Executive Enterprises, Albuquerque, New Mexico, Junc 1990, Design and Construction of RCRACERCLA Final Covers, sponsored by EPA, Chicago, August 1990.

Advisor. Melissa Sipe, A.S. candidate, Roane State Community College; Guy Reiler, B.S. candidate, Cornell University; Joel Ehrfurth, B.S. candidate, University of Wisconsin; Rochclle Martino, B.S. candidate, Texas A\&I University. 
GARIEN, C T, Jr.

Participant: International Chemical Congress of the Pacific Basin Societiex, sponsored by the American Chemical Society, Honolulu, December 1989. Annual Meeting of the Ecological Society of America, Snowbird, Utah, July 1990, International Conference on Acidic Deposition, sponsored by the Royal Society of Edinburgh, Glasgow, Scotland, September 1990.

Ad hoc reviewer. Joumal of

Environmental Quality.

GEHRS, C W.

Participant: UT-TVA-ORNL Research Consortia Briefing, sponsored by the Tennessee Congressional Delegation. Washington, D.C., November 1989, Subsurface Science Meeting Program Review, sponsored by DOEOHER, Germantown, Maryland, March 1990, DOE. Environmental Biotechnology Review Workshop. sponsored by DOE/OTD, Idaho Falls, Idaho, April 1990; RDDT\&E Mid-Year Review, sponsored by DOENOTD, Germantown, Maryland, June 1990, Technical Review of RFPs for OTD R\&D, sponsored by DOEDTD, Breckenridge, Colorado, July 1990.

GRAHAM, R L Member. Technical Steering

Committee, Center for Forest

Environmental Studies.

Participant: Review of Park Service Research Proposals on Climate Change, sponsored by the U.S. Park Service, New Orkans, May 1990; Interagency Meeting on FAO 1990 Tropical Forest Resource Assessment, sponsored by the USDA Forest Service, Washington, D.C., August 1990.

Ad hoc reviewer. Landscape Ecology; DOE; EPA.

Other: Lecturer, ORAU

undergraduate programs and Oak Ridge

Muscum of Science; Speaker, ORNL
Conference for College Women; Advisor, DOE High School Honors Program.

GUNDERSON, C A

Member. American Society of Plant Physiologists.

Pericipant: Annual Mecting of the American Society of Plant Physiologists, Indianapolis, August 1990.

HAASE, C S

Odher. President, East Tennessee Geological Society.

HANSON, P. J.

Member. Air and Waste Management Association, American Association for the Advancement of Science, American Society of Agronomy, American Society of Plant Physiologists.

Participant: International Conference on Environmental Research with Plants in Closed Chambers, sponsored by Geselkchaft für strahlen und unureltforschung, Munich, Federal Republic of Germany, October 1989, International Congress on Forest Decline Research, Friedrichshaften, Federal Republic of Germany, October 1989, First Annual Walker Branch Watershed Research Symposium, sponsored by ORNL, Oak Ridge, Tennessee, March 1990, Measurement of Toxic and Related Air Pollutants, sponsored by EPA and the Air and Waste Management Association, Raleigh, North Carolina, May 1990, 13th North American Forest Biology Workshop, sponsored by the University of Georgia and the Tree Physiology Working Group of the Society of American Forestry. Athens, Georgia, June 1990; Peer Review Workshop for Nitrogen Oxide Criteria Document, sponsored by EPA, Research Triangle Park, North Carolina, July 1990, Annual Meeting of the American Socicty of Plant Physiologists, Indianapolis, August 1990. 
Advisor. Kelly Maas, B.S. candidate, Doane College; D. Susansac Ramer, B.S. candidate, Artansas State University.

Ad hoc reviewer. Tree Physiology. Joumal of Envirommental Quality. Physiologia Plantanum; NSF, USDA, Natural Environmental Research Council grants.

\section{HARRINGTON, R R}

Participant: dBase Introduction and Advanced dBase, sponsored by The University of Tennessee Training and Development Center, Knowille. Tennessee, September 1990, Data Analysis Interpretation for Environmental Surveillance, sponsored by ORNL, Lexington, Kentucky, February 1990, ESRI 1990 User Conference, sponsored by Environmental Systems Research Institute, Palm Springs, California, May 1990, Principles of Ground Water Hydrology, sponsored by the National Water Well Association, Portland, Oregon, July 1990, ARCINFO Training Course, sponsored by Environmental Systems Research Institute. Redlands, California, August 1990. Southeast ARCINFO User Conference, sponsored by Georgia Institute of Technology, Atlanta, September 1990.

Faculy: Prolessor, Mathematics, Roane State Community Colkge; Professor, Mathematics, Pellissippi State Community College.

\section{HATCHER, R D, Jr.}

Member. Board on Radioactive Waste Management, National Research Council, Earth Sciences Advisory Committee. Corporate Fellows Subcommittee on Geosciences, Structural Geology/Tectonics Division Career Award Nominating Committce.

Participant: Gcology of the Eastern Bluc Ridge of Northeastern Georgia and the Adjacent Carolinas, sponsored by the Gcorgia Gcological Socicty, Dillard. Gcorgia. October 1989; Gilbert Fellowship
Panel Meeting. sponsored by the U.S. Geological Survey, Reston, Virginia, October 1989, Oal Ridge Reservation Geology Field Trip, sponsored by ORNL, Oak Ridge, Tennessee, October 1989, Sixteenth Natural Areas Conference, sponsored by TVA, Knouville, Tennessee, October 1989. Annual Meeting of the Geological Society of America, St. Louis, November 1989, New Madrid Seismic Zone Workshop, spensored by the U.S. Geological Survey, Memphis, November 1989, Savannah River Site Seismicity Workshop, sponsored by Lawrence Livermore Laboratory, Hilton Head, South Carolina, December 1989, EDGE Workshop, sponsored by the Houston Area Research Center, Philadelphia, January 1990; Geology and Geophysics Seminar/Special Lecture, sponsored by Rice University, Houston, January 1990, Structure and Tectonics of the Southern Appalachians, sponsored by Exoon Company, Houston, January 1990; Geology Department Seminar, sponsored by Vanderbilt University, Nashville, Tennessee, February 1990, Lithoprobe Panel Meeting, sponsored by the National Research Council of Canada, Vancouver, British Columbia, Canada, March 1990, EDGE Workshop, sponsored by the Houston Area Research Center, Houston, April 1990; Thrust Tectonics Intemational Conference, sponsored by Royal Holloway and Bedford New College, Egham, England, April 1990; International Drilling Symposium, sponsored by Kontinentales Tieibohrprogramm der Bundesrepublik Deutschland, Regensburg, Germany, September 1990; Symposium on Radioactive Waste Disposal, sponsored by the National Academy of Sciences,

Washington, D.C., September 1990.

Faculty: Distinguished Scientist and Professor of Geology, The University of Tennessec.

Advisor. Keith I. McConncll, John O. Costcllo, Alice L. Sticve, Ph.D. candidates, 
University of South Carolina; Timothy L Davis, Peter J. Lemiszki, Janet L Hopson, Elizabeth A McClellan, Angang Liu, Ph.D. candidates, The University of Tennessee; H. Ann Burns, Michael J. Quinn, Master's candidates, The University of Tennessee.

Ad hoc reviewer. Tectonics; Geology; Southeastem Geology, Science; Academic Press; NSF, DOE, American Chemical Society proposals.

Other. Editor, special issue, Tectonophysics; Invited lecturer, National Science and Technology Week, Oak Ridge. Tennessee; Coordinator, Georgia Geological Society Field Trip, Dillard, Georgia; Co-chairman, EDGE Planning Committee.

\section{HAYNES, G. J.}

Member: Environmental Education Comnittee, Southern Appalachian Man and the Biosphere Cooperative; PIP Symposium.

Participan: PIP Symposium, sponsored by Martin Marietta Energy Systems, Inc., Oak Ridge, Tennessee, November 1989, Southern Appalachian Man and the Biosphere Cooperative, spensored by ESD, Asheville, North Carolina, November 1989; Values Quarterly Meeting, sponsored by Portsmouth Values Committee, Portsmouth, Ohio, February 1990, Values Quarterly Meeting. sponsored by Paducah Values Committee, Paducah, Kentucky, May 1990.

Advisor. Beatrice Jones, Bachelor's candidate, Selma University.

Other: Coordinator, Values Committee, Martin Marietta Energy Systems, Inc.

\section{HERBES, S. E}

Faculty: Adjunct Associate Professor, Graduate Program in Ecology. The University of Tennessee.

Ad hoc reviewi,: Environmenial Science and Technology.
HIIDEBRAND, S G. Chaiman: The Scientific Challenges of NEPA, sponsored by DOE and others, Knoxville, Tennessee.

Member. Public Relations Committce, American Fisheries Society.

Participant: International Conference on Acidic Deposition: State of Science and Technology, sponsored by the National Acid Precipitation Assessment Program, Hilton Head, South Carolina, February 1990.

Faculty: Adjunct Faculty, Graduate Program in Ecology, The University of Tennessee.

Other: United Way Allocations

Committee, Knoxville Metropolitan Area.

\section{HOFFMAN, F. $O$.}

Chaiman: IAEAVAMP, Multiple

Pathways Assessments, sponsored by the International Atomic Energy Agency, Vienna; BIOMOVS, Swedish National Institute for Radiation Fiutection, Ottawa and Paris; National Council on Radiation Protection and Measurements.

Participant: BIOMOVS-8, sponsored by the Swedish National Institute for Radiation Protection, Ottawa, November 1989, IAEAVAMP, Validation of Assessment Model Predictions, sponsored by the International Atomic Energy Agency, Vienna, December 1989; BIOMOVS-9, sponsored by the Swedish National Institute for Radiation Protection, Paris, April 1990; Screening Models for Air, Surface Water, and Groundwater, sponsored by the National Council for Radiation Protection and Measurements, Sequim, Washington, July 1990.

Advisor: Richard Graham, Deborah A Mohrbacher, Ph.D. candidates, The University of Tennessee. Ad hoc reviewer. Health Physics; Radiochimica Acta; Joumal of En'ironmental Quality; Risk Analysis; BIOMOVS tcchnical reports. 
Other. Presentation, Roane/Anderson County Economic Commission.

HUFF, D. D.

Chaiman: Annual Meeting, National Council on Radiation Protection and Measurements, Washington, D.C.; Third Tennessee Water Resources Symposium, sponsored by the American Water Resources Association, Nashville, Tennessee.

Member: National Water Well Association, American Geophysical Union, American Institute of Hydrology.

Participant: Environmental

Biotechnology Working Group, sponsored by DOE, Berkeley, California, December 1989; Annual Meeting of the National Council on Radiation Protection and Measurements, Washington, D.C. April 1990; Review of Portsmouth RCRA Closures, sponsored by Environmental Restoration, Piketon, Ohio, May 1990; Third Tennessee Water Resources Symposium, sponsored by the American Water Resources Association, Nashville, Tennexsee, August 1990.

Faculy: Adjunct Professor,

Department of Geological Sciences, The University of Tennessee.

Ad hoc reviewer. DOE.

Other. President, Tennessee Section, American Institute of Hydrology.

\section{HUNSAKER, C. T.}

Chaiman: Riparian and We:land

Ecotones, U.S. Man and the Biosphere Program, Oak Ridge, Tennessee; Fifth Annual Landscape Ecology Symposium, Oxford, Ohio; Wildlife Workshop for Ecological Indicators, sponsored by the EPA Environmental Monitoring and Assessment Program, Las Vegas; 62nd Annual Conference, Water Pollution Control Association, San Francisco. Member. Ecological Socicty of America. EPA Science Advisory Board, DOE Scicnce and Enginecring Rescarch
Advisory Council, Waręr Pollution Control Federation, National Association of Environmental Professionals, Society of the Sigma Xi, DOE Multi-Laboratory Climate Change Committee.

Participant: Task Force on Mapping,

Convention on Long Range

Transboundary Air Pollution, sponsored by the United Nations Commission for Europe, Bad Harzburg, Federal Republic Germany, November 1989;

Characterization Workshop for the Environmental Monitoring and Assessment Program, sponsored by EPA, Las Vegas, March 1990; Evaluation of the Ecological Indicators for the Environmental Monitoring and Assessment Program, sponsored by EPA, Washington, D.C., May 1990; Evaluation of the Ecoregions Concept, sponsored by EPA, Corvallis, Oregon, May 1990; Making Decisions on Cumulative Impacts, sponsored by the Conservation Foundation, Council on Environmental Quality, EPA, and the National Science Foundation, Washington, D.C., June 1990. Advisor. Steven Kopp, M.S. candidate, Indiana State University; Daniel Levine, Ph.D. candidate, Indiana University; John Draves, M.S. candidate, Pennsylvania State University. Ad hoc reviewer. The Environmental Professional; Landscape Ecology; Environmental Management; U.S. Man and the Biosphere Program proposal; Leopold Center for Sustainable Agriculture proposal.

Other. Advisory Board, The

Environmental Professional.

HUSTON, M A Chaiman: Walker Branch Watershed Rescarch Symposium, sponsored by DOE, Cak Ridge, Tennessee; Advancing Toward Closure of the Carbon, Nitrogen and Hydrologic Cycles, sponsored by the National Science Foundation and the USDA Foı cst Scrvice, Granby, Colorado. 
Member. Southem Appalachian Man and the Biosphere Consortium; Steering Committee, Populations, Communities, and Ecosystems: An Individual Perspective, sponsored by the Electric Power Research Institute/UT-ORNL Science Alliance, Knoxville, Tennessee.

Participant: Annual Meeting of the Ecological Society of America, Snowbird, Utah, July 1990.

Faculty: Adjunct Professor, Graduate Program in Ecology, The University of Tennessee.

Advisor: Larry Pounds, Ph.D. candidate, The University of Tennessee; Aida Sulivan, B.S. candidate, University of Puerto Rico; Eric Hartzell, B.S. candidate, Miami University of Ohio.

Ad hoc reviewer. Ecology; Vegetatio; American Naturalist; NSF proposals.

Other: Environmental Quality Advisory Board, Oak Ridge, Tenncssee; Lecturer, Kingston High School, Kingston,

Tennessee.

JACOBS, $\mathbf{G}$. $\mathbf{K}$ Chaiman: Basic Research Needs in Performance Assessment for Environmental Restoration, sponsored by DOE, Oak Ridge, Tennessee.

Participant: Subsurface Science Program Review, sponsored by DOE, Gaithersburg, Maryland, March 1990.

Faculty: Adjunct Faculty, Department of Geological Sciences, The Univ'ssity of Tennessee.

Advisor: J. L Foreman, Ph.D. candidate, The University of Tennessee.

\section{JARDINE, P. M}

Participant: American Society of Agronomy National Meetings, Las Vegas, October 1989; Project Review-Subsurface Science Program, sponsured by DOE, Georgetown, Maryland, March 1990; Review of Intermediate-Scale Experiments for Subsurface Microbiology and Chemistry, sponsored by DOE, Lewis,
Delaware, April 1990; American Geophysical Union National Meetings, Baltimore, May 1990, Radionuclide Adsorption Workshop, sponsored by Los Alamos National Laboratory, Los Alamos, New Mexico, September 1990.

Advisor: Matt Averiall, B.S. candidate, Albion College; Matt Giorgi, B.S. candidate, Le Moyne College; Tanya Mehlhorn, Andy McNabb, John Stinitte, Virginia Harless, B.S. candidates, The University of Tennessee.

Ad hoc reviewer. Soil Science Society of America Joumal; Joumal of Hydrologic Processes; Journal of Environmental Quality, Geoderma; Water Resources Research; Environment Intemational; EPA proposals.

Other: ORNL Paper Recycling Program.

\section{JOHNSTON, J. W.}

Participant: NCR-135 Annual Meeting, sponsored by USDA-CSRS, Des Moines, Iowa, May 1990.

\section{KANCIRUK, $P$.}

Member. CEES Data Management Task Group, Interagency Working Group on Data Management for Global Changes.

Participan: International Symposium on Climate Change, sponsored by DOE and the People's Republic of China Ademica Sinica, Beijing, China, August 1990; USSR-USA Bilateral Meeting on Data Exchange, sponsored by the U.S. State Department, Obmisk, U.S.S.R., August 1990.

\section{KEILY, J. M}

Chaiman: Eighth North American Forest Soils Conference, Gainesville, Florida.

Member. Nominations and Awards Commitree, Soil Science Society of America.

Participant: Workshop on Modeling Plant Response to Interacting Stress, 
sponsored by the Electric Power Research Institute, Newport, Oregon, May 1990.

Faculty: Adjunct Professor, Graduate Program in Ecology and Department of Forestry, Wildlife and Fisheries, both The University of Tennessee; Adjunct Professor, Department of Forestry and Natural Resources, Purdue University. Other. Associate Editor, Soil Science Society of America Joumal.

\section{KIMME2, B. L} Member: Ecosystem Studies Program, Directorate for Biotic Systems and Resources, National Science Foundation; International Relations Committee, North American Lake Management Society; Commonwealth Center of Excellence in Reservoir Ecosystem Science, Murray State University.

Participant: NSF Ecosystems Program Panel Meetings, Washington, D.C., October 1989; Second Workshop on Water Science and Engineering, sponsored by the Center for Reservoir Research, Murray State University, Atlanta, April 1990; EMAP_Surface Waters Workshop, sponsored by EPA, New Orleans, May 1990; Environmental Regulations Conference, sponsored by Executive Enterprises, Inc., New Orleans, May 1990; Mid-Year Environmental Restoration Program Preview, sponsored by DOE, Portsmouth, Ohio, May 1990.

Faculty: Faculty Associate, Graduate Program in Ecology, The University of Tennessee.

Advisor. Pamcla Krahl, B.S. candidate. U.S. Naval Academy.

Ad hoc reviewer. Canadian Joumal of Fisheries and Aquatic Sciences; Ecology; Joumal of the North American Benthological Society; Lake and Reservoir Management; Limnology and Oceanography; NSF proposals.

Other. Editorial Board, Limnology and Oceanography: Editorial Board, Lake and Reservoir Management.
KING, A W.

Participant: Ecologists Workshop, sponsored by USDA Forest Service, Madison, Wisconsin. November 1989.

Ad hoc reviewer. DOE proposal; book chapter; EPA

KORTE, N. E

Ad hoc reviewer. Environmental Science and Technology; Environmental Management.

KROODSMA, R L

Ad hoc reviewer: Auk, Southeastern Association for Fish and Wildlife.

KSZOS, L A

Member. Water Pollution Control Federation, Society of Environmental Toxicology and Chemistry.

Participant: Annual Meeting of the Society of Environmental Toxicology and Chemistry, Toronto, October 1989; NPDES Wastewater and Stormwater Seminar, sponsored by CDM Eederal Programs Corporation, Oak Ridge, Tennessee, August 1990. Advisor. James Sumner, B.A candidate, University of New Hampshire. Other. Secretary, Association for Women in Science.

\section{LARSEN, I L}

Participant: DOE University Research Instrumentation Program, Salt Lake City, March 1990.

Advisor. Lisa Stetar, M.S. candidate, Colorado State University. Ad hoc reviewer. Water, Air, and Soil Pollution.

\section{LEE, S. Y.}

Member. Clay Minerals Society, Soil Science Socicty of America (ad hoc member).

Participant: Annual Mccting of the Clay Mincrals Socicty, Sacramento, California, September 1989; International 
Symposium on Hazardous Waste

Treatment, sponsored by EPA, Cincinnati,

February 1990.

Faculty: Adjunct Associate Professor, Department of Plant and Soil Science, The University of Tennessee.

Ad hoc reviewer. Soil Science Society of America Joumal; Soil Science; Clays and Clay Minerals.

\section{LIETZKE, D. A}

Advisor. Stanley Crownover, Ph.D. candidate, University of Florida.

Ad hoc reviewer: Scil Science Society of America Joumal.

Other. Secretary-Treasurer and

Executive Secretary, National Society of Consulting Soil Scientists.

\section{LINDBERG, S. E}

Chairman: U.S. National Atmospheric Deposition Program; Working Group on New Initiatives for the U.S. National Atmospheric Deposition Program; Session on Application. Throughfall Methods, International Conference on Acidic Deposition; Atmospheric Chemistry Review Panel, Swedish Environmental Protection Board Project on Mercury in the Swedish Environment.

Member. Expert Revicw Panel, Swedish Environmental Protection Board for Research on Mercury; Advisory Panel, Air and Deposition Monitoring Group of the EPA Program on Environmental Monitoring and Assessment; MAP3S/RAINE Precipitation Chemistry Network; Honorary Steering Committee, International Conference Series: Heavy Metals in the Environment; Exccutive Committee, NADP/NTN; Technical Organizing Committee, Eighth International Conference on Heavy Metals in the Environment (Edinburgh); Program Committee, International Conference on Metals in Soils, Waters, Plants and Animals; Conference on Global Atmosphere/Biosphere Interactions.
Participant: International Congress on Forest Decline, Fredrichshafen, Federal Republic of Germany, October 1989; Annual Technical Meeting of NADP, Provincetown, Massachusetts, November 1989; Sixth Annual Acid Rain Conference, sponsored by TVA, Gatlinburg, Tennessee, November 1989, NAPAP State of Science Conference, Hilton Head, South Carolina, February 1990; First International Conference on Mercury as an Environmental Pollutant, Gavke, Sweden, June 1990; International Conference on Acidic Deposition, Glasgow, Scotland, September 1990; NAS Review of DOE Atmospheric Chemistry Program, Georgetown, Maryland, September 1990; Symposium on Interdisciplinary

Environmental Research, sponsored by the Free University of Amsterdam,

Amsterdam, The Netherlands, September 1990.

Advisor. D. Goldbold, Habilitation candidate, University of Gottingen, Germany; W. Ivens, Ph.D. candidate, University of Utrecht, The Netherlands. Ad hoc reviewer: Tellus; Atmospheric Environment; Joumal of Environmental Quality; Water, Air, and Soil Pollution; Canadian Joumal of Forest Research; Springer-Verlag.

Other. Editorial Board, Advances in Environmental Science.

\section{LUXMOORE, R. J.}

Chaiman: Whole Plant Physiology

Working Party; Session chair, Solar Conversion Efficiency of Forests, IUFRO World Congress, Montreal.

Member. Committee on Ground Water Recharge; Board, Tennessee Citizens for Wilderness Planning.

Participant: Annual Meeting of the Soil Science Society of America, Las Vegas, October 1989; Advancing Towards Closure of the Carton, Water and Nutrient Cycles, sponsored by NSF and others, Granby, Colorado, June 1990; 
Workshop on Mathematics and

Environmental Waste Problems, sponsored by DOE, Oak Ridge, Tennessee, July 1990; 19th World Congress, sponsored by IUFRO, Montreal.

Faculty: Adjunct Professor, Life Sciences Consortium, The University of Tennessee.

Ad hoc reviewer. Water Resounces

Reseanch; Joumal of Environmental Qualiny; Tree Physiology, NSF, USDA proposals.

Other: Associate Editor, Tree Physiology; Technical Editor, Soil Science Society of America Joumal.

\section{MANN, L K}

Participant: Annual Meeting of the Soil Science Society of America, Las Vegas, October 1989; Environmental Research Park Workshop, sponsored by ESD, Oak Ridge, Tennessee, October 1989; Walker Branch Workshop, sponsored by ESD, Oak Ridge, Tennessee, April 1990.

Ad hoc reviewer. Eighth Central Hardwoods Conference manuscript.

Other. Secretary, Board of Supervisors, Soil Conservation Service, Roane County, Tennessee.

MARSH, J. D.

Participant: High School Honors Workshop, sponsored by DOE, Oak Ridge, Tennessee, July 1990; Workshop on Mathematics and Environmental Problems, sponsored by DOE, Oak Ridge,

Tennessee, July 1990.

Advisor. Evelith Olemda-Miro, M.S. candidate, University of Puerto Rico.

\section{MARSHALI, D. S.}

Paricipant: Third Tennessee Water Resources Symposium, sponsored by the American Water Resources Association, Nashville, Tennessec, August 1990.
MCCARTHY, J. F.

Chairman: Organics in Water and

Sediments-Biological Processes,

sponsored by the American Chemical

Suciety, Boston.

Member. Society for Environmental

Toxicology and Chemistry, American

Chemical Society.

Participan: Pacifichem 89, sponsored by the American Chemical Society, Honolulu, December 1989; Tenth Meeting of European Community's Colloid and Complexation Club, sponsored by Mirage Project of the European Community, Oxford, England, February 1990; Biological Monitoring at Hazardous Waste Sites, sponsored by the EPA Health Effects Laboratory, Research Triangle Park, North Carolina, April 1990; Symposium on Organics in Sediment and Water-Biological Processes, sponsored by the American Chemical Society, Boston, April 1990; ORNL Life Sciences Symposium, sponsored by ORNL, Gatlinburg, Tennessee, May 1990.

Faculty: Adjunct Faculty, Graduate Program in Ecology, The University of Tennessee.

Advisor: B. Satmark, Ph.D. candidate, Chalmers Institute of Technology, Göleborg, Sweden; J. Saiers, Ph.D. candidate, University of Virginia. Ad hoc reviewer. Environmental Science and Technology; Archives of Environmental Contamination and Taxicology; DOE; EPA; American Chemical Socicty.

McCORD, R A

Panicipant: Tennessee Natural

Resources GIS Users Meeting, sponsored by Tennessee Soil Conservation Services, Nashville, Tennessee, January 1990; ESRI User Conference, sponsored by Environmental Systems Rescarch Institutc, Inc., Palm Springs, California, May 1990. 
MCLAUGHIN, S. B.

Member. Panel on the Effects of Climate Change on Forest Response, Annual Meeting of the Air and Waste Management Association, Pitsburgh, June 1990.

Participant: Program Review, U.S. Forest Service North Central Station, Rhinelander, Wisconsin, July 1990.

Advisor: Alan Stam, Ph.D. candidate, The I'niversity oi Tennessee.

MCMASTER, W. M

Chaiman: Co-chairman,

Hydroforum-A Continuing Symposium

for Those Involved in Hydrology of ORR, Oak Ridge, Tennessee.

Member. National Water Well

Association.

MOORE, G. K

Participant: Third Tennessee Water Resources Symposium, sponsored by the American Water Resources Association, Nashville, Tennessee, August 1990.

\section{MULHOLLAND, P. J.}

Participant: Walker Branch Watershed Research Symposium, sponsored by the Walker Branch Watershed Project, Oak Ridge, Tennessee, March 1990; Annual Meeting of the North American Benthological Society, Blacksburg, Virginia, May 1990; Annual Mecting of the Ecological Socicty of America, Snowbird, Utah, July 1990; Watland and Riparian Ecotones in Landscape Dynamics, sponsored by U.S. Man and the Biosphere Program, EPA, and DOE, Oak Ridge, Tennessee, September 1990.

Faculty: Adjunct Faculty, Graduate Program in Ecology, The University of Tennessce.

Advisor. David Genereux, Ph.D. candidate, Massachusctts Institute of Technology; Terry Flum, Ph.D. candidate, The University of Tennessec; Amy
Rosemond, Ph.D. candidate, Vanderbilt

University, Mark Gallyoun, B.S. candidate, Southern Illinois University. Ad hoc reviewer. Ecology, Joumal of the North American Benthological Society; Joumal of Environmental Quality, NSF proposals; Hudson River Foundation proposaks.

Other. Editorial Board, Ecology.

NORBY, $\mathbf{R} \mathbf{J}$.

Participant: Research Planning

Workshop, sponsored by DOE,

Cambridge, Massachusetts, May 1990; 11th North American Forest Biology Workshop, sponsored by Society of American Foresters, Athens, Georgia, June 1990; Annual Meeting of the American Society ef Plant Physiologists, Indianapolis, July 1990; 19th World Congress, sponsored by IUFRO, Montreal, August 1990.

Faculty: Adjunct Faculty, Graduate Program in Ecology, The University of Tennessee.

Advisor: Jeff Amold, B.S. candidate, Purdue University, Marion Cockrill, B.A candidate, Kalamazoo College; Daniel Stewart, B.S. candidate, Pennsylvania State University.

Ad hoc reviewer. Environmental Pollution; Tree Physiology; Water, Air, and Soil Pollution; Canadian Joumal of Forest Research; New Phytologist; Forest Science; DOE, NSF, USDA proposals.

OLSEN, C R Chaiman: Co-organizer, Ocean Margins Workshop, sponsored by DOE/OHER, Virginia Beach, Virginia.

Panticipant: Radon Rescarch Program Review, sponsored by DOE/OHER, San Francisco, January 1990; Workshop on Radionuclide Tracers for Atmospheric Processes, sponsored by Yale University, New Haven, Connecticut, January 1990; Shelf-Edge Exchange Program (SEEP) Review, sponsored hy DOE/OHER, Brookhaven National Laboratory, Upton, 
New York, February 1990; Workshop on Coastal Ocean Prediction, sponsored by DOCANOAA, Charleston, South Carolina, June 1990.

Ad hoc reviewer: Earth and Planetary Science Letters; Geophysical Research Letters; Geochimica et Casmochimica Acia; Environmental Science and Technology, Estuarine, Coastal, and Shelf Science; DOE proposals.

\section{OLSON, R J.}

Participant: GIS/LIS 89, sponsored by ACSM and others, Orlando, Florida, November 1989; NAPAF 1990 International Conference, Hilton Head, South Carolina, February 1990; Tenth ESRI User Conference, Palm Springs, California, May 1990; NAPAP Final Task Force Mceting, Washington, D.C., September 1990.

ONEIL, E G.

Member. Ecological Society of America, American Association for the Biological Sciences.

Participant: First Annual Walker Branch Watershed Research Symposium, 'pc:ssored by DOE/OHER, Oak Ridge, Tunnessee, March 1990; Mycological Techniques Workshop, sponsored by the North American Conference on Mycorrhizae, Jackson, Wyoming. September 1990.

Advisor. William R. Lyon, B.S. candidatc, Indiana University.

Ad hoc reviewer. Soil Science Society of America Joumal; USDA proposal; book chapter.

Other. Treasurer and Membership Chairman, U.S. Soil Ecology Socicty.

ONEILL, R V.

Chaiman: Transect Workshop, sponsored by DOE/OHER, Las Cruces, New Mexico; Exccutive Committce, U.S. Chapter, Intcrnational Association for Landscape Ecology.
Member. Ecological Society of America; Executive and Award committees, U.S. Chapter, International Association for Landscape Ecology; American Society of Naturalists; International Society for Ecological Modeling.

Participant: EPAVEMAP Workshop, Las Vegas, March 1990; Transect Workshop, Las Cruces, New Mexico, March 1990; US-IALE Annual Meeting, Columbus, Ohio, April 1990; Annual Meeting of the Ecological Society of America, Snowbird, Utah, August 1990; Meeting of the Association of Ecosystem Research Centers, sponsored by the Ecological Society of America, Snowbird, Utah, August 1990, Ecotone Workshop, Oak Ridge, Tennessee, September 1990.

Faculy: Associate Professor, Graduate Program in Ecology, The University of Tennessee.

Advisor. Jackje Cunningham, Ph.D. candidate, The University of Tennessee. Ad hoc reviewer: Landscape Ecology; Ecology; American Naturalist; DOE, EPA, NSF proposals.

Other: Fellow, American Association for the Advancement of Science.

\section{PALUMBO, A V.}

Chairman: Annual Meeting of the American Chemical Society, Boston.

Participant: Superfund '89, Washington, D.C., November 1989; First International Symposium on Microbiology of the Decp Subsurface, Orlando, Florida, January 1990; Annual Meeting of the American Chemical Society, Boston, April 1990; Twelfth Symposium on Biotechnology for Fuels and Chemicals, Gatlinburg, Tennessee, April 1990; Annual Mecting of the American Socicty for Microbiology, Anahcim, California, May 1990; Annual Mecting of the Society for Industrial Microbiology, Orlando, Florida, July 1990. 
Advisor. Lilliam Arroyo-Casanas, M.S. candidate, University Central del Caribe, Puerto Rico; Igrid Rosario, M.S. candidate, University of Puerto Rico; Loyda Lozada-Rios, B.S. candidate, University of Puerto Rico; W. Eng. M.S. candidate, The University of Tennessee; Andrew A. Arrage, M.S. candidate, Virginia Polytechnic Institute and State University.

Ad hoc reviewer. Limnology and Oceanography, DOE proposals.

PARR, P. D.

Member: Environmental Education Committee, Southern Appalachian Man and the Biosphere Cooperative.

Darticipant: Erological Characteristics and Data Synthesis Workshop for DOE Research Parks, sponsored by DOE/OHER, Oak Ridge, Tennessee, October 1989, ParkNet Forum, sponsored by DOE/OHER, Washington, D.C., November 1989; Meeting of the Association of Southeastern Biologists, Baltimore, April 1990; Annual Meeting of the Ecological Society of America, Snowbird, Utah, July 1990; LTER, Estes Park, Colorado, September 1990. Advisor. Carlos Alicea, B.S. candidate, University of Puerto Rico.

Other. Treasurer, Association of Southeastern Biologists.

PENG, T.-H

Participant: Atmospheric ${ }^{200} \mathbf{R n}^{210} \mathrm{~Pb}$ ${ }^{7} \mathrm{Be}-{ }^{10} \mathrm{Be}$ Meeting, sponsored by Kline Geology Laboratory, Yale University, New Haven, Connecticut, January 1990; Second Workshop on Geological Indicators of Climate from Maine Environments, sponsored by the U.S. Geologicai Survey, St. Petersburg, Florida, January 1990; International Mceting on Modeling the Physics, Biology and Cheinistry of the Upper Occan and Its Interaction with the Atmosphere, sponsored by the Koyal Society, London, March 1990; Conference on Four Decades of Radiocarbon Studies: An Interdisciplinary Perspective, sponsored by the University of California Lake Arrowhead Conference Center, Lake Arrowhead, California, June 1990, Workshop on Physical and Chemical Tracers in the Ocean, Friday Harbor, Washington, July 1990, Second International Symposium on Gas Transfer at Water Surfaces, Minneapolis, September 1990.

Ad hoc reviewer. Joumal of

Geophysical Research; Earth and Planetary

Science Letters; Global Biogeochemical

Cycle; Journal of Air and Waste

Management; Science; Nature;

Intergovernmental Panel on Climate

Change; National Research Council; DOE, NSF, NOAA proposals.

POST, W. M, III

Chaiman: Individual-Based Modeling

Workshop, sponsored by the Electric

Power Research Institute/ORNL-UT

Science Alliance, Knoxville, Tennessee.

Participant: Arid Ecosystems Interactions Workshop, sponsored by Office for Interdisciplinary Earth Studies, University Consortium for Atmospheric Research, Boulder, Colorado, October 1989; Workshop on Greenhouse Gas Emissions for Agricultural Systems, sponsored by IPCC/EPA, Washington, D.C., December 1989; Tree Mortality Workshop, sponsored by NSF, Corvallis, Oregon, April 1990; Brookhaven National Laboratory Workshop on Global Climate Feedbacks, sponsored by DOE, Brookhaven, New York, June 1990; International Congress of Ecology, Yokohama, Japan, A'jgust 1990.

Faculty: Associate Professor, Graduate Program in Ecology, The University of Tennessee.

Advisor. Jill Hamilton, Master's candidate, University of Pucrto Rico. Ad hoc reviewer. Joumal of Environmental Quality; Science; Joumal of 
Thermal Biology; Nature; Joumal of the Tennessee Academy of Science; Canadian Joumal of Forest Research; American Naturalist; Intergovernmental Panel on Climate Change; EPA; NASA; NSF proposals.

Other. Director, Knosville Cooperative Action Project.

RAIISBACX, S. F.

Chaiman: Annual Conference on Water Resources, sponsored by the American Society of Civil Engineers, Fort Worth, Texas; Subcommittee on Global Climate Change, American Society of Civil Engineers; Adopt-a-River Technical Subcommittee, Tennessee Scenic Rivers Association.

Participant: Annual Conference of the Water Resources Planning and Management Division, sponsored by the American Society. of Civil Engineers., Ft. Worth, Texas, April 1990; Troubled Waters of the Greenhouse Earth, sponsored by the North American Benthological Society, Blacksburg, Virginia, May 1990; International Symposium on Water Resources Systems Applications, sponsored by the University of Manitoba, Winnipeg, Manitoba, Canada, June 1990; Workshop on Dissolved Oxygen, sponsored by TVA, Chattanooga, Tennessea, July 1990; Gas Transfer at Water Surfaces, sponsored by the American Society of Civil Engincers, Minncapolis, Scptember 1990. Ad hoc reviewer. U.S. Fish and Wildlife Service; Niagara Mohawk, Inc. Other. Secretary, Social and Environmental Objectives and Impacts Committec, American Society of Civil Engincers.

\section{RANNEY, J. W.}

Participant: Biofuels Program

Management Review, sponsored by DOE, Washington, D.C., April 1990;

Conservation and Renewable
Review-Cost-Benefit, sponsored by DOE, Golden, Colorado, May 1990; DOE Review (Public Review) of Renewable Technologies, Washington, D.C., June 1990, International Association of Clean Technologies, sponsored by EPANAA, Washington, D.C., June 1990; Southern Appalachian Man and the Biosphere, sponsored by DOESAMAB, Asheville, North Carolina, June 1990, Southeastem Regional Biomass Program/Regional Meeting, sponsored by DOE, Washington, D.C., June 1990; International Energy Agency Meeting on Feedstock Qualities, Toronto, August 1990. Advisor. Anantha Prasad, M.S. candidate, Miami University of Ohio. Ad hoc reviewer. Idaho Board of Eduction proposal.

\section{REED, R M}

Chairman: Session chair, Assessing Impacts of Ecological Resources, The Scientific Challenge of NEPA, sponsored by DOE and others, Knoxville, Tennessee. Participant: The Scientific Challenges of NEPA, sponsored by DOE and others, Knoxville, Tennessee, October 1989.

\section{ROSE K A}

Participant: Individual-Based Modeling of Populations, Communities, and Ecosystems, sponsored by the Electric Power Research Institute/UT-ORNL Science Alliance, Knoxville, Tennessee, May 1990.

\section{ROSEN, A E}

Participant: SPANS Users Conference, sponsored by TYDAC Technologies, Annapolis, Maryland, November 1989; SAS Users Group International Conference, Nashville, Tennessee, April 1990. 
ROY, W. R.

Participant: Sixth Annual Acid Rain

Conference, sponsored by TVA.

Gatlinburg, Tennessee, October 1989.

RYON, M G.

Member. Society of the Sigma Xi.

SALE, M J.

Chaiman: Session chair, The

Scientific Challenges of NEPA, sponcored by DOE and others, Knoxville, Tennessee; Third Tennessee Water Resources Symposium, sponsored by the American Water Resources Association, Nashville, Tennessee; ESD Computer Advisory Committee.

Member. Technical Advisory

Committee for the Response of Fish Populations to Altered Flow Project.

Participant: The Scientific Challenges of NEPA, sponsored by DOE and others, Knoxville, Tennessee, October 1989; Acid Deposition Effects in Mid-Atlantic States, sponsored by EPA Region III, Pittsburgh, November 1989; NAPAP Integrated Assessment Question 1 Writing Workshop, sponsored by EPAVAERP, St. Louis, November 1989; DOE NES Interim Report Writing Workshop, sponsored by the DOE Office of Renewable Energy Technologies, Washington, D.C., January 1990; NAPAP Integrated Assessment Question 3 Writing Workshop, sponsored by EPAAERP, Oak Ridge, Tennessee, January 1990; DOE Hydropower Resources Study Kickoff Workshop, sponsored by the DOE Office of Renewable Energy Technologies, Denver, February 1990; DOE NES Interim Report Writing Workshop-Resources Study, sponsored by the DOE Office of Renewable Energy Technologies, Washington, D.C., February 1990; NAPAP 1990 International Conference, sponsored by EPANAERP, Hilton Head, South Carolina, February 1990; COMPMECH Hydro Project Initiation Workshop and
Individua!-Based Modeling Workshop, sponsored by EPRI, Oak Ridge and Knoxville, Tennessee, May 1990; Chapman Conference on Hydrologic Aspects of Global Climate Change, sponsored by the American Geophysical Union, Lake Chelan, Washington, June 1990; COMPMECH Hydro Project Coordination Meeting and Site Visit, sponsored by EPRI, Minneapolis and Duluth, Minnesota, July 1990, Water Works: Promoting Hydropower and Its Values, sponsored by the National Hydropower Association, Washington, D.C., July 1990, DOE Hydro Resources Study Phase II Initiation Workshop, sponsored by the DOE Office of Renewable Energy Technologies, Portland, Oregon, August 1990; Third Tennessee Water Resources Symposium, sponsored by the American Water Resources Association, Nashville, Tennessee, August 1990; COMPMECH Smallmouth Bass Workshop, sponsored by EPRI, Madison, Wisconsin, September 1990; DOE Hydro Mitigation Study Questionnaire Design Workshop, sponsored by DOE/ORET, Atlanta, September 1990.

Ad hoc reviewer. Canadian Joumal of Fisheries and Aquatic Sciences; U.S. Fish and Wildlife Service; EPA.

Other. Secretary, American Water Resources Association.

\section{SALK, M. S.}

Participant: The Scientific Challenges of NEPA, sponsored by DOE and others, Knoxville, Tennessee, October 1989; Cultural Resources Management, sponsored by DOE, Santa Fe, New Mexico, July 1990; Southeast Wetlands Conference, sponsored by Executive Enterprises, Inc., Atlanta, September 1990.

SHARPLES, F. E Chaiman: Session chair, The Scientific Challenges of NEPA, sponsored by DOE and othes, Knoxville, Tennessee. 
Member: Committee on Science, Engineering, and Public Policy, American Association for the Advancement of Science.

Participant: Committee on Science, Engineering, and Public Policy, sponsored by the American Association for the Advancement of Scienca, Washington, D.C., June 1990, Ecoregions Subcommittee of the Biotechnology Science Advisory Committee, sponsored by EPA, Washington, D.C., July 1990; EPA Environmental Biology Revicw Panel, sponsored by EPA, Portland, Oregon, July 1990.

Advisor: Bob Booker, Law degree candidate, The University of Tennessee. Ad hoc reviewer. BiaScience; book chapters; NSF proposal.

Cther: ESD Coordinator, ORNL Savings Bond Drive; President, Oak Ridge Chapter, Society of the Sigma Xi.

\section{SHRINER, D. S.}

Participant: Critical Loads Planning Workshop, sponsored by EPA, Dallas, January 1990; Acidic Deposition: State of Science and Technology International Conference, sponsored by the National Acid Precipitation Assessment Program, Hilton Head, South Carolina, February 1990; NAPAP Integrated Assessment Workshop, Washington, D.C., March 1990; IUFRO World Congress, sponsored by the International Union of Forest Research Organizations, Montreal, August 1990; NAPAP Integrated Assessment and Final Task Force Meeting, Washington, D.C., September 1990.

Ad hoc reviewer. USDA Forest Service.

\section{SHUGART, L R}

Chaiman: 14th Symposium on Aquatic Toxicology and Risk Assessment, sponsored by the American Society for Testing and Matcrials, San Francisco.
Member. Society of Environmental Toxicology and Chemistry.

Participant: Summer School for Mu!tidisciplinary Assessment of Environmental Risks, sponsored by the University of Siena, Siena, Italy, October 1989, September 1990; DOE Long-Range Basic Research Planning Workshop, Washington, D.C., February 1990; Sediment Genotoxicity Workshop, sponsored by the U.S. Army Corps of Engineers, Vicksburg, Mississippi, March 1990.

Faculty: Adjunct Associate Professor, Graduate School of Biomedical Sciences, The University of Tennessee.

Advisor: Christine Gettys Hull, Chris Theodorakis, Ph.D. candidates, The University of Tennessee; Heather Smith, B.S. candidate, University of Utah.

Ad hoc reviewer. Aquatic Taxicology; Archives of Environmental Contamination and Taxicology; Chemical Research in Taxicology; National Cancer Institute; National Science and Engineering Research Council of Canada; NOAA; EPA

\section{SIEGRIST, $\mathbf{R}$ L}

Chairman: Co-organizer, Data

Sufficiency and Decision-Making for Site Remediation, sponsored by the University of Wisconsin, Madison, Wisconsin.

Member: American Society of Civil Engineers, Association of Ground Water Scientists and Engineers, Water Pollution Control Federation, Soil Science Society of America, American Society for Testing and Materials.

Participant: Demonstration of Remedial Action Technologies for Contaminated Land and Groundwater, sponsored by the NATO Committee for Challenges to Modern Society, Oslo, March 1990; Understanding Site Remediation, sponsored by the University of Wisconsin, Orlando, Forida, March 1990; Working Group, Supcrfund Issuc 
Paper on Sampling Soils for VOCs. sponsored by EPA, Las Vegas, May 1990, Symposium on Characterization and Cleanup of Chemical Waste Sites, Annual Meeting of the American Chemical Society, Washington, D.C., August 1990; Fourth National Conference on Hydrocarion Contaminated Soils, sponsored by the University of Massachusetts, Amherst, Massachusitts, September 1990.

\section{SIGAL, L L}

Participant: International Tark force on the Application of the Principles of Environmental Impact Assessment to Policies, Plans, and Programs, sponsored by EPA, Geneva, June 1990; DOE Tiger Team Environmental Assessments: Mound Plant, Nevada Test Site, Hanford, Pinellas Plant, Brooktaven National Laboratory, and Lawrence Livermore National Laboratory. Ad hoc reviewer. The Bryologist; DOE

SMITH, E D.

Participant: The Scientific Challenges of NEPA, sponsored by DOE and others, Knoxville, Tennessee, October 1989. Ad hoc reviewer. The Environmental Professional.

\section{SOLOMON, D. $\mathrm{K}$}

Chaiman: Lung-Term Base Research in Environmental Restoration, sponsored by DOE/OHER, Waterloo, Ontario, Canada. Union. Member. American Geophysical Ad hoc reviewer. Water Resources Research.

\section{SOUTHWORTH, G. R}

Participant: Annual Mecting of the Socicty of Environmental Toxicology and Chemistry, Toronto, October 1990. Ad hoc reviewer. Environmental Science and Technology; Water, Air, and
Soil Pollution; Environment Intemational; American Chemical Society.

SPALDNG, B. P. Ad hoc reviewer. NSF proposak.

STEINMAN, A D.

Member: Knoxville Metropolitan Planning Committee (Aquatic Ecologist Consultant).

Participant: Walker Branch Watershed Symposium, sponsored by ORNL, Oak Ridge, Tennessee, March 1990; Third Annual Algal Ecology Colloquium, sponsored by Proctor and Gamble and North Kentucky University, Erlanger, Kentucky, April 1990; Annual Meeting of the North American Benthological Society, Blacksburg, Virginia, May 1990.

Ad hoc reviewer. Joumal of the North American Benthological Society, Ecology,

Canadian Joumal of Fisheries and Aquatic Sciences; Joumal of Physiology.

\section{STEWART, A J.}

Participant: Annual Meeting of the North American Benthological Scciety, Blacksburg, Virginia, May 1990, LongTerm Base Research in Environmental Restoration, sponsored by DOE/OHER, Waterloo, Ontario, Canada.

Faculy: Adjunct Faculty, Graduate Program in Ecology, The University of Tennessee.

Advisor. Robert Woodward, Ph.D. candidate, University of Missouri; Audrey Barker, B.S. candidate, Carleton College; Alexis Howell, B.S. candidate, Southwest Missouri State University; Beatrice Jones, B.S. candidate, Selma University.

Other. Editorial Board, Joumal of Freshwater Ecology.

STOSS, F. W.

Chairman: Annual Meeting. Networking (Science and Technology Division), Public Relations and Program (Environment and Resource Management 
Division) committees, Specia! Libraries Association: Co-chair. Long-Range Planning Committee, Special Libraries Association.

Participant: Annual Meeting of the Energy Technology Data Exchange. sponsored by DOE/OSTI, Gatlinburg. Tennessee, April 1990; Annual Meeting of the Special Libraries Association.

Pittsburgh, June 1990.

Other. Technical advisor, Environmens Abstracts; Solumn editor, Environment and Resource Reviews, ERMD Newsletter. Technical Advisory Board, Environmental Information. Inc.

STOW, S. $\mathbf{H}$

Chaiman: Natural Systems part, International Conference on High Level Nuclear Waste, sponsored by DOE and the American Nuclear Society, Las Vegas; Education Committec, Southeastern Section, Geological Society of America.

Member. U.S. Representative, International Association of Hydrogcologists; Education Advisory Board, American Gcological Institute; DOE Office of Technology Development Education Task Force; Education Committec, Gcological Socicty of America; Gcology and Public Policy Committee, Southeastcrn Section, Gcological Socicty of .America; Science and Mathematics Advisory Board, Auburn University: Geosciences Advisory Board, The University of Tennessec.

Paricipant: Annual Mecting of the Geological Society of Amcrica, St. Louis, October 1989; Annual Mecling of the American Association for the Advancement of Science, New Orlcans, January 1990; Commission on Hazardous Waste, sponsored by the International Association of Hydrogcologists, Sede Bokar, Isracl, March 1990; Subsurface Science Program Review, sponsored by DOE/OHER, Germantown, Maryland, March 1990; Intcrnational High Level
Waste Conference, sponsored by DOE/ANS, Las Vegas, April i 990 , Meeting of the Southeastem Section of the Geological Society of America, Tuscalcosa, Alabama, April 1990, Council on Undergraouate Rescarch. San Antonio. Texas, June 1990, Task Force for the DOE Young Scientist Award, sponsored by DOENORAU, Washington, D.C., July 1990.

Faculy: Adjunct Professor, Department of Geological Sciences, The University of Tennessee. Ad hoc reviewer: Environmental Geology and Water Sciences; NSF; Environmental Research and Development Program, State of Lnuisiana Board of Regents.

Other. U.S. Representative, International Association of Hydrogeologists; Editorial Board, Environmental Geology and Water Sciences.

STRATTON, L E

Participant: Waste Operations (EM-30) Priority Sysicm Workshop, sponsored by DOE, Chicago, July 1990; Waste Operations (EM-30) Work Breakdown Strurtu:e Workshop. sponsored by DOE, Albuquerque, New Mexico, August 1990; Five-Ycar Planning Workshop, sponsored by DOE, Washington, D.C., September 1990.

\section{SUTER, G. W, I}

Member. Board of Directors, Society for Environmental Toxicology and Chemistry; Scientific Revicw Group, New York State Department of Environment.s] Conscrvation.

Participant: Colloquium on Applicability of the NAS Paradigm to Ecological Assessments, sponsored by the EPA Risk Assessment Forum, Washington, D.C., March 1990; Colloquium on Uncertainty Issucs in Hazard Asscssment, sponsored by the EPA Risk Assessment Forum, Washington, D.C., April 1990. 
Advisor. David L Macintosh, M.S. candidate, Indiana University.

Ad hoc reviewer. Environmental Management; Environmental Taricology and Chemisny: EPA.

TAMURA, T.

Member. Environmental Quality

Committee, American Society of

Agronomy.

Ad hoc reviewer. Health Physics; lask and remediation plans.

TOLBERT, V. R.

Chaiman: North American

Benthological Society, Associatioin for Women in Science.

Member. Oak Ridge Chapter, Society of the Sigma Xi.

Particip.nt: The Scientific Challenges of NEPA, sponsored by DOE and others, Knoxville, Tennessee, October 1989;

Annual Meeting of the North American Benthological Society, Blacksburg. Virginia, May 1990; Annual Meeting of the National Association of Environmental Prolessionals, San Antonio, Texas, June 1990.

Advisor: Hans E. Eckman, B.S. candidate, University of Georgia.

Other. Treasurer, North American Benthological Society; Science-by-Mail participant, East Tennessee Discovery Center.

TORAN, L E

Faculty: Adjunct Professor,

Department of Geological Sciences, The

University of Tennessce.

Ad hoc reviewer. Geochimica et

Cosmochimica Acta.

Other. Editorial Board, Ground Water.

TRABALKA, J. R.

Member. Scientific Committee 64,

Task Group 9, National Council on

Radiation Protection and Mcasurements.
Participant: Workshop for the Preparation of the Human Health and Envircnmental Effects Section of "Basic Research for Environmental Restoration--R\&D Plan, sponsored by DOEOHER, Washington, D.C., February 1990.

TSCHAPLINSK, T. J.

Participant: First Annual Walker

Branch Watershed S; mposium, sponsored by DOE, Oak Ridge, Tennessee, March 1990; 11 th North American Forest Biology Workshop, sponsored by the Society of American Foresters and the University of Georgia, Athens, Georgia, June 1990.

Advisor. Doris Garcia, Professor, Metropolitan University, Puerts Rico; Denise Kay, B.S. candidate, University of Michigan.

Ad hoc reviewer. Tree Physiology;

Environmental and Experimental Botany, EPA.

TURNER, M. G.

Chaiman: Sympasium on Methodology in Landscape Ecology, Fifth International Congress of Ecology, Yokohama, Japan; Contributed Papers Sexsion, Fifth Annual Landscape Ecology Symposium, Oxford, Ohio.

Member. National Science Foundation; Ecological Society of America; U.S. Man and the Biosphere Program, U.S. Chapter, International Association for Landscape Ecology; Society of the Sigma Xi.

Participant: European Conference on Landscape-Ecological Impacts of Climate Change, Lunteren, The Netherlands, December 1989; Fifth Annual Landscape Ecology Symposium, Oxford, Ohio, March 1990; Annual Meeting of the Ecological Society of America, Snowbird, Utah, July 1990; Fifth International Congress of Ecology, Yokohama, Japan, August 1990.

Ad hoc reviewer. Ecological Economics; Biological Conservation; BioScience; Climate Research; Landscape Ecology; 
DOE; NSF; EPA; U.S. Man and the Biosphere Program.

Other. Editorial Board, Climate Research.

\section{TURNER, R R.}

Chairman: State and Regional Competitions/Water, Water Everywhere, National Science Olympiad, Oak Ridge, Tennessee.

Participant: Mobility of Mercury in the Environment, sponsored by the American Chemistry Society, Raleigh, North Carolina, October 1989; Onondaga Lake Remediation Conference, sponsored by New York State Department of Environmental Conservation, Bolton Landing, New York, February 1990; Mercury as an Environmental Pollutant, sponsored by the Swedish Environmental Protection Agency, Gavle, Sweden, June 1990.

Advisor. Amanda Hood, B.S. candidate, Pembroke State University; Kristine Willett, B.S. candiaate, University of North Carolina.

Ad hoc reviewer. Water, Air, and Soil Pollution; Electric Power Research Institute.

TURNER, R S.

Member. Society of the Sigma $\mathrm{Xi}$.

Panicipant: Annual Meeting of the Soil Science Society of America, Las Vegas, October 1989; Critical Loads Project Planning Workshop, sponsored by EPA, Dallas, January 1990; Acidic Deposition: State of Science and Technology International Conference, sponsored by the National Acid Precipitation Assessment Program, Hilton Head, South Carolina, February 1990; Critical Loads Project Planning Woikshop. sponsored by EPA, Chicago, March 1990; Region 8 Air Effects Workshop, sponsored by the USDA Forust Service, Allanta, June 1990; International Conference on Acidic Deposition: Its Nature and
Impacts, Glasgow, Scotland, September 1990; NAPAP Final Task Force Meeting, sponsored by the National Acid Precipitation Assessment Program, Washington, D.C., September 1990; NAPAP Integrated Assessment Writing Workshops (eight), sponsored by the National Acid Precipitation Assessment Pre gram.

Ad hoc reviewer. Soil Science; EPA; NAPAP.

\section{TUSKAN, J. A}

Participant: Great Plains Agriculture Council Forestry Meeting, sponsored by Colorado State University, Colorado Springs, Colorado, June 1990; North American Forest Biology Workshop, sponsored by the University of Georgia, Athens, Georgia, June 1990; IEA Tree Ideotype, Wood Quality, and Ecophysiology Meeting, sponsored by the University of Toronto, Toronto, August 1990.

Ad hoc reviewer. Canadian Joumal of Forest Research; Plant, Cell, Tissue and Organ Culture; USDA; USDA Forest Service; state universities.

\section{VAN HOOK, R L}

Chaiman: Research Subcommittee, Executive Committee, Southern Appalachian Man and the Biosphere Program.

Participant: EPA Public Meeting on Ecological Research, Philadelphia, June 1990.

Faculty: Adjunct Faculty, Graduate Program in Ecology, The University of Tennessee.

Other. Board of Directors, Biomass; ORNL Representative, Cooperating Institutions Committce, Great Smoky Mountains National Park Long-Term Ecological Research Monitoring Program; Co-chairman, 1990 ORNL. United Way Campaign. 
VAN MIEGROET, $H$.

Chairman: Co-chair, Education

Committee, East Tenressee Chapter, Association for Women in Science.

Participant: Annuil Meeting of the

Soil Science Society of Amerisa, Las

Vegas, October 1989; Sixth Annual Acid

Rain Conference, sponsored by TVA,

Gatlinburg. Tennessee, October 1989;

IEABBE Group A6 Workshop on

Long-Term Effects of Harvesting, sponsored by the International Energy Agency, Florida, February 1990; NAPAP International Conference, Hilton Head, South Carolina, February 1990; Critical Loads Workshop, sponsored by EPA, Chicago, March 1990, Wrrkshop on Air Pollution Effects on Class I Wilderness Areas, sponsored by USFS Region 8, Atlanta, June 1990.

Advisor. Efrain Delgado, B.S. candidate, University of Turabo, Puerto Rico; John D. Goodlaxson, B.S. candidate, University of Wisconsin. Ad hoc reviewer. Soil Science Society of America Joumal; Forest Science; Joumal of Environmental Quality; Canadian Joumal of Forest Research; Environmental Management; DOE; EPA; USDA; International Energy Agency.

Other. Co-chair of the Education Committee and Vice President, East Tennessee Chapter, Association for Women in Science.

\section{VAN WINKIE, W.}

Chairman: COMPMECH Workshop on Smallmouth Bass, sponsored by ORNL and the University of Wisconsin, Madison, Wisconsin; COMPMECH Workshop on Striped Bass, sponsored by ORNL, Arlington, Virginia.

Member. Stcering Committce, Populations, Communities, and Ecosystems: An Individual Perspective, sponsored by the Electric Power Research Institutc/UT-ORNL Science Alliance,
Kiloxville, Tennessee: ESD Committee on Mentoring. Participcnt: Management Forum on Quality Assurance, sponsored by Martin Marietta Energy Systems, Inc., Oak Ridge, Tennessee, October 1989; Sixth Annual Acid Rain Conference, sponsored by TVA, Gatlinburg, Tennessee, October 1989; ParkNet Colloquium, sponsored by DOE/OHER, Washington, D.C., November 1989; Workshop on the 1990 Monitoring Program in the Hudson River, sponsored by the New York Depariment of Environmental Conservation, Albany, New York, November 1989; Lake Acidification and Fisheries Project: Results and Conclusions, sponsored by EPRI, Arlington, Virginia, December 1989; Briefing on the Walker Branch Watershed Project, sponsored by DOE/OHER, Germantown, Maryland, January 1990; Annual Workshop on the California Striped Bass Population, sponsored by the California Department of Fish and Game, Stockton, California, February 1990; Annial Meeting of the American Fisheries Society, Pittsburgh, September 1990.

Faculty: Adjunct Faculty, Graduate Program in Ecology, The University of Tennessee.

Ad hoc reviewer. Ecology; Canadian Joumal of Fisheries and Aquatic Sciences; North American Journal of Fisheries Management; Michigan Sea Grant College Program proposal; Hudson River

Foundation proposal.

Other. Treasurer, Oak Ridge Chapter, Society of the Sigma Xi.

\section{VON DAMM, K. L}

Member. Alvin Revicw Committce;

East Pacific Rise Detailed Planning

Group; Geochemical Society;

Geochemistry Division, American Chemical Society; American Gcophysical Union. 
Participant: Fall Meeting of the American Geophysical Union, San Francisco, December 1989; 1990 VENTS Workshop on the Cleft Segment, Southern Juan de Fuca Ridge, sponsored by Pacific Marine Environmental Laboratory, NOAA, Seattle, March 1990.

Faculy: Adjunct Faculty, Department of Geological Sciences, The University of Tennessee.

Ad hoc reviewer: Geochimica et Cosmochimica Acta; Nature; Deep-Sea Research; Earth and Planetary Science Letters; Geophysical Research Letters; Marine Geology; NSF, NOAA proposals; U.S. Geological Survey; University of Hawaii Sea Grant College Program proposal.

\section{VOORHEES, L D.}

Chaiman: Natural Subgroup, Oak Ridge Reservation Resource Management Organization.

Participant: DOE Model Conference, Oak Ridge, Tennessee, October 1989; The Scientific Challenges of NEPA, sponsored by DOE and others, Knoxville, Tennessee, October 1989; SPANS GIS Software Users Conference, sponsored by TYDAC Technologies, Annapolis, Maryland, November 1989; Data Analysis and Interpretation for Environmental Surveillance, sponsored by ORNLDOE, Lexington, Kentucky, February 1990; SAS Users Group International Conference, Nashville, Tennessee, April 1990; Geographic Information Systems-East, sponsored by Government Computer News and GIS Research Corporation, Washington, D.C., June 1990. Ad hoc reviewer. Joumal of the Tennessee Academy of Science.

VOSE, R. S.

Participant: Annual Meeting of the Association of American Geographers, Toronto, April 1990.
WALTON, R T.

Member. Society of Environmental Toxicology and Chemistry, American Board of Toxicology.

Participant: Annual Meeting of the Society of Environmental Toxicology and Chemistry, Toronto, October 1989; Board of Directors Meeting, American Board of Toxicology, Miami Beach, Florida, February 1990; Past Presidents Council, Society of Environmertal Toxicology and Chemistry, Pensacola Beach, Florida, February 1990; Board of Directors Meeting, American Board of Toxicology, Washington, D.C., July 1990.

Faculy: Adjunct Faculty, Graduate

Program in Ecology, and Graduate Program in Environmental Toxicology, both The University of Tennessee. Advisor. Mark S. Jen, B.S. candidate, California State University, Los Angeles; Todd A. Anderson, Anne M. Hoylman, Ph.D. candidates, The University of Tennessee. Ad hoc reviewer. Environmental Taxicology and Chemistry; Chemasphere; Water, Air, and Soil Pollution; DOE. Other. Editorial Board, Environmental Toricology and Chemistry.

WATTS, J. A. Member. Board of Directors, WATTec, Inc. Chairman: Sponsors Committee, 17th Annual WATTec Conference and Exhibition, Knoxville, Tennessee; Science-in-Action Education Program, WATTec, Knoxville, Tennessee; Vice. chairman, DOE High School Honors Program.

Participant: WATTec 90, Knoxville, Tennessee, February 1990; Science and Technology Week, Women in Science, sponsored by ORNLORAU, Oak Ridge, Tennessee, April 1990; Army Depot Site Visit and Scoping Mceting, sponsored by the DOD Chemical Demilitarization Program, Pueblo, Colorado, June 1990. 
Other. President and Sponsors Committee Representative, East Tennessee Chapter, Association for Women in Science; Science-by-Mail participant, Oak Ridge and Knoxville; Volunteer, Knoxville Zoological Gardens.

WEBB, J. W.

Participant: DOE Tiger Team

Environmental Assessments: Hanford, Savannah River, Argonne National Laboratory, and Nevada Test Site.

WHITE, T. W.

Participant: Tenth Annual

Environmental Systems Research Institute User Conference, Palm Springs, California, May 1990.

WRIGHT, L L

Chaiman: Membership Committee,
Association for Women in Science.

Participant: National Energy Strategy

Planning Meeting, sponsored by the Solar

Energy Research Institutc, Golden,

Colorado, December 1989; Annual

Meeting of the American Association for the Advancement of Science, New Orleans, February 1990; Forest Service Work Unit Review, sponsored by the North Central Forest Experiment Station, Rhinelander, Wisconsin, March 1990; Herbaceous Energy Crops Annual Meeting, sponsored by Iowa State University/SRWCP, Ames, Iowa, July 1990.

Ad hoc reviewer. Canadian Joumal of Forest Research; Biomass; Energy Sounces; World Resources Institute report.

Other. Secretary, Oak Ridge Chapter, Society of the Sigma Xi. 


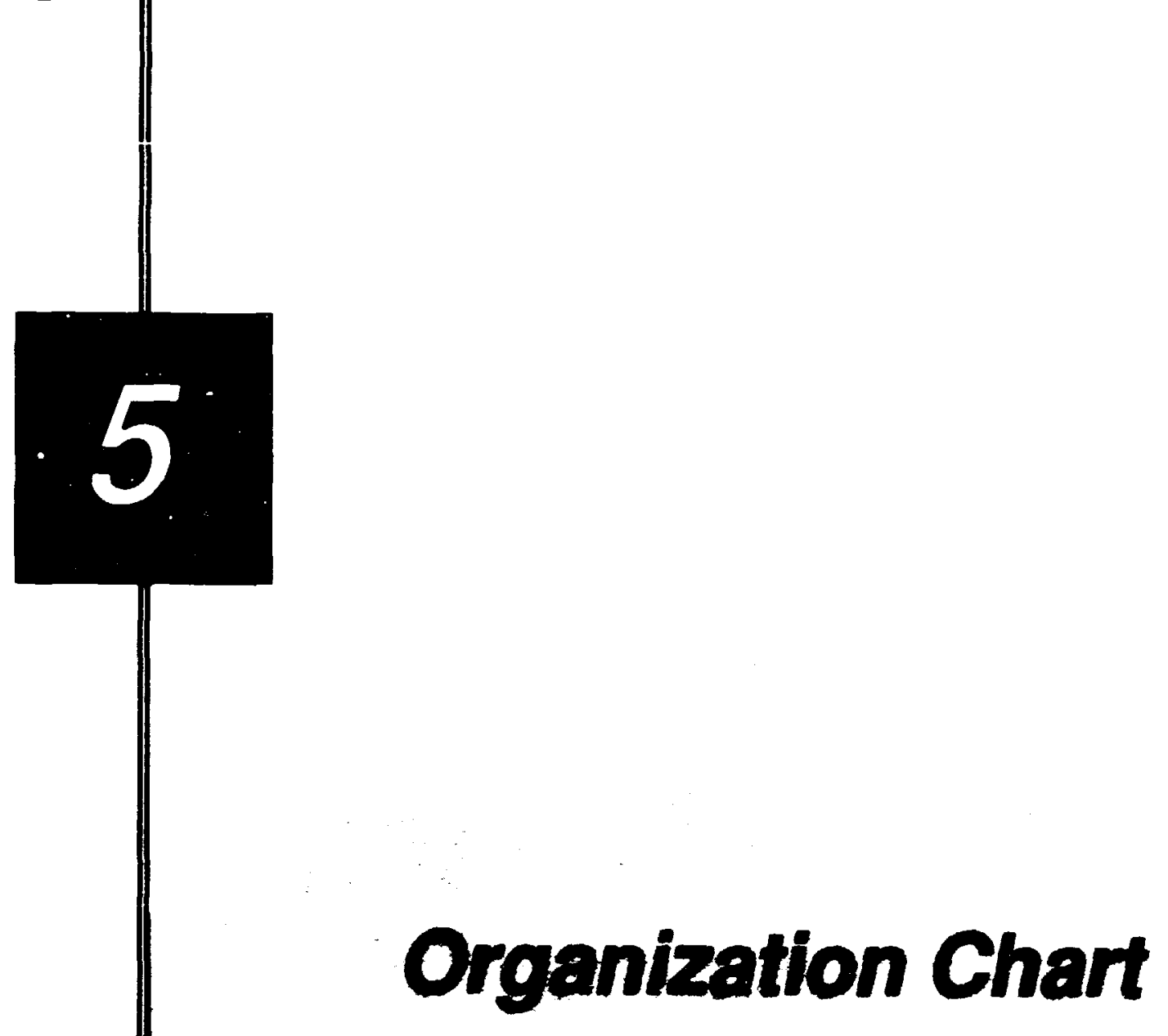




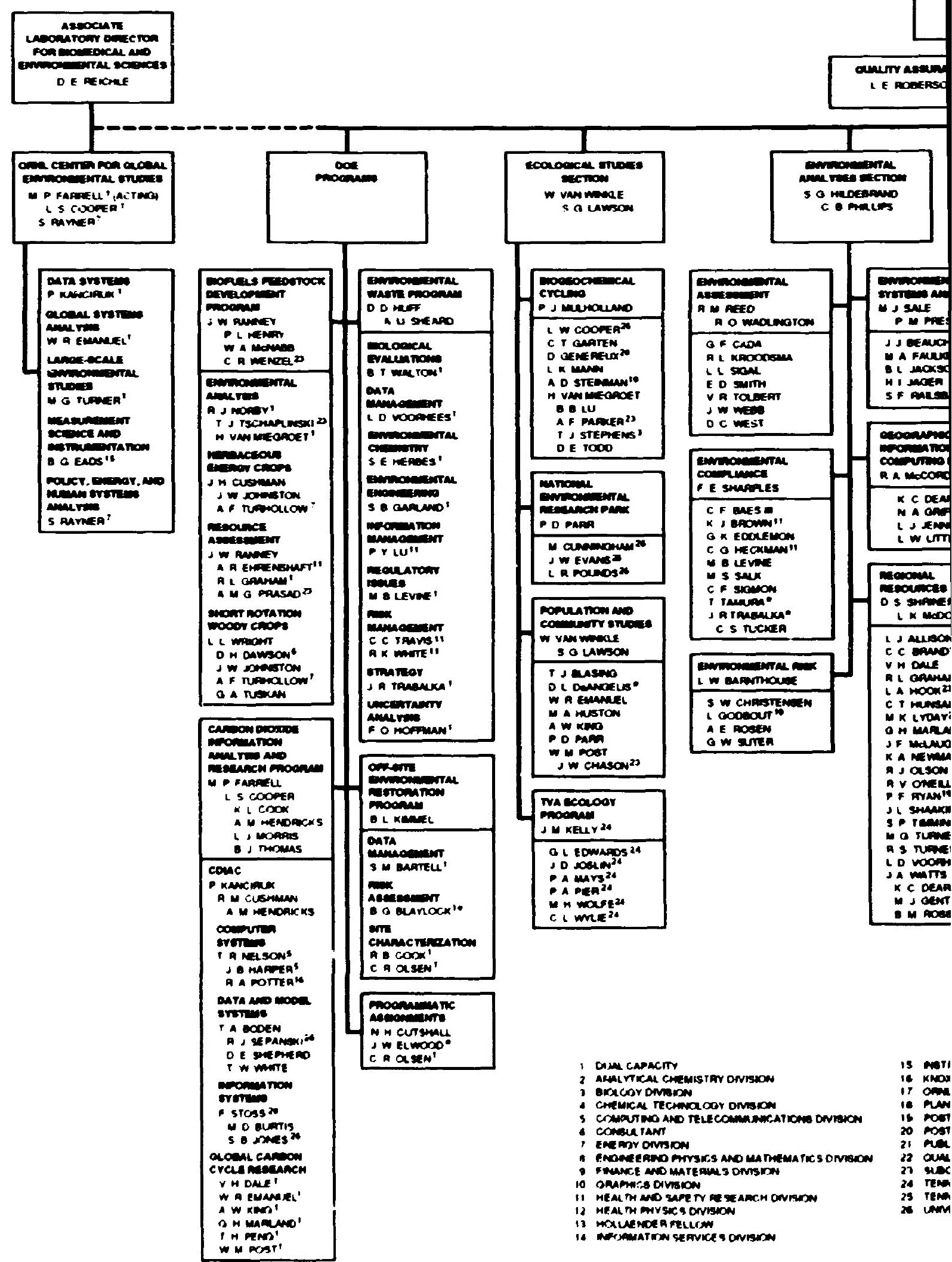




\section{Abbreviations}

$\begin{array}{ll}\text { BFDP } & \text { Biofuels Feedstock Development Program } \\ \text { BIOMOVS } & \text { International Biospheric Model Validation Study } \\ \text { BMAP } & \text { Biological Monitoring and Abatement Program } \\ \text { BMWTD } & \text { Biofuels and Municipal Waste Technology Division } \\ \text { CDLAC } & \text { Carbon Dioxide Information Analysis Center } \\ \text { CDIARP } & \text { Carbon Dioxide Information Anatysis and Research Program } \\ \text { CDRD } & \text { Carbon Dioxide Research Division } \\ \text { CERCLA } & \text { Comprehensive Environmental Response, Compensation, and } \\ & \text { Liability Act } \\ \text { CFR } & \text { Code of Federal Regulations } \\ \text { COMPMECH } & \text { compensatory mechanisms in fish populations } \\ \text { DDRP } & \text { Direct/Delayed Response Project } \\ \text { DOD } & \text { U.S. Department of Defense } \\ \text { DOE } & \text { U.S. Department of Energy } \\ \text { EEO } & \text { equal employment opportunity } \\ \text { EIS } & \text { environmental impact statement } \\ \text { EPA } & \text { U.S. Environmental Protection Agency } \\ \text { EPRI } & \text { Electric Power Research Institute } \\ \text { ESD } & \text { Environmental Sciences Division } \\ \text { ESRI } & \text { Environmental Systems Research Institute } \\ \text { FERC } & \text { Federal Energy Regulatcry Commission } \\ \text { GIS } & \text { geographic information system } \\ \text { GSMNP } & \text { Great Smoky Mountains National Park } \\ \text { HBCU } & \text { historically black colleges and universities } \\ \text { IAEA } & \text { International Atomic Energy Agency } \\ \text { IEA } & \text { Institute for Energy Analysis; also International Energy Agency } \\ \text { IFS } & \text { Integrated Forcst Study (funded by EPRI) } \\ \text { IIASA } & \text { International Institute for Applied Systems Research } \\ \text { IUFRO } & \text { International Union of Forest Research Organizations } \\ \text { LTER } & \text { Long-Term Ecological Reserve } \\ \text { MEI } & \text { minority cducational institution } \\ \text { NADP } & \text { National Atmospheric Deposition Program } \\ \text { NAPAP } & \text { National Acid Prccipitation Asscssment Program } \\ \text { NAS } & \text { National Acadcmy of Scicnces } \\ & \end{array}$




$\begin{array}{ll}\text { NAS/NRC } & \text { National Academy of Sciences/National Research Council } \\ \text { NASA } & \text { National Aeronautics and Space Administration } \\ \text { NATO } & \text { North Atlantic Treaty Organization } \\ \text { NEPA } & \text { National Environmental Policy Act } \\ \text { NOAA } & \text { National Oceanic and Atmospheric Administration } \\ \text { NPDES } & \text { National Pollutant Discharge Elimination System } \\ \text { NRC } & \text { National Research Council; also Nuclear Regulatory Commission } \\ \text { NSF } & \text { National Science Foundation } \\ \text { OHER } & \text { Office of Health and Environmental Research (DOE) } \\ \text { ORAU } & \text { Oak Ridge Associated Universities } \\ \text { ORGDP } & \text { Oak Ridge Gaseous Diffusion Plant } \\ \text { ORNL } & \text { Oak Ridge National Laboratory } \\ \text { ORR } & \text { Oak Ridge Reservation } \\ \text { PIP } & \text { Performance Improvement Process } \\ \text { QA } & \text { quality assurance } \\ \text { R\&D } & \text { research and development } \\ \text { RCRA } & \text { Resource Conservation and Recovery Act of 1976, as amended } \\ \text { RIFS } & \text { remedial investigation/teasibility study } \\ \text { SARA } & \text { Superfund Amendments and Reauthorization Act of 1986 } \\ \text { SCOPE } & \text { Scientific Committee on Problems of the Environment } \\ \text { SERP } & \text { Sedimentary Rock Program } \\ \text { SRIC } & \text { short-rotation intensive culture } \\ \text { SRWCP } & \text { Short Rotation Woody Crops Program } \\ \text { STRIVE } & \text { Science Teachers Research Involvement for Vital Education } \\ \text { SWDA } & \text { Solid Waste Disposal Act } \\ \text { SWSA } & \text { solid waste storage area } \\ \text { TVA } & \text { Tennessee Valley Authority } \\ \text { UEP } & \text { University and Educational Programs Office } \\ \text { UNESCO } & \text { United Nations Educational, Scientific, and Cultural Organization } \\ \text { USDA } & \text { U.S. Department of Agriculture } \\ \text { USGS } & \text { U.S. Gcological Survey } \\ & \end{array}$




\section{Author Index}

Indexed here are the technical summaries by number. The number in parentheses denotes the page on which the technical summary is found.

Anderson, T. A., 24 (46)

Ashwood, T. L., 34 (63)

Auerbach, S. I., 21 (38)

Baes, C. F., III, 10 (23)

Beauchamp. J. J., 14, $53(28,91)$

Berven, B. A., 37 (68)

Blaylock, B. G., 27 (50)

Boden, T. A, 63, 64 (121, 123)

Boerman, P. A., 22 (43)

Bogle, M. A., 57 (97)

Boston, H. L., 28 (51)

Brandt, C. C., 13 (27)

Bredemeier, M., 46 (81)

Brown, C. H., 37 (68)

Cada, G. F., 9 (21)

Chang, L. H., 19 (36)

Chason, J. M., 1 (5)

Clapp, R. B., 36, $48(67,84)$

Cline, J. E., 48 (84)

Cockrill, M., 33 (58)

Conklin, N. G., 55 (95)

Cook, R. B., 14, $49(28,85)$

Cooper, L. W., 49 (85)

Cunningham, M., 6, $7(12,13)$

Cutshall, N. H., 39 (70)

Dalc, V. H., 16 (32)

DeAngelis, D. L, 8 (14)

DePaoli, D. W., 55 (95)

Dickerson, K. S., 44 (79)

Drcicr, R. B., 45 (80)
Dunne, W. M., 43 (77)

Dunnivant, F. M., 30 (54)

Early, T. O., 35, $58(65,99)$

Easterly, C. E, 37 (68)

Eddlemon, G. K, 9, $11(21,24)$

Eng, W., 22 (43)

Fitts, R. B., 39 (70)

Foreman, J. L., 43 (77)

Francis, C. W., 39, $48(70,84)$

Frohn, R. C., 16 (32)

Gardner, R. H., 18 (34)

Garten, C. T., Jr., 2 (6)

Godbout, L, 8 (14)

Graham, R. L., 59 (109)

Grebmeier, J. M., 49, $50(85,87)$

Grizzard, T., 33 (58)

Gunderson, C. A, 31 (55)

Haase, C. S., $41,42(74,75$,

Hanson, J. A., 54 (93)

Hanson, P. J., 31 (55)

Hatcher, R. D., 41 (74)

Heckman, C. G., 9 (21)

Herbes, S. E., 22, $55(43,95)$

Hill, W. R., 28 (51)

Hillsman, E., 16 (32)

Hook, L. A., 20 (37)

Howard, S. C., 48 (84)

Huff, D. D., 39 (70)

Hunsaker, C. T., 17 (33)

Huston, M. A., 1, $5(5,11)$ 
Hyder, L K, 48 (84)

Jackson, B. L., 17 (33)

Jacobs, G. K., 37, 43, $47(68,77,82)$

Jager, H. I., 15 (30)

Jardine, P. M., 30 (54)

Johnson, D. W., 4 (9)

Jolley, R. L, 37 (68)

Kearl, P. M., 38, $44(70,79)$

Kennard, R. O., 45, $52(80,90)$

Kim, K. H., 51 (88)

King, A. W., 61 (117)

King, H. L, 42 (75)

Korte, N. E. 38, $44(70,79)$

Kroodsma, R. L, 12 (26)

Kszos, L A, 29 (52)

Larsen, I. L, 49, $50(85,87)$

Lee, S. Y, 51 (88)

Levine, M. B., 10, $11(23,24)$

Lewis, B., 52 (90)

Lindberg, S. E., 46 (81)

Loar, J. M., 25, $26(47,49)$

Luxmoore, R. J., 37 (68)

Marland, G., 62 (119)

Marsh, J. D., Jr., 56 (96)

McCarthy, J. F., 30 (54)

McMaster, W. M., 41 (74)

Moore, G. K, 36 (67)

Morrissey, C. M., 34 (63)

Mulholland, P. J., 3 (8)

Naney, M. T., 47 (82)

Norby, R. J., 33 (58)

Nyquist, J. E, 55 (95)

O'Neill, E G., 33 (58)

O'Neill, R. V., 16 (32)

Olsen, C. R., 49, $50(85,87)$

Olson, R. J., 14 (28)

Overton, W. S., 15 (30)

Palumbo, A. V., 22 (43)

Panr, P. D., 6, $7(12,13)$

Perlack, R. D., 59 (109)

Peterson, J. E, 38 (70)

Phelps, T. J., 23 (44)

Post, W. M., 5 (11)

Powell, T., 47 (82)

Prasad, A. M. G., 59 (109)

Railsback, S. F., 19 (36)
Ranney, J. W, 59 (109)

Ringelberg, D. B., 23 (44)

Romme, W. H., 18 (34)

Ross-Todd, B. M., 14 (28)

Ryan, P. F., 13 (27)

Ryon, M. G., 25 (47)

Schmoyer, D. D., 13 (27)

Selfridge, R. J., 45, $52(80,90)$

Sharples, F. E, 10, $11(23,24)$

Sigal, L L, 9 (21)

Sigmon, C. F, 10 (23)

Smith, E D., 11 (24)

Smith, J. G., 26 (49)

Solomon, D. K, 37, 49, $55(68,85,95)$

Southworth, F, 16 (32)

Spalding, B. P., 47 (82)

Speece, M. A, 54 (93)

Steurer, P. M., 64 (123)

Stewart, A. J., 28, 29 (51, 52)

Stow, S. H., 37, $41(68,74)$

Suter, G. W., II, 20 (37)

Switek, J., 34, 35, 52, $54(63,65,90,93)$

Taylor, D. T., 30 (54)

Taylor, G. E, Jr., 31 (55)

Taylor, P. A, 29 (52)

Timmerman, C. L., 47 (82)

Timmins, S. P., 17 (33)

Todd, D. E, 4 (9)

Toran, L E, 40, $56(72,96)$

Trabalka, J. R., 21, $37(38,68)$

Tschaplinski, T. J., 32 (S7)

Tumer, M. G., 18 (34)

Tumer, R. R., 53, 57 (91, 97$)$

Turner, R. S., 13 (27)

Van Miegroet, H., 4 (9)

Von Damm, K. L, 50 '87)

Vose, R. T., 64 (123)

Walker, K. R., 43 (77)

Walton, B. T., 24 (46)

Waters, A. E, 27 (50)

White, D. C., 23 (44)

Wickliff, D. S., 34 (63)

Willett, K L, 53 (91)

Williams, R. T., 54 (93)

Wilson, J. H., 55 (95)

Wright, L. L, 60 (111) 